Florida International University FIU Digital Commons

FIU Electronic Theses and Dissertations

University Graduate School

3-30-2011

\title{
A Diagnostic Framework for Demand Amplification Problems in Supply Chains
}

Rene A. Amaya

Florida International University, ramaya@uninorte.edu.co

DOI: $10.25148 /$ etd.FI1 1042502

Follow this and additional works at: https://digitalcommons.fiu.edu/etd

\section{Recommended Citation}

Amaya, Rene A., "A Diagnostic Framework for Demand Amplification Problems in Supply Chains" (2011). FIU Electronic Theses and Dissertations. 410.

https://digitalcommons.fiu.edu/etd/410

This work is brought to you for free and open access by the University Graduate School at FIU Digital Commons. It has been accepted for inclusion in FIU Electronic Theses and Dissertations by an authorized administrator of FIU Digital Commons. For more information, please contact dcc@fiu.edu. 


\section{FLORIDA INTERNATIONAL UNIVERSITY}

Miami, Florida

\section{A DIAGNOSTIC FRAMEWORK FOR DEMAND AMPLIFICATION PROBLEMS IN SUPPLY CHAINS}

A dissertation submitted in partial fulfillment of the requirements for the degree of DOCTOR OF PHILOSOPHY in

INDUSTRIAL AND SYSTEMS ENGINEERING

by

René A. Amaya

2011 
To: Dean Amir Mirmiran

College of Engineering and Computing

This dissertation, written by René A. Amaya, and entitled A Diagnostic Framework for Demand Amplification Problems in Supply Chains, having been approved in respect to style and intellectual content, is referred to you for judgment.

We have read this dissertation and recommend that it be approved.

Chin-Shen Chen

Martha A. Centeno

Ronald M. Lee

Ronald E. Giachetti, Major Professor

Date of Defense: March 30, 2011

The dissertation of René A. Amaya is approved.

\begin{tabular}{r} 
Dean Amir Mirmiran \\
College of Engineering and Computing \\
\hline Interim Dean Kevin O'Shea \\
University Graduate School
\end{tabular}

Florida International University, 2011 
(C) Copyright 2011 by René A. Amaya

All rights reserved. 


\section{DEDICATION}

I dedicate this dissertation to my wife, Monica, and my children, Kathy, Laura and Alejandro. 


\section{ACKNOWLEDGMENTS}

I wish to give special thanks to my students, in particular Milton Soto, Fernando Gonzalez, Daniel Romero and Claudia Prada, for assisting me in this investigation. The decided involvement of the participating firms of the study, and the support of Colciencias and Universidad del Norte made possible the current research.

I also give my recognition and gratitude to my Major Professor, Dr. Ronald E. Giachetti, for his relentless dedication and patience in guiding me throughout these years. Above all, I thank God and my family for giving me the thrust and space for completing this work. 


\title{
ABSTRACT OF THE DISSERTATION \\ A DIAGNOSTIC FRAMEWORK FOR DEMAND AMPLIFICATION \\ PROBLEMS IN SUPPLY CHAINS
}

by

\author{
René A. Amaya
}

Florida International University, 2011

Miami, Florida

Professor Ronald E. Giachetti, Major Professor

This dissertation delivers a framework to diagnose the Bull-Whip Effect (BWE) in supply chains and then identify methods to minimize it. Such a framework is needed because in spite of the significant amount of literature discussing the bull-whip effect, many companies continue to experience the wide variations in demand that are indicative of the bull-whip effect. While the theory and knowledge of the bull-whip effect is well established, there still is the lack of an engineering framework and method to systematically identify the problem, diagnose its causes, and identify remedies.

The present work seeks to fill this gap by providing a holistic, systems perspective to bull-whip identification and diagnosis. The framework employs the SCOR reference model to examine the supply chain processes with a baseline measure of demand amplification. Then, research of the supply chain structural and behavioral features is conducted by means of the system dynamics modeling method.

The contribution of the diagnostic framework, is called Demand Amplification Protocol (DAMP), relies not only on the improvement of existent methods but also contributes with original developments introduced to accomplish 
successful diagnosis. DAMP contributes a comprehensive methodology that captures the dynamic complexities of supply chain processes. The method also contributes a BWE measurement method that is suitable for actual supply chains because of its low data requirements, and introduces a BWE scorecard for relating established causes to a central BWE metric. In addition, the dissertation makes a methodological contribution to the analysis of system dynamic models with a technique for statistical screening called SS-Opt, which determines the inputs with the greatest impact on the bull-whip effect by means of perturbation analysis and subsequent multivariate optimization. The dissertation describes the implementation of the DAMP framework in an actual case study that exposes the approach, analysis, results and conclusions. The case study suggests a balanced solution between costs and demand amplification can better serve both firms and supply chain interests. Insights pinpoint to supplier network redesign, postponement in manufacturing operations and collaborative forecasting agreements with main distributors. 


\section{TABLE OF CONTENTS}

CHAPTER

PAGE

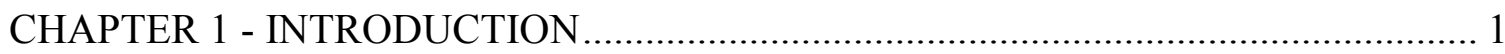

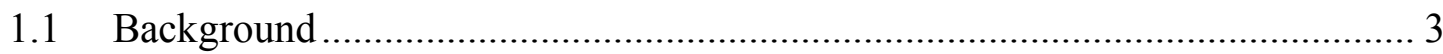

1.1.1 Causes of the Bullwhip Effect ………………...................................... 5

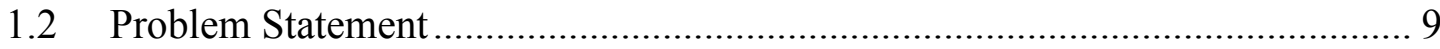

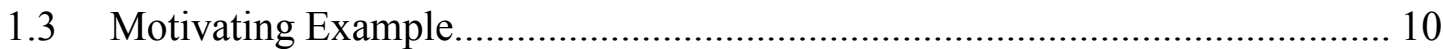

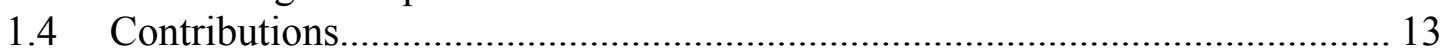

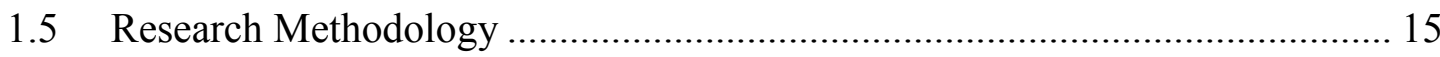

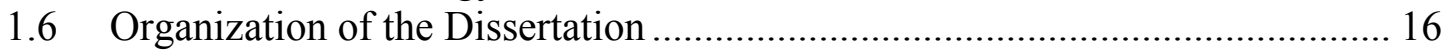

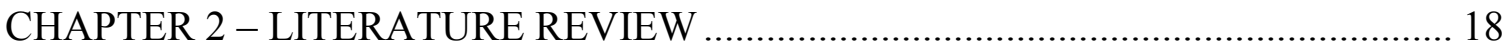

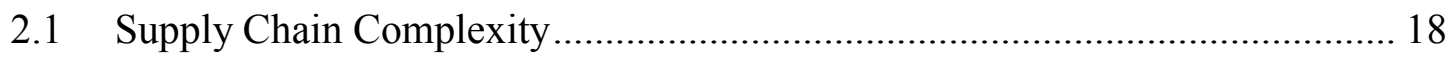

2.2 Supply Chain Diagnoses .............................................................................. 20

2.3 System Dynamics Modeling in Supply Chain Management ............................ 28

2.3.1 System Dynamics in Actual Supply Chain Case Studies …………………... 33

2.4 Bullwhip Effect Measurement ......................................................................... 42

CHAPTER 3 - DAMP DIAGNOSTIC FRAMEWORK ……....................................... 48

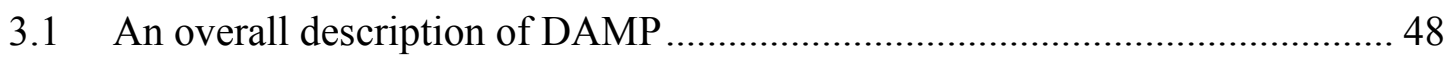

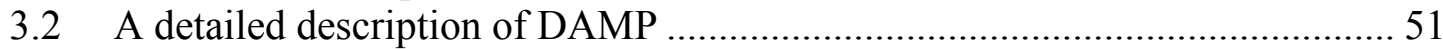

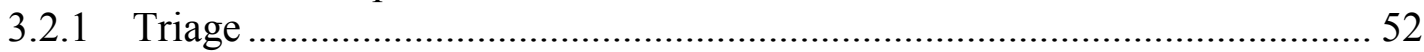

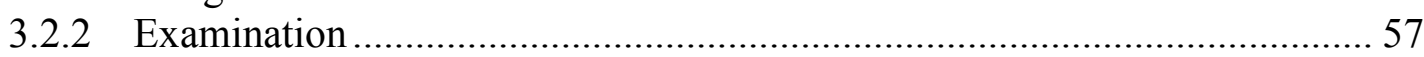

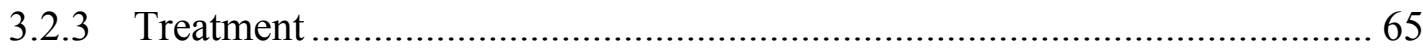

3.3 Measuring the Bullwhip Effect in Actual Supply Chains.................................... 66

3.4 Automated Calibration in System Dynamics................................................... 76

CHAPTER 4 - DAMP BUSINESS PROCESS DIAGNOSIS............................................. 83

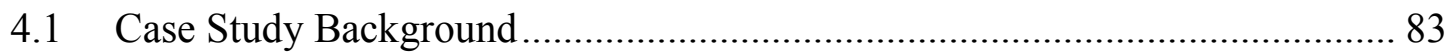

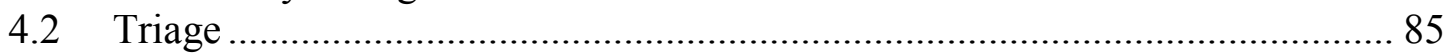

4.3 Examination - Business Process Diagnosis ……………………………….... 86

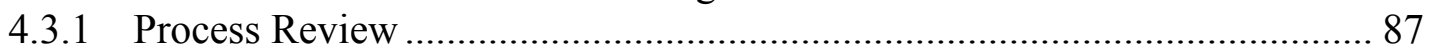

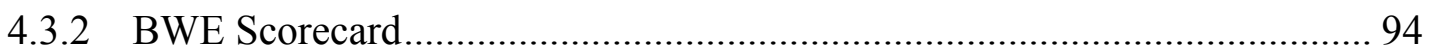

CHAPTER 5 - DAMP DYNAMIC DIAGNOSIS …………………………........... 108

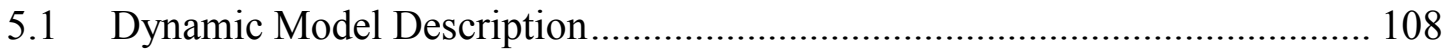

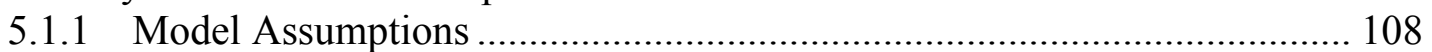

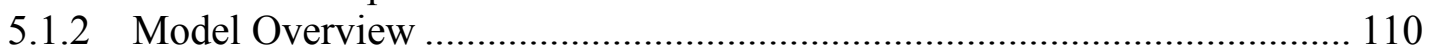

5.1.3 Manufacturer Model Components ............................................................ 113

5.1.4 Distributor Model Components ............................................................... 135

5.1.5 Retailer Model Components …………………….................................. 140 
5.1.6 MedLab Cost and Revenue Model ..................................................... 142

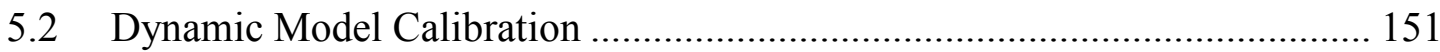

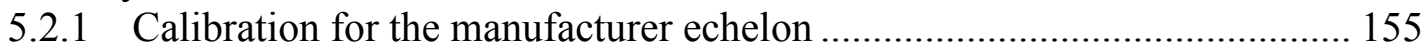

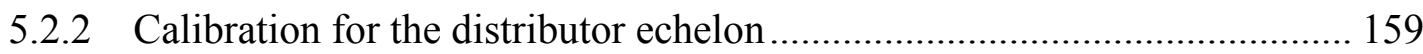

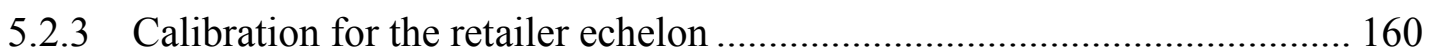

5.3 Dynamic Model Validation..................................................................... 162

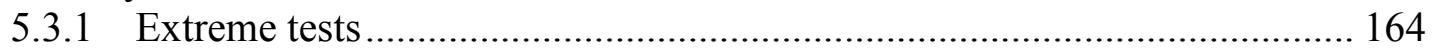

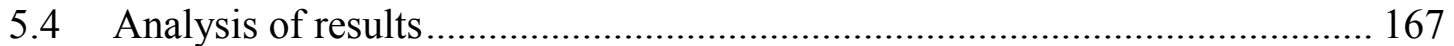

5.4.1 Perturbational Analyses ......................................................................... 168

5.4.2 Optimization Analyses....................................................................... 188

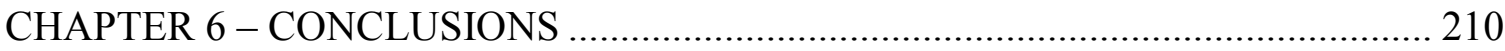

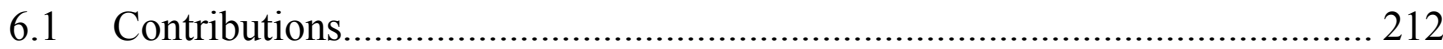

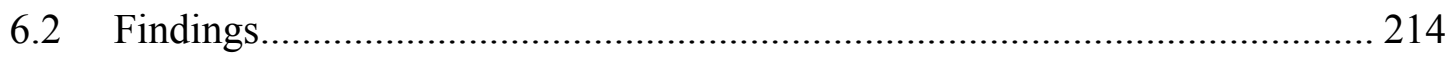

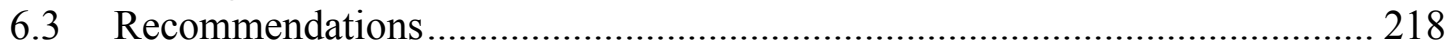

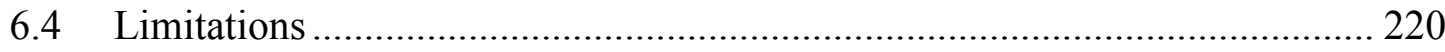

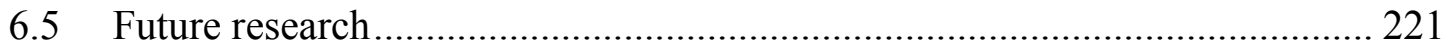

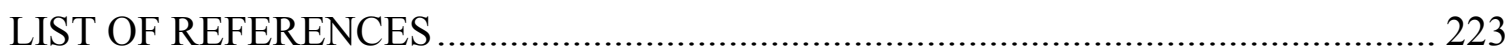

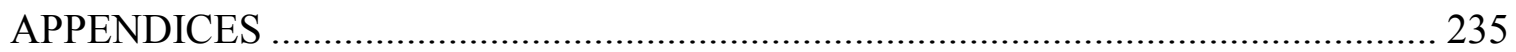

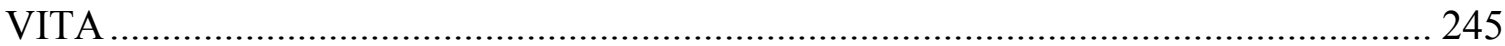


Table 1. Causes and counter-measures of the Bullwhip effect.................................... 7

Table 2. Comparisons of commercial and academic supply chain diagnostic tools........ 22

Table 3. Twelve rules for simplifying material flow ................................................ 23

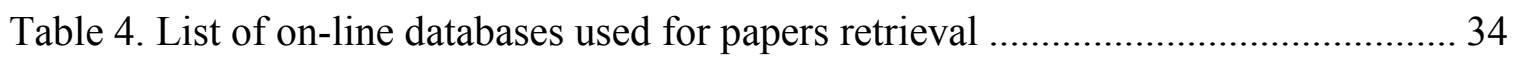

Table 5. Set of Metrics used in the Realistic Settings cases ...................................... 44

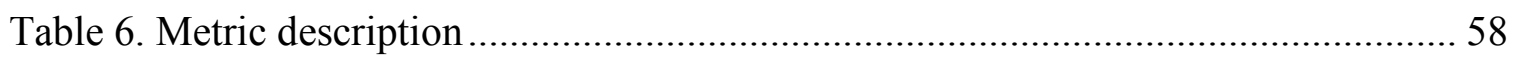

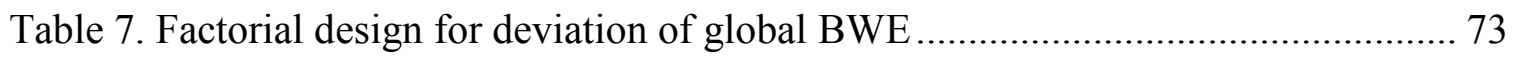

Table 8. Summary of techniques for estimating lengths and orders of delays ................ 78

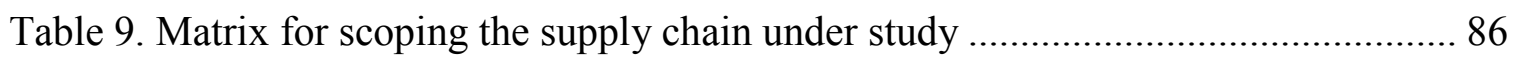

Table 10. Demand Amplification Quotient $(\omega)$ per Raw Material ................................. 95

Table 11. Export Orders variables definition............................................................ 124

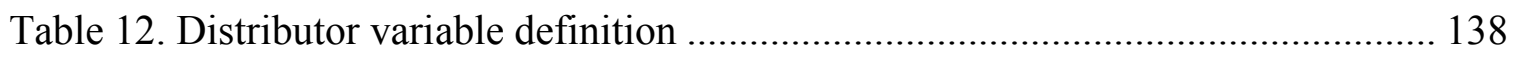

Table 13. Retailer variable definition ................................................................. 142

Table 14. Calibration reference variable per echelon ............................................. 153

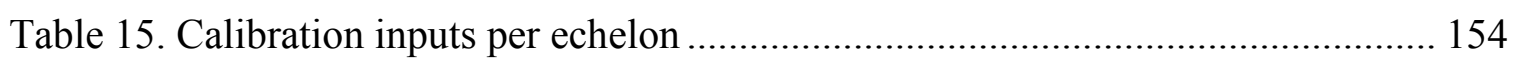

Table 16. Parameters to be calibrated, feasible ranges and fitted value per echelon...... 154

Table 17. Tests for assessment implemented in the model....................................... 162

Table 18. Balanced equilibrium SC model conditions ............................................. 173

Table 19. Step function parameters used …............................................................. 175

Table 20. Manufacturer Step Amplification Results ............................................... 175

Table 21. Supply chain step amplification results for separate inputs......................... 181 
Table 22. Supply chain step amplification results for combined input........................ 182

Table 23. Screened manufacturer's variables with levels........................................ 192

Table 24. Parameters for DAMD and statistical significance.................................... 193

Table 25. Parameters for GPRT and statistical significance....................................... 195

Table 26. Manufacturer significant parameters per response variable ......................... 195

Table 27. Screened supply chain's variables with levels........................................ 197

Table 28. Significant parameters for RETMAN .................................................... 198

Table 29. Supply chain significant parameters for RETMAN .................................. 199

Table 30. Input parameters for Manufacturer's optimization..................................... 200

Table 31. Bi-variate optimization results for Manufacturer's demand amplification .... 202

Table 32. Manufacturer's parameters changes for DAMD and GPRT optimality ......... 204

Table 33. Input parameters for demand amplification optimization........................... 205

Table 34. Results for Supply Chain's demand amplification after bi-variate manufacturer optimization ............................................................................ 209

Table 35. Summary of diagnosis and correspondent treatment ................................ 219

Table A- 1. Supply Chain Definition Matrix ............................................................. 236

Table C- 1. Exogenous Variables and Values ........................................................... 243

Table C- 2. Table Functions and Values................................................................ 244 


\section{LIST OF FIGURES}

FIGURE

PAGE

Figure 1. Logistics Network Structure ................................................................ 3

Figure 2. Demand Amplification in a 4-Echelon Supply Chain..................................... 5

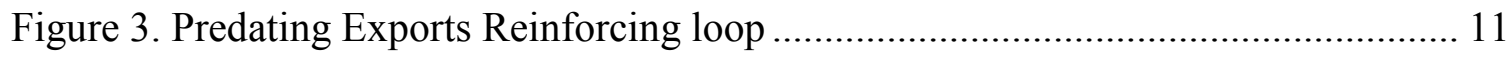

Figure 4. LSDG's integrated system dynamics framework for supply chain design. ...... 24

Figure 5. A Causal Loop: An Overview of the System Dynamics Modeling Approach.. 30

Figure 6. Stock and Flow variables and Underlying Differential Equation ................... 31

Figure 7. system dynamics modeling process..................................................... 33

Figure 8. Annual statistic of surveyed papers ......................................................... 35

Figure 9. Statistics of actual SC case studies modeled using SD ................................ 37

Figure 10. Framework for BWE Measurement Literature Review .............................. 42

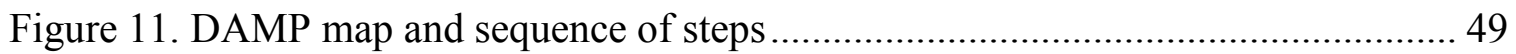

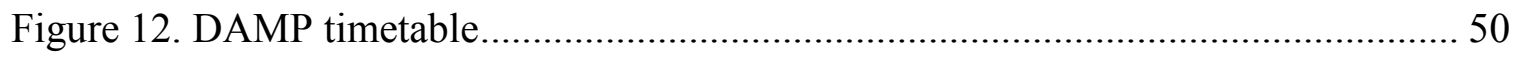

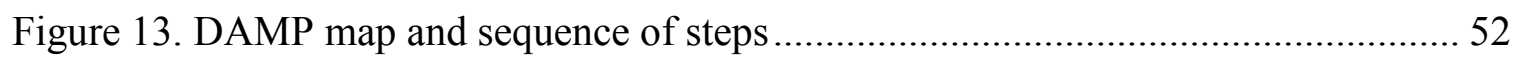

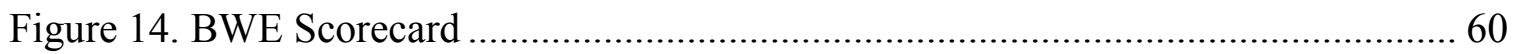

Figure 15. Dissimilar demand flows when sampling actual supply chains .................... 67

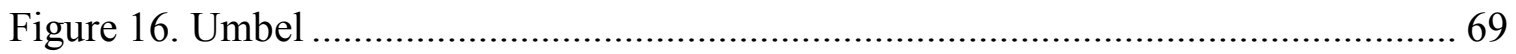

Figure 17. BWE estimation approach................................................................. 72

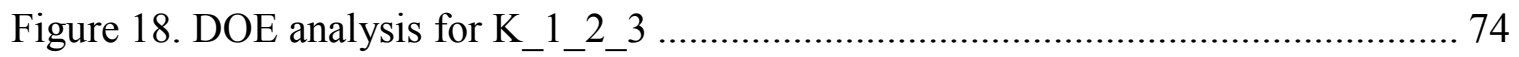

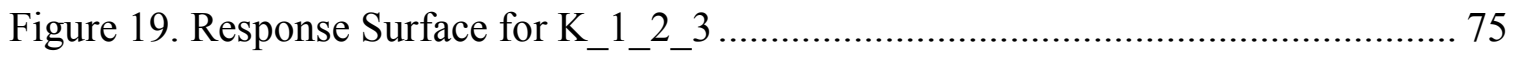

Figure 20. AS-IS Thread Diagram of MedLab Supply Chain ....................................... 89 
Figure 21. MedLab Process Connections at SCOR Level 3 ....................................... 93

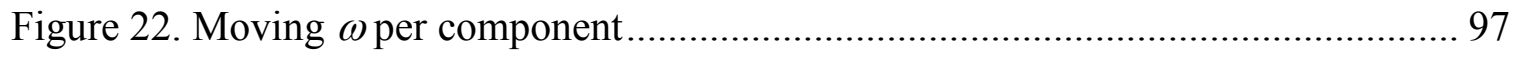

Figure 23. BWE overall and local measures along the MedLab-LM-RC chain.............. 98

Figure 24. Manufacturer's Operation detail for Partial BWE Measures ........................ 99

Figure 25. Partial BWE Measures for MedLab supply chain.................................... 100

Figure 26. BWE overall and local measures along the MedLab-LM-RC chain............ 102

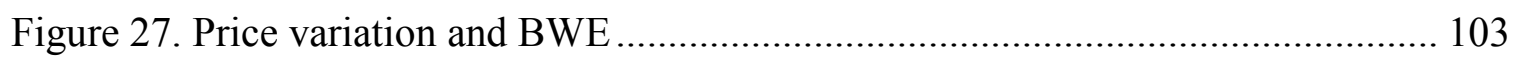

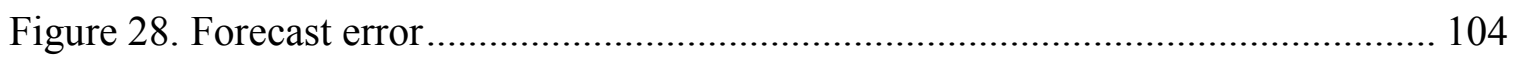

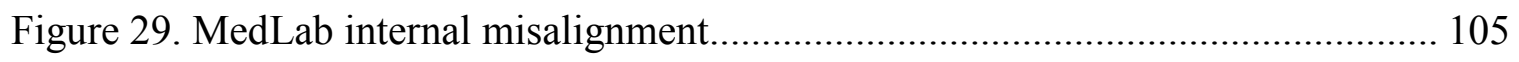

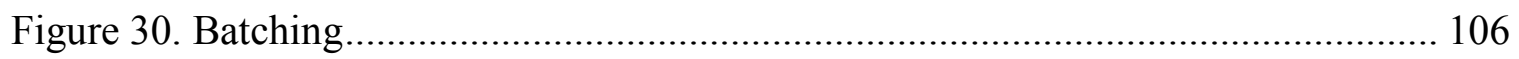

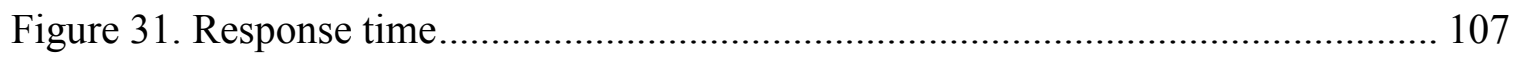

Figure 32. Policy Structure Diagram of the Supply Chain Model................................ 112

Figure 33. Overview of the SD Manufacturer Echelon Model..................................... 114

Figure 34. Order Fulfillment Ratio — Ideal and Actual.......................................... 120

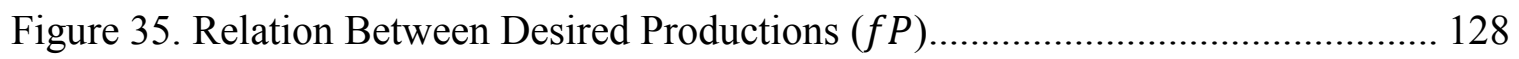

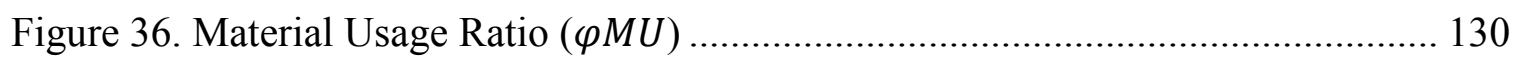

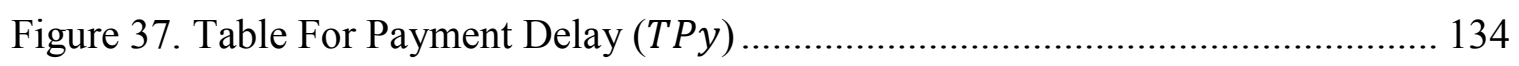

Figure 38. Overview of the SD Distributor Echelon Model..................................... 137

Figure 39. Overview of the SD Retailer Echelon Model.......................................... 141

Figure 40. Overview of the SD Manufacturer Profits Model ..................................... 144

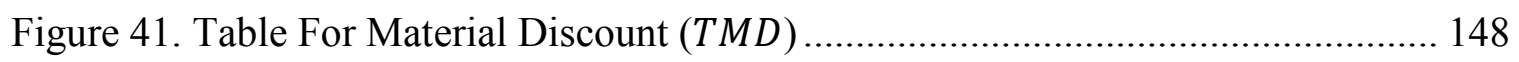

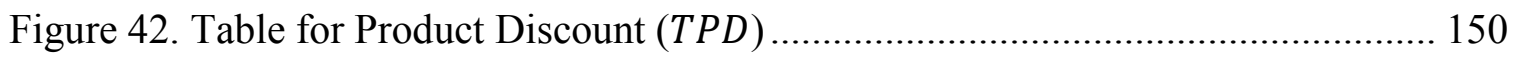


Figure 43. Materials Inventory (IM) graphical fit and Manufacturer's calibrated parameters

Figure 44. Manufacturer's residuals plot and analysis of fit for Materials

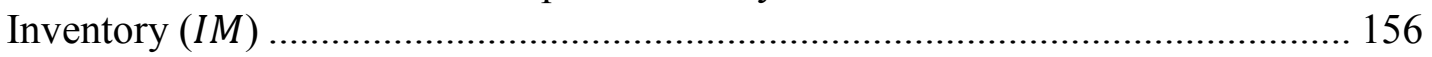

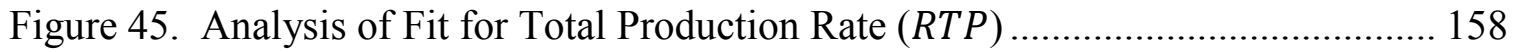

Figure 46. Manufacturer's residuals plot and analysis of fit for Total Production Rate $(R P T)$ 158

Figure 47. Analysis of Fit for Distributor Inventory (ID) 159

Figure 48. Distributor's residuals plot and analysis of fit for Distributor Inventory $(I D)$. 160

Figure 49. Analysis of Fit for Retailer Inventory $(I R)$ 161

Figure 50. Retailer's residuals plot and analysis of fit for Retailer Inventory $(I R) \ldots \ldots . .161$

Figure 51. Results for Extreme Test \#1 ............................................................. 165

Figure 52. Results for Extreme Test \#2 …......................................................... 167

Figure 53. Calibrated results for Gross Profit $(\mathrm{Pr})$................................................ 169

Figure 54. Calibrated results for Profit Rate $(R P r)$ and components ......................... 171

Figure 55. Equilibrium settings and inputs map ................................................ 174

Figure 56. MedLab Model's reaction to a Local and Export step ............................. 178

Figure 57. MedLab Model's reaction to a Combined demand step............................. 180

Figure 58. Demand amplification breaking points ............................................... 184

Figure 59. Manufacturer's demand amplification response for a combined step function 186

Figure 60. Demand amplification propagation through the supply chain model .......... 188

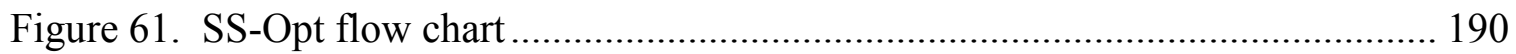

Figure 62. Standardized effects for DAMD screening ............................................. 194 
Figure 63. Standardized effects for GPRT screening .............................................. 196

Figure 64. Standardized effects for RETMAN screening............................................. 198

Figure 65. Optimization results for Manufacturer's Demand Amplification

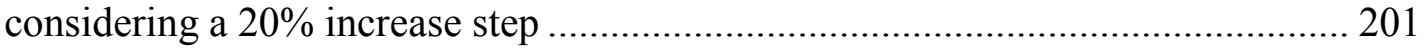

Figure 66. Optimized results for Manufacturer's Gross Profit considering a 20\%

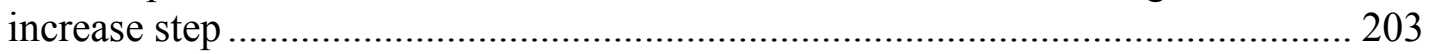

Figure 67. Optimization results for Supply Chain's Demand Amplification considering a 20\% increase step on the chain....................................................... 206

Figure 68. Optimized results for Gross Profit (GPRT) considering a 20\% increase

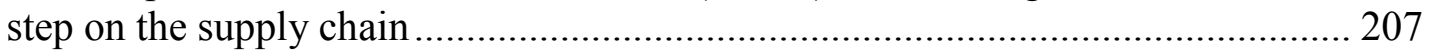




\section{LIST OF ACRONYMS}

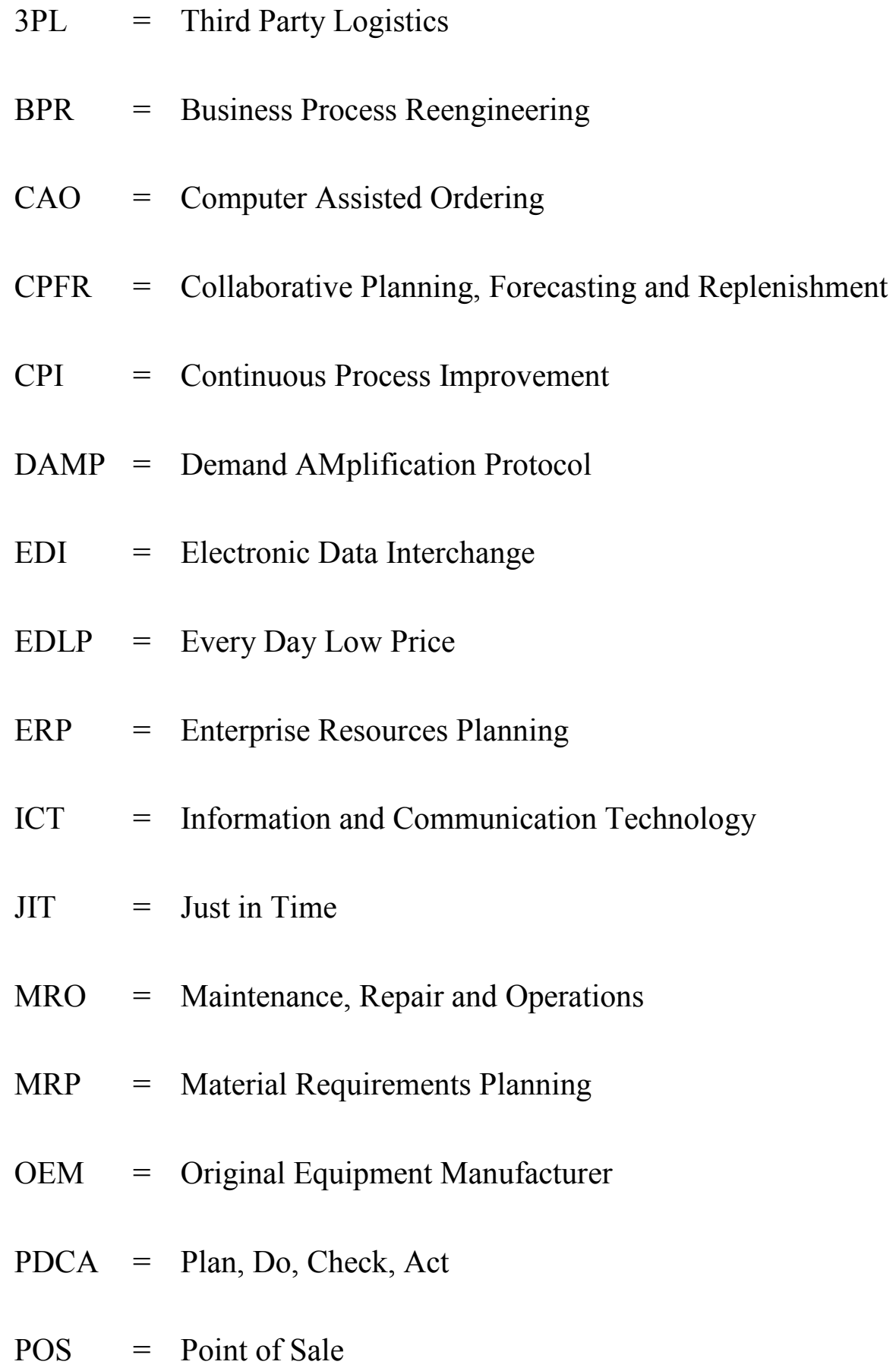




$$
\begin{array}{ll}
\text { QR } & =\text { Quick Response } \\
\text { QS } & =\text { Quick Scan } \\
\text { SC } & =\text { Supply Chain Management } \\
\text { SCM } & =\text { System Dynamics } \\
\text { SCOR } & =\text { Stock Keeping Unit } \\
\text { SD } & =\text { Theory of Constraints } \\
\text { SKU } & =\text { Vendor Managed Inventory } \\
\text { TOC } & =
\end{array}
$$




\section{CHAPTER 1 - INTRODUCTION}

Many companies continue to experience problems due to being part of poorly integrated supply chains that suffer from distorted demand information signals. Communication of needed information between companies in a supply chain can be difficult because of network complexity. The information is delayed and sometimes inaccurate when it is received at its destination. This brings about what is called the BullWhip Effect (Lee, Padmanabhan, and Whang, 1997b) or the demand amplification phenomenon (Forrester, 1961). The Bullwhip Effect (BWE) involves distorted information from one end of a supply chain to the other end, which can lead to tremendous inefficiencies such as excessive investment in inventory, poor customer service, lost revenues, misguided capacity plans, inactive transportation, and missed production schedules (Lee, Padmanabhan, and Whang, 1997a). Consequently, companies seek to eliminate or at least reduce the bullwhip effect.

Due to its relevance and profound impact in organizations, the bullwhip effect has become a significant research topic and there are even a large number of successful case studies reporting how the BWE was eliminated or mitigated in the literature (see next section). The present research addresses the bullwhip effect in supply chains because in spite of its being researched extensively and the many published case studies, we still lack a structured approach to diagnose the bullwhip effect that can be implemented in a wide set of actual supply chain scenarios. Thus, practitioners are left with a set of general guidelines that falls short in practical 
relevance when not accompanied by the expertise of a specialist. Childerhouse, Disney, and Towill (2004) state that regardless of the well documented and high profile supply chain success stories, the achievement of enhanced performance still tends to be the exception rather than the norm. They stress that the missing point is a robust, generic methodology to assist practitioners to plan, execute and successfully re-engineer supply chains.

The present work contributes with a systematical and structured approach to diagnose the bullwhip effect such that success does not depend on an expert's proficiency. There are a number of features that make DAMP unique: the use of the BWE scorecard including a low-data requirements method for estimating the overall BWE in actual supply chains, its dynamic diagnosis incorporating advanced system dynamics practices as model calibration and validation, and the use of newly-developed sensitivity and optimization methods for system dynamics models. The diagnostic framework has two model components we call Business Process Diagnosis and Dynamic Diagnosis. The first component uses classical business improvement methods such as process mapping and $\mathrm{PDCA}^{1}$ cycles to diagnose supply disruption signs and BWE causes. The second component is a simulation model to analyze and improve the dynamic performance of the supply chain. The research goal is to provide and demonstrate a diagnostic framework that will provide an affordable means for companies to diagnose and fix problems that lead to the bullwhip effect in their supply chains.

${ }^{1}$ PDCA: Plan, Do, Check, Act 


\subsection{Background}

The literature has offered a number of definitions for supply chain management. In this work, we use the following definition, "supply chain management includes all activities associated with the flow and transformation of goods from the raw material through to the end customer" (Handfield and Nichols, 1999).

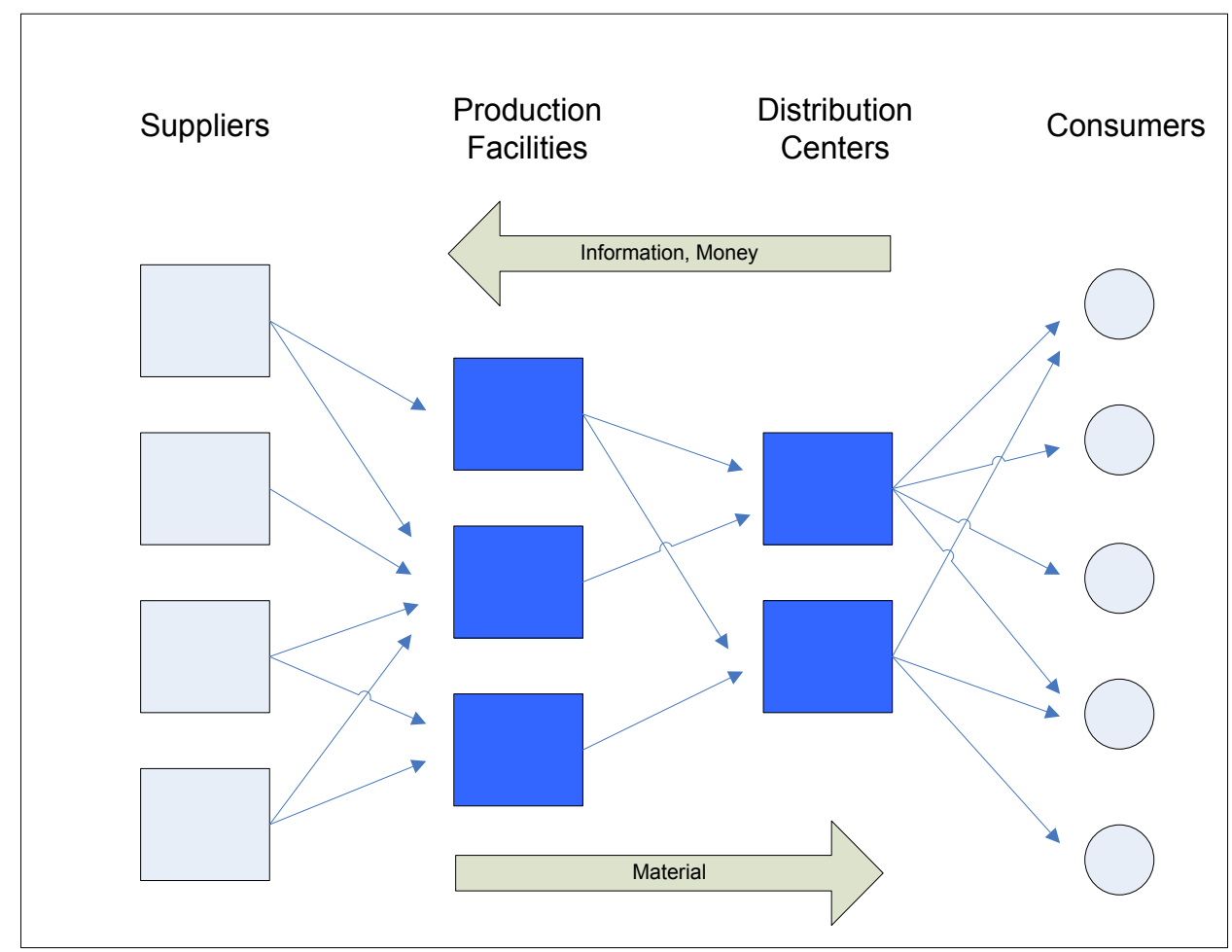

Figure 1. Logistics Network Structure

Figure 1 shows a typical supply chain configuration. Supply chains have bidirectional flows of materials, information, and money. In this work, the material flow is used as reference, and the term 'downstream' indicates the direction of the flow 
(e.g., supplier->factory->distributor->retailer->consumer). Conversely, 'upstream' denotes the opposite direction.

Forrester (1958) is the first author to formally document the demand amplification concept. Demand amplification, more commonly called the bullwhip effect, corresponds to the phenomenon where orders to suppliers tend to have larger variance than sales to buyers, and the distortion propagates upstream in an amplified form (Simchi-Levi, et al., 2004; Lee, et al, 1997; Sterman, 2000; Forrester, 1961). For instance, in examining the demand for Pamper's disposable diapers, executives at Procter \& Gamble noticed that even though retail sales of the product were fairly uniform, as expected for a product such as baby diapers, the distributors' orders placed to the factory fluctuated much more than retail sales. In addition, Procter \& Gamble's orders to its suppliers fluctuated even more (Lee, 2000). So clearly, something is happening between the customer and the supplier that distorts the demand signal.

Figure 2 shows a four-echelon supply chain consisting of a retailer, wholesaler, distributor, and a factory. The graph shows the demand at the customer level, which is the system input, and how the demand is seen at each echelon of the supply chain. The customer demand is level and then steps up momentarily and returns to its previous level. Yet, the demand at each of the supply chain echelons exhibits much greater and more chaotic behavior, creating problems for companies in trying to plan production and meet customer demand. Removing the causes of the bullwhip effect would go a long way to increase the efficiency of supply chain operations. 


\subsubsection{Causes of the Bullwhip Effect}

Table 1 lists a summary of causes and counter-measures relevant to the bullwhip effect. In addition, its last column includes the source of the contribution, chronologically addressed in the coming paragraphs.

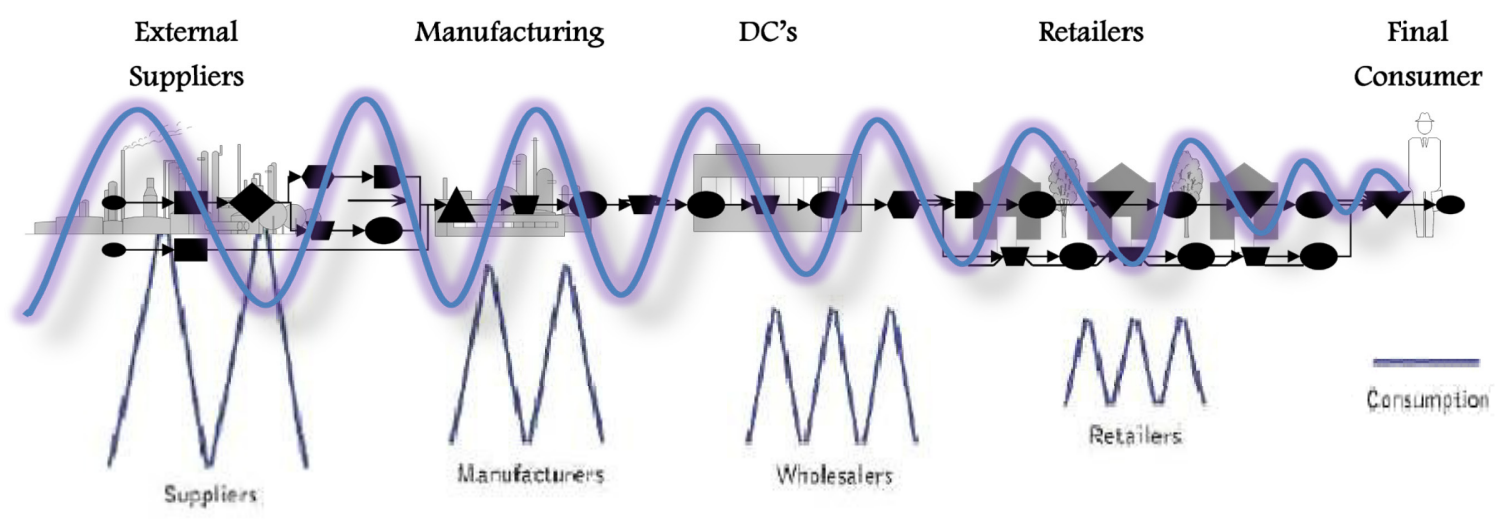

Figure 2. Demand Amplification in a 4-Echelon Supply Chain.

Forrester (1961) is one of the first authors to analyze the causes of the bullwhip effect. He states that the amplification and oscillation observed in multi-stage distribution systems can be answered by examining “...the basic internal behavior of the distribution system." He proposes that the usual combination of human decisionmaking reaction times, communication and transportation delays, and factory lead times will often yield systems that exhibit periodical oscillations. Such oscillations have serious cost implications. Forrester (1961) warns that “... typical manufacturing and distribution practices that can generate the type of business disturbances which are often blamed on conditions outside the company. Random meaningless sales fluctuations turn into annual, seasonal production cycles. Advertising and price discount policies of an 
industry can create two- and three-year cycles. Factory capacity, even though always exceeding retail sales, can seem to fall short of meeting demand, with the result that production capacity is overexpanded." The result is excess raw materials cost due to unplanned purchases of supplies, additional manufacturing expenses created by excess capacity, inefficient utilization and overtime costs, excess warehousing expenses and additional transportation costs due to inefficient scheduling and premium shipping rates. In the worst-case scenario, schedule variability increases, customer service goes down (dragging sales down), lead times lengthen, sales are lost, capacity is adjusted and costs go up.

Sterman (2000) proposes that the stock management structure ${ }^{2}$ can be used to explain the origin of oscillations observed in the supply chain. He explains it based on the presence of time delays with negative feedbacks that regulate the state of the system, with the joint and necessary condition of failure from the system's decision makers to account for these delays. This failure is part of what he has coined as human 'misperceptions' of system feedbacks (Sterman, 1989). Because supply chains are governed substantially by negative feedbacks and delays are recurrent, oscillation is a persistent condition in them. He states that these oscillations are endogenously produced by the interaction of the agents' decisions with the feedback structure of the system, instead of being produced by exogenous causes.

\footnotetext{
${ }^{2}$ A dynamic task involving a decision-maker that seeks to maintain a quantity at a particular target level, or at least within an acceptable range (Sterman, 1989)
} 
Table 1. Causes and counter-measures of the Bullwhip effect.

\begin{tabular}{|c|c|c|c|}
\hline Causes & Contributing factors & Counter-measures & Source \\
\hline $\begin{array}{l}\text { Long lead } \\
\text { times }\end{array}$ & $\begin{array}{l}\text { Communication and } \\
\text { transportation delays, } \\
\text { and factory lead times }\end{array}$ & $\begin{array}{l}\text { Reducing processes and } \\
\text { number of echelons, } \\
\text { improving response time }\end{array}$ & $\begin{array}{l}\text { Forrester } \\
(1961)\end{array}$ \\
\hline $\begin{array}{l}\text { Human } \\
\text { misperception }\end{array}$ & $\begin{array}{l}\text { Time delays with } \\
\text { negative feedbacks } \\
\text { that regulates the state } \\
\text { of the system, with } \\
\text { human failure to } \\
\text { account for these } \\
\text { delays }\end{array}$ & $\begin{array}{l}\text { Reduction of periodic } \\
\text { review, pull-based } \\
\text { operations, computer } \\
\text { systems }\end{array}$ & $\begin{array}{l}\text { Sterman } \\
\text { (1989) }\end{array}$ \\
\hline $\begin{array}{l}\text { Demand } \\
\text { signaling }\end{array}$ & $\begin{array}{l}\text { No visibility of end } \\
\text { demand. } \\
\text { Multiple forecasts. } \\
\text { Long lead-times. }\end{array}$ & $\begin{array}{l}\text { POS data sharing. } \\
\text { Centralized } \\
\text { replenishment control. } \\
\text { Lead-time reduction. }\end{array}$ & $\begin{array}{l}\text { Lee, et al. } \\
\text { (1997) }\end{array}$ \\
\hline $\begin{array}{c}\text { Order } \\
\text { batching }\end{array}$ & $\begin{array}{l}\text { High order cost. } \\
\text { Full-truck load } \\
\text { economies. } \\
\text { Random or correlated } \\
\text { ordering. }\end{array}$ & $\begin{array}{l}\text { EDI \& CAO. } \\
\text { Incentives on assorted } \\
\text { truckloads, 3PL } \\
\text { consolidation. } \\
\text { Regular delivery } \\
\text { appointment. }\end{array}$ & $\begin{array}{l}\text { Lee, et al. } \\
\text { (1997) }\end{array}$ \\
\hline $\begin{array}{l}\text { Fluctuating } \\
\text { prices }\end{array}$ & $\begin{array}{l}\text { High-low pricing. } \\
\text { Delivery \& } \\
\text { purchasing } \\
\text { asynchronized. }\end{array}$ & $\begin{array}{l}\text { Every Day Low Price } \\
\text { strategy. } \\
\text { Special purchase } \\
\text { contracts. }\end{array}$ & $\begin{array}{l}\text { Lee, et al. } \\
\text { (1997) }\end{array}$ \\
\hline $\begin{array}{l}\text { Rationing } \\
\text { game }\end{array}$ & $\begin{array}{l}\text { Proportional rationing } \\
\text { scheme. } \\
\text { Ignorance of supply } \\
\text { conditions. } \\
\text { Unrestricted orders \& } \\
\text { free-return policy. }\end{array}$ & $\begin{array}{l}\text { Allocate based on past } \\
\text { sales. } \\
\text { Shared capacity \& supply } \\
\text { information. } \\
\text { Flexibility limited over } \\
\text { time; capacity reservation. }\end{array}$ & $\begin{array}{l}\text { Lee, et al. } \\
\text { (1997) }\end{array}$ \\
\hline
\end{tabular}

Lee, et al. (1997) found that the bullwhip effect is an outcome of the strategic interactions among rational supply chain members, highlighting the fact that decisionmakers here are rational and optimizing as opposite to 'misperceptors' and incapable of optimizing. They develop supply chain's mathematical models that capture essential 
aspects of the institutional structure and optimizing behavior of members, also describing multiple sources of demand amplification.

Demand signal processing refers to the situation where demand is variable, and hence forecasting techniques are used to determine future demand; Lee, et al. (1997) reaffirm the results obtained by Forrester; proving that demand variance amplification takes place when implementing inventory periodic reviews based on forecasted demand. Further, they showed that the amplification is aggravated by increases in the replenishment lead times.

Another cause is the rationing game, which is when the supplier experiences shortage situations such that demand exceeds their capacity. In response to the risk of partial allocation of orders, several of their customers place inflated orders aiming to maximize their share of supplier's limited production since it is competing against the other supplier's customers.

Order batching is done to achieve economies of scale and involves a deliberate delay in actions to accumulate volume and reduce cost. As a result of batching, what initially tended to be a continuous demand pattern is transformed into a patchy demand pattern that depends on factors such as the retailer's perception of demand, forecasting ability, inventory policy and the extent of the order lead time. Each echelon in turn receives distorted information that is further distorted each time it goes through the similar ordering decision-making process of the next stage. For 
example, Caplin (1985) reported the presence of variability on aggregate demand with the use of $(\mathrm{s}, \mathrm{S})^{3}$ inventory policies.

Price variation corresponds to a situation of non-constant purchase prices of products (e.g., discounts, promotions). They also add to demand amplification because this introduces initial disturbances that might be interpreted as a false demand increase. It follows that during discount epochs, customers will stock up, and during regular epochs, customers will order as little as possible, clearly introducing variations that might introduce noise into the system.

Trade estimates suggest that the bullwhip effect can increase costs by $12.5 \%$ to 25\% (Kurt Salmon Associates, 1993). Metters (1997) estimates bullwhip costs of 5\%-10\% due to batching effects and $15 \%-10 \%$ due to special promotions. Further, McCullen and Towill (2002) provide a lower bound on the benefits of bullwhip reduction ranging from $22.1 \%$ up to $52.7 \%$ on profitability.

\subsection{Problem Statement}

This dissertation deals with the lack of engineering tools and methods to diagnose and identify solutions to the bullwhip effect in actual supply chains. The lack of a structured diagnostic framework capable of identifying the causes behind demand amplification in actual systems is one of the main reasons it continues to be a problem in supply chains (McCullen and Towill, 2002).

\footnotetext{
${ }^{3}$ Also known as Min-Max system. To pursue an (S, s) inventory policy, the retailer establishes a lower stock point $\mathrm{s}$, and an upper stock point $\mathrm{S}$. No order is placed until inventories fall to $\mathrm{s}$ or below, whereupon they are restored to the maximum of $\mathrm{S}$.
} 
Without adequate tools and methods, it is difficult for companies to identify and isolate the root causes of demand amplification. Existing diagnostic approaches are based on general principles that owe their success more to the analyst's expertise than to a systematical and structured approach to resolve demand amplification. These general guidelines are often difficult to apply in actual situations because of the difficulty in matching the actual supply chain structure to theoretical models and the unavailability of data. Hence, a customizable diagnostic approach is valuable when demand amplification sources are blurry and might hide or intertwine with others. Yet, the only existing diagnostic approach, capable of providing a customized modeling approach with dynamic diagnosis features, is the Cardiff Approach (Naim and Towill, 1994). The Cardiff approach is reviewed in Sections 2.2.

\subsection{Motivating Example}

This research has been motivated in part by a study of a company that experiences difficulties with the bullwhip effect. The study demonstrated that even though the BWE problem is well documented, it is difficult for companies to identify it, diagnose its causes, and take remedial action.

MedLab $^{4}$ is a South American manufacturer of sterile medical supplies, specializing in the production of plastic widgets. We conducted a study, using the statistical measures proposed by Fransoo and Wouters (2000), which confirmed the existence of the bullwhip effect. The bullwhip effect have put this firm under a lot of financial pressure. They have experienced lost sales in spite of the high levels of

\footnotetext{
${ }^{4}$ The actual name has been changed for confidentiality reasons
} 
inventory they carry. Concurrently, the company has had to deal with the incursion of Chinese competitors, which has forced down profit margins of the company. The supply chain inefficiencies and foreign competition have decreased the company's market share and reduced its cash flow, which together have the firm on the verge of going out of business.

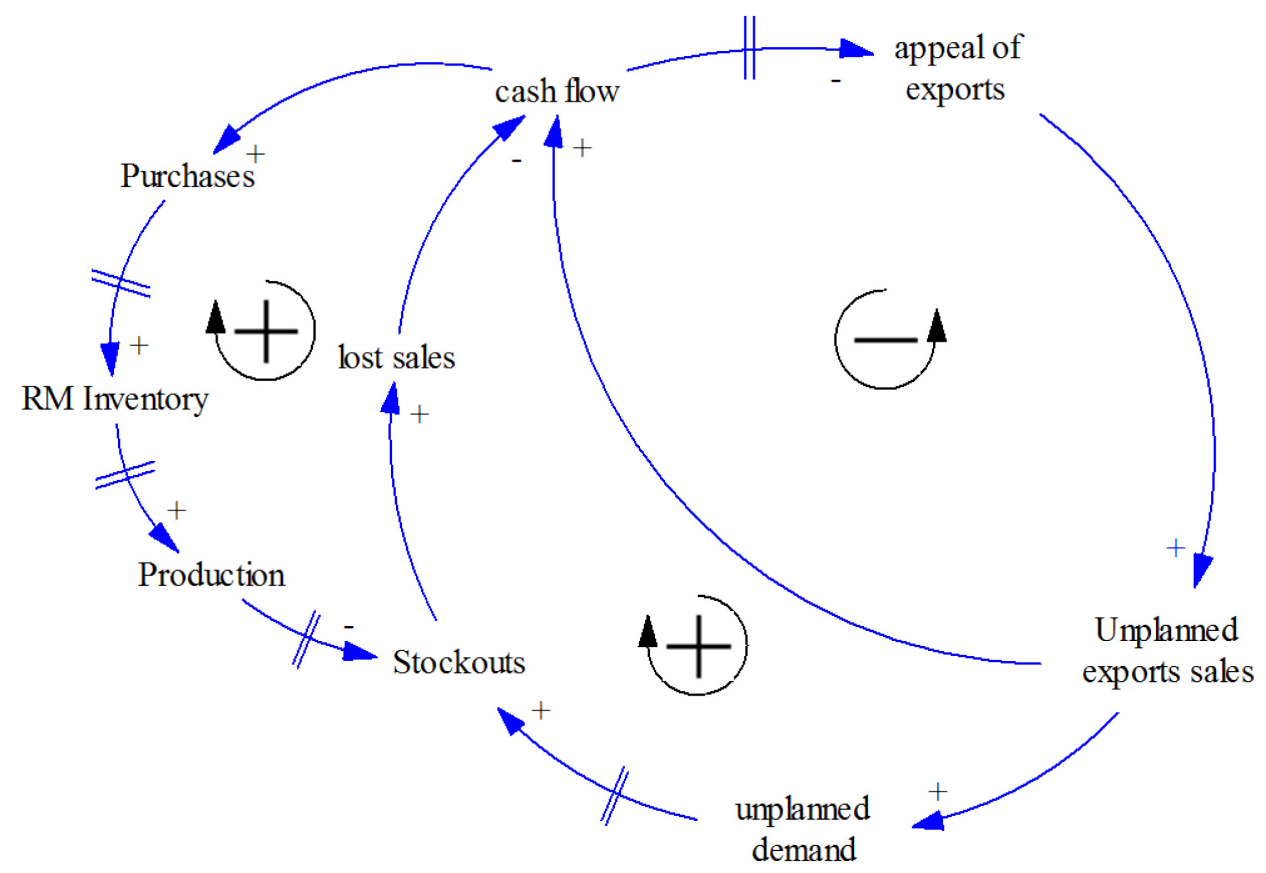

Figure 3. Predating Exports Reinforcing loop

A preliminary review of the company's processes and practices using classic BWE annalists approaches (Business Process Diagnosis) quickly revealed the presence of almost all of the acknowledged causes of demand amplification. Yet, in practice management did not think it prudent to undertake multiple radical changes to their operations, because under their diminished financial position, a wrong decision would have taken them out of business as well. It made more sense to prioritize measures to 
counteract demand amplification on a cost/impact basis. Unfortunately, current knowledge is insufficient to identify the most high-impacting actions to take because of the complexity and interdependencies inherent in supply chain operations.

In time and after a deeper diagnosis, it became clearer that one of the main BWE causes in MedLab was a poor production planning scheme, through which they planned for regular local sales and to, a large extent, improvised on exports sales. Even when margins tended to be narrower for exports than for local sales and the servicing cost of unplanned export orders was higher, a constrained cash flow situation gave higher priority to exports since they provided quick cash. For this reason, it seemed reasonable to relax commercial policies and to admit short notice orders, as exposed in the balancing loop denoted with the negative sign in Figure 3. Therefore, unplanned export sales dominated local sales and quickly consumed the finished goods inventory originally destined for local sales. Since manufacturing rates were not fast enough to replenish inventory as needed, stockouts occur and local sales are lost. Furthermore, even after a stockout the manufacturing capacity was oftentimes still dedicated to deliver pending exports orders due to late delivery penalty pressures and the risk of losing important accounts, further exacerbating the local market's strangulation. This in turn ended up in further reduced cash flow, in a vicious cycle featuring the systems dynamics archetype of exponential decline denoted by the lower positive sign reinforcing cycle of Figure 3. Moreover, a weaken cash flow induces a constrained purchased practice, which further delays the already slow replenishment rate of raw material inventory, affecting smooth production and again resulting in more lost sales. 
The former observations cannot be easily diagnosed with classical BWE analysts techniques. At best, there is a connection with 'demand signaling' since it is related to poor forecasting and planning, as well with the 'order batching' practice, but way beyond its original inception. The point made in this section is that it is not straightforward to find the causes of the BWE and it is difficult to apply general principles to specific cases. Bullwhip causes are not simple cause-effect but are more complicated networks of causes and effects, hence blindly tackling a single BWE cause would not necessarily reduce the overall BWE effect.

\subsection{Contributions}

This research contributes to the field of supply chain management by devising a diagnostic framework both implementable and effective for reducing the bullwhip effect in actual supply chains. Most published papers discussing the bullwhip effect concentrate on theoretical models assessed for establishing the presence or determining the causes of bullwhip. Only a few research papers, notably Supply-Chain Council (2003), Naim, Childerhouse, Disney and Towill (2002) and McCullen and Towill (2002), develop methods to diagnose supply chains, as discussed in Section 2.2.

Only one method comes close to bullwhip effect diagnosis, which is the Cardiff approach (P. McCullen and Towill, 2002; Naim and Towill, 1994). Yet, the Cardiff approach falls short of the diagnostic purpose because its diagnosis basis is currently based in prescriptive general principles. Regardless of the supply chain being diagnosed, the analyst only needs to apply twelve principles as to improve bullwhip. As showed in Section 1.3, actual cases are more complex and good practices may not be 
able to address the specifics of actual supply chains. Furthermore, the lacking of dynamic diagnosis capabilities prevents full BWE diagnosis.

To address the problem of diagnosing BWE, the diagnostic framework called Demand Amplification Protocol (DAMP) is proposed. DAMP constitutes a methodological contribution not only because it improves or synergize existing methods. Original contributions also include a new approach for estimating the overall bullwhip effect in actual multi-echelon supply chains (see Section 3.3). The method is tailorable to a particular company and its environment, it supports measurement in more than a dyadic relationship and it has low data requirements.

We have introduced what is herein termed as BWE scorecard, a novel instrument for monitoring in a single view a set of metrics related to BWE known causes and impacts. The BWE scorecard points to amplification causes by presenting time series and metrics that if correlated to a central BWE metric enables diagnosis, as shown in Figure 14 and described in Step 9 of Section 3.2.2.1.

In addition, we have devised a sequenced approach for identifying sensitive SD model parameters and optimizing towards desired targets, we call it SS-Opt. Using statistical screening (Ford and Flynn, 2005) via Design of Experiments (DOE), we determine the most sensitive inputs to a BWE model. Chosen inputs are used in a subsequent optimization of the model. The contribution is made possible because of original BWE metrics coded in the SD model as well as an automated extension of Ford and Flynn's method using VBA codes to interconnect Vensim ${ }^{\circledR}$ with external software, developed by Soto (2010). It contributes with the introduction of a structured method 
for a task that takes long even for an experienced SD modeler to master, in response to "largely missing (...) formal analysis tools needed to increase the efficiency of the existing (SD) practice" (Güneralp, 2006).

\subsection{Research Methodology}

This research follows the constructive research methodology. Constructive research is a semi-inductive approach starting from theory and case studies, shaping hypotheses, and from there building a theory, a model or framework( Kasanen and Lukka, 1993).

In the constructive research approach, an actual business problem is solved in one or more case organizations by developing a novel solution that also has a scientific contribution. In this rhetoric, the researcher relies on the diffusion of solution ideas and argues that the successful implementation of the solution concept in the case organizations makes it credible that the solution will also work in similar organizations elsewhere. The final proof is left for confirmation in additional case studies and other empirical research, in adherence to the pragmatist notion of truth (James, 1955; Lukka and Kasanen, 1995). A necessary condition for the credibility of such rhetoric is the real-world implementation and functioning of the proposed solution concept. This kind of research is aimed at designing 'solution-oriented research products,' rather than deducing 'analysis-based explanations.'

The constructive research method is more suitable to the applied nature of the research problem dealt with in this work. DAMP has grown from the experience of 
implementing its formula; a case study has been prominent to its present form, providing valuable feedback on its desirable and unwise features. The learning and research contributions comes to a great extent from experience in implementing the method from which it also validates results.

\subsection{Organization of the Dissertation}

The document is organized as follows: Chapter 1 introduces the reader to the bullwhip effect in supply chains, it states the research problem and it describes the research method to achieve an effective BWE diagnosis framework.

Chapter 2 reviews the literature on the bullwhip effect, specifically targeting diagnostic frameworks and current methods to measure BWE in supply chains. Special attention is given to the system dynamics method applied in supply chains.

Chapter 3 describes the Demand Amplification Protocol (DAMP framework) and its steps and tools. It describes the composing stages of the methodology distinguishing Triage, Examination and Treatment. From the Examination stage, it highlights the main diagnostic approaches: the Business Process and Dynamic diagnosis

Chapter 4 illustrates with a case study the Business Process Diagnosis, one of the two main components of DAMP. It describes the Triage as well as the initial part of the Examination stage.

Chapter 5 describes on the application of the Dynamic Diagnosis to the case study, the second main component of DAMP. Extensively, illustrates a formal method for conducting SD based analysis in actual cases. Chapter 5 also includes model 
description, calibration and validation. It closes with the application of SS-Opt, a sequential method for conducting sensitivity analysis and optimization.

Chapter 6 describes the research contributions and conclusions. It discusses limitations of the DAMP framework and outlines future research. 


\section{CHAPTER 2 - LITERATURE REVIEW}

This chapter integrates a number of different literature reviews conducted for the study. The first section describes complexity arising from supply chains that sustain the need for diagnostic methods. The next section discusses current supply chain diagnostic methods and the extent in which these relate to the bullwhip effect. The third one reports on the use of system dynamics in supply chains, with special emphasis in actual implementation on case studies. The fourth section is concerned on the revision of bullwhip effect measuring approaches in supply chains.

\subsection{Supply Chain Complexity}

Supply chain systems are complex for a number of reasons. We distinguish between two sources of supply chain complexity: the first is associated with the difficulty of managing a high number of products and customers tied in a net governed by numerous firms and internal departments with misaligned processes and objectives. We term this conventional complexity, which originates from the numerous entities to be managed over a lengthy and fragmented process characteristic of a supply chain.

The second source of complexity arises from the particular structure of the supply chain, such as feedback structures, interconnections between variables that are not evident, numerous delays in processes, and human bounded rationality that make system behavior counterintuitive and difficult to predict or manage. After Senge (1993), we call this dynamic complexity. Both sources of complexity add to BWE in supply chains. 
Supply chains are a large and distinctive sequence of intertwined processes linked to a good and/or a service that serves a particular group of customers. Since most firms transform and deliver diverse products to multiple customers, it follows that numerous supply chains might coexist in a single firm.

The bullwhip effect has been shown to emerge from a clear set of conditions dependent on the number of intermediaries, information quality and regular business practices such as forecasting, batching, promotions and unreliable partners (Lee, Padmanabhan and Whang, 1997b).

Such BWE conditions are listed in 4.3.2, and causes behind them includes conflictive interests, functional orientation, fragmented chains and local optimization. We denominate as Conventional Complexity conditions and originating causes aforementioned because they have been established for supply chains and there is ample diffusion of them. BWE conditions can be uncovered by a structured revision of processes, policies and business practices over an actual supply chain.

Another sort of complexity is termed Dynamic Complexity by Senge (1993).Forrester (1961) and Sterman (1989) propose structural factors of the system as endogenous origins of a complex system's behavior, which means that the magnitude of variables and the way in which they relate (e.g. loops) determines behavior. Yet, feedback structures within a system interact and exhibit relative dominance in time (Forrester, 1982), held responsible for a variety of behavior modes ranging from exponential decay, exponential growth or decay, sustained oscillation, convergent oscillation, divergent oscillation (Saleh and Davidsen, 2001; Sterman, 2000). 
Interestingly, BWE is associated with oscillatory modes of behavior which if properly diagnosed brings control to such phenomenon. A number of authors (Kampmann, 1996; Oliva and Mojtahedzadeh, 2004; Richardson and Pugh, 1981; Saleh, 2002) have undertaken the research task of developing frameworks for linking structure to behavior by eigenvalue elasticity analysis of linearized models, since each behavior mode is uniquely determined by a particular conjugate pair of eigenvalue and eigenvector.

Because of its structural nature, behavior modes are borne out of the specifics of a given supply chain configuration. We claim that the incidence of Dynamic complexity in supply chains is by no means trivial to diagnose; rather, it requires expert intervention to determine the sources of oscillatory behavior specific to each case structure. Hence, a diagnostic method lacking exploration of dynamic sources of BWE also misses potential BWE causes that prevents full diagnosis.

\subsection{Supply Chain Diagnoses}

According to the Merriam-Webster Dictionary, the term diagnosis corresponds to "investigation or analysis of the cause or nature of a condition, situation, or problem." Further, the Encyclopædia Britannica defines diagnosis ${ }^{5}$ as "the process of determining the nature of a disease or disorder and distinguishing it from other possible conditions." The notion of diagnosis relates to sophisticated knowledge applied to the subject under study that enables the distinction of the causes of the subject's problem.

5 "diagnosis." Encyclopædia Britannica. 2006. Encyclopædia Britannica Online. 3 Apr. 2006 $<$ http://search.eb.com/eb/article-9106175>. 
Such knowledge is built upon deep involvement and intensive experiences that allows for reacting to minimum clues, to interrelate data, to notice what is incongruent, and to recognize what is experienced, felt and thought (Wolf, 1994).

Supply chain diagnostics is a structured, disciplined assessment of the supply chain (Allvine and Gore, 2003), designed to identify actionable improvement opportunities that will deliver sustainable improvements in a company's. Table 2 shows a summary of supply chain diagnostic methods gathered by Foggin, et al. (2004) and further reviewed by the author. A description and discussion of each reported diagnostic framework follows. However, the discussion and further description centers on the first framework, namely the Cardiff Approach, from the existing methods found as the most aligned with the current research objective.

Naim and Towill (1994), from the Cardiff University's Logistics Systems Dynamics Group (LSDG), present a relevant contribution denoted in Table 2 as Cardiff Approach. They claim that their methodology “(...) which has evolved over several decades, provides a suitable framework for effective change". They have condensed from its experience a set of indicators, models, smooth material flow principles and bullwhip causes (Childerhouse, Disney and Towill, 2004) posed as universal and sufficient to significantly reduce bullwhip (McCullen and Towill, 2002). 
Table 2. Comparisons of commercial and academic supply chain diagnostic tools

\begin{tabular}{|c|c|c|c|c|c|c|}
\hline Year & Title & Description & $\begin{array}{l}\text { Time to } \\
\text { complete }\end{array}$ & Scope & $\begin{array}{c}\text { Compliance } \\
\text { with business } \\
\text { process } \\
\text { diagnosis? }\end{array}$ & $\begin{array}{c}\text { Compliance } \\
\text { with dynamic } \\
\text { diagnosis? }\end{array}$ \\
\hline 1994 & $\begin{array}{c}\text { Cardiff } \\
\text { Approach }^{\mathrm{e}}\end{array}$ & $\begin{array}{l}\text { Supply chain } \\
\text { analysis }\end{array}$ & $\begin{array}{l}\text { Extensive and } \\
\text { unknown }\end{array}$ & $\begin{array}{c}\text { UDSO } \\
\text { BWE causes } \\
\text { identification } \\
\text { Four generic material } \\
\text { flow principles }\end{array}$ & Yes & Yes \\
\hline 1996 & $\begin{array}{l}\text { Supply Chain } \\
\text { Operations } \\
\text { Reference } \\
\text { Model } \\
(\text { SCOR) })^{\mathrm{a}} \\
\end{array}$ & $\begin{array}{l}\text { Self- } \\
\text { diagnostic } \\
\text { tool }\end{array}$ & $\begin{array}{l}\text { Extensive and } \\
\text { unknown }\end{array}$ & $\begin{array}{c}\text { General } \\
\text { applicability. Process } \\
\text { maps and metrics. }\end{array}$ & Yes & No \\
\hline 1999 & $\begin{array}{l}\text { Performance } \\
\text { Measurement } \\
\text { Group }^{c}\end{array}$ & $\begin{array}{c}\text { Benchmarking } \\
\text { tool }\end{array}$ & $\begin{array}{l}\text { 20-40 person } \\
\text { hours }\end{array}$ & $\begin{array}{c}\text { SCOR based } \\
\text { benchmark service. } \\
\text { Metrics }\end{array}$ & Yes & No \\
\hline 2002 & Quick Scan $^{\mathrm{d}}$ & $\begin{array}{l}\text { Supply chain } \\
\text { analysis }\end{array}$ & $\begin{array}{l}9 \text { person days; } \\
2 \text { weeks start to } \\
\text { finish }\end{array}$ & $\begin{array}{l}\text { SC Integration (initial } \\
\text { diagnostic). } \\
\text { Improvement of } \\
\text { information and } \\
\text { communication } \\
\text { technologies }\end{array}$ & Yes & No \\
\hline
\end{tabular}

Central to their framework, Towill (1999) proposed the set of twelve simplicity rules ${ }^{6}$ aimed at achieving a simplified material flow and shown in Table 3.

\footnotetext{
${ }^{6}$ Such rules can be traced back to Wikner, Towill and Naim (1991) and are claimed to be inspired upon the fundamental theoretical and practical work started in this field by Jay Forrester (Forrester, 1961) and Jack Burbidge (Burbidge, 1978). They can also be mapped into an updated version in the form of four material flow principles (P. McCullen and Towill, 2001) for dampening demand amplification. Similarly, they are rendered as appropriate to all those supply chains bearing a reasonably close resemblance to the multiechelon Forrester model (Forrester, 1961). These are:

1. Control systems principle: involves the selection of decision support systems which contribute to the dynamic stability of the total supply chain

2. Time compression principle: every activity should be done in the minimum time and achieve
} 
Although such general principles intuitively make sense, there seems to be a missing part between the original and current version of the Cardiff's Approach. Backtracking on LSDG works, Naim and Towill (1994) provides what seems to cover for such gap in the form of a holistic framework for diagnosing supply chains using systems dynamics. Figure 4 illustrates the approach, comprised by two overlapping phases, qualitative and quantitative.

Table 3. Twelve rules for simplifying material flow

\begin{tabular}{cl}
\hline \multicolumn{1}{c}{ \# } & $\begin{array}{l}\text { Only make products which you can quickly dispatch and } \\
\text { invoice to customers }\end{array}$ \\
Rule 1 & $\begin{array}{l}\text { Only make in one period those components you need for } \\
\text { assembly in the next period }\end{array}$ \\
\hline Rule 2 & Minimize the material throughput time \\
\hline Rule 4 & $\begin{array}{l}\text { Use the shortest planning period (i.e., the smallest run } \\
\text { quantity which can be managed efficiently) }\end{array}$ \\
Rule 5 & $\begin{array}{l}\text { Only take deliveries from suppliers in small batches as and } \\
\text { when needed for processing or assembly }\end{array}$ \\
\hline Rule 6 & Synchronize 'Time Buckets' throughout the chain \\
Rule 7 & $\begin{array}{l}\text { Form natural clusters of products and design processes } \\
\text { appropriate to each value stream }\end{array}$ \\
\hline Rule 8 & Eliminate all process uncertainties \\
\hline Rule 9 & $\begin{array}{l}\text { Understand, document, simplify and only then optimize } \\
\text { (UDSO) the supply chain }\end{array}$ \\
\hline Rule 10 & Streamline and make highly visible the information flows \\
\hline Rule 11 & Use only proven simple but robust Decision Support Systems \\
\hline Rule 12 & The business process target is the seamless supply chain \\
\hline
\end{tabular}

Source: extracted from Towill (1999)

their goals accurately.

3. Information transparency principle: emphasize the importance of sharing most updated information without noise and bias.

4. Echelon elimination principle: involves the elimination of echelons and functional interfaces 


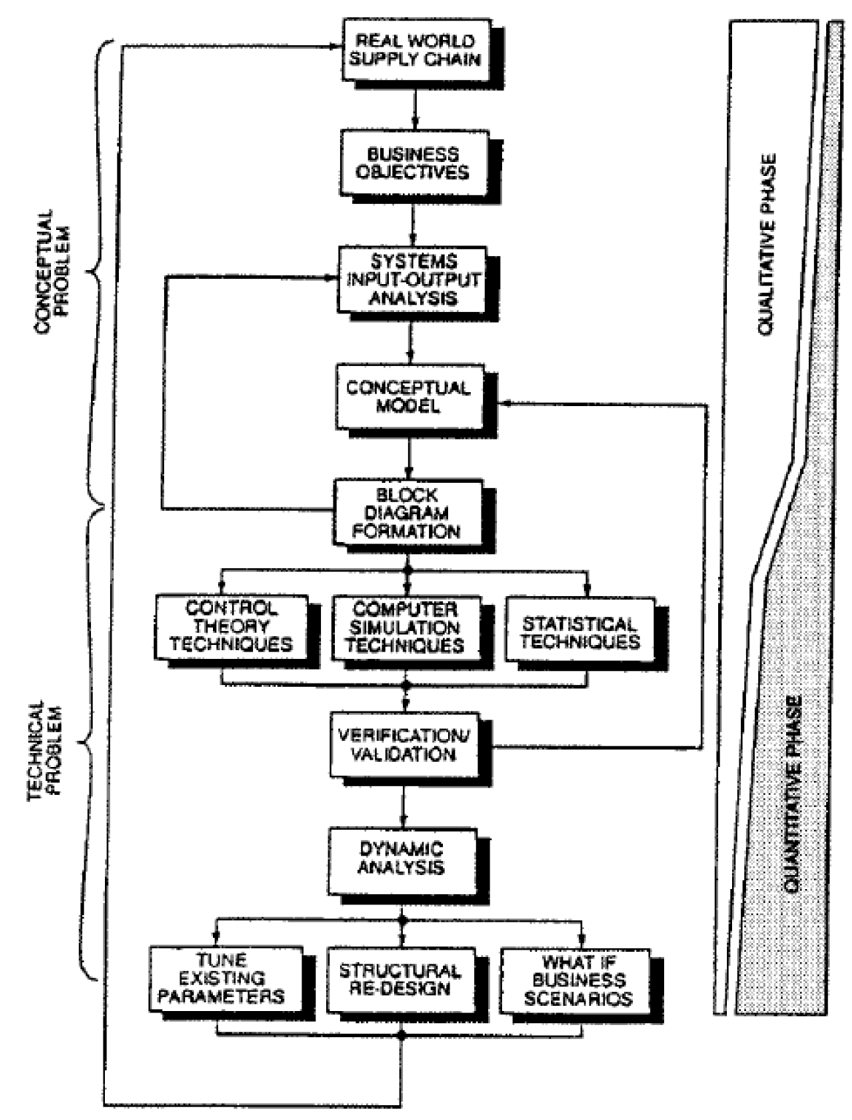

Figure 4. LSDG's integrated system dynamics framework for supply chain design. Source: Naim and Towill (1994)

LSDG's integrated system dynamics framework decomposes a supply chain into distinct autonomous business units, and approaches each one in an iterative process. What is called the qualitatitive phase supplies technical means for acquiring intuitive and conceptual knowledge to understand supply chain operations. The qualitative phase features 'soft' techniques such as system input-output analysis, conceptual modeling, block diagram formulation, along with typical data collection techniques like flowcharting, Pareto charts, interviews, and the like. On the other hand, 
the quantitative approach includes a set of 'hard' tools ranging from control theory, computer simulation and statistical analysis (Griffiths, Hafeez and Nairn, 1993), enabling dynamic diagnosis capabilities granted by the system dynamics computer simulation. Use of the former tools is determined by the degree of complexity in setting up a mathematical model and data availability for statistical analysis.

Strikingly, the LSDG makes negligible mention in their recent works of their original Cardiff approach grounded in system dynamics and control theory. It is appreciable an evolution of their method shifting towards a diagnostic rationale based more on pursuing a set of lean businesses practices (general guidelines) than to their initial inspiration. Such late orientation raises uncertainty on the extent in which known counter-measures to eliminate amplification would apply given the specifics of an actual case. The contemporary LSDG method based on lean business benchmarks is arguably in possession of a robust diagnostics foundation because underestimates the complexity of finding and eradicating BWE sources in actual supply systems (see Section 1.3).

In the second entry of Table 2 the Supply Chain Council's Supply Chain Operations Reference (SCOR) model was developed in 1996 as a cross-industry standard diagnostic tool for supply chain management (Supply-Chain Council, 2003). This is an open framework for all types of supply chains with a descriptive and measuring focus that serves well the (partial) purpose of exploring processes in search of BWE causes, hence incorporated in the Business Process Diagnosis; yet, it does not provides with diagnostic capabilities for dynamic complexity. 
When regarded as a BWE diagnostic method on its own right, Kasi (2005) asserts that even though SCOR assists in problem formulation, it does not deal with implementation of specific solutions into the supply chain, probably by reasons of being a generic model applicable for all supply chains, and certainly does not in the case of BWE. Although it helps into assessing business practices, other than the aforementioned BWE causes of Table 2, there are no specific processes or practices' patterns against which to determine the incidence of BWE. Further, being in its nature a normative model, SCOR provides standard descriptions, measures, and benchmarks but lacks an analytic framework to determine BWE presence. From our experience, we have found that the SCOR implementation is useful in discovering BWE problems, but not causes.

Next in Table 2, a Supply Chain Council subsidiary, the Performance Measurement Group, offers an online subscription service called the Supply Chain Management Benchmark Series that allows subscribers to compare their performance on SCOR model metrics with the performance of other participating companies. This is a complement of the SCOR model extending its benchmarking features; hence, the same diagnostic limitations annotated for SCOR apply here.

Another contribution from the Logistics Systems Dynamics Group (LSDG) is called Quick Scan (QS). QS is a lighter version of the formerly discussed Cardiff Approach featuring its qualitative phase, used at the start of a project to automate supply chain tasks and specially suited for implementation and improvement of information and communication technologies. Regarding the purpose of this research, this is a relevant contribution from Naim, Childerhouse, Disney and Towill (2002); yet, even 
though it considers a longer-term approach (to reengineer a supply chain), it is silent about a standard method to achieve long term diagnostic. It merely mentions the need to set up a re-engineering project. Quick Scan does not provide any dynamic diagnosis capabilities either.

Summarizing, this review suggests that there is not currently available a detailed methodology aimed at systematically reducing demand amplification in supply chains within a long-term scope, with the plausible exception of the Cardiff approach for supply chain design that had seemingly dropped its system diagnostic features. Still, existing diagnostic approaches can be subject of some methodological improvement as argued in coming Section 2.3.1.

Thus, some of the reviewed sources center in short term diagnostic applicability as in the case of Childerhouse, et al. (2004). Others, report successful cases on the grounds of rather general supply chain design principles (see Childerhouse, Hermiz, Mason-Jones, Popp and Towill, 2003; Childerhouse, et al., 2004; Childerhouse and Towill, 2003a; Childerhouse and Towill, 2004; Dejonckheere, Disney, Lambrecht, and Towill, 2002; Mason-Jones and Towill, 1998; McCullen and Towill, 2002; Naim, et al., 2002; Towill, 1997; Towill, 1999) or concentrates in theoretical models making little or none effort in adapting such model to a real diagnosed supply chain (Dejonckheere, et al., 2002; Disney, Lambrecht, Towill, and Van de Velde, 2008; Rubiano-Ovalle and Crespo-Marquez, 2003; Towill, 1997; Towill and Vecchio, 1994). Some provide diagnostics for specific applications (i.e.: tools devised for third-party logistics (3PL) to identify potential problems they can cover for to their clients, as in 
Foggin, Mentzer and Monroe (2004) or contribute with general measurement frameworks, most necessary but certainly not enough for analyzing the origins of complex supply chain problems (Supply-Chain Council, 2003; Van Landeghem and Persoons, 2001).

\subsection{System Dynamics Modeling in Supply Chain Management}

The application of system dynamics modeling in supply chain management has its roots in Industrial Dynamics (Forrester, 1958; Forrester, 1961). A model of a production-distribution system, the 'Forrester Model', is described in terms of six interacting flow systems, namely the flows of information, materials, orders, money, manpower, and capital equipment. Based on the development and use of a system dynamics simulation model, Forrester describes and analyses issues evolving around supply chain management. Angerhofer and Angelides (2000) highlights that many current research issues in supply chain management have already been pointed out by Forrester in 1961, including among others, demand amplification. Moreover, important lean supply chain's design specifications are attributable to Forrester, for this reason would be rightful to regard Forrester "not only as the 'father' of system dynamics, but also as the originator of many of the techniques of modern supply chain management" (Towill, 1996).

A supply chain system is an ongoing process of transformation and delivery of an item towards a consumer. This process happens in an array of interrelated firms, and more specifically in a variety of hierarchical organizational boundaries spread over such array, whereby the rhythm of the material flow depends on as well as determines 
the related flow of information and monetary resources. The use of system dynamics as means for analyzing supply chains becomes natural given its inherent faculty of modeling flow dynamics. Moreover, it is able to grasp both at the overall and detail level the complexity of such flow, due to its ability to reproduce the phenomena of delays and to capture as well the set of formal and informal feedback and feedforward connections within the process. Furthermore, the last appointed feature enables to closely reproduce systemic properties of an actual nonlinear supply chain even with a relatively simplified modeling construction that endogenously reproduces the live features of the observed object. In short, the system dynamics (SD) framework provides a simpler and more flexible modeling and simulation framework.

Akkermans and Dellaert (2005) propose a number of ways in which SD can contribute to the further development of supply chain management. It can be used to analyze the effect of different supply chain control systems on overall and long-term supply chain performance, such as new software (e.g. ERP, APS); to evaluate the performance of JIT and pull versus push control mechanisms; and more generally to support BPR efforts. Typically, to make the business case for improvement to a nonoperational audience; to identify the "sweet spots" for improvement and hence select the most promising improvement areas; to develop better policies for robust performance, and to train people in the new ways of working.

Figure 5 shows an overview of the systems dynamics approach to modeling, expressed as causal loop (influence) diagrams; a causal loop diagram captures the major feedback mechanisms. These mechanisms are either negative (balancing) or positive 
feedback (reinforcing) loops. Causal loop diagrams play two important roles in SD. First, during model development, they serve as preliminary sketches of causal hypotheses and secondly, they can simplify the representation of a model.

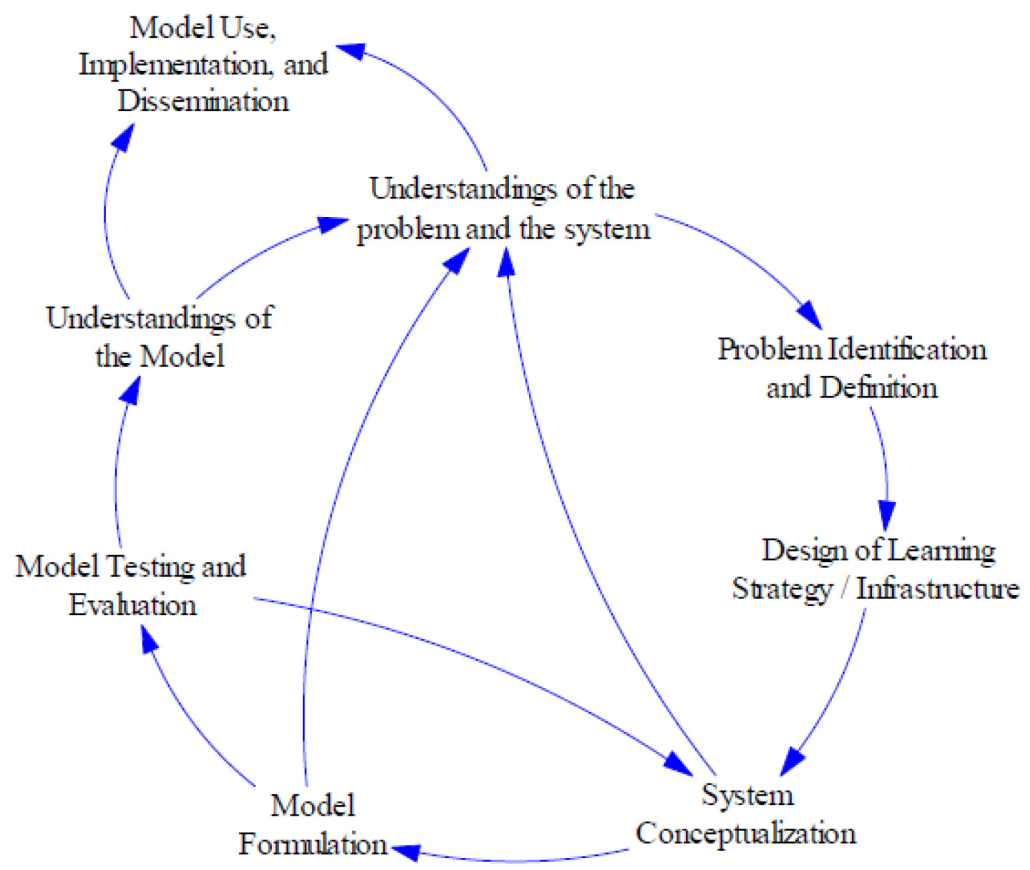

Figure 5. A Causal Loop: An Overview of the System Dynamics Modeling Approach Source: Richardson and Pugh (1981)

System dynamics deals with constructs used to reproduce live characteristics of modeled objects, which emanate, regulate, and store continuous flow. Rectangles stand for stock variables (state variables) used as flow buffers, double arrows pointing into stock variables represent inflows and when pointing out of the stock variables symbolize outflows. Stocks incorporate and release flows, characterize the state of the system, give systems inertia and provide them with memory. Double triangles $(\nabla)$ 
placed on double-lined arrows represent valves, which control the flows; the valves depends on the decision-making processes. Variables are denoted by unframed labels. Variables are usually connected by single arrows representing the causal influences among the variables. These arrows represent causal links such that the direction and sign ("+" or "-") of each causal link explains the direction and polarity of the causeeffect relationship.

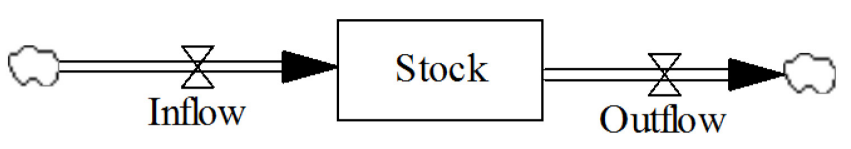

$$
\operatorname{Stock}(t)=\int_{t_{0}}^{t} \operatorname{Inflow}(s)-\text { Outflow }(s) d s+\operatorname{Stock}\left(t_{0}\right)
$$

Figure 6. Stock and Flow variables and Underlying Differential Equation Source: Sterman (2000)

The structure of a dynamic system model contains stock (state) and flow (rate) variables. Stock variables are the accumulations (i.e. inventories) within the system, while flow variables represent the flows in the system (i.e. order rate), which are the byproduct of the decision-making process. The model structure and the interrelationships among the variables are represented by stock-flow diagrams as shown in Figure 6. The mathematical mapping of a SD stock-flow diagram occurs via a system of differential equations, which has to be numerically solved via simulation for higherorder systems. 
As cited in Suryani, Chou, and Chen (2010), Sterman (2000) has developed a set of steps ${ }^{7}$ to create system dynamics models which are shown in Figure 6. Modeling is a feedback process that goes through constant iteration. It is embedded in a larger cycle of learning and action, constantly taking place in organizations and represented by the following steps described in Figure 7:

Step 1: Problem articulation: In this step, the real problem is specified, and the key variables and concepts identified, so as to establish clarity of purpose for the model. It is necessary to determine the time horizon and characterize the problem dynamically for understanding and designing a policy to solve it.

Step 2: Dynamic hypothesis: The modeler should develop a theory of how the problem arose. Such theory guides modeling efforts by focusing on certain structures. In this step, a causal loop diagram is generated, providing a hypothesized cause-effect liaison among variables. The causal loop diagram later on evolves to a stock and flow diagram.

Step 3: Formulation. to define a system dynamics model, after the causal loop diagram is transformed into flow diagram, the system description should be translated into level, rate and auxiliary equations. There is the need to estimate some parameters, behavioral relationships and initial conditions. Writing equations will reveal gaps and inconsistencies that must be remedied in the prior description.

Step 4: Testing: the purpose of testing is to gain confidence in the model. This is done in several ways, such as: comparing the simulated behavior of the model to the actual behavior of the system and performing statistical analysis of results, checking model's robustness under extreme conditions, and performing sensitivity analysis to: a) find flawed responses of the model to certain changes, or b) learn about counterintuitive, yet true, leverage points in the structure of the problem under study.

${ }^{7}$ See also (Randers, 1976) 


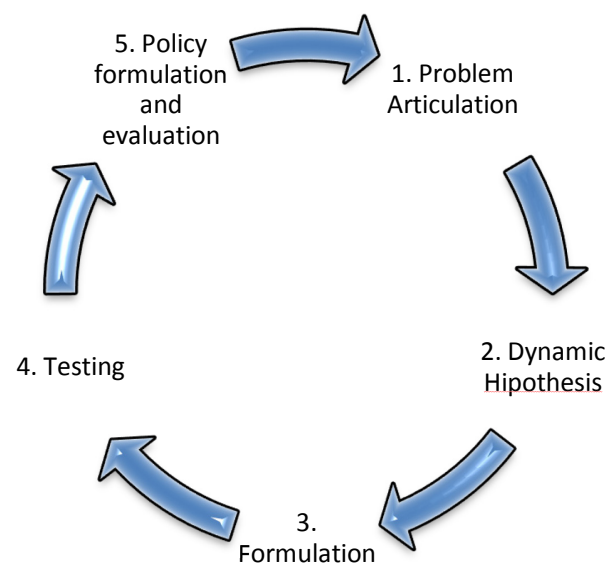

Figure 7. system dynamics modeling process.

Source: Sterman (2000)

Step 5: Policy formulation and evaluation. Once modelers have developed confidence in the structure and model behavior, it can be used to design and evaluate policies for improvement. The interactions of different policies must also be considered, because the real systems are highly nonlinear, the impact of combination policies is usually not the sum of their impacts alone.

\subsubsection{System Dynamics in Actual Supply Chain Case Studies}

The core of the present research is on the use of system dynamics (SD) as a central piece of a framework for diagnosing demand amplification in actual Supply Chains (SC). In order to document current practice of SD applications in live supply chains, a survey on the literature of reported supply chain actual diagnostic attempts was conducted, focusing exclusively on peer-reviewed journal papers since they constitute a frequent vehicle of case study publications. 
To make sure an extensive coverage of system dynamics applications in real supply chain case studies, the most representative databases on both system dynamics and supply chain management journals were included, considering a time horizon expanding from year 1987 to 2009. The final list of indexes is shown in Table 4.

To identify the relevant articles, we searched the indexes using the following query: ""system dynamics" AND "supply chain" AND "case study"', since each of its composing terms unambiguously pinpoints to the intended research subject, with the results shown in Table 4 for each on-line index. After this, a crosscheck of the outputs from all the sources followed in order to extract the intersected list of papers to consider for this review.

Table 4. List of on-line databases used for papers retrieval

\begin{tabular}{lr}
\hline Database & \# hits \\
\hline Science Direct & 295 \\
Emerald & 96 \\
Jstor & 43 \\
Wiley & 12 \\
\hline
\end{tabular}

Figure 8 shows the time series per year of the overall sample of reviewed papers, detailing the number of instances respectively discarded and included for scrutiny after a preliminary assessment. At this point, is important to emphasize that the focus is on examining exclusively system dynamics modeling efforts in actual case studies on supply chain topics.

Thus, there was a substantial number of papers discarded due to the fact that they did not correspond to live implementations in a real organization, oftentimes corresponded to incorrect classifications as to being regarded as systems dynamics 
application, mistakenly considered as supply chain subjects, and/or erroneously being regarded as a case study.

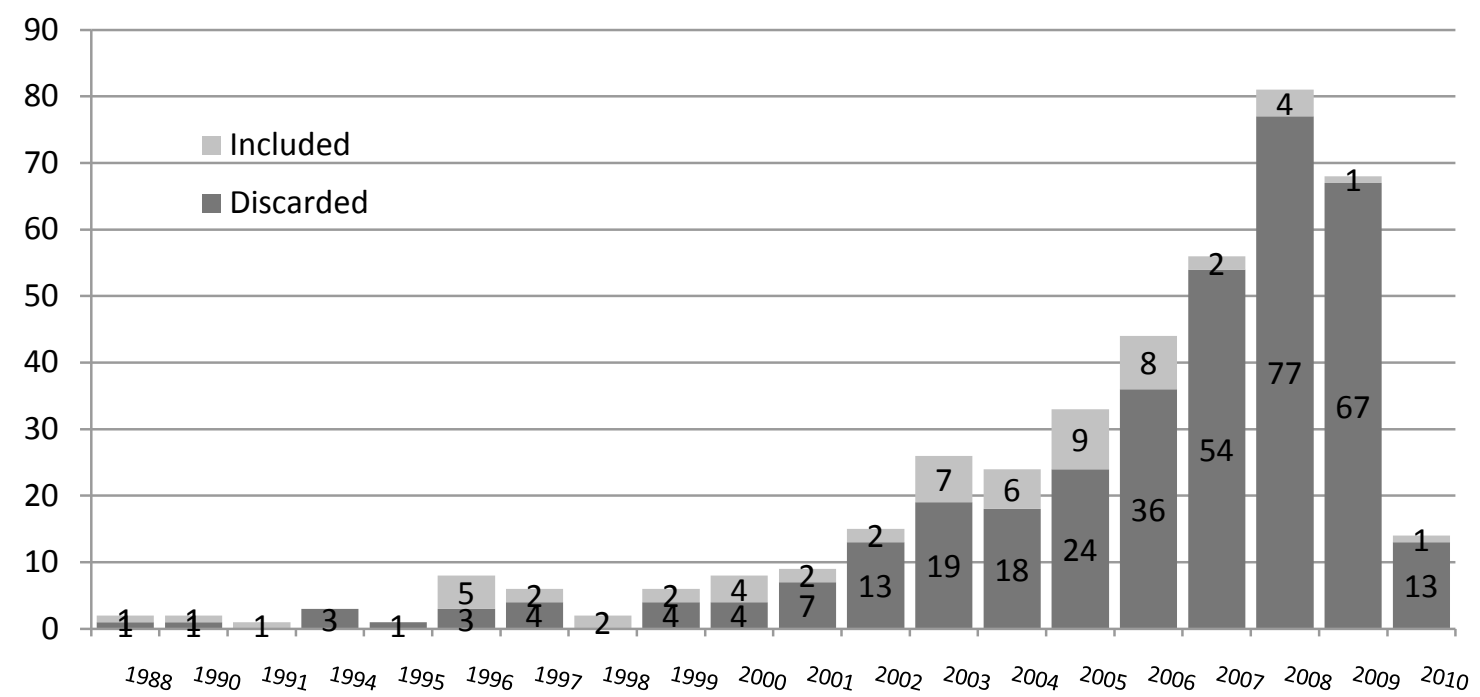

Figure 8. Annual statistic of surveyed papers

Figure 8 also supports the claims of both Akkermans and Dellaert (2005) and Towill (1996) regarding the "rediscovery" or "re-emergence" of the use of system dynamics modeling of real-life supply chains. It shows an evident concentration of publications in recent years ${ }^{8}$ exhibiting exponential growth, although it is appreciable that the bulk of papers included for the study predominates from year 2003 to 2006, with an appreciable surge since year 1996.

\footnotetext{
${ }^{8}$ The apparent decline of the years 2009 and 2010 can be explained in terms of eventual delays of the publication posting in the indexes, since the closing date of the present survey was in December 2009.
} 
A more in-depth examination of the labeled "Included" literature was performed, and is shown in Figure 9. From left to right on top of the page, a pie chart discriminates a further reduction of the base sample of papers to be examined after a finer revision. On a one-to-one basis inspection the original sampled were thoroughly scanned which brought about the elimination of an additional $72 \%$ of the base sample, leaving a small number of papers (labeled as "Ok") that could fairly fit the target of actual supply chain cases using system dynamics.

Yet, the refined sample also included theoretical studies that made use of generic SD models, which were further discarded. In addition, there were a number of papers that surprisingly did not even include a model description, also banned from the sample for reasons of not reporting/not meeting the minimal technical requirements of the SD modeling process. These are shown in the second pie chart from left to right with the labels "Ok, Generic" and "Ok, No Model". The remainder, an extra-refined sample of merely twelve (12) papers labeled as "Ok, Customized" accomplished that the devised models were actually custom-made for the specific supply chain situation at hand. Strikingly, this narrows to a $20 \%$ down of the original sample composed of sixty case study articles over a period of twenty years. 


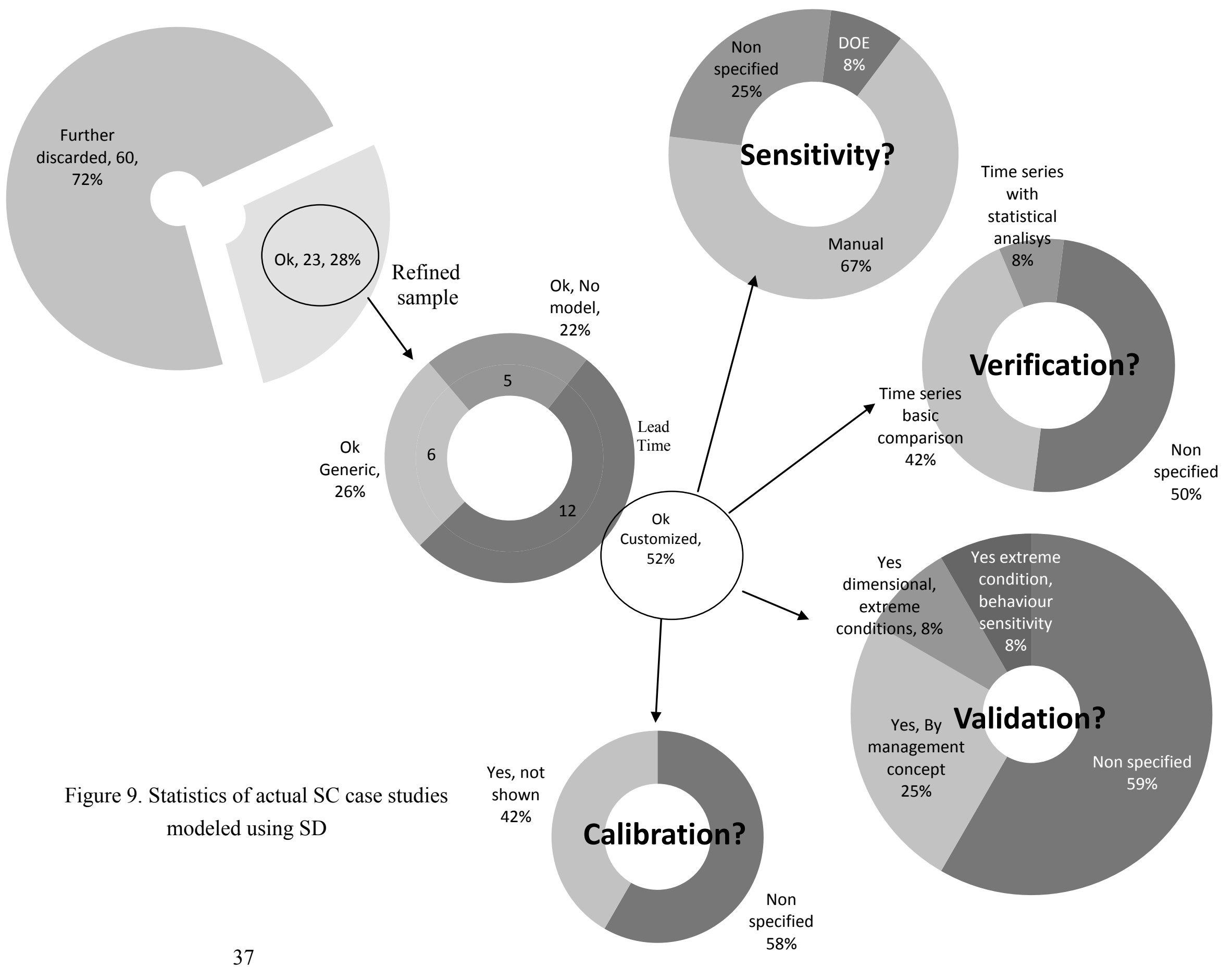


The purpose of the conducted analysis was to determine the extent on which the reported literature followed the system dynamics modeling process as portrayed in the former section. In particular, the focus of the attention have been placed on the SD model's Testing activity as considered in step 6 of Figure 7, since there have been previous questionings (see Barlas (1996) and Oliva (2003)) on the strictness of this practice among SD practitioners. Sensitivity analysis was considered as well, given its preponderant role in the usefulness of the model.

We established a very simple analysis framework that questioned all examined literature instances about four standard modeling practices: validation, verification, calibration and sensitivity analysis. Figure 9 shows as well the correspondent results obtained from the proposed framework inquiry realized on the previously termed extra-refined sample of the literature, expanding from the circle demarking the sample as arrows pointing out to the four modeling practices aforementioned.

Beginning with the validation activity, it becomes evident a relaxed posture of the modelers in front of the task of gaining confidence in their creations, herein supported by a $59 \%$ of 'Non specified' reports from the sample. There is a wealth of tests (see Barlas, 1989; Barlas, 1996; Forrester and Senge, 1980; Sterman, 1984) aimed towards SD model validation, prominently ignored by the additional $25 \%$ of modelers, who exclusively validates based on the client's expert opinion. The remaining $16 \%$ shyly attempted dimensional consistency, extreme conditions and behavior sensitivity validation tests. 
Validation is concerned about the model's correctly reproducing the modeler's mental model of the observed reality (structure validity). Subsequently, verification concentrates on the capability of the model of closely behaving as the reality portrayed (behavior validity), but reproducing the right behavior for the right reasons.

In contemporary $\mathrm{SD}$ practice, both model verification and calibration are closely related and tend to form part of a continuum cycle. Yet, in the observed literature sample, both seemed to be treated as separate activities. Verification of the model is quantitatively assessed by means of graphically and statistical matching of actual and simulated time series (Oliva, 2003; Sterman, 1984). Current SD software provides with automated calibration (AC) features that automates the process of enhancing such match, using optimization engines that iteratively varies a specified choice of input parameters for minimizing the mean square error of the residuals (for details, see Section 3.4). Input parameters that yield the best match are said to be calibrated or tuned, and are subject of further examination to realize their compliance to known data or exposed to expert opinion.

Model calibration is indispensable in real-life case studies for parameter estimation in order not to incur in an excessive and costly data collection exercise. However, the calibration pie chart of Figure 9 shows that only $42 \%$ of studies make use of it. Furthermore, in the majority of papers what is available is a simple mention on this practice, not including major technical reference of the process. 
Model verification is associated with the fitting appraisal between actual and simulated responses, notoriously abandoned by half of the sample. Moreover, most of the verification is done by means of graphical comparison of time series with no statistical analysis whatsoever, remaining an $8 \%$ of the sample that performs statistical analysis of results. The informality of audited SD modelers is manifest and far from formal practices exhibited in Gonçalves, Hines, Sterman, and Lertpattarapong (2005) and Oliva (2003).

Sensitivity analysis is undertaken by $75 \%$ of the sample, of which the largest portion recurs to manually introducing changes in the parameters inputs and/or further developing alternate scenarios in order to gain insight from the models. Only an $8 \%$ of the sample made an extra-effort in introducing complementary tools like Design of Experiments (DOE; see Kleijnen (2005)) for improving the manual process of SD sensitivity analysis.

It comes to the attention a couple of sensitivity analysis shortcomings: i) The powerful capabilities of optimization engines from commercial SD suites provides the means for performing thorough sensitivity analysis and seem to be ignored in the bulk of surveyed works. ii) Absence of promising SD sensitivity analysis techniques based in the linearization of SD models for eigenvalue and eigenvector assessment of the model structure and observed behavior, known as Loop Eigenvalue Elasticity Analysis (LEEA; Forrester, 1982; Güneralp, 2006; Saleh and Davidsen, 2000; Saleh and Davidsen, 2001)) 
We close this section summarizing the findings derived from the literature survey. It is remarkable the reduced number of supply chain actual cases that had been approached by means of customized system dynamics modeling. This is, the available literature on SD modeling applied to supply chain issues is numerous, yet the purposeful use of SD to diagnose specific supply chain instances by modeling their specifics, is rare.

Moreover, the scarce attempts that meet the stated requirements are followed by a very slight testing process that leaves ample room for improvement. It is argued here that the reliability of conclusions obtained from these models is scant and there is evident lack of stringent validation and verification practices. Not surprisingly, Akkermans and Dellaert (2005) cannot help the comparison with researchers using the discrete time simulation approach or the control theory approach, since "SD researchers often seem to be satisfied with some examples showing the managerial insights, rather than having at least a statistical proof of significance." The basic units consistency, extreme condition testing, management concept, behavior sensitivity and time series appraisal must be accompanied by residuals statistical testing including r-squared measures and error discrimination evaluators such as the Theil's inequality statistics (Oliva, 2003).

Sensitivity analysis cannot be regarded as underplayed but must certainly could be significantly improved with the introduction of techniques such as Loop Eigenvalue Elasticity Analysis (LEEA; Forrester, 1982; Saleh and Davidsen, 2000) and the Pathway Participation Method (PPM; Mojtahedzadeh, Andersen, and Richardson, 
2004). These techniques endow with a long hoped structure method for performing SD sensitivity analysis and more precisely tying the relationship between structure and behavior.

\subsection{Bullwhip Effect Measurement}

A conceptual framework on bullwhip effect measurement is shown in Figure 10. It is set out for a wide BWE measurement efforts classification by providing an organized reference for the analysis of reported BWE measures in diverse conditions. Yet, herein is concerned with the use of metrics in actual implementations, or what is termed in the framework as realistic settings, focused on diagnosing real supply chains. A general description of the framework is provided, followed by a discussion on the reported BWE metrics only for actual SC cases.

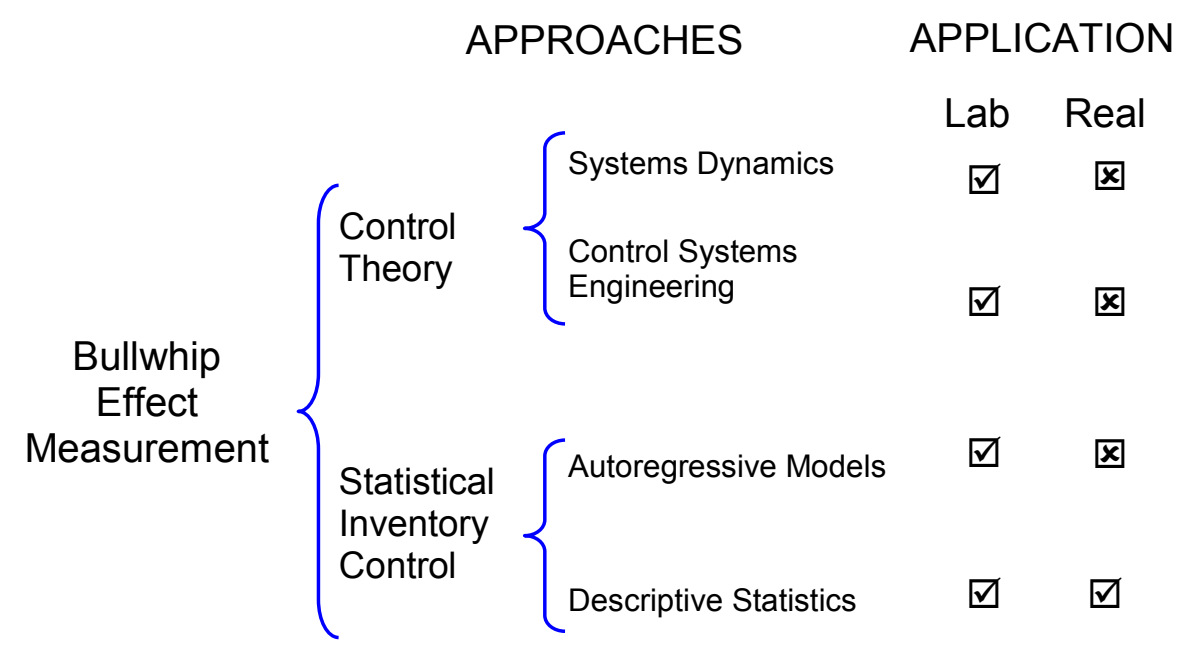

Figure 10. Framework for BWE Measurement Literature Review 
Dejonckheere, Disney, Lambrecht, and Towill (2003) distinguish between control theory and statistical approaches to measure the bullwhip effect, as shown in Figure 10. The control theory approach relies on modeling supply systems using differential equations usually solved by computer methods, and within this one it can be further distinguished both the system dynamics school (Forrester, 1958; Sterman, 2000) and the classical control systems engineering methods (Dejonckheere, et al., 2003; Towill, Naim, and Wikner, 1992). There is, on the other hand, readily visible in the literature the statistical inventory control approach, featured by the use of autoregressive models assuming correlated demand for logistics chains (Chen, Drezner, Ryan, and Simchi-Levi, 2000; Lee, Padmanabhan, and Whang, 1997a;). The statistical approach also includes the use of descriptive statistics for the sakes of measuring BWE (Fransoo and Wouters, 2000; Holmstrom, 1997; P. McCullen and Towill, 2001).

In addition, to the right side of Figure 10 there is an additional pair of columns marking the presence/absence from the reviewed literature of reported measures applied to what is termed as laboratory settings and those that are geared toward actual supply chains, or realistic settings. The first group is notoriously prevalent on the available literature and the measuring is done over theoretical constructs like analytical models, enterprise games and computer simulations, as opposed to the realistic settings group. To further clarify, the realistic settings imply that data comes from an actual system, rather than from an artificious reality.

The realistic settings cases observed fully overlap the descriptive statistic approach, such that so far none of the indexes devised for laboratory settings is found 
suitable for use in actual cases. Realistic setting cases are typically approached by means of collection of data samples from the actual systems, processed with the use of combinations of simple statistics and operands that oftentimes includes dispersion measures, such as sums or quotients of variances, standard deviations and coefficients of variation.

Table 5. Set of Metrics used in the Realistic Settings cases

\begin{tabular}{|c|c|c|c|c|c|}
\hline \multirow{5}{*}{$\begin{array}{l}\text { Descriptive } \\
\text { Statistics }\end{array}$} & Metric & Definition & Parameters & Formula & Eq. \\
\hline & $\begin{array}{l}\text { Standard } \\
\text { Deviation } \\
\text { (Sample) }\end{array}$ & $\begin{array}{l}\text { A quadratic measure } \\
\text { concerned with the } \\
\text { average distance from } \\
\text { each observation to the } \\
\text { sample mean, expressed } \\
\text { in the original units of } \\
\text { the variable. }\end{array}$ & $\begin{array}{l}s=\text { Standard Dev. } \\
s^{2}=\text { Variance } \\
\bar{X}=\text { sample avg. } \\
X_{i}=i^{\text {th }} \text { observation } \\
n=\text { sample size }\end{array}$ & $s=\sqrt{\frac{\sum_{i=1}^{n}\left(X_{i}-\bar{X}\right)^{2}}{n-1}}$ & [1] \\
\hline & $\begin{array}{l}\text { Average } \\
\text { Unsigned } \\
\text { Difference }\end{array}$ & $\begin{array}{l}\text { Measures in absolute } \\
\text { terms the average } \\
\text { difference between time } \\
\text { series }\end{array}$ & $\begin{array}{l}\bar{D}=\text { Average Unsigned } \\
\text { Difference } \\
V(t)=\text { Demand time series } \\
P(t)=\text { Production time } \\
\text { series } \\
T=\text { number of periods }\end{array}$ & $\bar{D}=\frac{\sum_{t=1}^{T}(\| V(t)-}{T}$ & [2] \\
\hline & $\begin{array}{l}\text { Pearson's } \\
\text { Coefficient } \\
\text { of Variation }\end{array}$ & $\begin{array}{l}\text { A normalized measure } \\
\text { of dispersion, defined as } \\
\text { the ratio of the standard } \\
\text { deviation to the mean. }\end{array}$ & $\begin{array}{l}C V \square=\text { Coefficient of } \\
\text { Variation } \\
S=\text { Standard Dev. } \\
\bar{X}=\text { Average }\end{array}$ & $C V=\frac{s}{\bar{X}}$ & [3] \\
\hline & $\begin{array}{l}\text { Demand } \\
\text { Amplificati } \\
\text { on Quotient }\end{array}$ & $\begin{array}{l}\text { The quotient of the } \\
\text { coefficient of variation } \\
\text { of demand generated by } \\
\text { a particular set of } \\
\text { echelons (i.e.: an } \\
\text { echelon, or the entire } \\
\text { supply chain) and the } \\
\text { coefficient of variation } \\
\text { of demand received by } \\
\text { it. }\end{array}$ & $\begin{array}{l}\omega=\text { Demand Amplification } \\
\text { Quotient } \\
D_{\text {in }}=\text { incoming demand } \\
\text { from the next downstream } \\
\text { echelon } \\
D_{\text {out }}=\text { demand placed to the } \\
\text { next upstream echelon. } \\
\left.D_{\text {in }}(t, t+T) \text { and } D_{\text {out }}(t, t+T)\right) \\
\text { represent demand during } \\
\text { the period }(\mathrm{t}, \mathrm{t}+\mathrm{T})\end{array}$ & $\begin{array}{l}\omega=\frac{c_{\text {out }}}{c_{\text {in }}} \\
\text { Where, } \\
c_{\text {out }}=\frac{\sigma\left(D_{\text {out }}(t, t+T)\right.}{\mu\left(D_{\text {out }}(t, t+T)\right.} \\
\quad \text { and } \\
c_{\text {in }}=\frac{\sigma\left(D_{\text {in }}(t, t+T)\right.}{\mu\left(D_{\text {in }}(t, t+T)\right.}\end{array}$ & [4] \\
\hline
\end{tabular}

Martín-Andino Benítez (2006) extensively reviews different bullwhip related indexes, mostly based on the comparison of variances or coefficient of variation of inbound and outbound demand series relative to a single firm in the supply chain. The 
variation concept is in the center of the bullwhip effect definition. Diverse authors (Chen, et al, 2000; Fransoo and Wouters, 2000) have found of use to introduce the statistical parameter of coefficient of variation as an indicator of demand amplification. This is a convenient measure since it express in a non-dimensional form the degree of variation of the variable 'normalized' with respect to its central tendency, and by far the more popular one among others.

Yet, it is argued that extant measures are not capable of appropriately estimating the system-wide impact of the bullwhip effect actual in supply chains, preventing overall improvement efforts to take place instead of local. Fransoo and Wouters (2000) explain that current variance-based measures impose complete availability on the incoming and salient demand (i.e., sales and orders) data of all instances composing the chain under study. The dissimilar size of the measured flow of goods on different sampling points in actual supply chain case studies, poses a mathematical and logical error since ignores pooling effects in comparing variances. We termed this as flow conservation violation, which raises a significant practical issue for the measurement of actual supply chains given the prohibitive number of instances characteristically composing these.

Chronologically, Hölmstrom (1997) makes use of the coefficient of variation listed as Equation [3] in Table 5, expressed as percentage in an early study on an actual European grocery supply chain. Hölmstrom reports the existence of bullwhip in two product categories of the observed logistic system. There is an evident increase in the measures of the coefficients of variation and a global measure of demand amplification 
is provided. Anyway, such measure is questionable due to its flagrant violation of flow conservation when it is evident that it only considers a partial sample of outlets on its downstream extreme, simply ignoring the rest of the system.

Then, Taylor (1999) proposes a practical approach to identify and measure the demand amplification and demonstrates in a real application on an automotive supply chain in the U.K. This study contains information over a period of twenty-six weeks of the upstream part of the chain, considering a steel mill, steel distributors and first tier autopart manufacturers. On the analysis of the average and standard deviation (see Equation [1] in the previous table) and the graphical study of the corresponding time series, Taylor observes that as moving away from the final client, the average demands and deviations increased. The measurement approach is focused on individual links without an integral measure of the system.

Next, McCullen and Towill (2001) exhibit interesting results of bullwhip reduction as a consequence of re-engineering a real global supply chain from the precision mechanical engineering sector. Three echelons were considered for the study: a factory, a central warehouse and global distributors (international). Yet, the bulk of the statistical diagnosis relies on the six-year demand and production time series of the first node. McCullen and Towill used a variant of the traditional dispersion measurement, denoted in Equation [2]. In six products, they obtained an average reduction of demand amplification of $36 \%$ plus a $45 \%$ reduction of global inventory. Again, the measurement ignores the global consequences on the whole supply system. 
Lastly, we review the proposed bullwhip measurement framework for actual settings, by Fransoo and Wouters (2000). Such framework is implemented on an instance of two chains of convenience food composed of a single manufacturing site, a distribution center and retail franchisees. Fransoo and Wouters used a variant of the Variance Ratio (VR) metric developed for actual cases and shown in Equation [4]. Fransoo and Wouters when faced with the flow conservation issue in practice, simply discard the option of a global measurement for the system and get by with a variety of local echelon's metrics comparison with different levels of data aggregation.

From the former review, it is inferred that there is lack of a practical approach to estimate the global impact of the bullwhip effect of an actual multi-echelon supply chain. 


\section{CHAPTER 3 - DAMP DIAGNOSTIC FRAMEWORK}

This chapter presents the Demand Amplification Protocol (DAMP), which consists of the Diagnostic Framework posed to counteract demand amplification in actual supply chains. There are a number of features that make DAMP unique: the use of the BWE scorecard including a low-data requirements method for estimating the overall BWE in actual supply chains, its dynamic diagnosis incorporating advanced system dynamics practices as model calibration and validation, and the use of newlydeveloped sensitivity and optimization methods for system dynamics models. The first part of the chapter marks a distinction between DAMP and existing contributions, then extends on the description of DAMP and in the last section addresses a more detailed reference of DAMP' selected procedures given its important role in the framework.

\subsection{An overall description of DAMP}

Figure 11 shows an overview of the DAMP Diagnostic Framework consisting of three major phases denoted as Triage, Examination and Treatment. The first phase addresses the initial activities that need to be performed prior to the actual diagnostic work and consists of the customary opening set of steps frequently shared by methodologies that are implemented as part of a project.

The second phase corresponds to Examination, which aggregates the core of the present work. The Diagnostics stage is broken down into two steps, as the set of tools and people necessary for its implementation differ in their nature. 


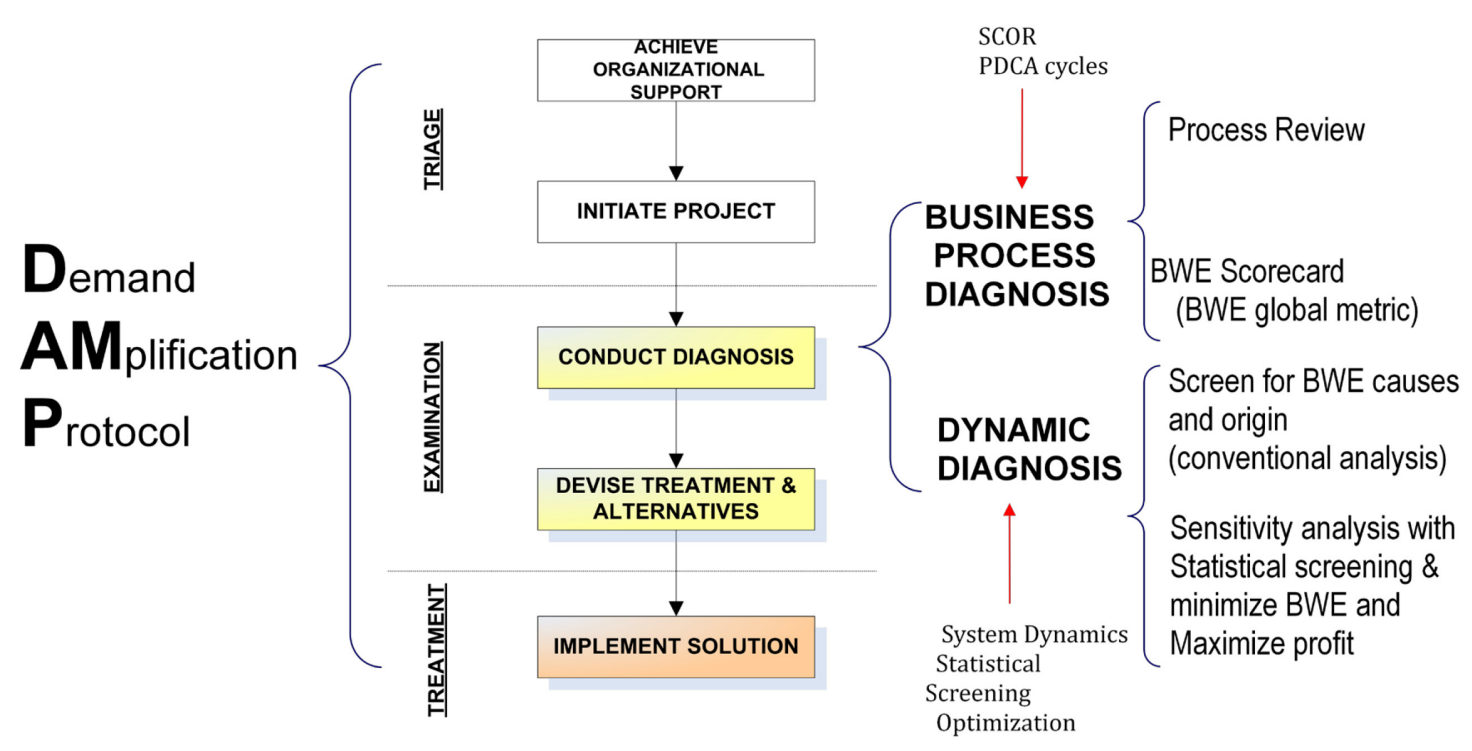

Figure 11. DAMP map and sequence of steps

Within the Examination phase, the diagnosis is twofold: there is an initial approach termed 'Business Process Diagnosis', aimed to explore the logistics workflow based on system depiction - questionnaires, interviews, process mapping and direct observation. System depiction models the informational and physical dynamics of the supply arrangement. In parallel, there is system evaluation, in which the existing system is assessed against a range of performance measures. The SCOR Reference Model (Supply-Chain Council, 2003) augmented with a bullwhip measurement framework (Amaya and Giachetti, 2009) denoted as BWE Scorecard serves as the foundation for both systems depiction and evaluation activities respectively. It renders significant advantages by using a standard model and metrics that were devised for the purpose of holistic supply chain monitoring. 
On the other hand, 'Dynamic diagnosis' captures the relations in the supply chain's structure and behavior. This approach is based on system prototyping - a valid model of the real system capturing relevant variables pertaining demand amplification - and model evaluation - alternative configurations and sensitivity analysis performed as to diagnose and prescribe tailored treatment. The system dynamics (SD) approach (Forrester, 1961) is the central part of the modeling framework along with the use of state-of-the-art validation (Oliva, 2003) and sensitivity analysis techniques.

The Treatment phase refers to a given choice of improvement formulations and its implementation in the supply chain. Since the number of potential actions for the implementation is unrestricted, details of this phase are left out of the framework description.

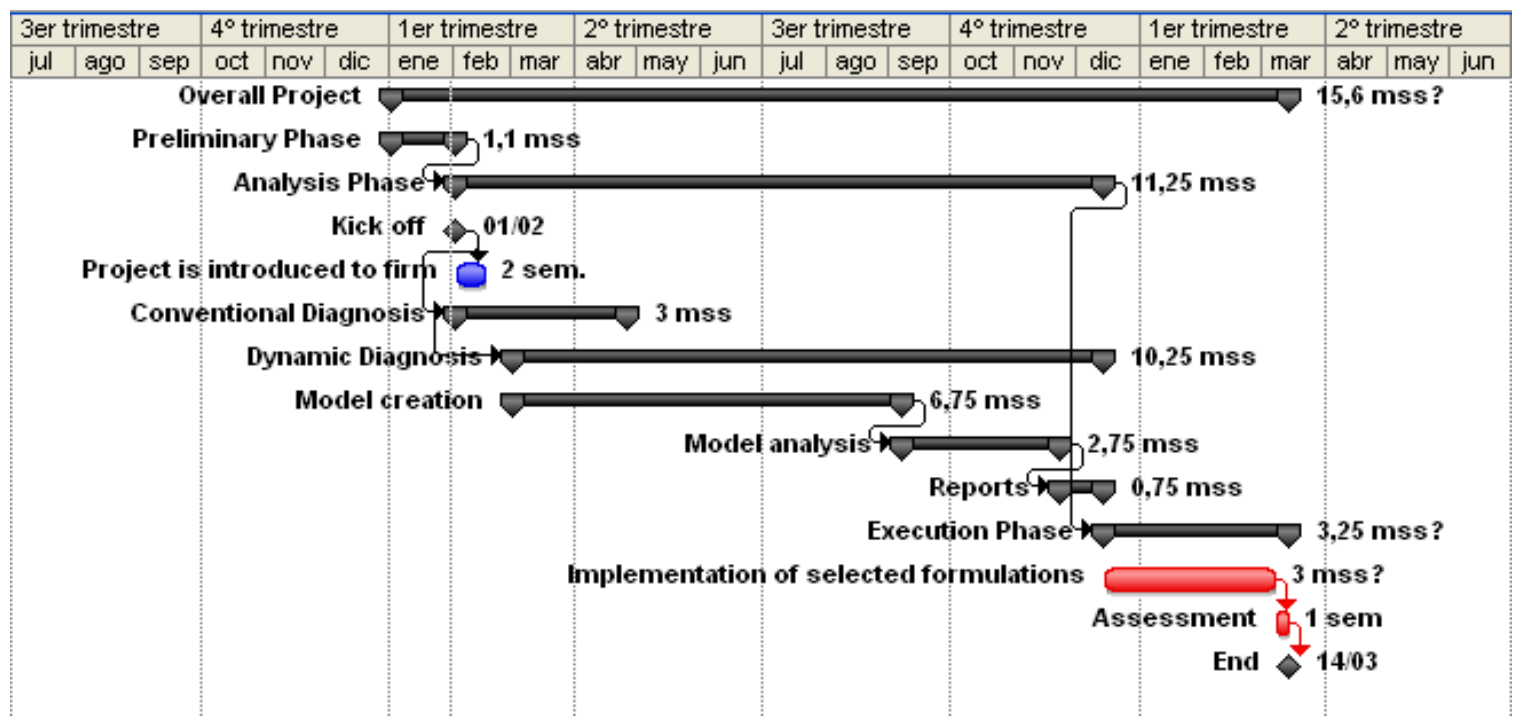

Figure 12. DAMP timetable 
Figure 12 shows the expected time sequence and precedence relations for a mid-sized company in a supply chain composed of three echelons and a single family of

products. Overall, it takes roughly sixteen months to complete a project using DAMP. The Triage phase takes approximately one month followed by eleven and a half months for the Examination phase. The dynamic diagnosis portion constitutes the bulk of the Examination phase, accounting for more than ten months. Much of this time is the SD model creation - the most time consuming activity of the framework. The Treatment phase is a variable time because it depends on the choice of improvement formulations to be implemented. For purposes of general estimation, it is projected to require three months, but Treatment could easily extend to several years of ongoing improvement execution. Due to its variable duration feature, it seems reasonable that practitioners are more interested in the completion of the first two phases of the framework, which require approximately one year.

\subsection{A detailed description of DAMP}

The following paragraphs give a description of each of the phases shown in Figure 11 with the details of their composing stages and steps as shown on the right side of Figure 13. 


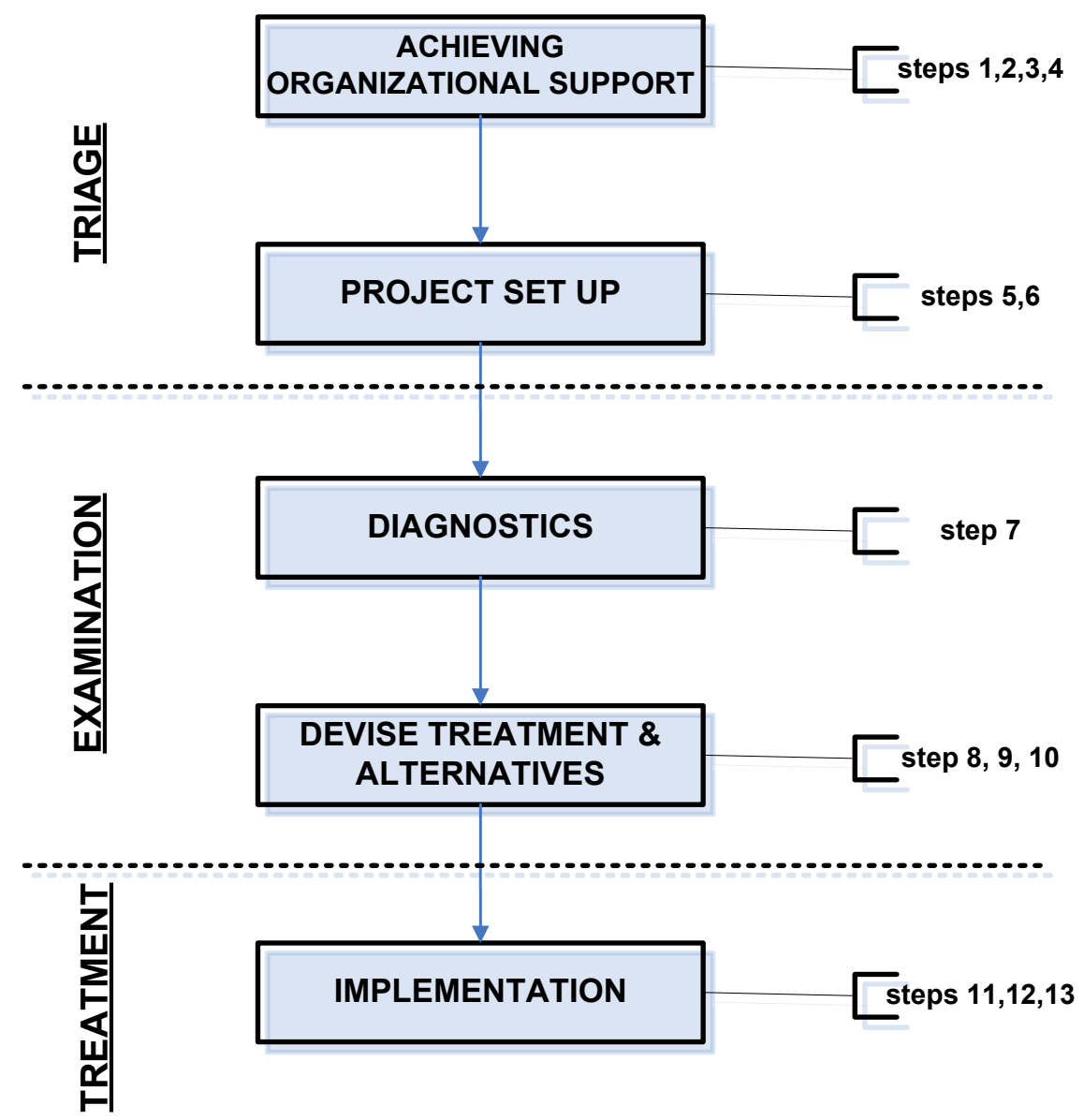

Figure 13. DAMP map and sequence of steps

\subsubsection{Triage}

\subsubsection{Achieving Organizational Support}

This stage aims to obtain buy-in from the firm's top management, and consequently gain access to apply the diagnostic framework on a supply chain. It is composed of the following steps: 
Step 1. Subject selection: from a given supply chain, select the one firm that will serve as the bridge to the remaining echelons (primary firm). Most likely, the ones farther apart from the customer will be more liable to engage on the project. It is also a practical suggestion to look for a supply chain dominant echelon, one who can easily exert leadership on the others and persuade them to participate in the project.

Step 2. Initial contact: establish an appointment with a potential 'champion candidate' from the primary firm (the owner of logistics processes: logistics, operations or production management). The objective of this step is to explain the framework and its purpose to the most likely responsible of the project within the company, and gain access to the primary firm of the study. At this point, is imperative to check that the company meets the underlying assumptions of the framework as well as to attain the firm's commitment to a pre-diagnostic phase in order to establish solid grounds for the need to implement the methodology. In addition, a preliminary scope of the project must include critical supply chain partners, products and markets following the guidelines provided in Appendix A.

\section{Step 3. Conduct Initial diagnosis:}

a. Establish connections with Corporate Planning and Logistics Strategy. Is there a clear obstacle posed by demand amplification? What are the liaisons with the competitive position of the firm? Determine this by means of assessing inputs such as SWOT analysis and the corporate planning, as well as the competitive 
strategy analysis of the firm (see Porter, 1985) and the competitive positioning of each candidate supply chain to be audited.

b. Determine the candidate products for the study. At a later stage, more often than not it will be necessary to broaden categories, from products to product families. At this point, select a sample of representative products considering:

i. Choose products with higher sales, to ensure that those selected have a stable and continuous output. The underlying assumption is that bestsellers are more important for the supply system, hence are more interesting subjects for BWE measurement.

ii. Exclude products whose sales mode is zero. Products with sudden sales spikes should not be taken into account, in spite of high sales volumes. These are most probably special sales, e.g., exports, which by definition are particular in terms of variation therefore should be treated as such.

iii. Choose products with lower inventory turnover. A slow moving inventory is a sign of BWE.

iv. Check with the people close to the firms (employees and customers). They have a better understanding of the behavior of different products (demand signals), so one can detect those products or family of products experiencing the events and issues specific to the Bullwhip Effect.

c. Collect and assess preliminary information about demand amplification in the

firm. In order to so, start by getting the inventory data of the last three years from computer files. These is most convenient since includes all at once BWE inputs such as incoming and outgoing demand. In any case, time series of purchases, sales, returns (all transactions affecting inventory) must be collected. Next, use the measurement framework proposed by Fransoo and Wouters (2000) to compute BWE indexes.

d. Results of the initial diagnosis may suggest several degrees of BWE severity. Careful consideration must be taken in interpreting BWE indexes, since these 
are relative measures ${ }^{9}$ highly dependent on the time units chosen. As a rule of thumb, numerical values for a single node denoting weekly demand amplification not exceeding a range between one point three to one point eight $[1.3 \rightarrow 1.8]$, indicates an amplification condition that suggests the need of moderate changes. Greater than that, implies major changes to be introduced. If comprehensive changes are foreseen, then the firm (and related supply chains) is subject of this framework.

Step 4. Project presentation: Once the need for the framework is established, have the champion schedule a presentation with the Top Management. Expose there:

a. Basics on demand amplification and symptoms.

b. Present Initial Diagnosis analysis. Discuss some of the results; obtain impressions from the audience about what was observed, and their probable causes. The objective is to establish the need to overcome BWE. Assess the maturity of the supply chain practices observed, concerning BWE known triggers.

c. Impact to the firm: in terms of lost sales, customer service, production scheduling, inventory management and financial liabilities. A conservative estimate specific to the firm must be attempted. Then, it is important to open

\footnotetext{
${ }^{9}$ When considering a single node, one could infer from a BWE index a normal situation covering hidden issues. This is due to the relativity of the measure, which focuses on the difference between the input and output signals, but pays little attention to the signals in itself. I.e., an amplified signal that comes from another party might not be worsen, or further, could it be improved, yet remains undetected by the BWE index if there are no internal changes. There is the latent risk of overlooking an extant issue that lies ahead or before of the reference node.
} 
the scope of the project and preview the overall impacts to the set of firms composing the supply chain.

\subsubsection{Project Set Up}

Under the assumption of project acceptance, now the main objective of this stage is to formalize the organization, infrastructure and methodological approach that supports the project. The following steps are considered:

Step 5. Project Charter: document the current findings, and state a guiding map that informs about what the project is all about. Consider here to:

a. State project objectives

b. Explain methodology: activity schedule, milestones, time horizon and scope, activities, resources to commit, costs.

c. Describe organization chart and communication plan

d. Expose expected outcomes: what to anticipate in terms of improvement.

Step 6. Project start: Define the project team. This includes the strategic role designation of the primary firm champion, who will support privileged access to the other echelons. Repeat then steps 2 to 4 , for each new echelon(s) to be recruited. 
Step 7. Refine the scope: Consider the scope of the project initially attempted on step 2, but look for a wider consensus and validity within the Project Team and from several staff levels including top management.

Step 8. Distribute deliverables: Formulate assignments and deliverables for each member of the team. Make each person accountable for a piece of the timetable.

\subsubsection{Examination}

\subsubsection{Diagnostics}

The central activity of the framework happens here, generating the diagnostic. Continuous improvement PDCA cycles based on supply chain's scorecards and process maps plays an important feature at this stage, as well as system's simulation and assessment. This activity is composed of the following steps:

Step 9. Business Process Diagnosis - System Evaluation: Define system-wide measures (SCOR and customized; see Section 2.4) and collect the data. The first order of business is to define how many scorecards to administer (i.e., one for each identified supply chain). It is necessary first to educate the team on definitions, metric decomposition and query strategies for each metric considered.

Consider, for instance, the BWE Scorecard shown in Figure 14. To facilitate a single view of the different indexes proposed, a diagram was developed that contains a summary of the indicators. Each metric exhibits a standard structure, as shown: 
Table 6. Metric description

\begin{tabular}{|l|l|}
\hline Metric name & $\begin{array}{l}\text { Math } \\
\text { equation }\end{array}$ \\
\hline Inputs \\
\hline Conceptual meaning \\
\hline
\end{tabular}

In Figure 14 the relative position in the scorecard has a meaning. The lower part of the diagram lists BWE causes, the middle place shows the central metric directly measuring the targeted problem and on top are the BWE effects. Note that each class might contain indexes grouped together into a cause or effect.

With scorecards and metrics defined, a plan to collect actual data to feed the indicators with periodic deliverables and accountables must be executed. We describe below the usual BWE measures:

i. Local Measurement: refers to the quantification of BWE on a single node of the chain, i.e., the added noise to the demand signal as a result of its participation in the chain. The measurement at this level can take place in two ways:

1. Full Measure: an overall measure $(\omega)$ of the node, comparing the coefficient of variation $(\mathrm{CV})$ of its incoming and outgoing demand, as shown in Equation [4] of Table 5, Section 2.4. A drawback of the former measure is its static nature, meaning that it does not capture changes within the sample period. For dynamic information about BWE over time, a moving $\omega$ is proposed that allows obtaining a greater number of time-dependent measurements. The computation of the moving $\omega$ starts from the definition of a fixed-length moving time window $(W)$ over which the mean and standard deviation of demand, in and out of the 
business, is determined. Usually $W$ is conveniently specified as a one-year period to include trends and seasonality that occurs annually, and is a widespread management period. Yet, careful consideration should be taken in defining $W$ given that larger windows tend to derive to a less sensitive measure, and vice versa. The importance of a moving measurement is to visually identify times when abnormal BWE happened or not, therefore facilitates determining which policies and decisions over time positively or negatively affects BWE.

2. Partial measures: perform breakdown measures on each link, over smaller subsystems through which demand flows. These measurements are intended to detect the greatest demand amplification happening over specific segments of the operation. Taking the case of a factory, consider measuring Sales, Production and Purchasing interfaces, as an example. Readers are referred to Section 3.3 for a detailed description of a method for measuring bullwhip in an actual supply chain.

ii. Assessment of the incidence of established Bullwhip origins in the supply chain. This is the complement of former BWE hypotheses (e.g., from Initial diagnosis:) but now with additional data and including information from the secondary firms. Most often there are always delays in data processing since not commonly found in convenient format, or in magnetic media. 


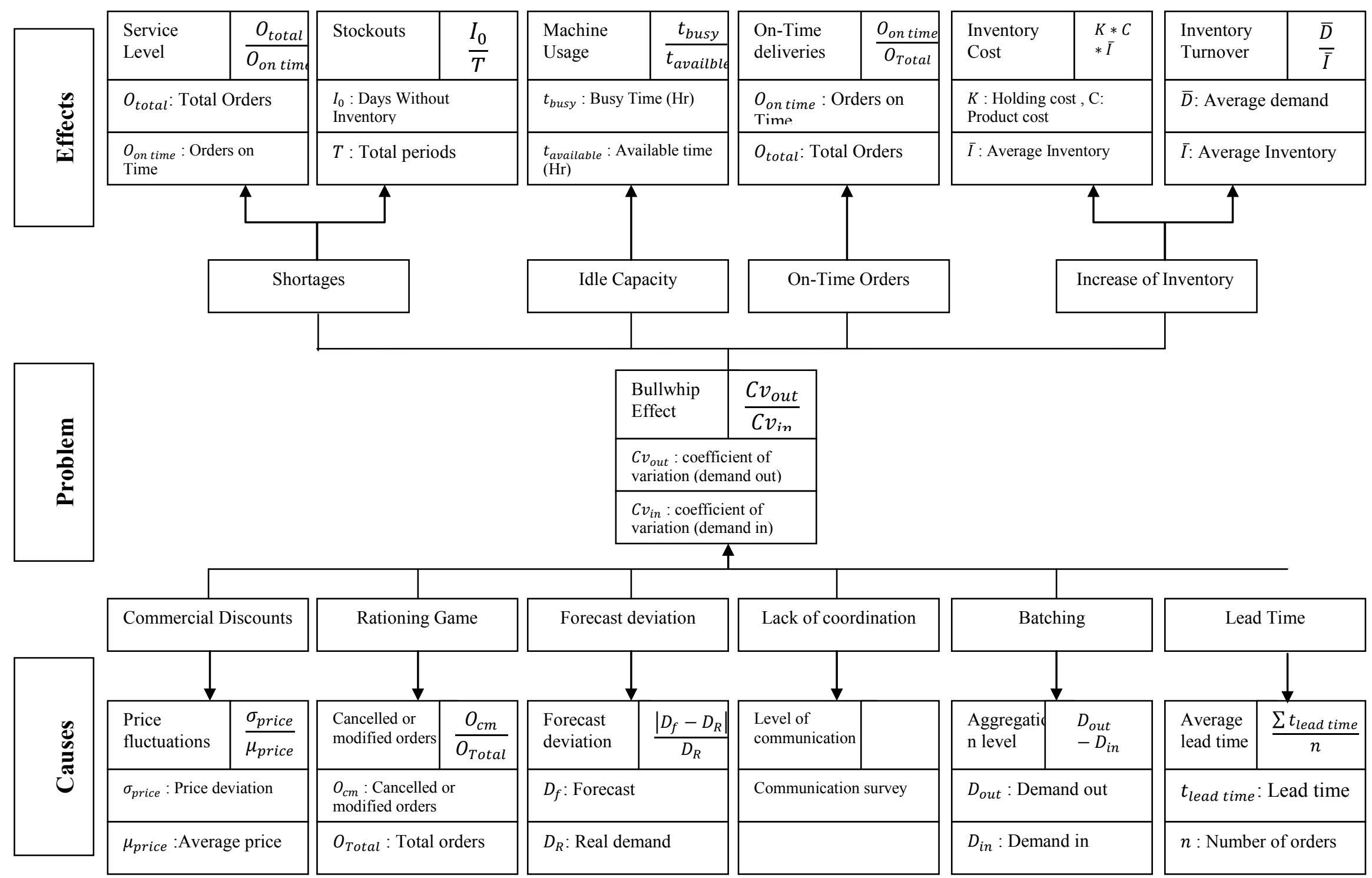

Figure 14. BWE Scorecard 
Step 10. Business Process Diagnosis - System Depiction: Clarify knowledge of the process by means of process mapping. An important consideration is the choice of aggregation level of products to be mapped, as initially proposed in step 2 and defined in step 6. By using SCOR process mapping constructs (Supply Chain Council, 2003) and cascading down scorecards data to the maps, we obtain both a useful graphical and quantitative framework to illustrate inefficiencies, which can be compared with current best practices. In particular, the output of this exercise should regard interesting opportunities to eliminate BWE sources and slack lead times along the supply chain. The final deliverable of this step is a documented To-Be version of the process under study.

Step 11. Dynamic Diagnosis - Create Systems Dynamics model: Take the model of supply chain developed in Sterman (2000) as the basis for modeling the particular features of the supply chain under study. Next,

a. Customize the model with the peculiarities of each echelon. Prior to that, care to be certain about the purpose of the model, in doing so build a customized problem articulation, reference modes and dynamic hypothesis.

b. Use estimated parameters and plan the collection of parameters data. Refer to Section 3.4 for detailed guidelines in estimating by means of automated calibration (AC). Model calibration consists of initially getting a preliminary collection of most accessible data for the model's variables and estimating for the remaining ones in an iterative process where, under low confident results, more real data is collected. Under a calibration approach the objective is to 
obtain the best statistical fit between simulated and actual response(s), while adjusting (calibrating) the values of undetermined model's inputs. The traditional fit statistic for time series is the r-squared (r2), which indicates what percentage of the series can be explained by the model so the closer to $100 \%$ is better. In practice, $\mathrm{r} 2$ values between $60 \%$ and $80 \%$ are considered to be a good fit for actual data.

where

$$
\operatorname{MSE}=1 / \mathrm{n} \sum_{\mathrm{t}=1}^{\mathrm{n}}\left(\mathrm{y}_{\mathrm{t}}-\mathrm{d}_{\mathrm{t}}\right)^{2}
$$

$\mathrm{y}_{\mathrm{t}}$ model variable at time $\mathrm{t}$,

$d_{t}$ data for variable at time $t$,

$\mathrm{n} \quad$ the number of variable - data pairs

The Theil's inequality statistics decompose the mean-square-error (MSE) between simulated and actual series into three components: bias $\left(\mathbf{U}^{\mathbf{m}}\right)$, unequal variation $\left(\mathbf{U}^{\mathbf{s}}\right)$, and unequal covariation $\left(\mathbf{U}^{\mathbf{c}}\right)$. Bias represents the simulated and actual series means difference and should tend to zero, or else inform on the extent of displacement. Unequal variation is the difference between variances of both series and as in the previous, the smaller the better. Unequal covariance gauges the correlation factor between compared series, this is, compares the noise of the series. Thiel's measure takes the unexplained variance from the model (which is the complement of $r 2$ value) and indicates what percentage of it is due to noise from the error due to systematic variances between the model and reality (Sterman, 1984). Typically, a large error in unequal covariance (commonly termed as imperfect covariation) is expected since it is known that 
the model and actual series have different randomness. In this way, the majority of the error should be accounted for what is not related to the purpose of the model (Sterman, 1984), therefore the model should not be faulted.

c. Calibrate the model for each link in the supply chain, using the automatic calibration (AC) enabled by Vensim ${ }^{\circledR}$ 's optimization engine, and if a good match is acquired by means of automatic calibration, there is no urgent need to collect real data for the whole model (Oliva, 2003). Have in mind that for certain model variables this process is iterative and/or continuing during the project.

d. Screen the model to determine the most impacting parameters and reinforce data collection on these (Ford and Flynn, 2005). Notice that this step is an early special-purpose kind of sensitivity analysis, a modeling activity contemplated on a later step.

e. Validate and verify the customized model. There is a series of steps described by several authors (Barlas, 1996; Forrester, 1961; Oliva, 2003; Sterman, 2000) to conduct this critical step.

\section{Step 12. Dynamic analysis}

a. Perform sensitivity analysis. Obtain confidence intervals for the results of interest (demand amplification ratio, inventory coverage, delivery delays, and costs). To achieve this step, it is critical to identify the model's sensitive parameters (and plausible ranges), structure and boundaries of the model. Most contemporary system dynamics modeling software provide with automated 
tools to perform some of this changes. There is a set of options for conducting dynamic model' sensitivity analysis, such as perturbation analysis, statistical screening and LEEA. Refer to Appendix B for further considerations on the subject.

b. Perform optimization on the main responses, by varying sensible inputs identified in the former sensitivity analysis. Using the insights obtained, formulate policy counterfeiting underlying causes of demand amplification in the system.

c. Present results to the team, discuss and obtain insights.

d. Formulate with the team feasible improvement measures, clearly define the actions that will generate improvement (what) and (who) will be responsible for that. Discuss possible barriers.

\subsubsection{Devise Treatment(s) \& Analysis of Results}

This stage is the natural evolution of the diagnostic, taking the output of the earlier stage (causes of amplification, misfits) and turning them into countermeasures (new policies, system improvements) to be recreated in model scenarios and tested as previously described. It includes the following steps:

Step 13. Re-create improvements.

a. Model To-Be. Evaluate the solutions devised in the earlier step, by introducing changes in the model to create specific scenarios that portrays their conditions. 
Consider solutions separately and jointly implemented (if several) and document results.

b. Perform sensitivity analysis. Obtain confidence intervals for the results of interest (demand amplification ratio, inventory coverage, delivery delays, costs), similarly as in step 7.3.1

Step 14. Results assessment.

a. Thoroughly discuss the results and insights obtained with the team and with varying levels of staff from the organizations involved. Evaluate the solutions and compare results with expectations.

b. Present results to Top Management

Step 15. Review of alternatives: decisions about Adopt, Adjust, or Abandon for each of the solutions devised, as well as its joint implementation. Prepare final document with detailed proposals and expected benefits, and expose to the Steering Committee.

\subsubsection{Treatment}

This is the final step regarding the specific actions to put in practice the proposals obtained from the past stage. Once they have been agreed and approved by the Top Management of the organizations involved, and provided the correspondent funding available, new projects are developed and managed over a scope that goes beyond the one of the present work. Typical steps include: 
Step 16. Plan actions to implement improvements in the real system.

Step 17. Measure the benefits obtained, compare with expectations as exposed in the final document.

Step 18. Revise proposed improvements, customize for current settings and standardize operating procedures.

\subsection{Measuring the Bullwhip Effect in Actual Supply Chains}

This section develops an overall estimation method of the bullwhip effect in real supply chains, initially introduced in Amaya and Giachetti (2009). The necessity of such method comes from the systematic miscalculation of BWE observed in the literature when it deals with live and extended (i.e., composed of more than two echelons) actual systems, mainly due to disregarded pooling effects on the sampled demand flow. The novelty of the measure is it has low data requirements, which is significant in practice because any single echelon of the supply chain has limited information on the entire supply chain.

Fransoo and Wouters (2000) proposed a comprehensive approach to measure the bullwhip effect of a multi-echelon supply chain based on coefficient of variation comparisons, so far the more advanced to date in the author's view. Still, their approach falls short on two important considerations for implementation in actual systems. These are:

(1) The overall bullwhip measure has high data requirements - essentially all demand data for the supply chain nodes of interest. Otherwise, the sampler is exposed to 
different aggregation levels of the available data from the nodes composing the chain under study, an issue first raised in Fransoo and Wouters (2000), i.e., when confronting demand from a given node with a partial sample of its customers, as exposed in Figure 15. If it were to be used only a fraction of demand from the customers instead of the total demand data, the analyst would incur in a non-valid measure since it compares different flows. This is, it matches coefficients of variation ignoring pooling effects and disregards the effects of the discarded demand portion on the overall variance. In addition, it forces an incoherent mean contrast.

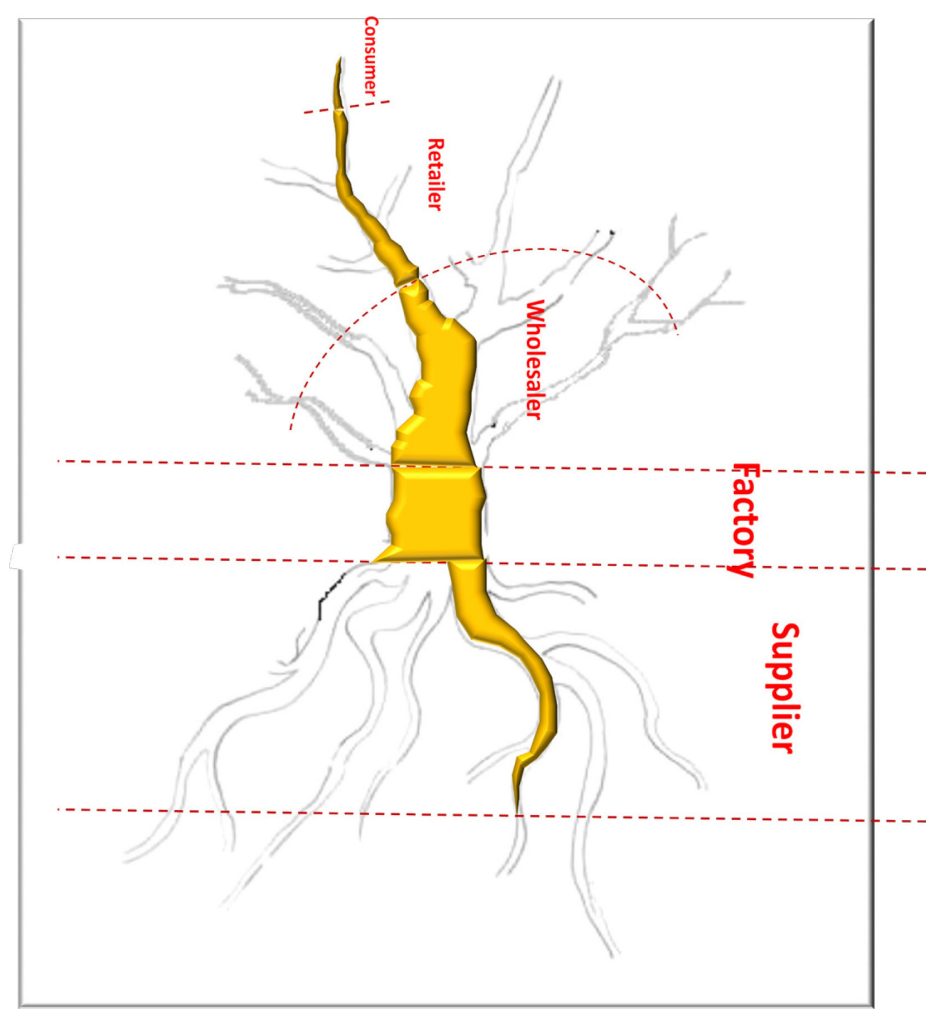

Figure 15. Dissimilar demand flows when sampling actual supply chains 
Demand flow conservation is granted by using full demand data, which overcomes the issue annotated before, but it is unlikely that any single company in the supply chain has access to all customers' data. Moreover, a single company is part of many supply chains, and they would need data on all these supply chains. The measure places an unattainable data-gathering burden on the company wanting to use the measure.

(2) In the absence of full information, the second best option is to compromise with an estimate of the global BWE of the system based on a collection of nodal measures. Yet, this option does not seem to suffice when dealing with multiechelon supply systems, where BWE is born out of a complex interrelation of causes arising from undetermined instances. Therefore, reliable systemic measures are crucial for its mitigation and without them important improvement efforts might be missed. For instance, the Demand Amplification Quotient $(\omega)$ detailed in Equation [4] of Table 5, is a relative measure since it compares incoming vs. outgoing demand. However, a (relative) improvement in a certain portion of the system does not necessarily imply the overall wellness of the system.

After this discussion, the important matter is how to obtain a reliable and feasible overall BWE measure of an actual multi-echelon system. It has been established that sampling the system with current methods particularly induces issues in variance comparison, which is in the center of BWE manifestation. Nonetheless, sampling is the only affordable option to cope with live systems. The proposed solution to this matter is a method that delivers an overall BWE estimate making use of partial 
data available from the real system. It does not attempt to determine an exact measure, deemed as unfeasible; it rather aims at indirect measures that approximate the desired global measure.

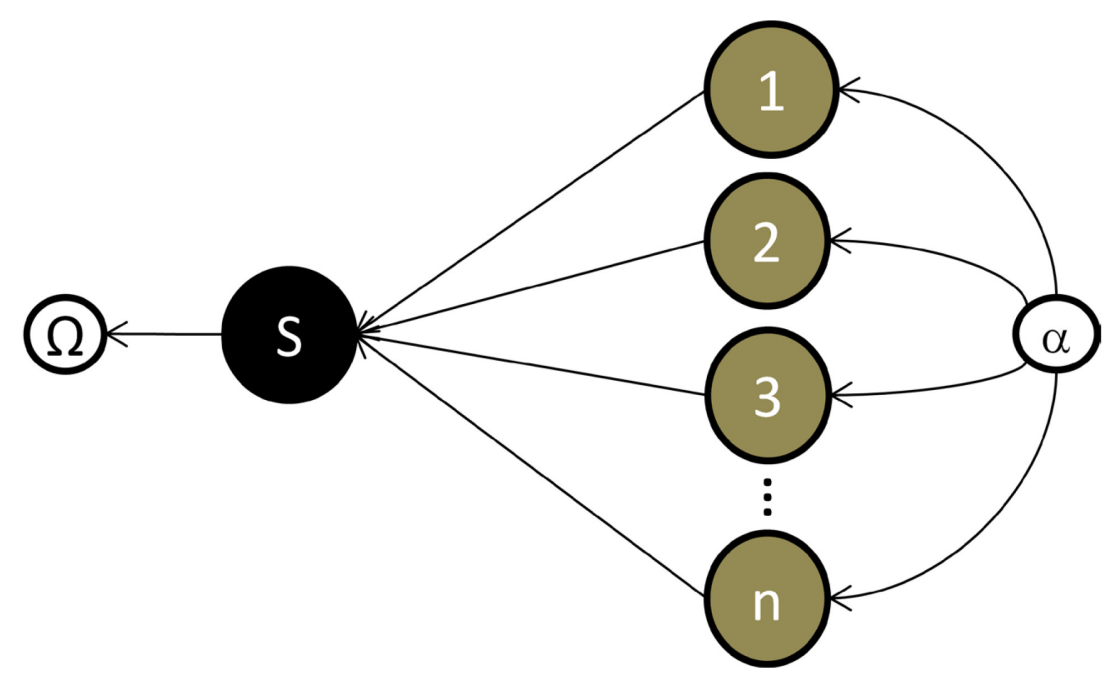

Figure 16. Umbel

Full demand data availability is unrealistic; hence, the departing point is a sample of firms that has given access to examiners to accessed nodes. This investigation proposes a method that initially focuses in obtaining a feasible BWE measure for a subset of nodes of the system under study. Figure 16 shows the basic node array used for computing the BWE measure, herein termed 'umbel' after the flower morphology. Although an actual supply chain topology is not as simple, it can always be reduced to a finite number of umbles. We illustrate the BWE index computation of a single umbel, after which the SC BWE computation becomes trivial. 
An umbel is composed of a single supplying node (S) attending any given number (n) of customer nodes, typically a large number. Figure 16 shows the information flow in the sense of the arrows, emerging from the imaginary node $(\alpha)$ and converging to the fictional node $(\Omega)$. Readers should notice the existence of two echelons conformed by the actual nodes, to the left hand of the figure the one conformed by the sole node $\mathrm{S}$ and to the right the set of $\mathrm{n}$ customer nodes.

The underlying assumption is there is access to node $\mathrm{S}$ and to a certain number of connected instances of the n-th customer nodes, which defines the initial sample used in determining BWE. Let us consider the umbel as a finite graph $\mathrm{G}=(\mathrm{N}$, A), where G denotes such graph, with non-empty sets of arcs and nodes, respectively A and N. We define $\bar{A}$ and $\bar{A}^{C}$ correspondingly as the subset of nodes that has and has not granted access to its data. Denoting $D_{i}^{\text {in }}$ and $D_{i}^{\text {out }}$ in that order as the incoming and outgoing demand to/from the i-th node, it follows that $D_{i \in \bar{A}^{c}}^{i n}$ is unknown, which makes unfeasible the computation of $B W E_{A}$, or the overall $\mathrm{BWE}$ measure of the nodes that belong to A. This comes from considering exclusively the accessed nodes $\bar{A}$ as the new system of reference, which is simulated to reproduce the decisions that determine the information flow resulting from the exclusive input of the accessed customer nodes. Notice that: a) the variance of the information flow is mostly attributed to the ordering policies (i.e., the re-ordering policy, forecasting method, discount policy and cash flow); b) demand flow although reduced, is conserved and known in the new reference system, e.g., the supplying node original data is disregarded and replaced by the simulated output, thus coherent with its input by design. As a result, it is feasible to 
obtain an exact BWE measure of $\bar{A}$, hereafter named as $B W E_{\bar{A}}$, by means of the Fransoo and Wouters (2000) measuring framework.

After the former simulation model has gained credibility, with the proper inquiries and subsequent to a refined set of assumptions it is possible to characterize and reproduce the unknown $D_{i \in \bar{A}^{c}}^{i n}$ to compute an overall measure termed as $\widehat{b w} e_{A}$. Yet, the ultimate goal it is not to estimate $B W E_{A}$ by means of $\widehat{b w} e_{A}$, considered as a very long shot ${ }^{10}$ for estimating the index due to the large proportion of $D_{i \in \bar{A}^{c}}^{i n}$ in relation to $D_{i \in \bar{A}}^{i n}$, or expressed in words, the large dominance of unknown input rather than known.

Thus, it is posed as a more tractable issue to derive a mathematical relationship between $\widehat{b w} e_{A}$ and $B W E_{\bar{A}}$ in order to understand factors that determine favoring sampling conditions that minimize their distance, or error $(\varepsilon)$, by means of a Design of Experiments (DOE). Thus, the proposal aims at initially relating a couple of simulation-derived measures in order to determine directions for a second stage of smart sampling and refined measures using DOE. Out of a refined $B W E_{\bar{A}}$ via further sampling and with the chosen $\varepsilon$ from the DOE results is computed the desired BWE estimate, let us term it as $\widehat{B W E}_{A}$, where

Let us consider in more detail $D_{i \in \bar{A}^{c}}^{i n}$, which is the union set of incoming demands to all non-accessed nodes. When reflecting on the nature of incoming demand, the troublesome part of its inference lies on the large number of non-accessed nodes, and then on estimating as many times the variance and shape of their probability distributions (rather than its mean values, more affordable), which poses the difficulty of directly addressing $B W E_{A}$ estimation. 


$$
\widehat{B W E}_{A}=\frac{B W E_{\bar{A}}}{(1+\varepsilon)}
$$

In order to summarize the series of steps described in the former paragraphs, an illustrative flowchart is introduced below.

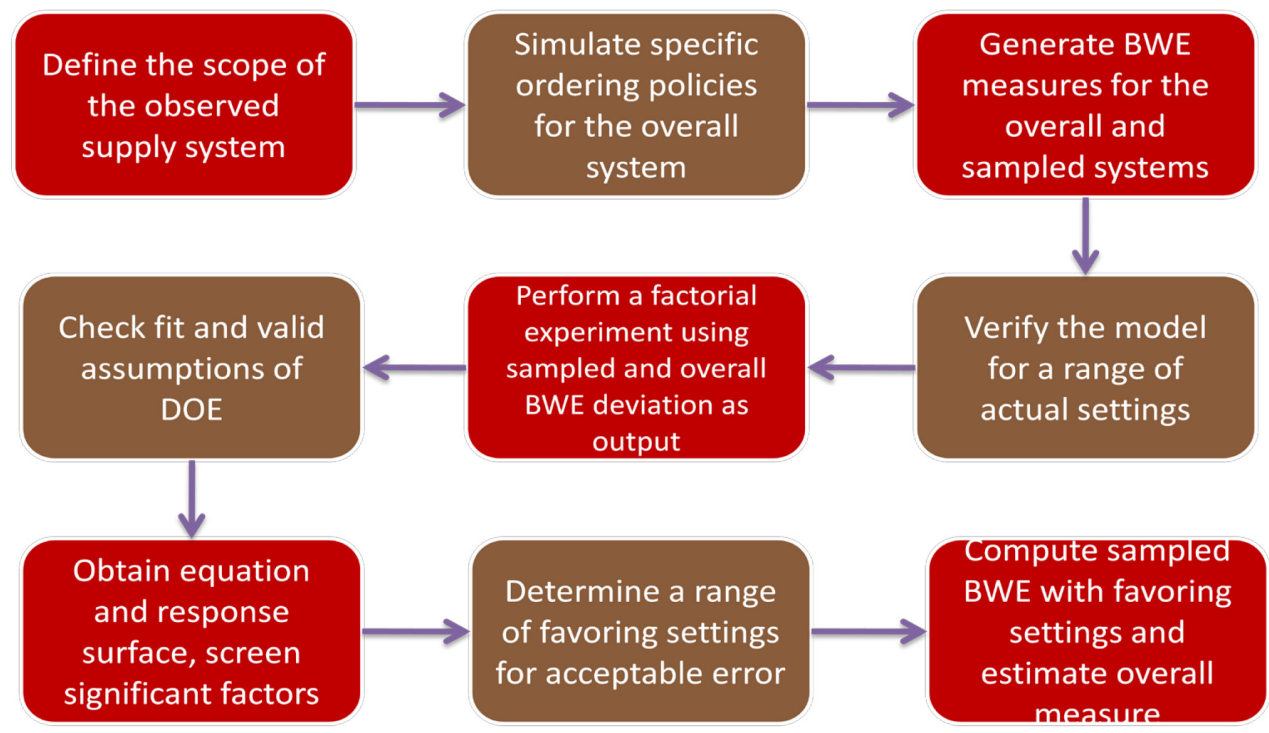

Figure 17. BWE estimation approach

The methodology described is still experimental and in need of further validation. However, results of it are developed in Amaya and Giachetti (2009), where an illustrating example is provided by emulating an inexistent two-echelon umbel in a spreadsheet, considering a single product following normal demand. Some of the features of the simulation include a variable number of nodes with its mean flow following a Pareto distribution. Variation input is uniformly distributed among customer nodes and propagated within by a $(r, S)$ reordering policy for all the nodes. An array of 
input parameters for multiple settings with the use of a VB simple algorithm to systematically read inputs and write results is in use.

Table 7. Factorial design for deviation of global BWE

\begin{tabular}{|c|c|c|}
\hline Number of experimental factor: & Responses & Units \\
\hline Number of blocks: 30 & K_1 & deviation \% considering inflow due to 1 \\
\hline Number of responses: 7 & K_1_2 & deviation $\%$ considering inflow due to $1+2$ \\
\hline Number of runs: 58320 & K_1_2_3 & deviation $\%$ considering inflow due to $1+2+3$ \\
\hline
\end{tabular}

\begin{tabular}{|c|c|c|c|c|l|}
\hline Factors & Name & Low & High & Levels & \multicolumn{1}{|c|}{ Description } \\
\hline A & Flow & 500 & $1,00 \mathrm{E}+06$ & 3 & Total amount of demanded units \\
\hline B & \# of nodes & 5 & 95 & 3 & $\begin{array}{l}\text { \# of nodes constituting the } \\
\text { distributor echelon }\end{array}$ \\
\hline C & \%_flow_1 & 0,05 & 0,15 & 3 & Incoming flow to 1 \\
\hline D & \%_flow_2 & 0,05 & 0,15 & 3 & Incoming flow to 2 \\
\hline E & \%_flow_3 & 0,05 & 0,15 & 3 & Incoming flow to 3 \\
\hline F & Cin_1 & 0,4 & 0,8 & 2 & Coefficient of variation of 1 \\
\hline G & Cin_2 & 0,4 & 0,8 & 2 & Coefficient of variation of 2 \\
\hline H & Cin_3 & 0,4 & 0,8 & 2 & Coefficient of variation of 3 \\
\hline
\end{tabular}

Main assumptions include demand flow conservation, and linearity behavior for the mean of the flows, so they can be estimated. Note that the features of the flow out of a given node are due to a particular re-ordering policy. Next, shows the multiresponse factorial design considered for the experiment, where three outputs are differentiated considering a sampling size ranging from one to three accessed nodes.

Taking only in consideration the results obtained for K_1_2_3, which is the response variable $\varepsilon$ when $\bar{A}$, the subset of accessed (sampled) nodes is of cardinality 
three, Figure 18 exposes the significant effects with interactions, the goodness of fit of the linear model expressed in several tests and statistics, and the mathematical expression relating the output with the inputs considered.

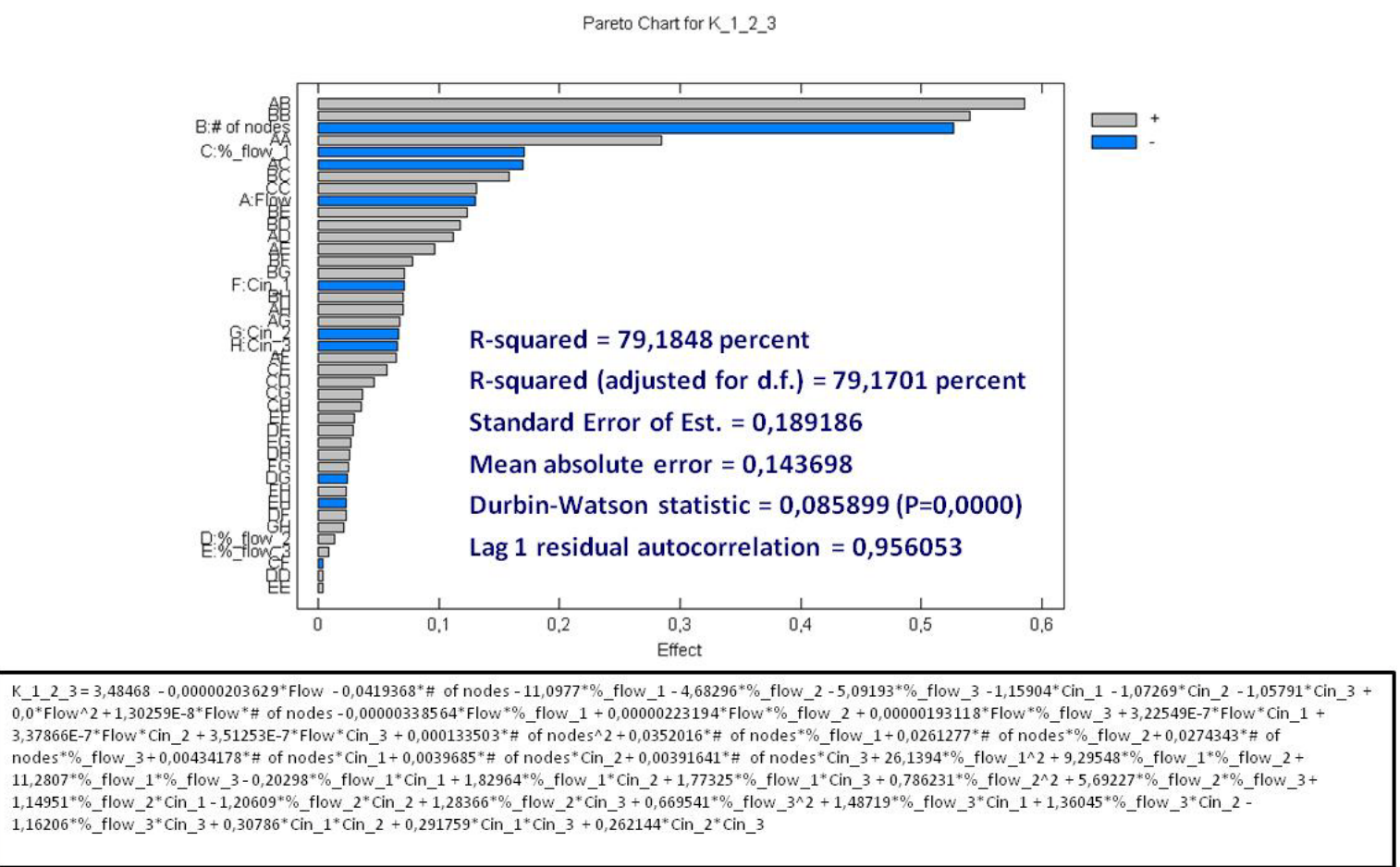

Figure 18. DOE analysis for $\mathrm{K} \_1 \_2 \_3$

Note in Figure 19 an estimated 3-D response surface for K_1_2_3 built upon the most significant pair of factors, in this case the number of nodes of the rightmost echelon (see Figure 16) and the amount of (demand) flow faced by the umbel. 


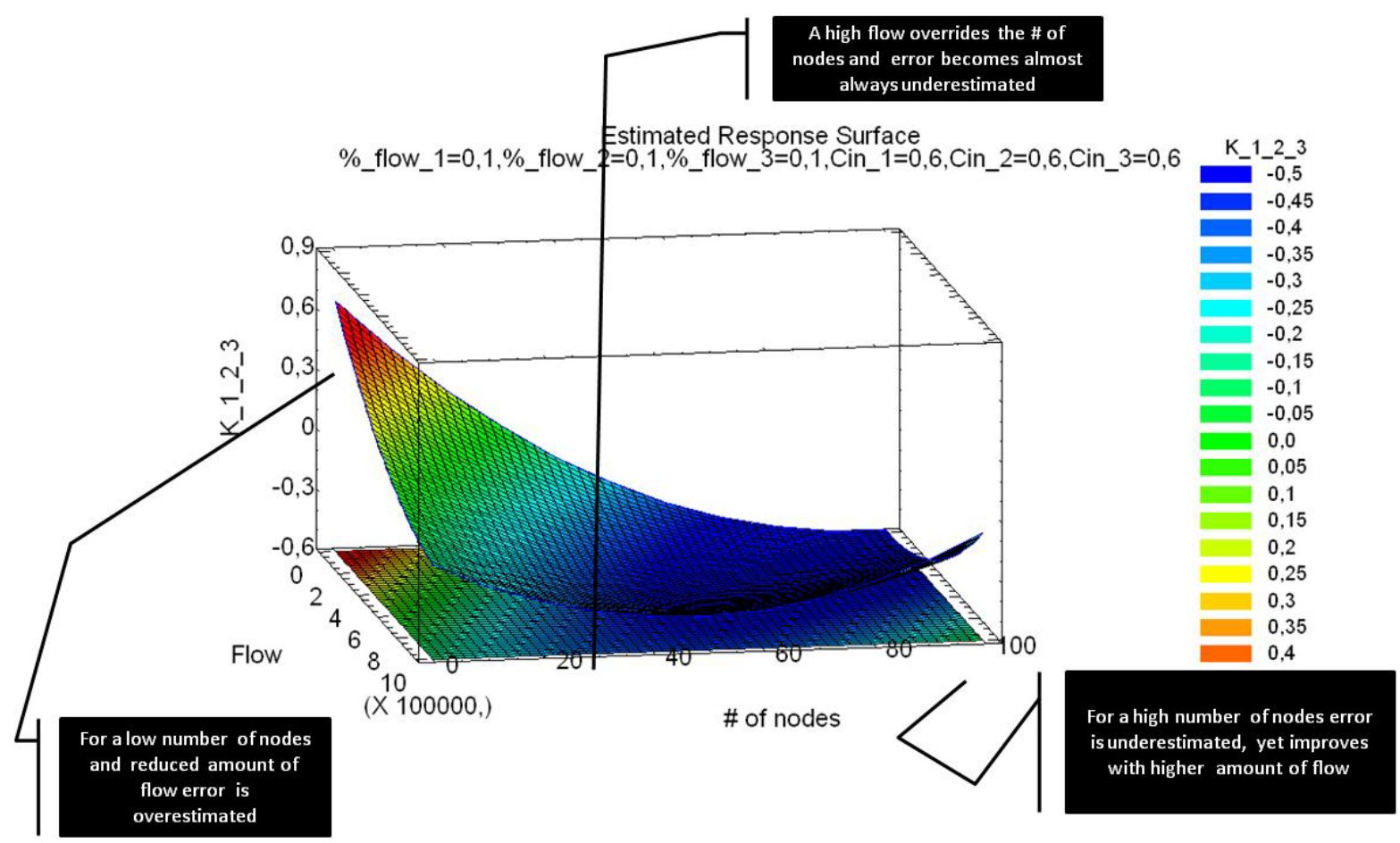

Figure 19. Response Surface for K_1_2_3

The important thing to notice from the figure above is the colorful mapping of the variable $\varepsilon$ all along the dimensions found to be determinant to it. As a result, it is possible to identify significant factors and acceptable error zones to match sampling design with operating restrictions from a practitioner's perspective. The illustration of the method does not go beyond this point due to the artificial nature of the case study, however serves the purpose of demonstrating its development. The next steps would lead to further sampling after determining attractive conditions, for a refined $B W E_{\bar{A}}$ that would lead to $\widehat{B W E}_{A}$ as in equation [5]. 


\subsection{Automated Calibration in System Dynamics}

In dynamic models variables can evolve over time simulation naturally describing a time path of state variables we call 'behavior' of the model. This behavior is determined by the relationships between exogenous and endogenous variables that make up the model, what is usually termed as the 'structure' of the model.

Calibrating system dynamics models is the process of estimating model parameters for a statistical coincidence between simulated and observed behavior. This is, forcing the model behavior to fit a given response by changing parameters of the model structure under certain constraints. Implies that, for unknown model inputs, the modeler trust the model to adjust its response to a known system response by adjusting (calibrating) unset inputs instead of collecting data from reality to infer the input value. The confidence conferred to a given model structure as a valid representation of the real system increases, if such structure is able to generate the observed behavior without assigning unreasonable values for the calibrated inputs (Barlas, 1996; Oliva, 2003).

The calibration process, however, has some limitations. Remarkably, the calibration is only a partial test of the structure represented by equations and parameters, since is possible that a set of parameter values may be able to reproduce the behavior observed by means of unrealistic formulations, generating correct behavior for the wrong reasons. Hence, a complete structure test must include an assessment of the adequacy of the model equations (Oliva, 2003; Randers, 1976). 
There are automated and hand-made calibration processes. Lyneis and Pugh (1996) describe the manual calibration process as follows: model calibration is usually done 'by hand'. In an iterative process, the designer examines the differences between the simulated and observed data, identifying possible reasons for these differences; then, adjusts the parameters of the model in an effort to correct the discrepancy, and re-runs the model. The process of estimation just described is based on the expertise and experience of the modeler.

Yet, statistical approaches have been adopted from other fields in an attempt to make the parameter estimation process more rigorous. According to Oliva (2003), two approaches have been consistently adopted to estimate the parameters for whole model: full-information maximum likelihood through optimal filtering (FIMLOF; (Peterson, 1969; Peterson, 1980)), based on engineering statistics; and, model reference optimization (MRO; Lyneis and Pugh (1996)), based on non-linear optimization algorithms that search across the parameter space. Both approaches are data - and computational—intensive, and since this computerized support is highly desired, most simulation suites nowadays offer automated calibration (AC) features; they require an error function containing all data available, and access to the set of model parameters to be adjusted. The techniques, however, yield an optimal fit with the given structure and adjusted parameters; outstandingly, even novice modelers can generate good fits (Lyneis and Pugh, 1996) and replicable results. 
Table 8. Summary of techniques for estimating lengths and orders of delays

$$
\begin{array}{ll} 
& \min _{p} \sum_{i=1}^{n} w_{i} \sum_{t=T_{0}}^{T_{f}} f\left(y_{i t}-d_{i t}\right), \\
& \text { s.t.: } y_{t}=c\left(s_{t}, p, u_{t}\right), l l \leq p \leq \mathrm{ul} \\
& \text { where } \\
w_{i} \quad & \text { weight of ith error series, } \\
y_{i t} & \text { model variable i at time } \mathrm{t}, \\
d_{i t} & \text { data for variable i at time } \mathrm{t}, \\
s_{t} & \text { model state variables, } \\
p & \text { model parameters, } \\
u_{t} & \text { known inputs (data series), } \\
l l & \text { lower limit of parameter feasible range, } \\
u l & \text { upper limit of parameter feasible range, } \\
T_{0} & \text { initial simulation time, } \\
T_{f} & \text { final simulation time, and } \\
n & \text { the number of variable - data pairs in } \\
& \text { error function }
\end{array}
$$$$
\text { Source: extracted from (Oliva, 2003) }
$$

The type of calibration used in this project corresponds to the MRO approach. Oliva (2003) asserts that under MRO, the calibration problem from longitudinal data is specified as an optimization problem for the adjustment of parameters $(p)$, aimed at minimizing a function of the differences between available data series $\left(d_{t}\right)$ and the fitted model variable $\left(y_{t}\right)$. Since several data sets might be available, the objective function must specify the relative weight $(w)$ for each series. Model output variables depends on state variables $\left(s_{t}\right)$, parameters $(p)$ and known inputs (u) of the model. Finally, the values of system parameters can be limited to a feasible range $[l l, u l]$. Formally, the problem of calibration is set as in Table B-1.

The restriction in terms of $c$ is given by the equations of the model, and in many cases will not be linear. There is a variety of available optimization algorithms suitable for searching the parameter space to minimize the deviation between the model 
output and historical data, even in the face of noise, nonlinearity inherent discontinuities and dynamic models (see Miller (1998) as cited in Oliva (2003))

Although AC techniques are capable of generating an optimal fit to historical data for a given structure and parameters, criticisms have been made against this approach to infer parameter values. Oliva (2003) groups these criticisms into three main categories: the source of the values of the estimated parameters, the tractability of mismatches and model diagnosis, and the nature of implied testing process. The first one refers to the inherent weakness of estimation dependent on a conceptual creation instead of an independent measure taken from reality; the second, draws attention to the fact that under certain conditions, specifying the calibration problem as a single optimization problem with an error function might provide enough degrees of freedom as to obtaining a good fit with a wrong model structure; the third one regards to the test ethos, since AC constitutes a confirmation test - rather than a falsification test - of the structure's ability to replicate historical behavior, unless there are obvious mismatches the method is likely to confirm our current beliefs and does not support a process aiming to reject the dynamic hypothesis.

There is a number of measures that can be taken to counteract the former issues. Oliva (2003) provides as well a recipe for leveraging the strengths of AC without simultaneously overriding the process of testing the dynamic hypothesis. He proposes three heuristics in order to judiciously use calibration and maintain his power: 1) If parameters can be directly observed—or estimated from data below their level—-they should be estimated. Conversely, if knowledge about a parameter is not precise, but it 
can be limited to a feasible range, such information should be introduced into the calibration problem by restricting the search range for that parameter. 2) Apply AC to the smallest possible calibration problems. That is, a reduced number of equations and, consequently, parameters, i.e., partial-model testing (Homer, 1983). And, 3) Use AC to test the hypothesis "The estimated parameter matches the observable structure of the system." since AC yields the best possible set of parameters to match the observed behavior, setting the null hypothesis to test the a priori parameter estimates is a much more powerful test.

Arguably, the first measure is straightforward and decisions regarding parameter calibration are made in the face of the modeled reality and knowledge about available data sources. As for the second, the consideration is to partition the model as finely as possible which requires understanding of the structure of the model and the role of individual parameters to determine the model behavior. Working with small calibration problems reduces the risk that the structure is forced to fit the data by yielding a wrong estimation, increases efficiency of the estimate by reducing confidence intervals and focuses on the differences between simulated and observed behavior right in the segment of the structure responsible for such behavior.

With regards to the third, Oliva (2003) breaks down the test of coherency between estimated parameters and structure into three tests: feasibility, consistency, and confidence. Feasibility checks for nonnegativity of estimated time constants, compliance to matter conservation laws of initial conditions for physical stocks, 
"fractions" with values between zero and one, and for the resulting formulation to be robust enough for successful extreme condition testing.

The evaluation of the feasibility of estimated parameters is context- sensitive, and should be performed with full understanding of model formulation. A way to facilitate this test is to limit a parameter's search range to its feasibility area. However, if the result of the estimation is at one of the limits specified for the search space, the adequacy of the dynamic hypothesis or the model formulation should be put under question. Normally, when $\mathrm{AC}$ results in parameter estimates at one of the limits in the search space, indicates that the model structure is being "bent to fit" the data up to a feasible limit. Hence, is about verifying where the estimate falls into the specified parameter's range.

As another assessment of parameters feasibility, analysis of the calibration tests should explicitly verify compliance of their underlying assumptions. For a complete diagnose of the error source is necessary to explore the residuals of the test (Sterman, 1984). A graphical inspection of the residuals over time is useful in detecting bias, trends and cyclical components (Oliva, 2003).

The assumptions adequacy relies in the statistical model implemented for verifying the fitness. When simulated time series from one (or more) model outputs are confronted against the actual system ones, the traditional measure for determining the degree of fit to the real data points is the r-squared $\left(R^{2}\right)$ statistic. However, a more complete indicator of the nature of the statistical adjustment is the Theil inequality (Theil, 1966), introduced in Step 11 of Section 3.2.2.1. 
The next test is to determine if the parameters are consistent with what is known about the system structure. Estimated parameters need to match other sources such as interviews and direct observations.

As for confidence, under MRO and for the case when the error function $f$ is defined as the square of the predicted error, the objective function corresponds to the likelihood equation, and the parameter estimates are the maximum-likelihood estimates (Greene, 1997). Using the response surface of the likelihood equation it is possible to determine confidence intervals for the parameter estimates from the curvature of the response surface by varying each parameter and measuring the change in response (Long and Cliff, 1997; Peterson, 1980). If the response surface around the optimal point is steep, small variations of the parameter will yield a significant drop in the objective function. This tightness of the reported confidence interval measures how useful the data are for estimating a parameter, therefore reported confidence intervals could also be interpreted as a sensitivity analysis. A tight confidence interval means that datastructure combination was effective in discriminating among parameter values, whereas a wide confidence interval implies that, at least for the variables in the error function, the model is not sensitive to variations in that parameter. 


\section{CHAPTER 4 - DAMP BUSINESS PROCESS DIAGNOSIS}

This chapter illustrates the application of the Demand Amplification Protocol (DAMP) to an actual supply chain for the production and distribution of plastic widgets. A case study is used to illustrate and extend the theoretical proposals defined in the previous chapter. The DAMP framework is a twofold approach comprised by a Business Process and Dynamic Diagnosis. The present chapter focuses on the first one and provides with the business background and implementation detail for the case study. The Dynamic diagnosis is described in Chapter 5.

\subsection{Case Study Background}

The company being studied, MedLab, is an international, mid-sized manufacturer of sterile disposable medical devices founded in 1981. They have annual sales in excess of eighteen million dollars to all continents. Manufacturing facilities are located in the city of Barranquilla, an industrial and logistics hub on the northern Caribbean coast of Colombia. They offer a complete line of plastic widgets and related laboratory supplies.

In the course of its historical evolution, MedLab has reduced its reliance on domestic markets with exports, particularly to Central and South America. The markets MedLab competes in have had foreign competitors, however more recently, from 2004, the company has faced a dramatic increase in aggressive Asian competition in their local widget market, which has had a strong impact on their overall market share and led to declining sales of its flagship products. 
In response to this situation, and particularly for the local market, the company has deployed a defensive strategy to preserve local market share and retain customer loyalty by differentiating its offer against foreign competition based on an ample portfolio of high quality products with impeccable delivery compliance. To retain their competitive edge the company decided to do the bulk of its business with Chinese suppliers. However, the long-term economic implications of this move remain unknown.

In practice, the implementation of the previous strategy has not been as successful as planned, and there have been significant difficulties in meeting promised delivery times for a wide range of products. In addition, MedLab has historically been increasing its cash-to-cash $(\mathrm{C} 2 \mathrm{C})$ cycle for these products, which signifies a high risk for the company's financial viability over the medium term.

The firm has increasingly become more dependent on global variables, such as currency rate exchange and raw material prices (mostly dependent on oil prices). There are also global customers who, given its bargaining power, had managed to gain dominance over the company's operating decisions, exerting pressure in manufacturing capacity and limiting the share of production/inventory for other customers. The combined effect of such global variables make the management of the company a complex task, which in words of MedLab's COO makes "most appealing the possibility of a managerial switch that enables MedLab's internal rhythms to adapt to the changing external conditions." 
Preliminary audits had shown that the firm exhibited known accelerators and symptoms of BWE in their main lines of products. The company consistently faced serious difficulties in determining the actual figures of local and external demand for their products, and consequently, experimenting with unsuccessful operations plans. These considerations were only for the manufacturing facility and did not include other echelons in the supply chain, which should also experience disturbances in their demand signal. Hence, MedLab is a prime candidate for the application of DAMP.

The Demand Amplification Protocol (DAMP) diagnoses the bullwhip effect in a supply chain. Its scope surpasses the mere study of an individual firm, therefore, it is first necessary to select a subset of products within the firm and identify supply chain partners which to include in the study. The selected product for study was the line of widgets, in particular the families of $5 \mathrm{ml}$ and $10 \mathrm{ml}$ volume widgets that are assembled with two and three parts. This product line is a best-selling one, and remarkably, a product with prominent participation in the company's overall results as well as of great importance to the distributor and retailer.

\subsection{Triage}

MedLab is the primary firm of this particular supply chain and the nuclear company of the study. As the supply chain leader was involved in enlisting relevant satellite firms to conduct the diagnosis. 
Table 9. Matrix for scoping the supply chain under study

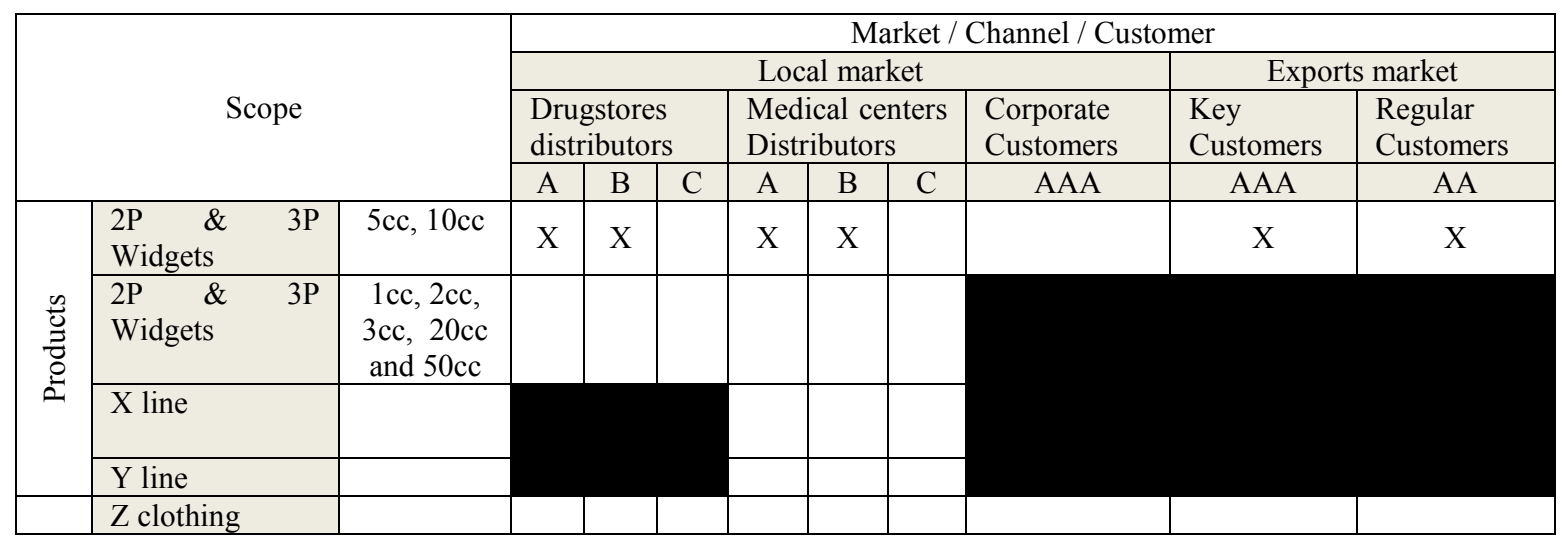

Table 9 shows selected lines of widgets $2 \mathrm{P} \& 3 \mathrm{P}$ with combinations of distribution channels, whose intersections are marked with "X". The company's product portfolio includes a complete line of disposable widgets of 2 and 3 pieces, in sizes of $1 \mathrm{cc}, 2 \mathrm{cc}, 3 \mathrm{cc}, 5 \mathrm{cc}, 10 \mathrm{cc}, 20 \mathrm{cc}$ and $50 \mathrm{cc}$, featuring fitting systems secure and securer with a variety of calibers for disposable couplings. It was found as determinant the sales and market share performance of 5 and $10 \mathrm{ml}$ widgets, selected as the backbone of the study. Shadowed spaces designate not available options, whereas clear spaces are feasible but not considered in the scope.

\subsection{Examination - Business Process Diagnosis}

The purpose is to identify points of precedence associated with the bullwhip effect by developing process maps following the SCOR® model framework (SupplyChain Council, 2008) and analysis of indicators and measurement processes, through a scorecard built for this purpose. In this section, we will address separately both process description and metrics. 


\subsubsection{Process Review}

A business process model is an abstraction of a business that shows how business components relate to each other and how they operate. Its ultimate purpose is to provide a clear picture of the enterprise's current state and to determine revenue and value generators within a business model's value network (Trkman, Stemberger, Jaklic, and Groznik, 2007). The SCOR Model is a business process reference model that provides a comprehensive toolset linking business processes to metrics, best practice and technology (Supply-Chain Council, 2008). SCOR ${ }^{\circledR}$ uses a "building block" approach based on five management processes to describe supply chains. This building block approach allows a supply chain description to be "assembled" across organizations, internal and external, across industry segments, and across geographies.

The SCOR model decomposes from five Level One process categories: PLAN, SOURCE, MAKE, DELIVER, and RETURN. In turn, level one process category decomposes in level two process types, as listed:

P1: Plan Supply Chain; P2: Plan Source; P3: Plan Make; P4: Plan Deliver; P5: Plan Return

S1: Source Stocked Product; S2: Source Make-to-Order Product M1: Make-to-Stock; M2: Make-to-Order

D1: Deliver Stocked Product; D2: Deliver Make-to-Order Product

SR1/DR1: Return Defective Product (Source Return/Deliver Return)

SR3/DR3: Return Excess Product (Source Return/Deliver Return)

EP, ES, EM, ED, ER: Enabler corresponding to a SCOR Process, respectively Plan, Source, Make, Deliver, Return. 
Figure 20 shows the process categories at level two defined for the overall MedLab supply chain, which considers not only MedLab itself but two additional downstream echelons. In MedLab, all starts with the company's annual planning (P1). This process begins with the demand forecast (EP.1), which requires estimating the aggregate demand for products and market size (EP.3). In terms of market size, the Sales department is responsible for computing the forecasted amount of sales of the previous year by vendor in order to dimension the market pie and MedLab's share. The reliability of such important information is questionable, since computed by oversimplified forecast technique plus management intuition.

MedLab exhibits typical processes of a push production system. Regular customers serve their monthly needs from inventory, which in turn results from the balance of current demand and the production outcome. Production planning estimates (P3) come from the basis of a company's budget, a monthly forecast, firm orders in place and a safety stock margin characterizing an M1 process. Yet, in parallel coexists with a M2 process occurring whenever export orders are placed featuring a make-toorder manufacturing policy. A noticeable misalignment in current manufacturing operations is that they are not coherent with the flexibility and speed compromised in the stated competitive position of the firm. As in typical push-based environments, MedLab operations policies, product design and hardware are devoted to economies of scale by means of mass production. 


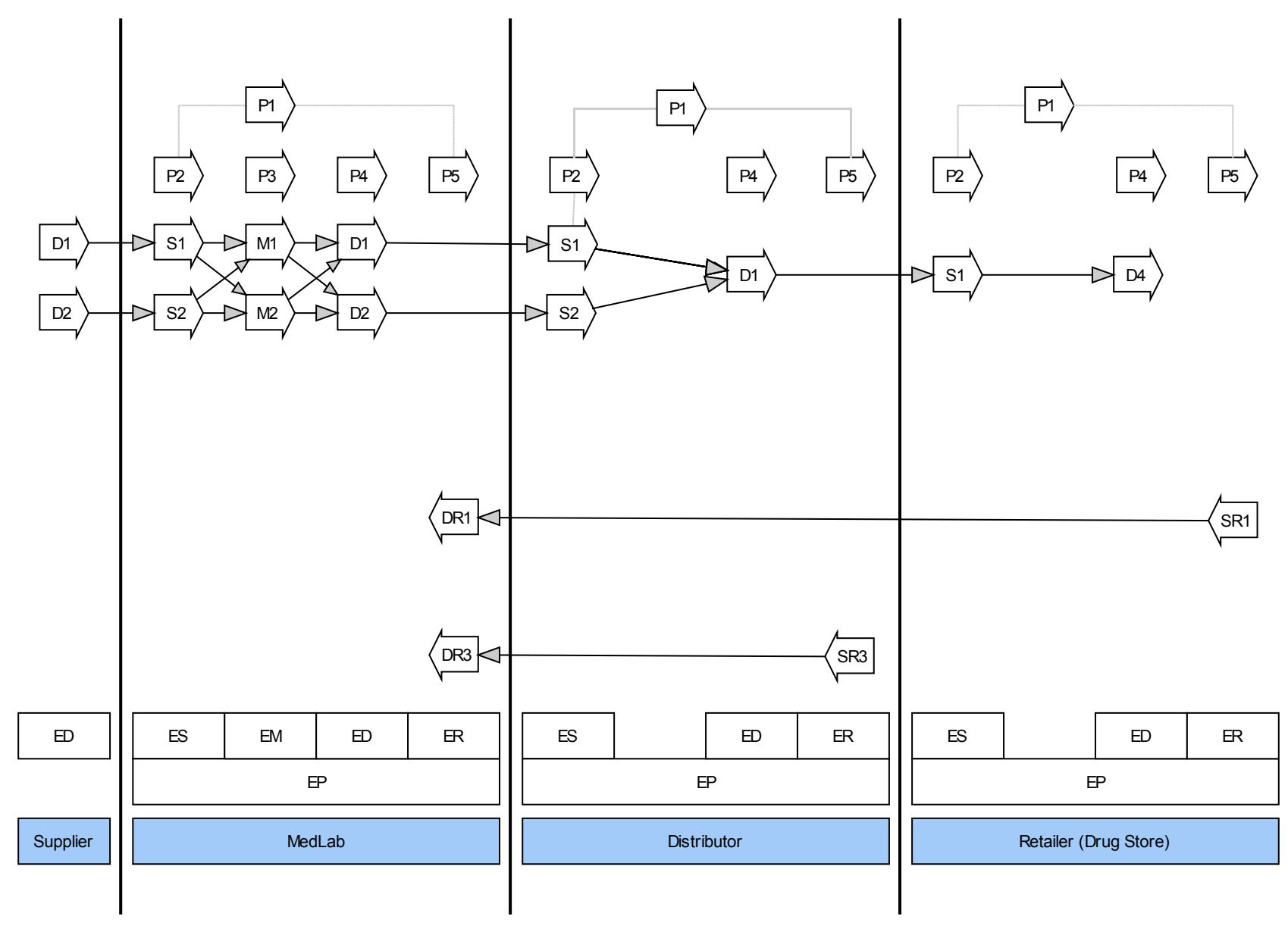

Figure 20. AS-IS Thread Diagram of MedLab Supply Chain 
Production plan becomes an input for computing the replenishment plan (P2). In conjunction with the materials inventory level, the purchasing budget, and historical consumption data, a monthly periodical review policy for reordering comes in place but with two main drawbacks, specially for the S2 process (imports sourcing): a non-reliable forecast for export orders, and long lead times for most part of purchases (imports), which forces a huge batch of (overseas) imports in order to keep transactional costs down, but leaving a significant inventory load. In addition, recent changes in the supplier base (Chinese vendors) have placed an additional financial burden due to a required downpayment $(\sim 30 \%)$ at order reception.

The company's delivery promise is within one week to local customer's order (D1), and it is negotiated on a case by case basis for exports (D2) depending on the availability of raw materials and production capacity vs. the demanded amount and desired delivery date (P4). In any case, it is company's policy not to accept export orders with preamble of no less than two weeks.

In MedLab's distribution channel distributors plays an important role. The firm has deliberately avoided direct contact with consumers, and relies on dealers for both local and exports sales. As for local sales, there is a national distributor network divided in two markets: drug stores and medical institutions. For the case of exports, MedLab depends on a limited number of foreign importers that in turn resale to other parties abroad. 
There is an outsourced execution by third party players of transport operations (D1/D2), both in local and export deliveries. Yet, the delivery sequencing and prioritizing of orders come from the internal P4 delivery planning process. An important process disconnection is identified in $\mathrm{P} 4$, since the company in temptation of receiving an immediate input of cash (reinforced by a critical financial position) oftentimes bends its exports preamble policy and accepts rush orders. The former implies a non-planned entry of huge firm orders that quickly predates all product, material and equipment capacity available, leaving regular firm orders (mostly local) delayed for lengthy periods ( \pm 1 month) and incoming ones unattended.

Delivery performance might even worsen because of local delivery policy. Such policy compels local product delivery down the distribution pipeline, by means of a volume discount deal offered to all distributors. Even when the spirit of such measure is to preserve their distributors and enforce its sale performance against competition, instead it might pointlessly exerts pressure (and cost) to dealers in their financial, inventory and warehousing capacity to push sales down to consumers when actual sales at the end of the pipeline are blocked. Market reality suggests that, ceteris paribus, a consumer will decide for the favored price option, certainly outperformed by MedLabs' Asian competition. Thus, the mere push exercise without any other ingredient leads to nothing but internal distributor cannibalization to a high cost of both the company and its channel. Furthermore, is a proven trigger of bullwhip effect.

As for Returns, these are rarely seen, so P5 process is practically nonexistent. DR and SR processes are conducted through the forward channel but in 
opposite direction, once they have reached a certain critical mass to justify economies of scale.

Figure 21 shows SCOR level 3 process detail only for MedLab. It merges the planning and execution stages in one view and does not include channel operations, available in Figure 20. Distributors are categorized on a wide range from SME's to large-sized commercial intermediaries with different types of affiliation to MedLab, where some feature exclusive distribution dealing only with MedLab's products, whereas other exhibit a wider product portfolio. For such firms cash flow is a very delicate matter and in general terms are sensitive to variables affecting its financial turnover, such as inventory levels, fixed costs and investments (warehouse capacity), payment terms, accounts receivable, volume discounts, early payment discount, etc. In particular, it is critical the productivity of its warehousing space and its cash conversion cycle from sales since government-subsidized institutions, which constitutes a significant part of the market, are very slow payers.

Distributors operations deal with correctly anticipating demand with the least possible inventory (P1). Yet, the anticipation exercise is poorly executed with a low tech forecast, or none at all. Hence, the S1 process must consider higher inventory levels for dampening fluctuations in the local market and overcoming an anticipated forecast error. S2 process (for importers) is prone to high inventory levels. Such high levels are reinforced by pushed volume-discounted orders. However, there the compelling restriction of cubic space available. Delivery operations (D1) are executed with private truck fleet to a high dense network of retailers. 


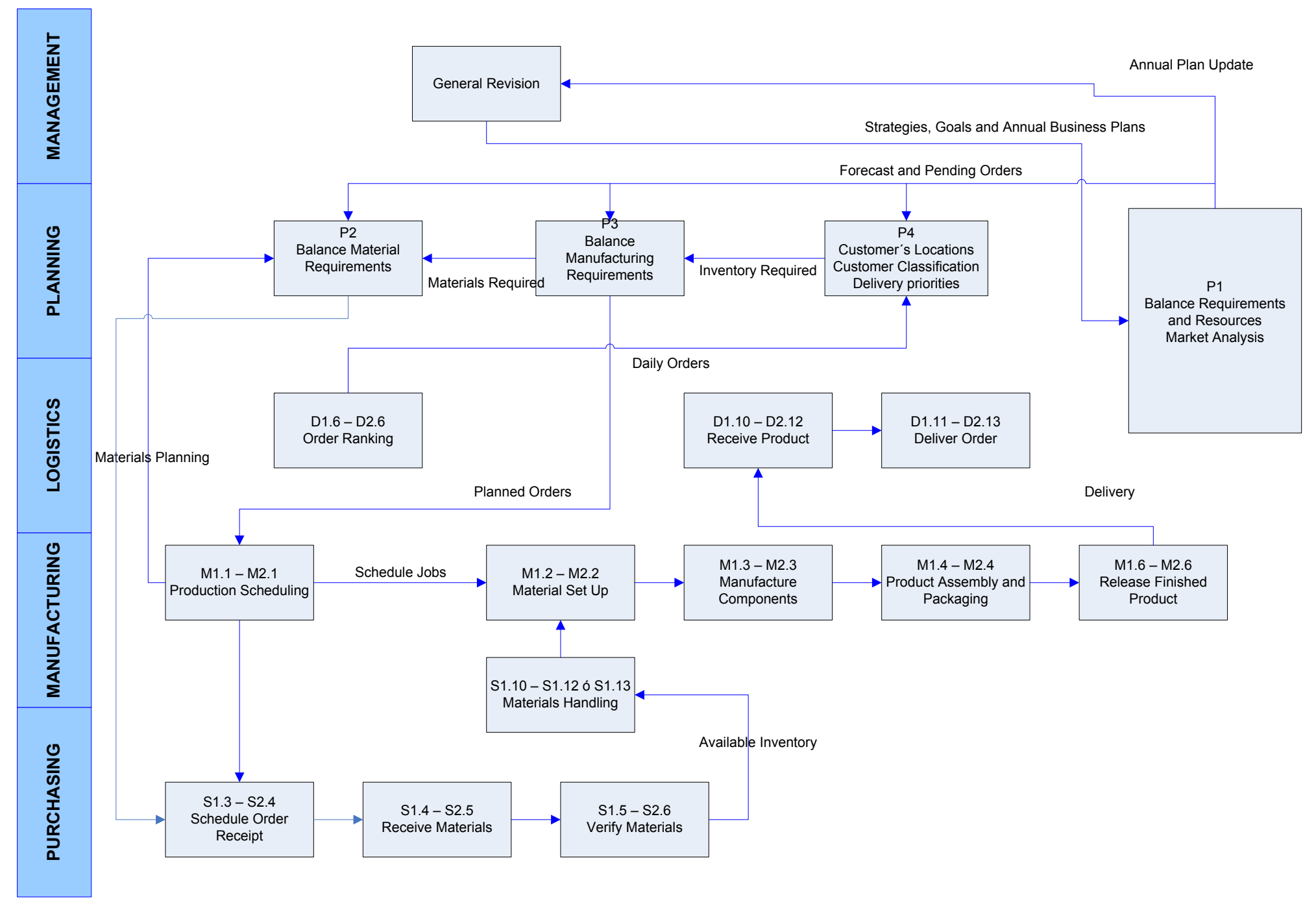

Figure 21. MedLab Process Connections at SCOR Level 3 
Retailing operation replicates the Distributor's one on a smaller scale. They share some of its former shortcomings, for instance a flawed forecasting technique and further reduced warehouse space, which implies a substantial reduction of inventory. This mandates a more frequent sourcing (S1) process, commonly on a weekly basis, of reduced dispatches.

Another difference found is in the nature of the delivery to consumers (D4) process. This process is commonly shared with an extended portfolio of other products. For the case at hand, there are two retailing scenarios: drug stores and medical institutions. The first one is more related to the classical retail setting, with autoservice shelves and Point-of-Sale (POS) stations. The consumer directly selects and buys the product. The second one assists medical interventions, the product is held in an internal pharmacy from where is subtracted and administered to consumers (patients) by technical staff. Normally in both scenarios, there is close follow up of the products with an order-up-to-level inventory policy in place to prevent stockouts.

\subsubsection{BWE Scorecard}

The central indicator for measuring the Bullwhip Effect, termed as Demand Amplification Quotient $(\omega)$, is introduced in Fransoo and Wouters (2000) and detailed in Equation [4] of Table 5, Section 2.4. This measure makes sense when located in a certain spot of a chain, and from this perspective, interpreting the incoming flow of customer's orders as $D_{i n}$ and orders placed to suppliers as $D_{\text {out }}$. If the value of Demand Amplification Quotient $(\omega)$ is greater than one, it indicates the presence of the Bullwhip

Effect, and as this magnitude grows, BWE is stronger. Conversely, if it is less than one, 
it means that there is dampening of variance at this spot, which is rarely observed unless an already seriously distorted demand signal comes in.

Measurements were made for the main raw materials involved in the manufacture of widgets over a period of eighty-seven months covering from January 01' to March 2008. Time series were obtained from MedLab's databases, extracting registered product orders from customers (incoming demand) and component orders placed to suppliers (outgoing demand). With these data and using Equation [4], computed results are shown in Table 10.

Table 10. Demand Amplification Quotient $(\omega)$ per Raw Material

\begin{tabular}{|c|c|c|}
\hline $\begin{array}{c}\text { Imported/ } \\
\text { Domestic }\end{array}$ & COMPONENTS & $\omega$ \\
\hline D & RC & 1.4 \\
\hline D & 10 Ml Master & 2.6 \\
\hline I & DS-38 & 6.1 \\
\hline I & BNE95 & 6.2 \\
\hline D & 5 Ml Master & 5.7 \\
\hline I & $21 \mathrm{G} \mathrm{x} \mathrm{1} \mathrm{1/2} \mathrm{C} \mathrm{+} \mathrm{N}$ & 4.2 \\
\hline I & I kds WP & 6.4 \\
\hline I & hi-2053 P & 3.3 \\
\hline
\end{tabular}

The values obtained measure how many times demand variation is amplified when passing through MedLab. Each BWE index is computed using either 5 or $10 \mathrm{ml}$ sales data, or both depending on the material usage on the product. Notice all values are higher than one, indicating the BWE presence in every demand signal. Imported raw 
materials have distortions greater than $500 \%$ in demand, due to the large and infrequent batches that are characteristic of imports. Strikingly, domestic inputs such as $5 \mathrm{Ml}$ Master show evidence of extensive amplification without the benefit of a straightforward explanation, hence are made subject of diagnosis efforts.

$\omega$ is a static measure that is based on the average and standard deviation. However, for the sake of introducing a time line for registering BWE incidence moving measurements were introduced as described in Step 9 of Section 3.2.2.1. The computation of the moving $\omega$ uses a fixed-length moving time window (W) of 1 year. For this reason, the first 12 months are not included, after which computed moving $\omega$ is shown.

Each of the raw materials demands have values greater than five. In particular, 5Ml Master and 10Ml Master confirm certain relative stability periods followed by irregular amplification patterns. The figure also shows a general magnitude of increase in demand amplification, which peaks around the end of 2004 and remains even in later years. An explanation for this crest rests on a major business renovation performed in MedLab, when markedly imports from Asia began and the company raised prices for its widgets. Another visible observation is a cyclical tendency for BWE increase by the year end. 


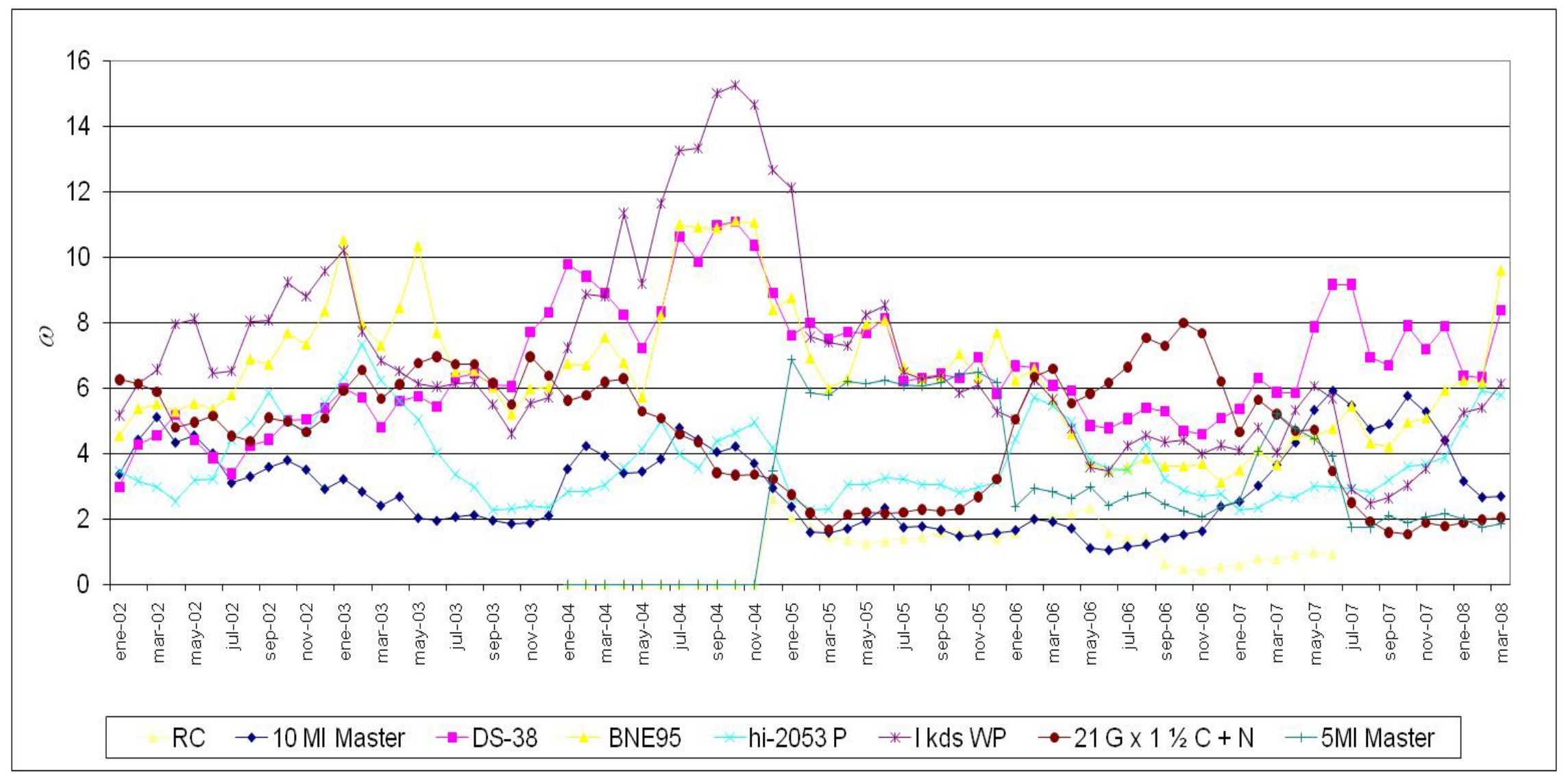

Figure 22. Moving $\omega$ per component 
Figure 18 illustrates monthly BWE measures taken over a six-month period (Dec 06 - Jun 07) for the manufacturer, MedLab, a distributor (LM), and a retailer (RC). These results make apparent that all companies amplify demand variability, and notably most of the amplificaton resides in the manufacturer while it manifests moderately in the downstream links. Results also show that $10 \mathrm{ml}$ widgets have slightly higher BWE values, which can be explained by irregular order patterns because this 10 $\mathrm{ml}$ product is not often domestically demanded.

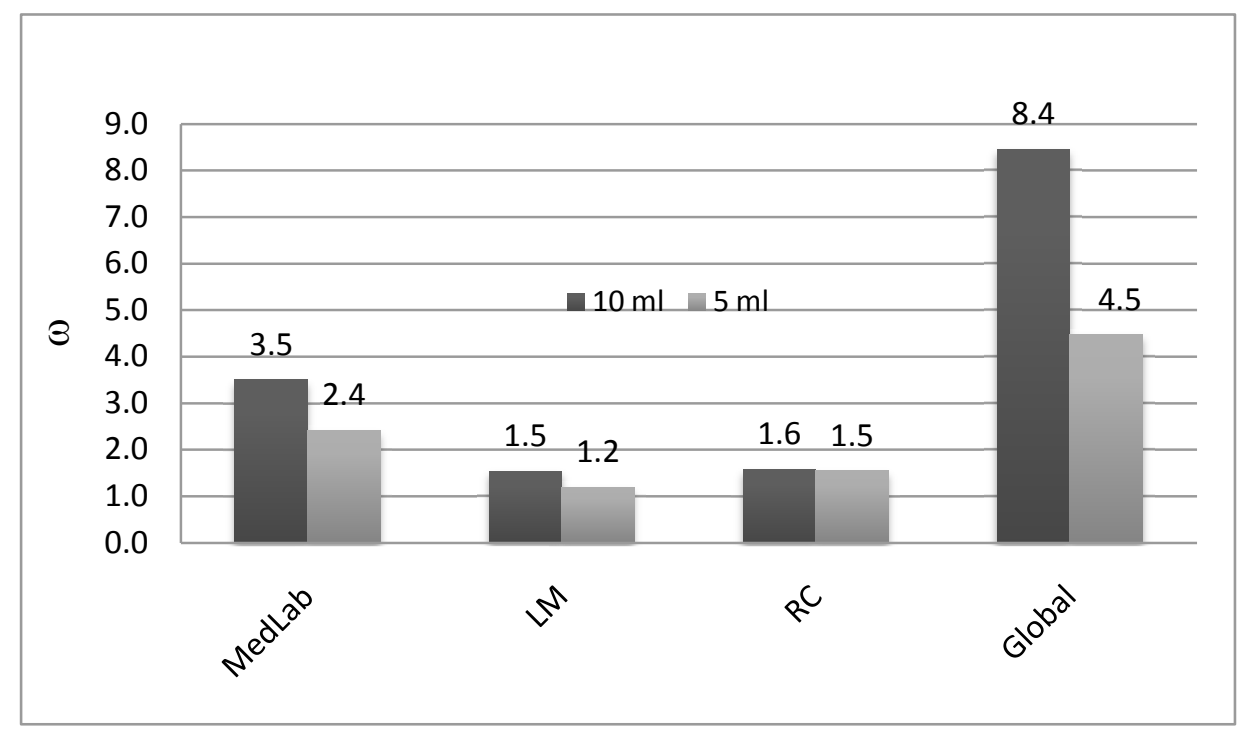

Figure 23. BWE overall and local measures along the MedLab-LM-RC chain

In order to determine the extent of BWE and its possible points of intensification along the sampled system a systemic measure was attempted and the results obtained are shown in the rightmost bar of Figure 18. The increased BWE index speaks about the combined effect of all echelons considered, which accounts for more 
than eight and five times amplification, respectively for 10 and $5 \mathrm{ml}$ products. Again, the latter strongly suggest greater amplification for $10 \mathrm{ml}$.

The formulation used for measuring systemic BWE in Figure 18 is introduced in Fransoo and Wouters (2000), and described next:

$$
\omega_{\text {total }}=\omega_{1} \cdot \omega_{2} \cdot \omega_{3} \cdot \ldots . . \cdot \omega_{n}
$$

Where, $\omega_{\text {total }}$ denotes global BWE ; $\omega_{i}$ denotes the $i^{\text {th }}$ local BWE

Although the validity of a joint BWE measure in actual cases is questioned by these authors, the factoring of nodal measures brings about a dimension of the aggregate BWE in the observed system. Figure 23 shows a substantial global BWE magnitude and supports the need of intervening the examined supply system to reduce signal distortion in demand.

BWE is greater in manufacturing. Hence, a finer measure to determine BWE origins is performed by breaking down the manufacturer's operations as shown in Figure 24. Such partition introduces supplementary sampling points enabling to further refine and localize BWE sources.

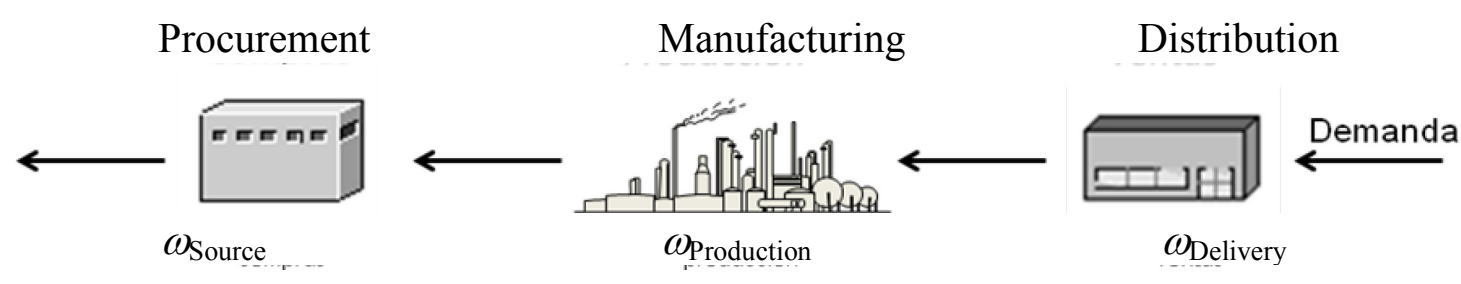

Figure 24. Manufacturer's Operation detail for Partial BWE Measures 
Thus, it is possible to separately consider an interface between the market and purchasing, taking as a reference production scheduling. In this way, it is possible to compare incoming orders from the market with production orders ( $\left.\omega_{\text {production }}\right)$ and similarly consider purchases as well $\left(\omega_{\text {sourcing }}\right)$. Note that deliveries is excluded because there are no major variations introduced in incoming orders from the standpoint of distribution. Figure 25 shows both partial measures .
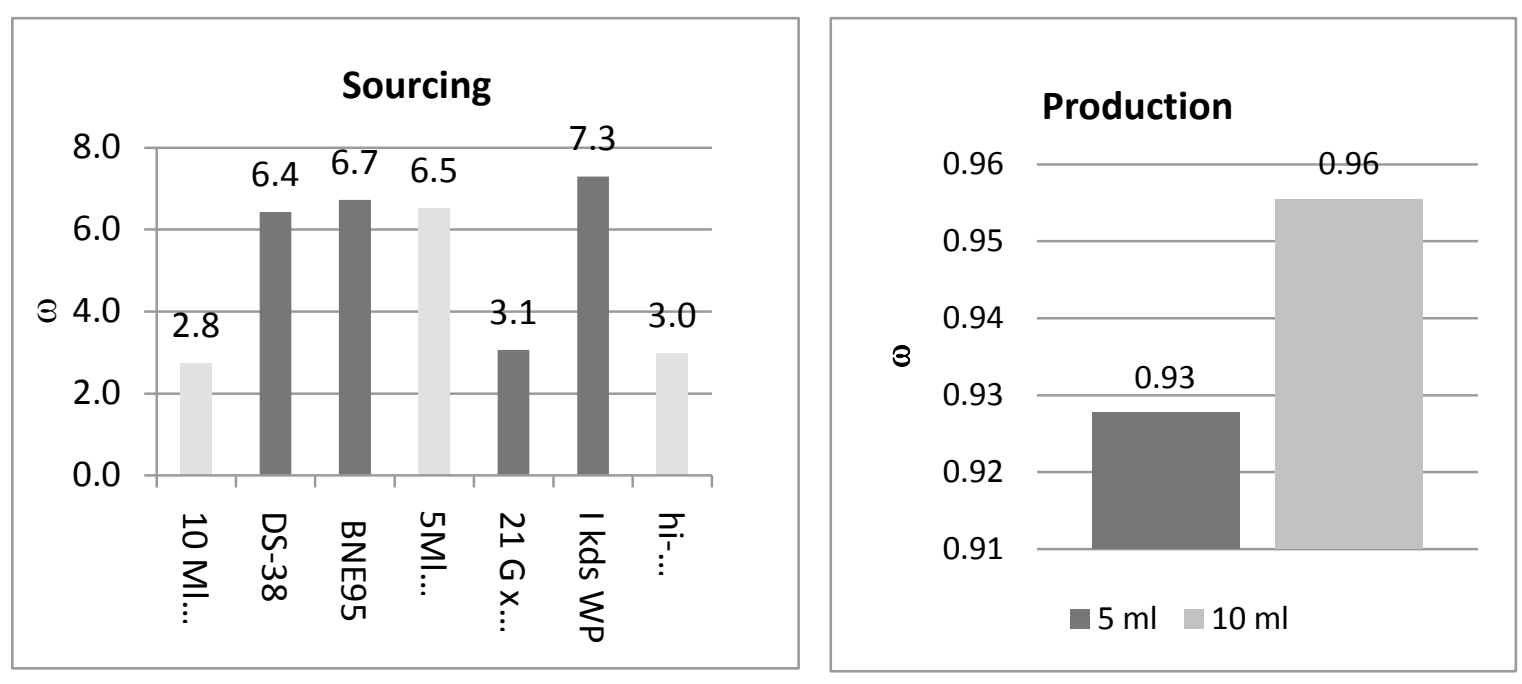

Figure 25. Partial BWE Measures for MedLab supply chain

The left chart in Figure 25 shows the BWE measures obtained for each component. The darker bars represent imported supplies and lighter bars stand for domestic supplies. Notice that such results are different from those of Table 10, since the latter are intended for the overall MedLab operation while here these aim for a shorter segment between purchasing and production. 
The right side of Figure 25 shows amplification results for production-sales interface for both 5 and $10 \mathrm{ml}$ products. Noticeably, the bulk of amplification is in the procurement-manufacturing interface, with large BWE values, while on the downstream side it seems to dampen amplification. The results lead us to conclude that maximum amplification of the system is found in MedLab, and furthermore, within MedLab's operations BWE occurs due to an evident mismatch between purchasing and production decisions.

Figure 26 shows an instance of BWE Scorecards developed for each firm. As portrayed in Step 9 of the Diagnostics Section in Chapter 2, such tool can pinpoint at a glance related results or causes that bring about the BWE phenomena.

For the sake of brevity, while manifestations are not discussed only relevant causes found to be positively related with BWE are described. The lower part of Figure 26 shows the variables identified to had exhibited signs of connection with BWE phenomenon, out of them stand out price variation, forecast error, internal organizations misalignment, batching and response time among relevant causes.

The charts of the relevant causes are replicated in a more legible size in the coming pages. The definitions of the metrics were exposed in the former chapter (see Figure 14). 
Figure 26. BWE overall and local measures along the MedLab-LM-RC chain 

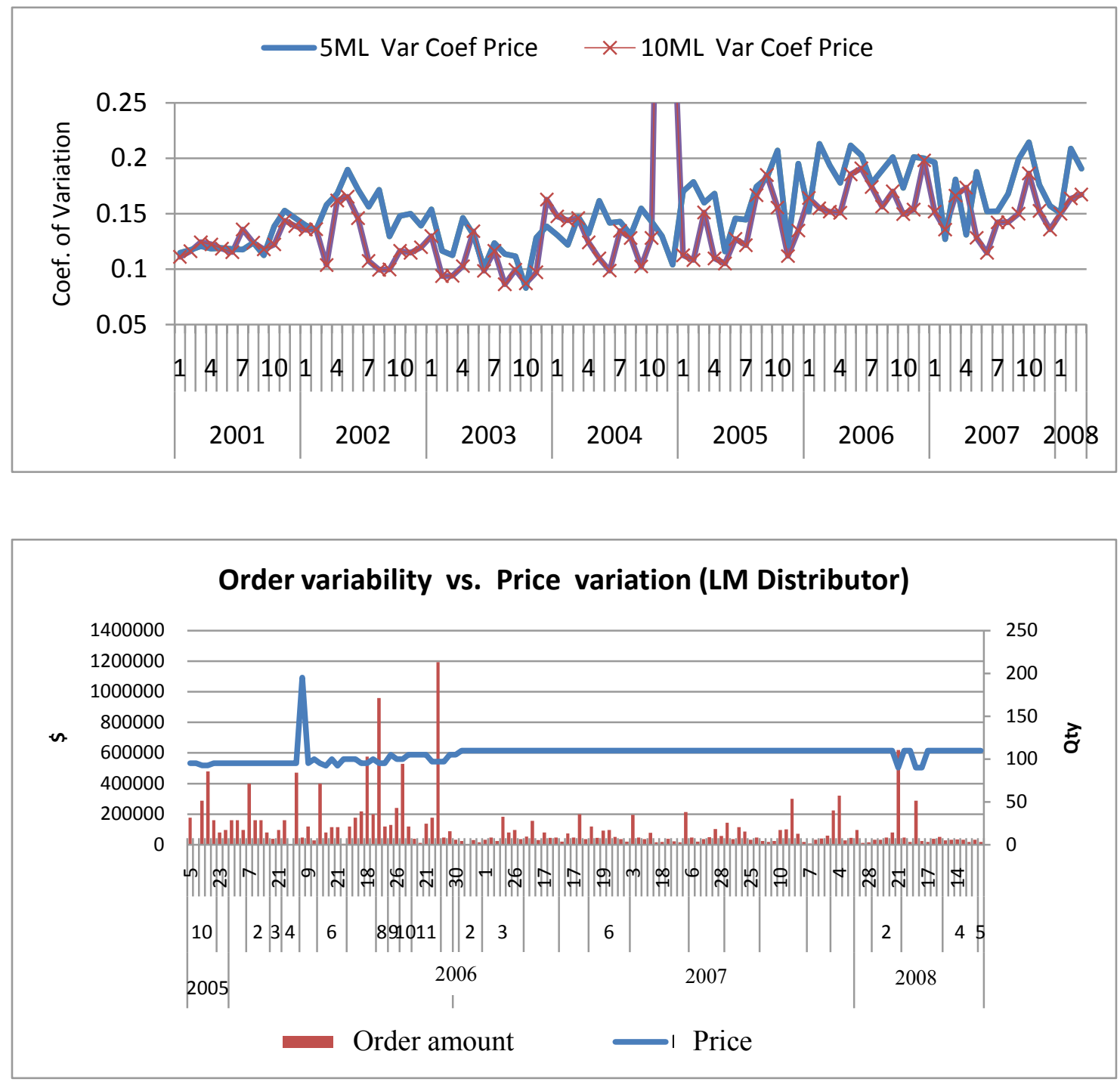

Figure 27. Price variation and BWE

Price variation: the top chart of Figure 27 shows the coefficient of variation of prices from monthly bills. It is possible to determine that 5 and $10 \mathrm{ml}$ products under study follow a similar pattern of variability, which increases from 2005. MedLab makes extensive use of push-based policies such as volume discounts and differentiated price lists. Price variation induces amplification as observed in the lower part of Figure 27, 
which exposes the behavior of orders against volume discount and constant prices policies, a change effective since 2007 for LM Distributor. It is noticeable the correlation with Price changes and BWE incidence.

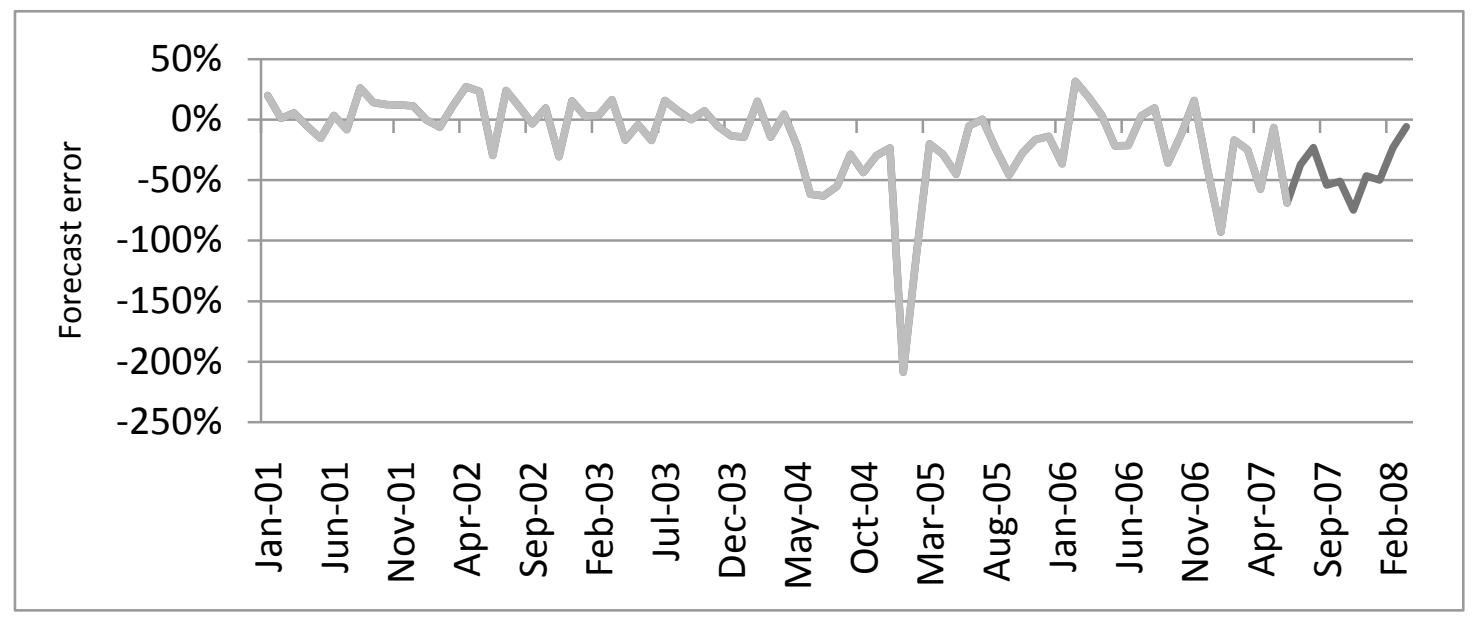

Figure 28. Forecast error

Forecast Error: major biases in MedLab's forecast, especially in the month of January 2005 , where the error rate reached $200 \%$ but as seen always seem to oscillate decidedly away from zero, especially from 2004 and on. There is a prevalent randomness, since the error series are not constant. The average error for all periods is $18.5 \%$, which hardly classifies for a reliable forecast. For this reason, it is asserted that the forecast connects with the Bullwhip Effect. 


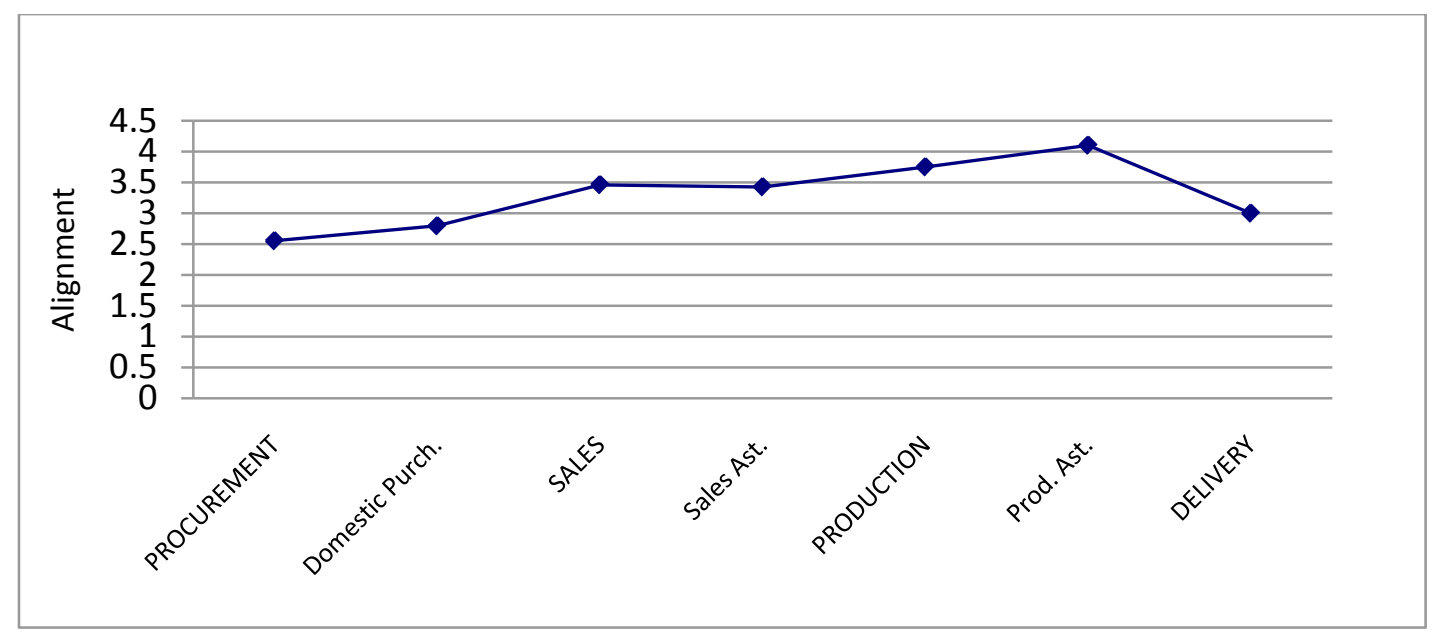

Figure 29. MedLab internal misalignment

Internal organizations misalignment: during the month of September 2009 we surveyed MedLab's internal departments in search of possible internal disconnections that resulted in BWE occurrence. Such survey was designed as a qualitative questionnaire following Simatupang and Sridharan (2002) and Simatupang and Sridharan (2005). Each major point of the survey was assessed over a Likert scale ranging from one (worst result) to five (best result). Figure 29 shows the average perception of each department regarding internal process alignment. Strikingly, the purchasing department consistently gives relative lower scores to this feature, as they complain to be a frequently overlooked process where the important information gets late. Because of this, they stress they are oftentimes forced to take decisions under great uncertainty. 


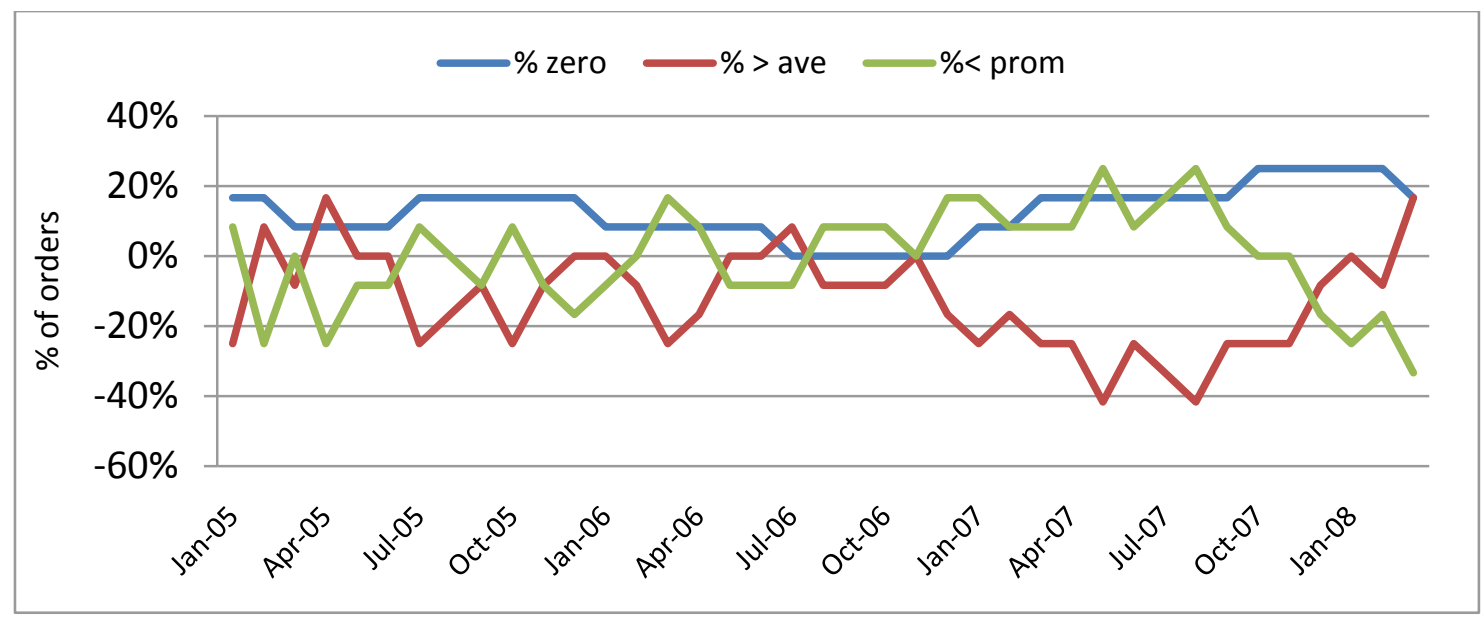

Figure 30. Batching

Batching: this indicator is based on a comparison of how purchasing behaves in relation to what the business sells, considering a moving period of observation of a quarter. The greater the difference in the percentage of zero-order or above average orders, the more evidence of batching in the purchase of products. Between the periods of November, 2006 to December, 2007 a significant surge $(20 \%$ - 40\%) in the difference of zero-orders happened, which is an indication that the company intensified big purchases in lots during this time range.

On Time Delivery Percentage: domestic orders are on time compared to export orders, as in Figure 31 . For international orders, there is greater variability in the percentage of orders delivered on time being in some periods of $100 \%$, but in others to the extent of only $32 \%$. This affects the continuity of foreign customer purchases, due to delays in deliveries. As in the previous cases, the Bullwhip Effect can be decisive in these results, showing adversity in production planning: in certain periods, supply does not meet demand despite the presence of idle machines during the same. 


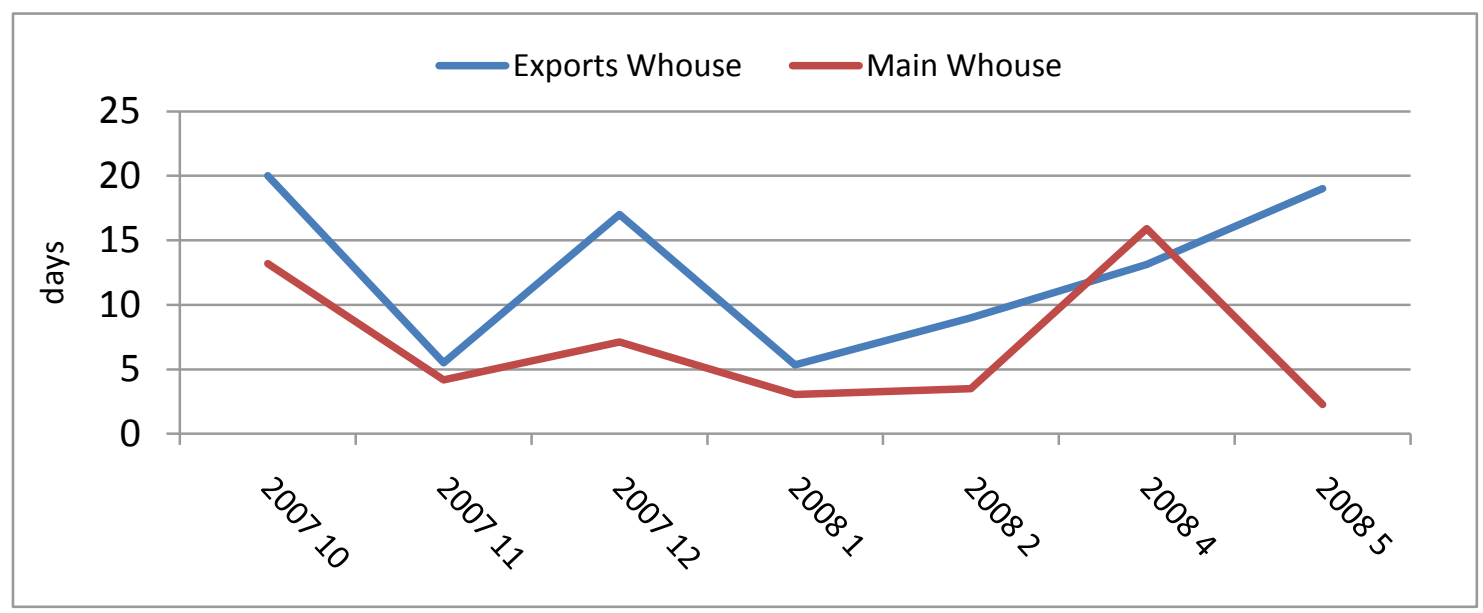

Figure 31. Response time

To summarize the chapter, the business background and competition arena description for the MedLab's case study has been offered, exposing the company's current problem conception and counter actions devised against it. The discussion is detailed and centered in implementing DAMP on an actual case study; in particular, the chapter illustrates DAMP initial steps (Triage, as described in Section 3.2.1) and the Business Process Diagnosis stage that opens the Examination phase. Such diagnosis aims to detect known manifestations and to trace back the causes of bullwhip in the examined supply chain. As exposed in the chapter, the means for the task includes process maps and metrics organized in what is been termed as the Bullwhip Scorecard. The results and preliminary analysis obtained from the former is included in this chapter, while conclusions are still kept in wait of the Dynamic diagnoses results and analysis reported in the next chapter. 


\section{CHAPTER 5 - DAMP DYNAMIC DIAGNOSIS}

This chapter illustrates the modeling of demand amplification in an actual supply chain by means of system dynamics. As stated, the case study is a medical device supply chain composed of three echelons: a manufacturer, distributor and retailer. In this chapter, we extend on the model formulation and calibration, and perform validation tests and data screening sensitivity analysis. Vensim ${ }^{\circledR}$, the system dynamics simulation suite from Ventana Systems, is used to build the dynamic model.

\subsection{Dynamic Model Description}

This section describes the system dynamics model developed for the diagnostics of the medical device case study.

\subsubsection{Model Assumptions}

Customer demand and material supply are exogenous to the model. Order fulfillment is constrained only by the available inventory. Other possible restrictions due to insufficient capital (e.g. layout, capacity), labor or quality (defectives, delays) are excluded. The intended period of the study is short enough to assume the capital and labor availability do not change during the modeling period.

The model represents a make-to-stock manufacturing policy and customer

orders that are not immediately served are backlogged. The forecast method is a moving average method, which in this case study is used by the actual companies. Periodic review is the replenishment policy. 
The time units for the model are weeks. The observed company operation has multiple products, but we aggregate these products into a single product. This simplification is justified because it greatly reduces the size of the model without a significant lost of its characterizing capability. In order to aggregate product flows, the model introduces formulations that correct the flow of a single component to its equivalent of multiple components by emulating stockout joint probability. Since a generic product could be anyone, its stockout probability should be higher. Hence,

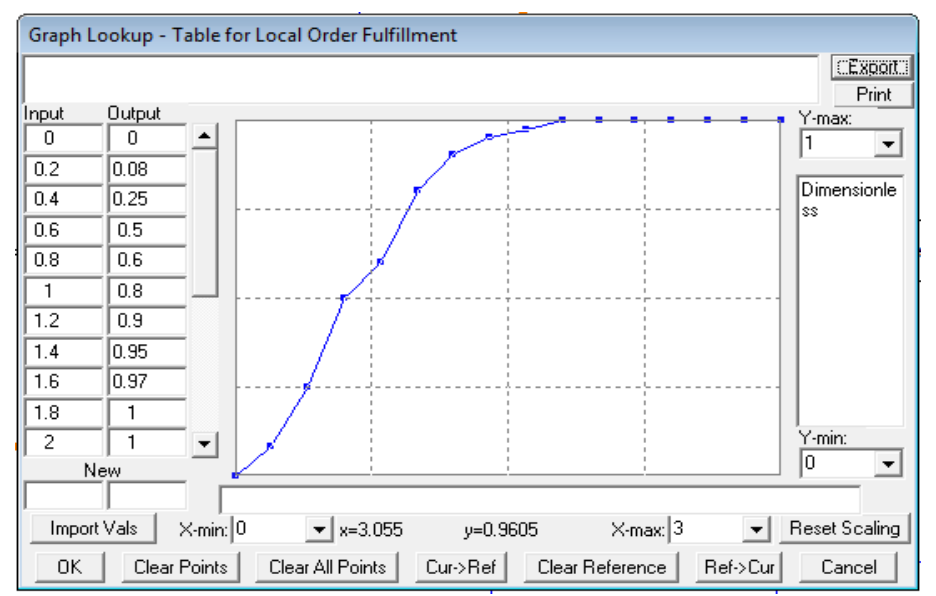

Figure 34 shows a table function that 'corrects' the amount of actual dispatches, regardless of high inventory available (for aggregate items) to compensate for the event of a stockout of a single item that might prevent a dispatch; alternatively, see Sterman (2000) in page $712 .$.

The model represents a multi-echelon structure where a single company resides in each echelon. However, the distributor and retailer echelon logic is capable of enlarging to a more realistic size by means of a scalable formulation that enables 
incorporating larger flow (e.g., the aggregate demand of a larger number of distributors/retailers) emulating a larger number of companies per echelon.

The model only represents information and material flows. The financial flow is not explicitly modeled except for the financial constraints imposed on the manufacturer.

\subsubsection{Model Overview}

Figure 32 shows the model includes three supply chain echelons framed in rectangles. The three echelons are: Manufacturer, Distributor and Retailer. A model of a supply chain is an aggregation of multiple nodes, and can be successfully created by combining several generic echelon models (Sterman, 2000). Nevertheless, each node represents different companies and thus requires a certain degree of customization. We

use a generic system dynamics model for the echelons as a template, which is customized to the particular configuration of the supply chain under study (Forrester, 1961; Oliva, 1996).

Figure 32 is a policy structure diagram (Morecroft, 1988) that provides a global description of the model showing its overall structure, denoting organizational subunits, in squares; decision milestones, as circles; as well as the customary representation of stocks and flows. The figure also highlights some of the most visible feedback loops of the model.

Figure 32 shows a series of numbered inputs with larger font size; these, represent the main exogenous data inputs to the model. As described on later pages, 
there is a different set of inputs to be used depending on the nature of the tests (i.e., local or systemic analysis, model calibration, model validation, balanced equilibrium). For example, we have Input 1 and Input 2 respectively for Manufacturer's export and local sales, used in individual echelon analysis. Input 3 is the exogenous input to the Distributor echelon, and Input 4 to Retailer and Overall Supply Chain input.

In Figure 32, the rightmost rectangle represents the Retailer who receives orders from consumers. Orders are the input demand signal that triggers the Order Fulfillment process. The Retailer's product flow decisions are influenced by forecasting and ordering processes that takes into account only the on-hand inventory. Such simplicity is due to the fact that the retailer is affiliated to the distributor, although they are separate firms.

The Distributor receives orders from the retailer. The basic logic of most processes considered for the retailer is the same as for the distributor and manufacturer as well. This is the case for the Order Fulfillment process that deals both with inventory (products) and backlog (orders), differing only in the parameters used on each instance. There is in addition a Procurement process that regulates the in-line flow of products by several feedback mechanisms considering forecasted demand, on-hand and backlogged products, and the timing of each process — internal and supplier's lead time - in compliance with on-time delivery. 


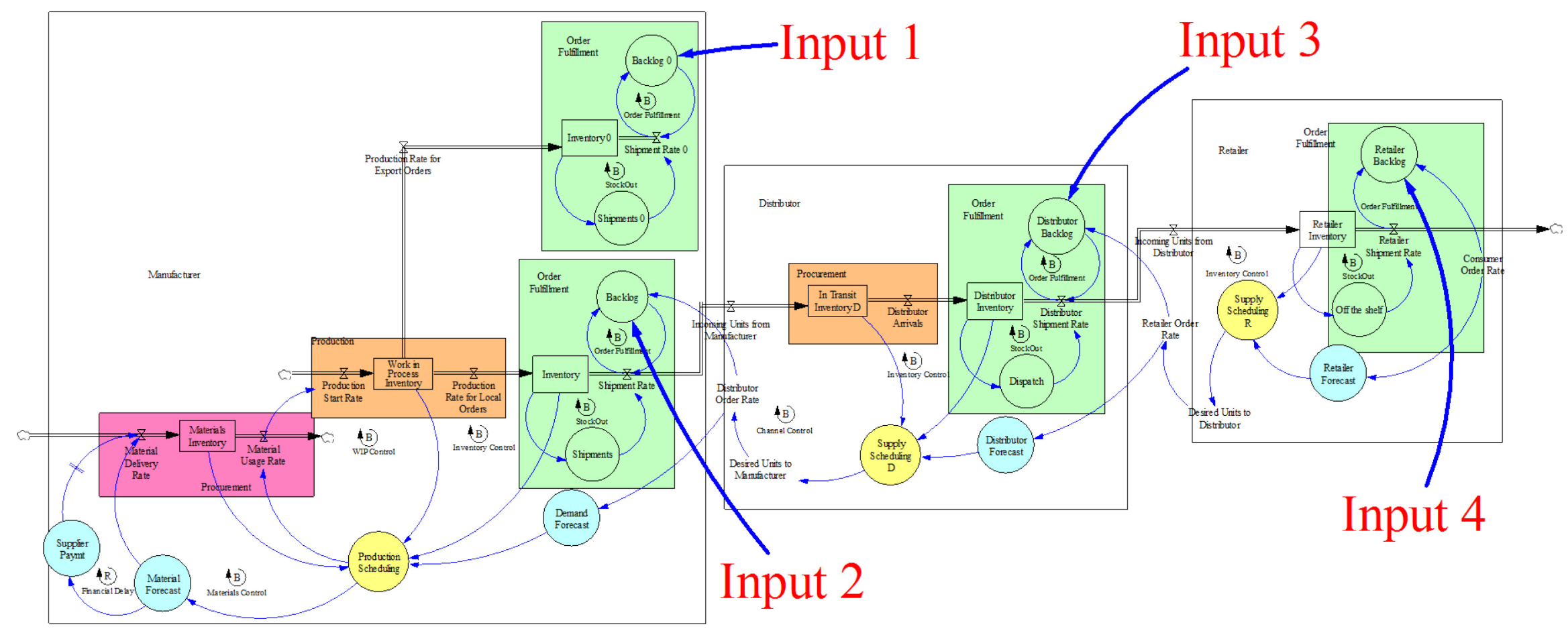

Figure 32. Policy Structure Diagram of the Supply Chain Model 
The first rectangle to the left represents the Manufacturer with a high-level description of Order Fulfillment, Production and Procurement processes, for both local and exports markets. The manufacturer is not affiliated to the distributor yet provides them with the necessary supply of products in the conventional vendor-client relationship. On the other end of supply, the manufacturer's supplier is left out of the scope of the study hence is treated as exogenous. The model includes information and material flows of all the supply chain but only considers the manufacturer's cash flow implications on the material supply performance.

\subsubsection{Manufacturer Model Components}

Figure 33 shows the SD model for the manufacturer echelon describing the variables and their relations, which is detailed later. It further details the major components described in Figure 32, specified in causal loops, variable, causal links, stocks and flows.

Figure 33 divides the model into right and left halves for improved reading. The right half in Figure 33 (cont'd) shows two pipelines, the higher one is for export orders and the lower is for Local orders. The two processes represent the order fulfillment to achieve a desired service level for domestic and export customers. Since the two of them correspond to a push policy are very similar; however, display significant difference in their forecast and inventory practices. 


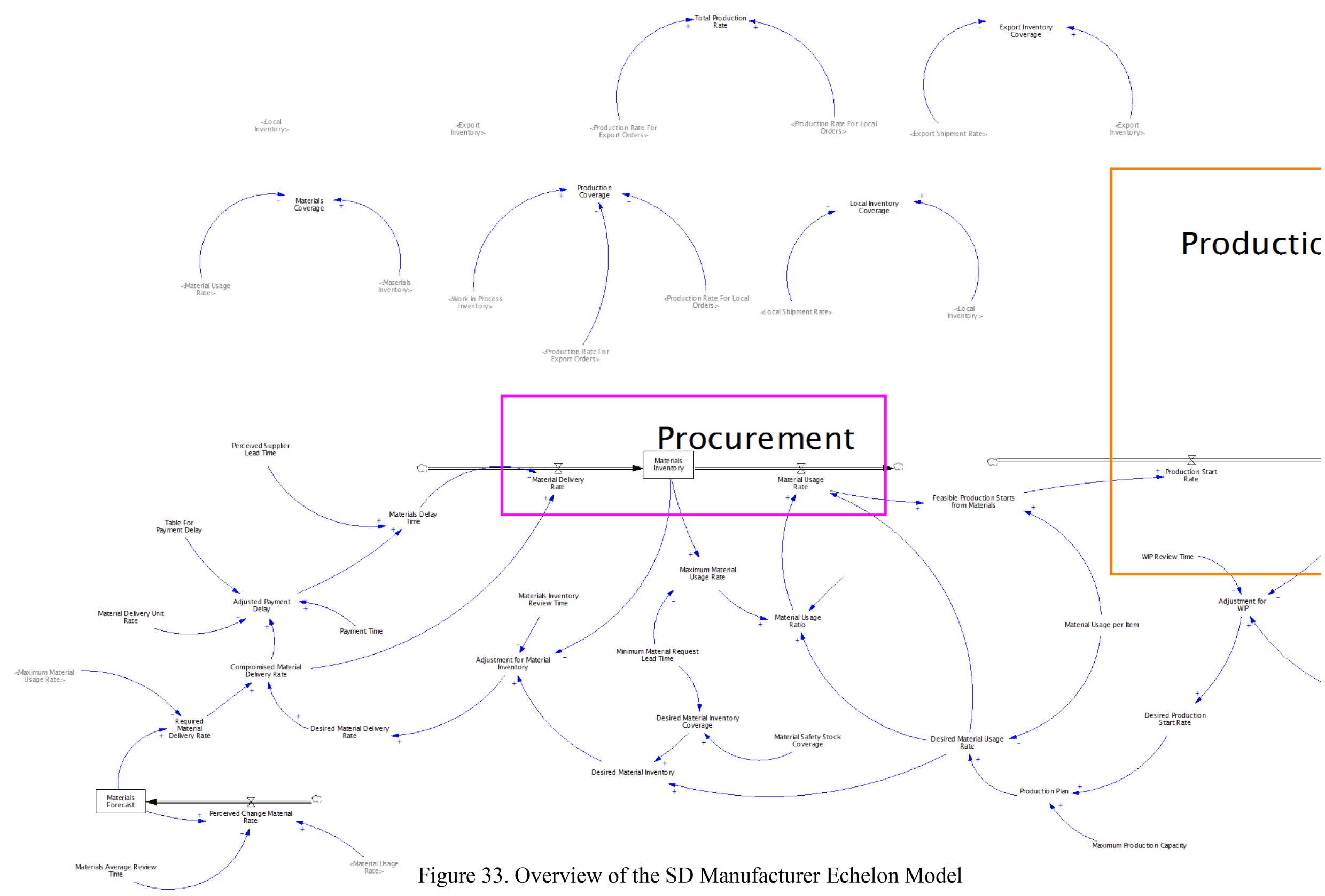




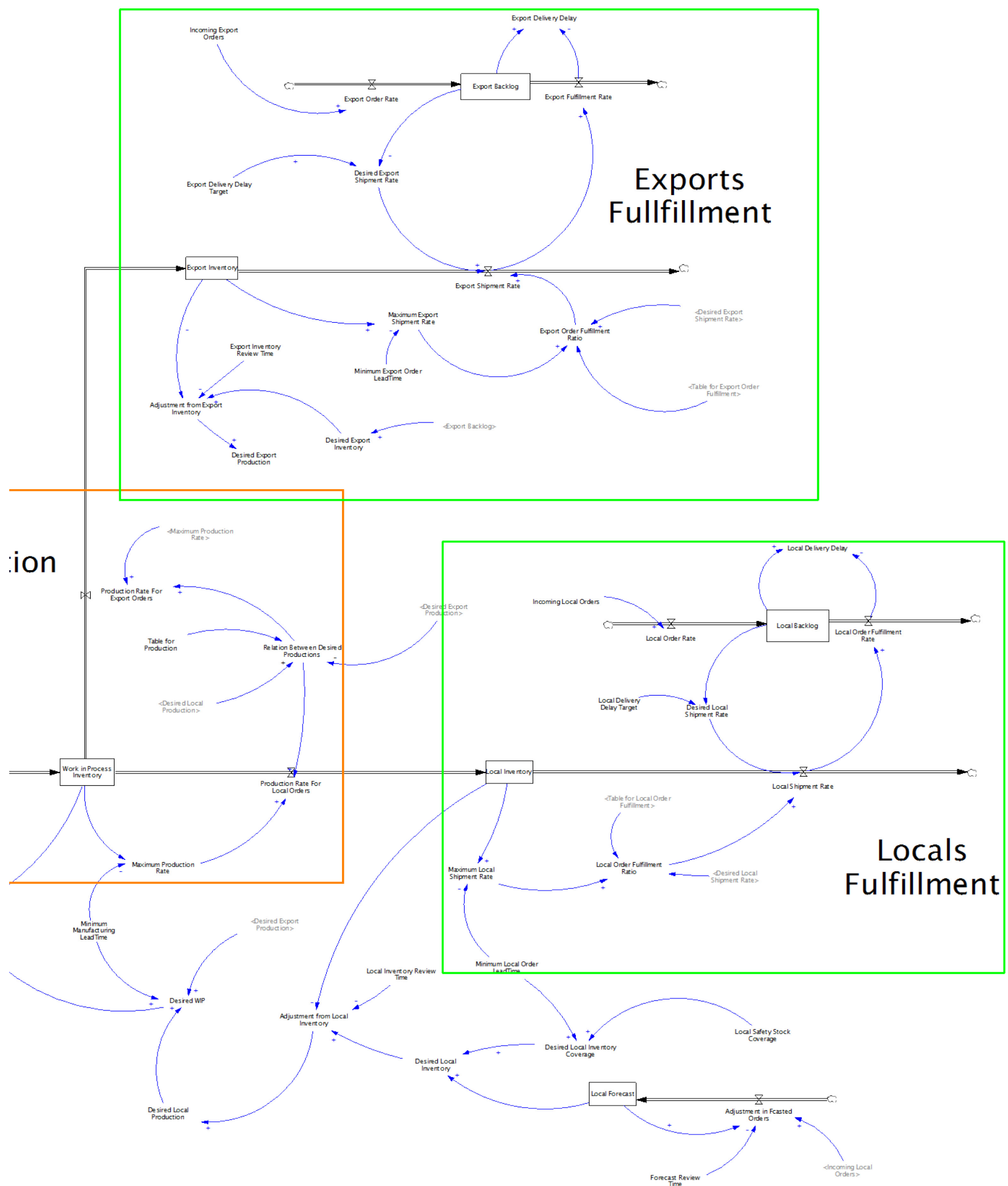

Figure 33 (Cont'd). Overview of the SD Manufacturer Echelon Model 
Manufacturing, in the center rectangle, closely follows standard push-based production practices, where the amount to be produced targets a predefined forecast plus realized sales. It also includes the logic for demand forecast and production scheduling. Such logic extends its scope to Procurement, represented by the leftmost rectangle on Figure 33. Again, these are customary push practices featured by an independent material forecasting process and the introduction of a payment delay that mimics financial constraints in reality.

\subsubsection{Order fulfillment}

There are two fulfillment processes differentiating exports and locals. The fulfillment for local orders actually pushes inventory after forecast, whereas exports regularly does not intend to keep stock, lacks a formal forecast, and since there are no substantial differences in the product, other than packing, does opportunistically serve from available local inventory when necessary. Both are represented by a similar set of equations and logic, thereby the more elaborated local fulfillment is described first and then the differential portion for exports follows.

The variable Local Order Rate $\left(R_{L O}\right)$ represents incoming customer orders. In order to connect the manufacturer portion with the rest of the system, it is important to notice that Local Order Rate $\left(R_{L O}\right)$ is not an exogenous input but actually corresponds to the Required Distributor Delivery Rate $\left(R_{R M D}\right)$ from the Distributor, to be described in coming Section 5.1.4. Thus,

$$
R_{L O}=R_{R M D}
$$


The Local Order Rate defines the arrival of customer orders to the system that by design are not meant to be served right away. Hence, orders are temporarily stored in the local order Backlog $\left(B_{L}\right)$ until they are used, usually in batches, by the Local Order Fulfillment Rate $\left(R_{L F}\right)$, which discharges pending orders at the same speed as the Local Shipment Rate $\left(R_{L S}\right)$. The mathematical expression is:

$$
\begin{gathered}
(d / d t) B_{L}=R_{L O}-R_{L F} \\
R_{L F=} R_{L S}
\end{gathered}
$$

Local Delivery Delay Target $\left(\delta_{L D}^{*}\right)$ is the intended interval of time in which the manufacturer fulfills orders once they are placed by their customers. The Desired Local Shipment Rate $\left(R_{L S}^{*}\right)$ is defined in terms of the amount of pending items, or backlog, and the promised delivery time. Thus,

$$
R_{L S}^{*}=B_{L} / \delta_{L D}^{*}
$$

The actual Local Delivery Delay $\left(\delta_{L D}\right)$ is similarly defined in terms of the backlog and the actual shipment rate, or Local Order Fulfillment Rate $\left(R_{L F}\right)$ as previously denoted in [9]. Hence,

$$
\delta_{L D}=B_{L} / R_{L S}
$$

Now, the structure of the Shipments process is discussed. The Stockout loop regulates shipments in accordance to the Local Inventory $\left(I_{L}\right)$ level. First, Local 
Inventory is the repository of finished products of the manufacturer and is stocked up by Production Rate for Local Orders $\left(R_{L P}\right)$, which stands for the local product output from production. Local Inventory, on the other hand, is depleted by the previous Local Shipment Rate $\left(R_{L S}\right)$. That is,

$$
(d / d t) I_{L}=R_{L P}-R_{L S}
$$

The Maximum Local Shipment Rate $\left(R_{L S}^{+}\right)$is introduced as the highest viable delivery frequency, determined by the current level of items (Local Inventory) and the minimal lapse of time to process and deliver an order, denoted as the Minimum Local Order Lead Time $\left(\lambda_{L O}^{-}\right)$. Therefore, we have

$$
R_{L S}^{+}=I_{L} / \lambda_{L O}^{-}
$$

The Desired Local Shipment Rate $\left(R_{L S}^{*}\right)$ was defined in equation [9]. It follows that the actual Local Shipment Rate $\left(R_{L S}\right)$ should equal the desired whenever there is appropriate inventory availability, otherwise it should conform to a feasible Maximum Local Shipment Rate $\left(R_{L S}^{+}\right)$. This is straightforward for the case where customer orders only include a single SKU. Yet, considering that a typical order includes multiple 'items', even when the number of available orders equals the demanded in reality there is the chance that several orders might not be fulfilled because of the lack of inventory of any included item.

In order to compensate for this effect, a nonlinear function denoted as Local Order Fulfillment Ratio $\left(\varphi_{L F}\right)$ is introduced. Since the actual Local Shipment Rate 
$\left(R_{L S}\right)$ is now defined as a fraction of the Desired Local Shipment Rate $\left(R_{L S}^{*}\right)$ as in Equation [14], note that the former fraction is given by the Order Fulfillment Ratio $\left(\varphi_{L F}\right)$, hence this function defines the actual Local Shipment Rate $\left(R_{L S}\right)$.

$$
R_{L S=} R_{L S}^{*} \cdot \varphi_{L F}
$$

In addition, let Minimum Local Order Lead Time $\left(\lambda_{L O}^{-}\right)$be the fastest possible response time for setting up dispatches from available inventory. It follows that the Maximum Local Shipment Rate $\left(R_{L S}^{+}\right)$is defined by the available inventory on hand and the minimal feasible lead time, as follows:

$$
R_{L S}^{+}=I_{L} / \lambda_{L O}^{-}
$$

The Order Fulfillment Ratio $\left(\varphi_{L F}\right)$ takes as input the ratio of the Maximum Local Shipment Rate $\left(R_{L S}^{+}\right)$divided by the Desired Local Shipment Rate $\left(R_{L S}^{*}\right)$ and provides with the value of the ratio as output.

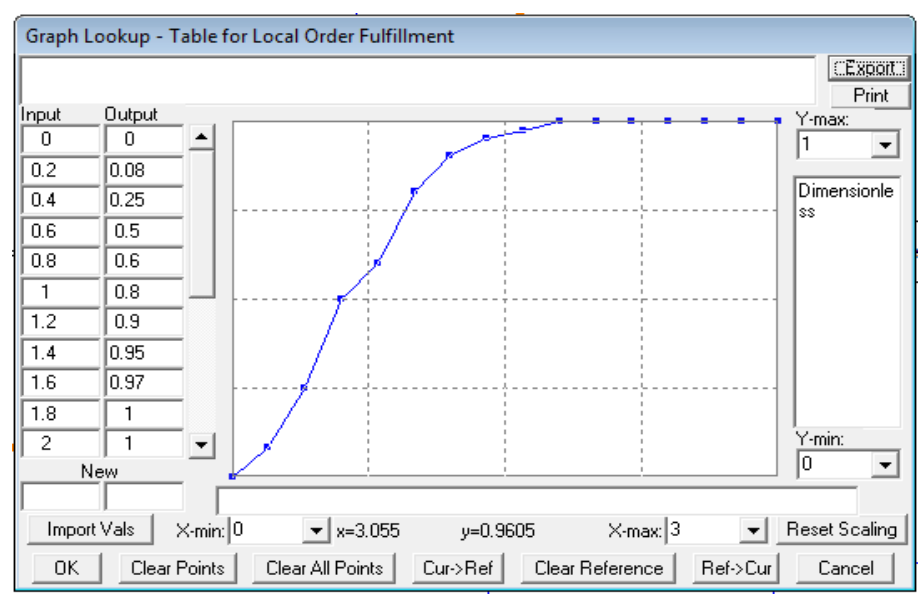




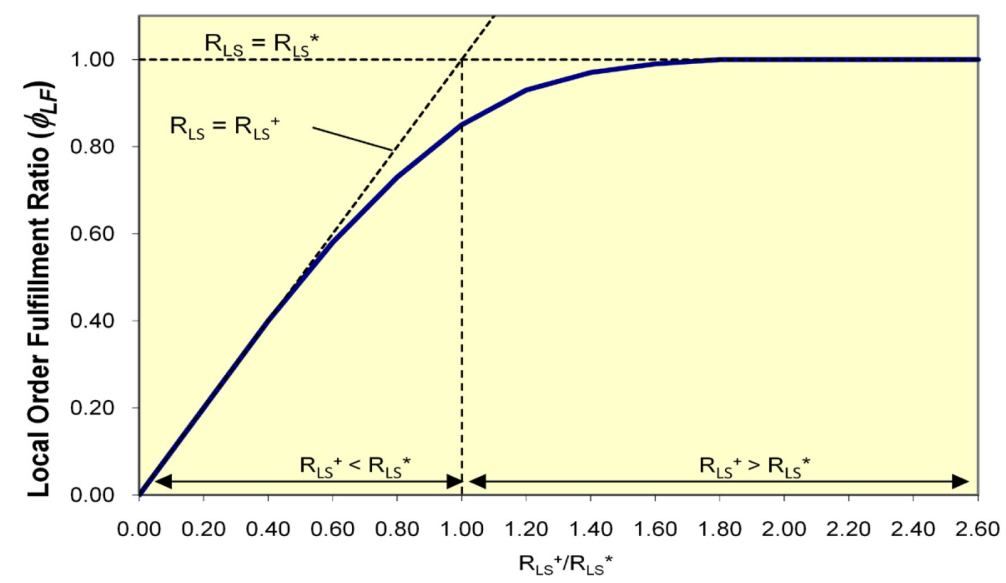

Figure 34

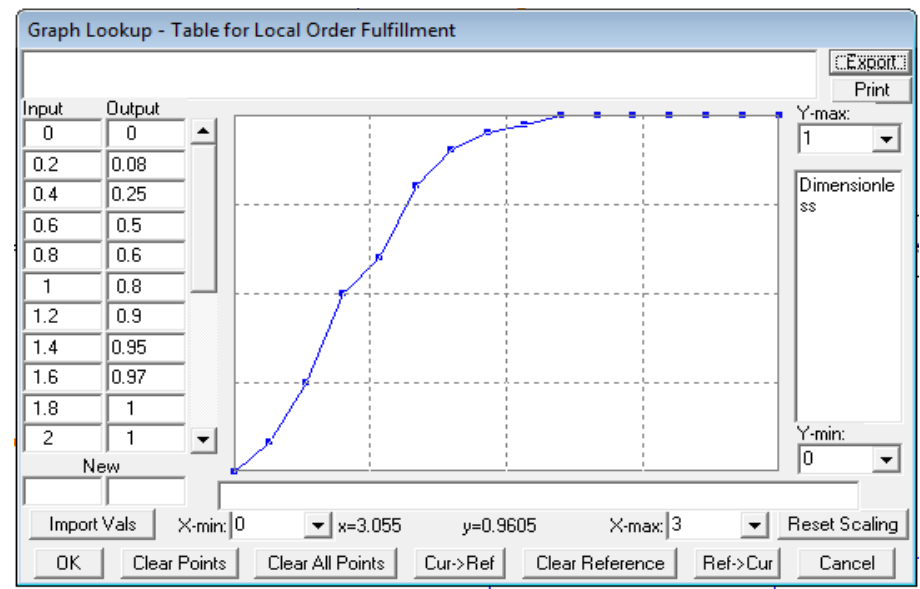

Figure 34. Order Fulfillment Ratio — Ideal and Actual

Figure 34 shows on top a theoretical figure of $\varphi_{L F}$ (Sterman, 2000) and below the actual and validated values used in the model. Note $\varphi_{L F}$ in the y-axis and the ratio of desired vs. maximum rates on the $\mathrm{x}$-axis.

Figure 34 shows the nonlinear nature of the Order Fulfillment Ratio. On top, the ideal function $\varphi_{L F}$ is circumscribed by the 45 degrees line $\left(R_{L S}=R_{L S}^{+}\right)$, which represents the policy "ship all the feasible", and the horizontal line $\left(R_{L S}=R_{L S}^{*}\right)$, 
standing for "ship all the desired". Note that the actual function, at the bottom of Figure 34 , is a compromise between both (extreme) policies. Also, notice two regions on the $\mathrm{x}$ axis, one where the Desired Shipment Rate exceeds the Maximal Shipment Rate, and its complement. This can be interpreted as follows: whenever there is relatively ample Inventory, the Maximal Shipment Rate will exceed the Desired Shipment Rate, the greater the ratio the less the probability of stockouts, hence the Order Fulfillment Ratio will tend to one. As the relative difference between the Maximal Shipment Rate and the Desired Shipment Rate decreases, so does the Order Fulfillment Ratio. The Order Fulfillment Ratio steadily decreases to the desired shipment ratio crossing into the region where the Desired Shipment Rate no longer exceeds the Maximal Shipment Rate, until at a given point it aligns with the reference line denoting the equality with the Maximum Shipment Rate. It should be noted at the point where the feasible rate equals the desired $\left(R_{L S}^{+} / R_{L S}^{*}=1\right), \varphi_{L F}$ is less than one in order to compensate for the aggregate inventory effect previously mentioned.

\subsubsection{Demand Forecasting}

The modeling logic here is based on the Adaptive Expectations and Exponential Smoothing model as presented in Sterman $(2000)^{11}$, representing the Manufacturer's moving average forecast technique. This model implies that there is a delay for the firm in registering and perceiving changes in demand, so the Manufacturer's belief on the value of demand gradually adjusts to the actual value of demand when it detects gaps between both (first order delay).

\footnotetext{
${ }^{11}$ See Section 11.3.1 on Sterman (2000).
} 
Let Local Forecast $\left(F_{L}\right)$ be the repository of the perceived changes every given review time, formally designated as Forecast Review Time $\left(\tau_{F}\right)$. Such changes arise from the difference between the present forecasted demand and the incoming demand, so we have

$$
\begin{gathered}
(d / d t) F_{L}=\Delta_{F} \\
\Delta_{F}=\left(F_{L}-R_{L O}\right) / \tau_{F}
\end{gathered}
$$

\subsubsection{Production and Production Scheduling}

The Production and Materials Management sections, dealing with the physical flow and Production Scheduling managing production decisions are highly intertwined in the model, so they will be described jointly. Replenishment decisions are based on the forecast of customer orders, the inventory policies and the levels of inventories, all ingrained in Production Scheduling.

Related to the previously defined Local Inventory, the Desired Local Inventory $\left(I_{L}^{*}\right)$ is defined as the expected amount of product such that supplies last over an ideal amount of time, namely Desired Local Inventory Coverage $\left(C_{L I}^{*}\right)$. Such time must cover for the amount of time to ship an order, previously denoted as Minimum Local Order Lead Time $\left(\lambda_{L O}^{-}\right)$, plus a time buffer denoted as Local Safety Stock Coverage $\left(C_{L S S}\right)$. Then, we have 


$$
\begin{aligned}
& C_{L I}^{*}=\lambda_{L O}^{-}+C_{L S S} \\
& I_{L}^{*}=F_{L} \cdot C_{L I}^{*}
\end{aligned}
$$

Note from [18] that the expected consumption is inferred from the Local Forecast. Getting back to Local Inventory $\left(I_{L}\right)$, a periodic review inventory policy is in place considering regular review intervals, or Local Inventory Review Time $\left(\tau_{L I}\right)$, as well as an Adjustment for Local Inventory $\left(\Delta_{L I}\right)$ to 'correct' the current Local Inventory $\left(I_{L}\right)$ level towards the Desired Local Inventory $\left(I_{L}^{*}\right)$ previously defined. This is a basic constituent of the Inventory Control negative feedback loop, expressed as

$$
\Delta_{L I}=\left(I_{L}^{*}-I_{L}\right) / \tau_{L I}
$$

An instance of the Anchoring and Adjustment heuristic ${ }^{12}$ by Kahneman, et al. $(1982)^{13}$, is used to define the Desired Local Production $\left(R_{L P}^{*}\right)$, or the rate at which decision-makers wish to add units to the Local Inventory $\left(I_{L}\right)$. The adjustment component is taken from Adjustment for Local Inventory $\left(\Delta_{L I}\right)$. Since this adjustment

\footnotetext{
${ }^{12}$ Anchoring and Adjusting is a common strategy in which an unknown quantity is estimated by first recalling a known reference point (the anchor) and then adjusting for the effects of other factors which may be less salient or whose effects are obscure

${ }^{13}$ Sterman asserts that in most realistic stock management situations the complexity of the feedbacks among the variables obscures the determination of an optimal strategy. Hence this order decision logic assumes that managers instead of optimizing exercise control through a heuristic that is locally rational. Furthermore, in Sterman (1989), he founds statistical significance of the use of the heuristic among the data from the sample. Also in Sterman (1987) it is argued that the decision rule characterizes actual decisions well because it captures the essential attributes of any minimally sensible stock procedure, which include replacement of expected losses, correction between discrepancies and actual stock, and an accounting for the supply line of unfulfilled orders.
} 
could be positive or negative and orders are nonnegative, a robust formulation for this term is as follows

$$
R_{L P}^{*}=\max \left(0, \Delta_{L I}\right)
$$

Up to this point it has been described all the constructs and equations of the Local Orders fulfillment, forecasting and production scheduling processes. Before moving on to the rest of the Manufacturer's model, it is opportune to address Export Orders. A full description of the Exports portion is unnecessary, since almost all formulations are the same as for local fulfillment. Hence, for the reader's convenience Table 11 lists in alphabetical order all the duplicated variables of Export Orders with its notation. As for equations, only the differential portion is reported below.

Table 11. Export Orders variables definition

\begin{tabular}{|c|c|c|c|}
\hline Notation & Description & Notation & Description \\
\hline$\Delta_{E I}$ & Adjustment for Export & $\tau_{E I}$ & Export Inventory Review Time \\
\hline \multirow[b]{2}{*}{$\beta_{E P}$} & Inventory & $I_{E}$ & Export Inventory \\
\hline & $\begin{array}{l}\text { Demand Amplification Export } \\
\text { Production Rate }\end{array}$ & $R_{E F}$ & Export Order Fulfillmentt Rate \\
\hline$\beta_{E \underline{S}}$ & Demand Amplification Export & $\varphi_{E F}$ & Export Order Fulfillment Ratio \\
\hline \multirow{2}{*}{$I_{E}^{*}$} & Shipment Rate & $R_{E O}$ & Export Order Rate \\
\hline & Desired Export Inventory & $R_{E S}$ & Export Shipment Rate \\
\hline$R_{E P}$ & Desired Export Production & $R_{F E S}$ & Fraction Export Shipment \\
\hline$R_{E S}{ }^{*}$ & Desired Export Shipment Rate & & Rate \\
\hline$B_{E}$ & Export Backlog & $R_{E S}^{+}$ & $\begin{array}{l}\text { Maximum Export Shipment } \\
\text { Rate }\end{array}$ \\
\hline$\delta_{E D}^{*}$ & Export Delivery Delay Target & $\lambda_{E O^{-}}$ & Minimum Export Order Lead \\
\hline$\delta_{E D}$ & Export Delivery Delay & $R_{-}$ & Time \\
\hline$C_{E I}$ & Export Inventory Coverage & $\kappa_{E P}$ & Orders \\
\hline
\end{tabular}


Note that the Export Order Fulfillment differs from the Local's in the lacking of a formal forecast and nonexistent exports safety stock, without any coverage inventory. This leaves to the Desired Export Inventory $\left(I_{E}^{*}\right)$ being equal to Export Backlog $\left(B_{E}\right)$. Therefore, we have

$$
I_{B}^{*}=B_{E}
$$

Operations are modeled as a succession of stock and flows with a disjunction in the finished product pipeline for local and export orders, with each important inventory stage represented as a stock. Each stock is influenced by different flows adding and reducing to them, controlled by several valves.

As customary, the model distinguishes finished product inventory, for the case of local sales designated as Local Inventory $\left(I_{L}\right)$ and for export sales denoted as Exports Inventory $\left(I_{E}\right)$; items being processed but not completed, Work in Process Inventory $\left(I_{W I P}\right)$ and raw materials and components purchased to external sources, Materials Inventory $\left(I_{M}\right)$.

Next, Work in Process Inventory is described. Equation [20] introduced the Desired Local Production $\left(R_{L P}^{*}\right)$, which in union to its equivalent Desired Export Production $\left(R_{E P}^{*}\right)$ defines the Desired Work in Process $\left(I_{W I P}^{*}\right)$. This accounts for the amount of necessary WIP to maintain steady production for as long as the Manufacturing Lead Time $\left(\lambda_{M}\right)$, which is the time it takes to complete a manufactured product. 


$$
I_{W I P}^{*}=\left(R_{L P}^{*}+R_{E P}^{*}\right) \cdot \lambda_{M}
$$

Replenishment decisions about the Work in Process Inventory stock are similar to the ones described for Local Inventory. The WIP Control loop adjusts an uninterrupted flow to Inventory by ensuring an appropriate level of Work in Process Inventory $\left(I_{W I P}\right)$. Such adjustment is provided by the auxiliary variable defined as Adjustment for WIP $\left(\Delta_{W I P}\right)$, which is

$$
\Delta_{W I P}=\left(I_{W I P}^{*}-I_{W I P}\right) / \tau_{W I P}
$$

The previous equation introduced the term Work in Process Review Time $\left(\tau_{W I P}\right)$, denoting the interval of time between each WIP Inventory level review and considering again Periodic Review inventory policy.

So far, the Desired Production Start Rate $\left(R_{P S}^{*}\right)$ can be formulated analogously to how we previously defined the Production Rate as

$$
R_{P S}^{*}=\max \left(0, \Delta_{W I P}\right)
$$

On the other hand, the actual Production Start Rate $\left(R_{P S}\right)$ stocks up the Work in Process Inventory ( $\left.I_{W I P}\right)$ that accumulates the inflow of items to be manufactured. Since not the product nor the process differentiates local and export products (not before this point), this repository pools undifferentiated WIP items and is depleted by two valves, the Production Rate For Local Orders $\left(R_{L P}\right)$ and the Production Rate For Export Orders $\left(R_{E P}\right)$, respectively for each corresponding pipeline and destination. Thus, 


$$
(d / d t) I_{W I P}=R_{P S}-R_{L P}-R_{E P}
$$

Both Local and Export Production Rates are dependent on a Maximum Production Rate $\left(R_{P}^{+}\right)$, defined as the current available Work in Process Inventory $\left(I_{W I P}\right)$ processed as fast as possible, that is, at the Minimum Manufacturing Lead Time $\left(\lambda_{P}^{-}\right)$. Thereby,

$$
R_{P}^{+}=I_{W I P} / \lambda_{P}^{-}
$$

Whenever there is simultaneous demand for local and export orders, the manufacturing capacity has to be allocated. However, it is evident from the manufacturer observation that exports have a higher priority than local sales. A fraction of the Production Rate is introduced, the Relation Between Desired Productions $\left(f_{P}\right)$, which enables splitting capacity among Production Rate For Export Orders $\left(R_{E P}\right)$ and Production Rate For Local Order $\left(R_{L P}\right)$. Hence,

$$
\begin{aligned}
R_{L P} & =R_{P}^{+} \cdot f_{P} \\
R_{E P} & =R_{P}^{+} \cdot\left(1-f_{P}\right)
\end{aligned}
$$

From the manufacturer observation over a period of two years, and inference over a sample of production schedules, we have developed an allocation policy that models the actual production decisions. The policy is modeled by a nonlinear function $\left(f_{P}\right)$ that takes as input the ratio between Desired Local Production and Desired Export Production, and delivers the Relation Between Desired Productions $\left(f_{P}\right)$ as shown in 
Figure 35 in the horizontal and vertical axis, respectively. It shows the marked prevalence of exports over locals. Up to a point where Desired Local Production reaches the half of the Desired Export Production, the Relation Between Desired Productions $\left(\mathrm{f}_{\mathrm{P}}\right)$ remains as zero, allocating all resources to Exports. Moving ahead to the case when both are equal, the Relation Between Desired Productions $\left(f_{P}\right)$ just allocates $40 \%$ of resources to Local Orders. It takes to the Desired Local Production to be five times greater, in order to be able to seize $100 \%$ of production capacity.

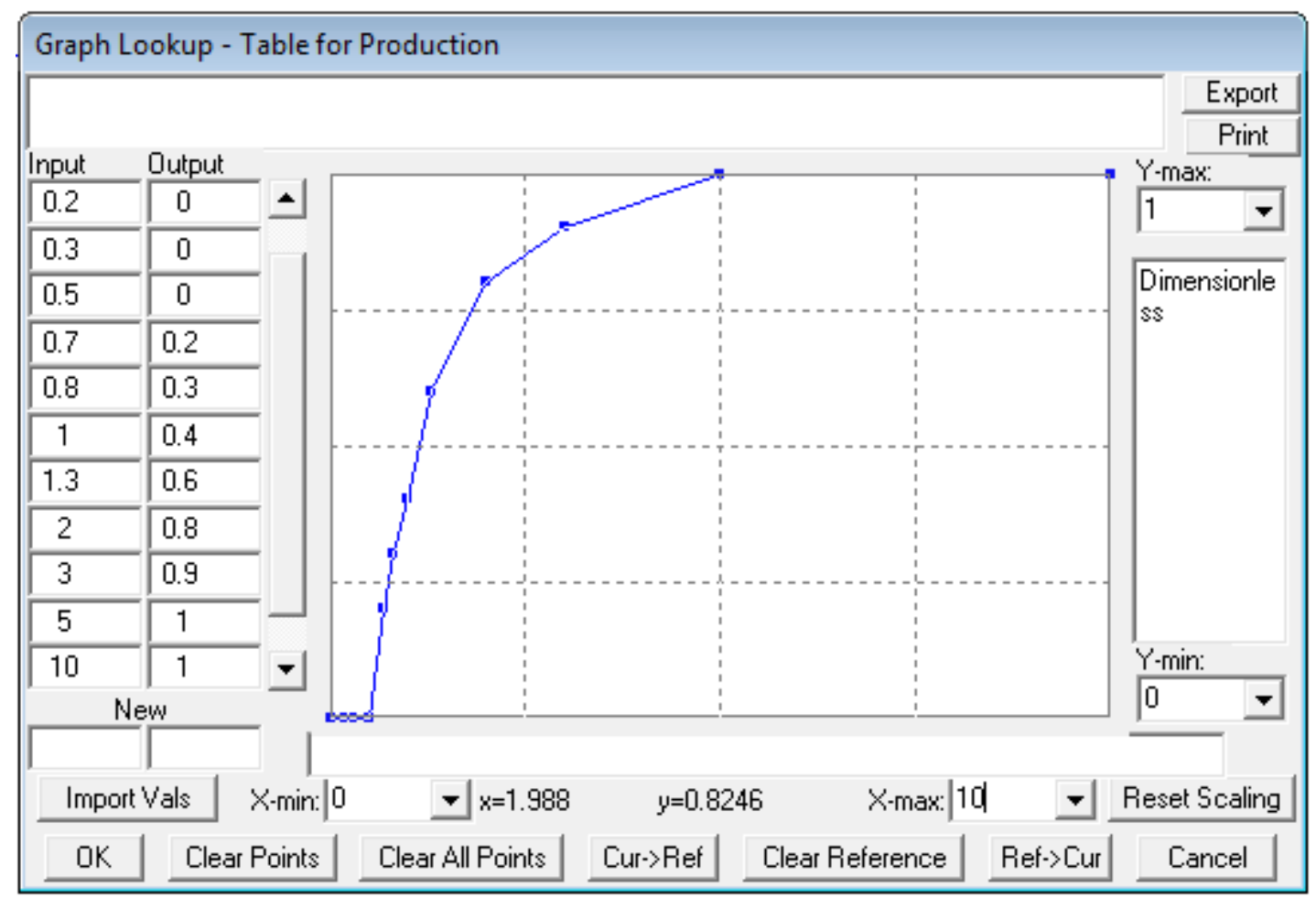

Figure 35. Relation Between Desired Productions $\left(f_{P}\right)$

The preceding paragraph finishes the description of Production. We now move back to the production decisions modeling, and more specifically to the Production Start Rate, which is still undefined. In order to close the negative feedback 
loops of Inventory Control and WIP Control is necessary to relate the actual and desired Production Start Rate. This is done by taking into account the availability of materials and devising connections between the materials and products pipelines.

Let Production Plan $(P P)$ account for the feasible production plan, which takes not only the Desired Production Start Rate $\left(R_{P S}^{*}\right.$; see [23]) but the Maximum Production Capacity $\left(K_{P}^{+}\right)$as reference. Therefore,

$$
P P= \begin{cases}K_{P}^{+}, & K_{P}^{+}<R_{P S}^{*} \\ R_{P S}^{*}, & \text { otherwise }\end{cases}
$$

\subsubsection{Procurement and Materials Management}

Materials Inventory $\left(I_{M}\right)$ is defined as a separate stock and flow structure, influenced by the Material Delivery Rate $\left(R_{M D}\right)$, or the frequency at which materials arrive from suppliers, and the Material Usage Rate $\left(R_{M U}\right)$ standing for the incidence of materials used by Production. Materials Inventory makes use of a separate pipeline because of the dissimilar nature of its flow ${ }^{14}$ when compared to Production. However, Production is constrained by the Material Usage Rate.

$$
(d / d t) I_{M}=R_{M D}-R_{M U}
$$

Once more, a relaxed version of the problem is used considering the Materials Inventory as an aggregation of generic components that constitutes the final product, denoted as 'materials'. The Material Usage per Item $(M U)$ describes the

\footnotetext{
${ }^{14}$ E.g.: items/wk vs. components/wk
} 
number of (generic) materials that conforms a unit of output (item per materials). Hence, we can define the Desired Materials Usage Rate $\left(R_{M U}^{*}\right)$ as:

$$
R_{M U}^{*}=\max \left(0, P P / R_{P}^{+}\right)
$$

The Material Usage Ratio $\left(\varphi_{M U}\right)$ is now defined as the proportion of the Desired Materials Usage Rate $\left(R_{M U}^{*}\right)$ that Materials Management is capable of delivering because of material inventory availability. This fraction is obtained by means of a nonlinear function of the ratio of the Maximum Materials Usage Rate to the Desired Materials Usage Rate. Material Usage Ratio $\left(\varphi_{M U}\right)$ is defined in Figure 36.

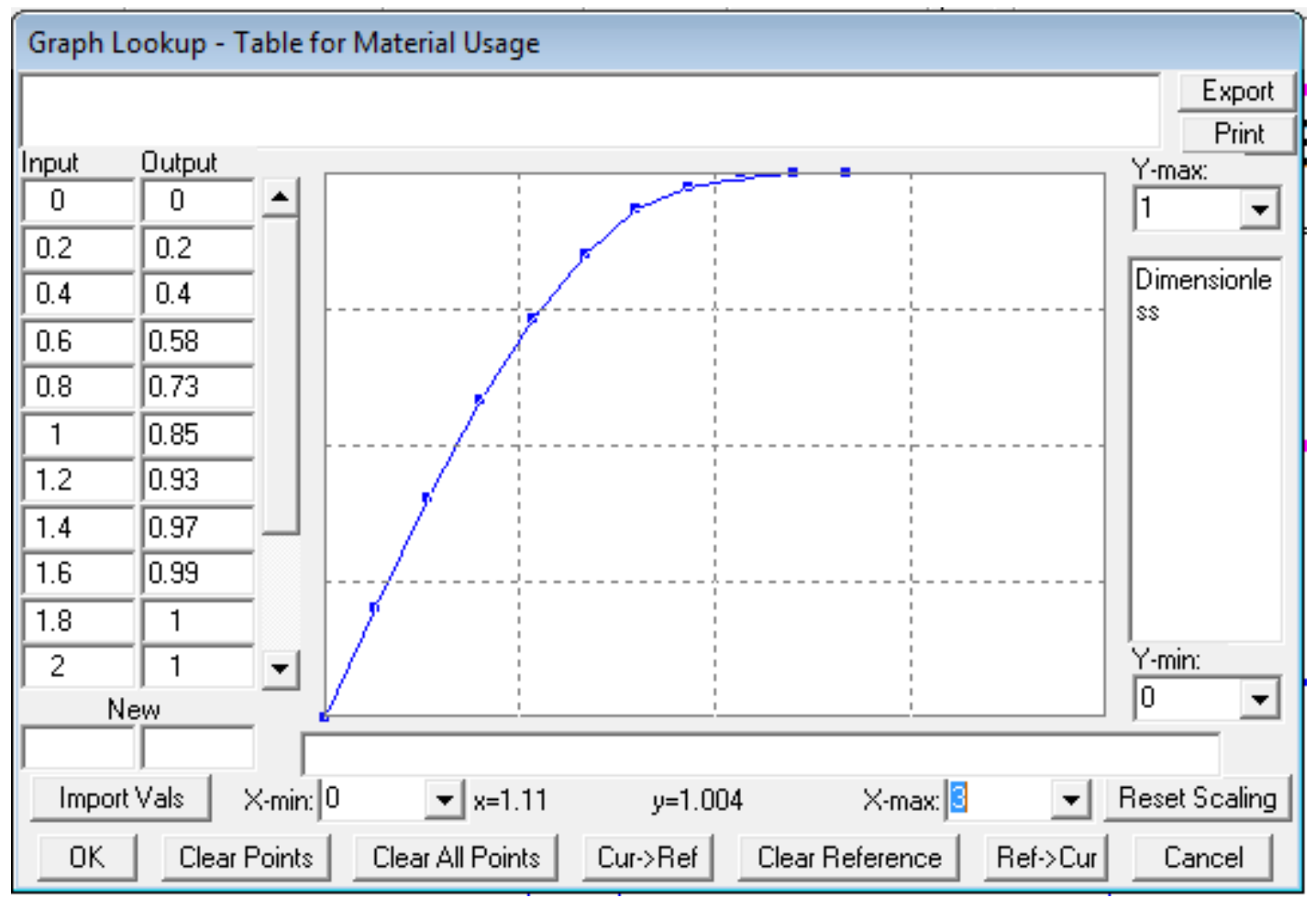

Figure 36. Material Usage Ratio $\left(\varphi_{M U}\right)$ 
In addition, the following formulations apply

$$
R_{M U}=R_{M U}^{+} \cdot \varphi_{M U}
$$

The Material Usage Rate $\left(R_{M U}\right)$ is the number of components delivered to Production, therefore by multiplying it by the Material Usage per Item $(M U)$ we obtain the viable amount of items to begin production, or the Feasible Production Starts from Materials $\left(R_{F P S}\right)$, equivalent to the Production Start Rate $(P S)$. Such equivalency ties up the actual and desired Production Start Rate and establishes the desired relationship. Thus,

$$
\begin{aligned}
& R_{F P S}=R_{M U} \cdot M U \\
& R_{F P S}=R_{P S}
\end{aligned}
$$

Next, the Materials Control negative feedback is delineated by characterizing the corrections to the Materials Inventory stock, or Adjustment for Materials Inventory $\left(\Delta_{M I}\right)$, as follows

$$
\Delta_{M I}=\left(I_{M-}^{*} I_{M}\right) / \tau_{M I}
$$

As before, the Material Inventory Review Time $\left(\tau_{M I}\right)$ corresponds to the intervals between periodic reviews of the materials inventory; the Desired Material Inventory $\left(I_{M}^{*}\right)$ to the ideal amount of material inventory to be kept. The latter, in turn, is defined by the Desired Material Inventory Coverage $\left(C_{M I}^{*}\right)$, a lapse of time that accounts 
for the Minimum Material Request Lead Time $\left(\lambda_{M R}^{-}\right)$, or time to deliver a request of material, and a safety amount of time to cover for variations, the Materials Safety Stock Coverage $\left(C_{M S S}\right)$. Therefore, the Desired Material Inventory Coverage's worth of the Desired Material Usage Rate specifies the Desired Material Inventory. The corresponding equations follow:

$$
\begin{aligned}
& C_{M I}^{*}=\lambda_{M R}^{-}+C_{M S S} \\
& I_{M}^{*}=C_{M I}^{*} \cdot R_{M U}^{*}
\end{aligned}
$$

The Desired Material Delivery Rate $\left(R_{M D}^{*}\right)$ is established as:

$$
R_{M D}^{*}=\max \left(0, \Delta_{M I}\right)
$$

This leaves to the quest of defining the actual Material Delivery Rate $\left(R_{M D}\right)$, naturally related to the former Desired Material Delivery Rate $\left(R_{M D}^{*}\right)$ but having been through the effects of a forecasting practice and delays due to financial constraints. At this point, the Manufacturer makes use of a double check for determining its supply, consisting of the autonomous determination of a parallel Required Material Delivery Rate $\left(R_{R M D}\right)$ by observing historical consumption.

As before, Moving Average is the forecasting choice used in Procurement. We define Materials Forecast $\left(F_{M}\right)$ as the continuous holder of changes detected every other Materials Forecast Review Time $\left(\tau_{M U F}\right)$. As usual, departures of current material consumption, the Material Usage Rate $\left(R_{M U}\right)$, from the estimated material consumption or Materials Forecast $\left(F_{M}\right)$ defines the updated forecast. Thus, 


$$
\begin{aligned}
& (d / d t) F_{M}=\Delta_{M U} \\
& \Delta_{M U F}=\left(F_{M}-R_{M U}\right) / \tau_{M U F}
\end{aligned}
$$

The Required Material Delivery Rate $\left(R_{R M D}\right)$ is defined by the nonnegative surplus of the Materials Forecast $\left(F_{M}\right)$ from the Maximum Materials Usage Rate $\left(R_{M U}^{+}\right)$, in trying to extract from the expected consumption what is already available. This is,

$$
R_{R M D}=\max \left(F_{M}-R_{M U}^{+}, 0\right)
$$

A comparison between the two independent sources of required material supply, namely the Desired Material Delivery Rate $\left(R_{M D}^{*}\right)$ and the Required Material Delivery Rate $\left(R_{R M D}\right)$, is in order. The manufacturer simply picks the larger amount, as in

$$
R_{C M D}=\max \left(R_{R M D}, R_{M D}^{*}\right)
$$

The previous equation presents the Compromised Material Delivery Rate $\left(R_{C M D}\right)$ that accounts for a robust determination of supplies under uncertainty conditions. $R_{C M D}$, in time, becomes the Material Delivery Rate $\left(R_{M D}\right)$ after an administrative lapse in which the manufacturer is able to secure a down payment for the order and the supplier's ordering lead time. 


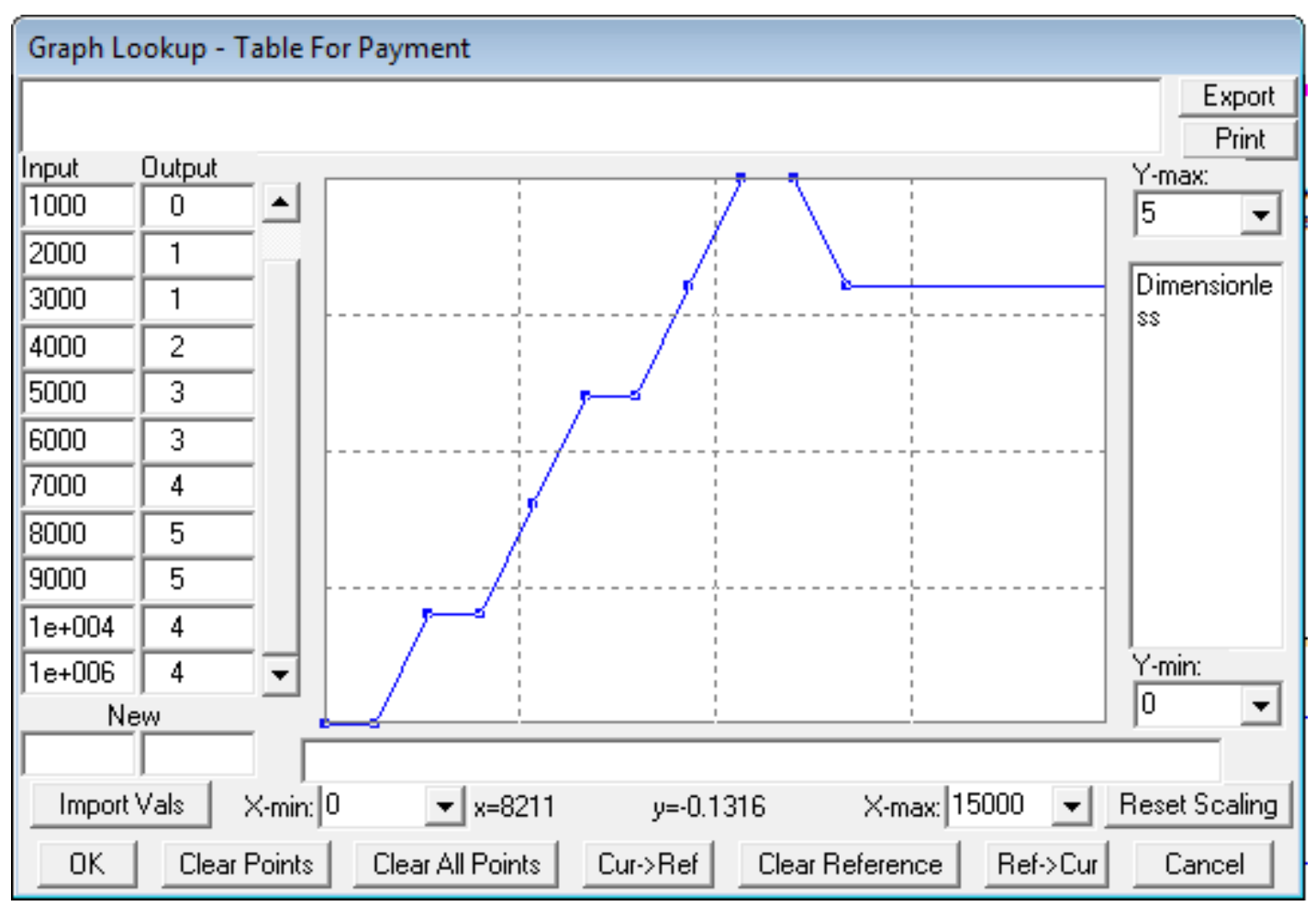

Figure 37. Table For Payment Delay $\left(T_{P y}\right)$

A survey on historical data from the company indicates that the manufacturer's payment time increases with the order size due to increasing cash flow restrictions. A relationship between the number of units and the ability to pay the company is shown in Figure 31. The nonlinear function Table For Payment Delay $\left(T_{P y}\right)$ takes as input the Compromised Material Delivery Rate $\left(R_{C M D}\right)$ divided by a Financial Material Review Rate $\left(R_{F M R}\right)$, so as to normalize the ratio. The table function returns a delay fraction, to be applied to a regular Payment Time $\left(\delta_{P y}\right)$ in order to render the Adjusted Payment Delay $\left(\delta_{A P y}\right)$. The latter is to be interpreted as the estimated delay for a particular ordered amount. 


$$
\delta_{A P y}=T_{P y}\left(R_{C M D} / R_{F M R}\right) \cdot \delta_{P y}
$$

In addition, we have the Materials Delay Time $\left(\delta_{M D}\right)$ which accounts for both the Adjusted Payment Delay $\left(\delta_{A P y}\right)$ and the Perceived Supplier Lead Time $\left(\delta_{S L T}^{\sim}\right)$. This is,

$$
\delta_{M D}=\delta_{A P y}+\delta_{S L T}^{\tilde{S}}
$$

Lastly, the Material Delivery Rate $\left(R_{M D}\right)$ is modeled as a first-order delayed Compromised Material Delivery Rate $\left(R_{C M D}\right)$. Thereby,

$$
\begin{gathered}
(d / d t) R_{M D}=\Delta_{R} \\
\Delta_{R}=\left(R_{C M D}-R_{M D}\right) / \delta_{M D}
\end{gathered}
$$

This section outlined the formal structure of the Manufacturer's echelon model from the supply chain under study. The coming section addresses the Distributor echelon.

\subsubsection{Distributor Model Components}

The Distributor is a medium-sized company, managed and owned by a large corporation. In the model, the Distributor is treated as a local customer because its facility is close to the manufacturer. Even though the distributor and manufacturer are independent companies with different owners and governance, they are very similar in 
processes and policies since both apply push-based practices. Figure 38 shows there is a close resemblance in overall structure between the Distributor's and Manufacturer's operations. The main difference is the distributor does not have a manufacturing process.

The structure of the Distributor's model does not change substantially from the Manufacturer's and basically replicates to a large extent the former model formulation with equivalent variables and logic but with different names and values. Table 12 lists the notation, but forgoes any description of what was already provided in the explanation of the manufacturer. The reader can verify the equivalent formulation by looking for the homonym name (i.e., Distributor Backlog can be looked up in the previous description as Local Backlog) or by contrasting the model charts in order to locate equivalent variables, and checking them in the prior model description. In the following paragraphs, we only explain what is new. 


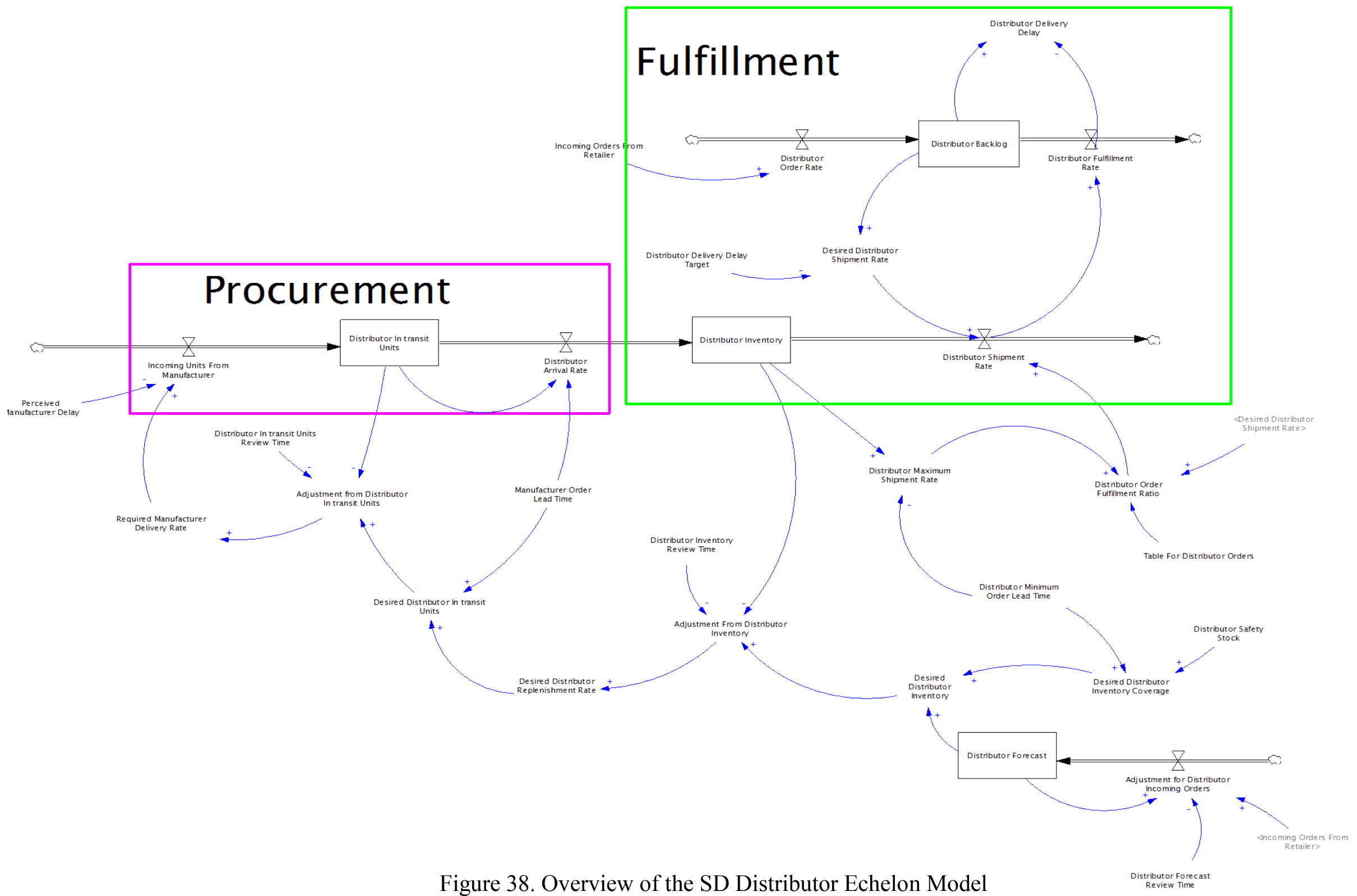


Table 12. Distributor variable definition

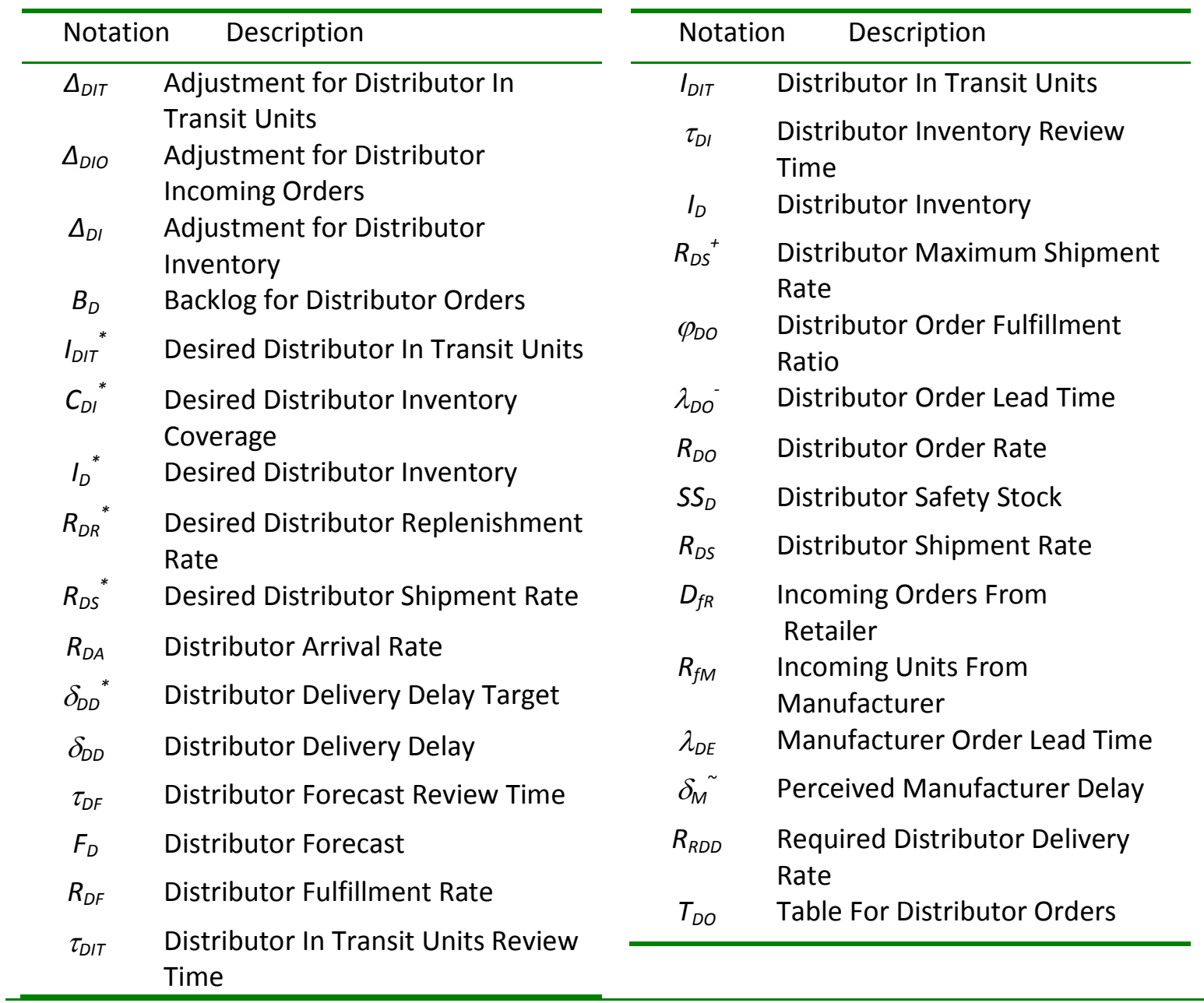

Figure 38 shows two framed areas denoting the Fulfillment and Procurement, which accounts for the main Distributor's processes. Let us start the description on Procurement since the Fulfillment is the exact replica of the Manufacturer's, as described in sections 5.1.3.1 and 5.1.3.2.

Let Incoming Orders From Retailer $\left(D_{f R}\right)$ represent the demand faced by the Distributor and generated by the Retailer. This corresponds to a time series that controls 
the pace of incoming orders to the Distributor Backlog $\left(I_{D B}\right)$, namely the Distributor Order Rate $\left(R_{D O}\right)$. Furthermore, in order to completely describe the connection Distributor/Retailer the Required Distributor Delivery Rate $\left(R_{R D D}\right)$ from the Retailer is related to the Incoming Orders From Retailer $\left(D_{f R}\right)$. In this way, we have:

$$
D_{f R}=R_{D O}=R_{R D D}
$$

Next, the description of Procurement follows. We start from the Desired Distributor Replenishment Rate $\left(R_{D R}^{*}\right)$, denoting the desired Distributor Inventory replenishment rate that already takes into account current orders, forecast, stock and safety stock considerations for computing the replenishment. In addition, Manufacturer Order Lead Time $\left(\lambda_{D E}\right)$ represents the time that it takes for the Manufacturer to deliver an order. The desired replenishment can be expressed in units rather than as rate, as

$$
I_{D I T}^{*}=R_{D R}^{*} \cdot \lambda_{D E}
$$

The former equation defines the Desired Distributor In-Transit Units $\left(I_{D I T}^{*}\right)$. Derivates from it and from the Distributor In-Transit Units $\left(I_{D I T}\right)$ the Adjustment for Distributor In-Transit Units $\left(\Delta_{D I T}\right)$, as

$$
\begin{gathered}
\Delta_{D I T}=\left(I_{D I T-}^{*} I_{D I T}\right) / \tau_{D I T} \\
\Delta_{D I T}=R_{R D D}=R_{L O}
\end{gathered}
$$


From [50] is obtained a replenishment that considers the flow of ordered units in the supplier's pipeline that ultimately constitutes the Required Distributor Delivery Rate $\left(R_{R D D}\right)$. This is the corresponding input of the manufacturer, which is also termed Local Order Rate $\left(R_{L O}\right)$ and formerly described in equation [6].

Distributor In-Transit Units $\left(I_{D I T}\right)$ is fed by the Incoming Units From Manufacturer $\left(R_{f M}\right)$, which is the materials from the supplier's pipeline, and is depleted by the Distributor Arrival Rate $\left(R_{D A}\right)$ that stands for the actual arriving rate of materials to the Distributor facility. Note that Distributor In-Transit Units $\left(I_{D I T}\right)$ is in fact a moving stock of products, in transportation from the Manufacturer to the Distributor, as expressed in the equation [52].

$$
(d / d t) I_{D I T}=R_{f M}-R_{D A}
$$

\subsubsection{Retailer Model Components}

The retailer of the case study is a series of drug stores affiliated to the Distributor; this is, although they are part of the same company and are the Distributors exclusive sales channel, they are a separate company with their own governance and trademark. Drug stores are autonomous in their replenishment decisions. The actual drug store modeled for the study is a local outlet, hence processes and decisions do not consider pipeline inventory due to the geographical proximity and reliable internal delivery from inside the company. 
As before, the similarity in the overall structure when comparing Retailer's with Distributor and Manufacturer's operations is evident. Figure 39 shows the model constructs for the Retailer.

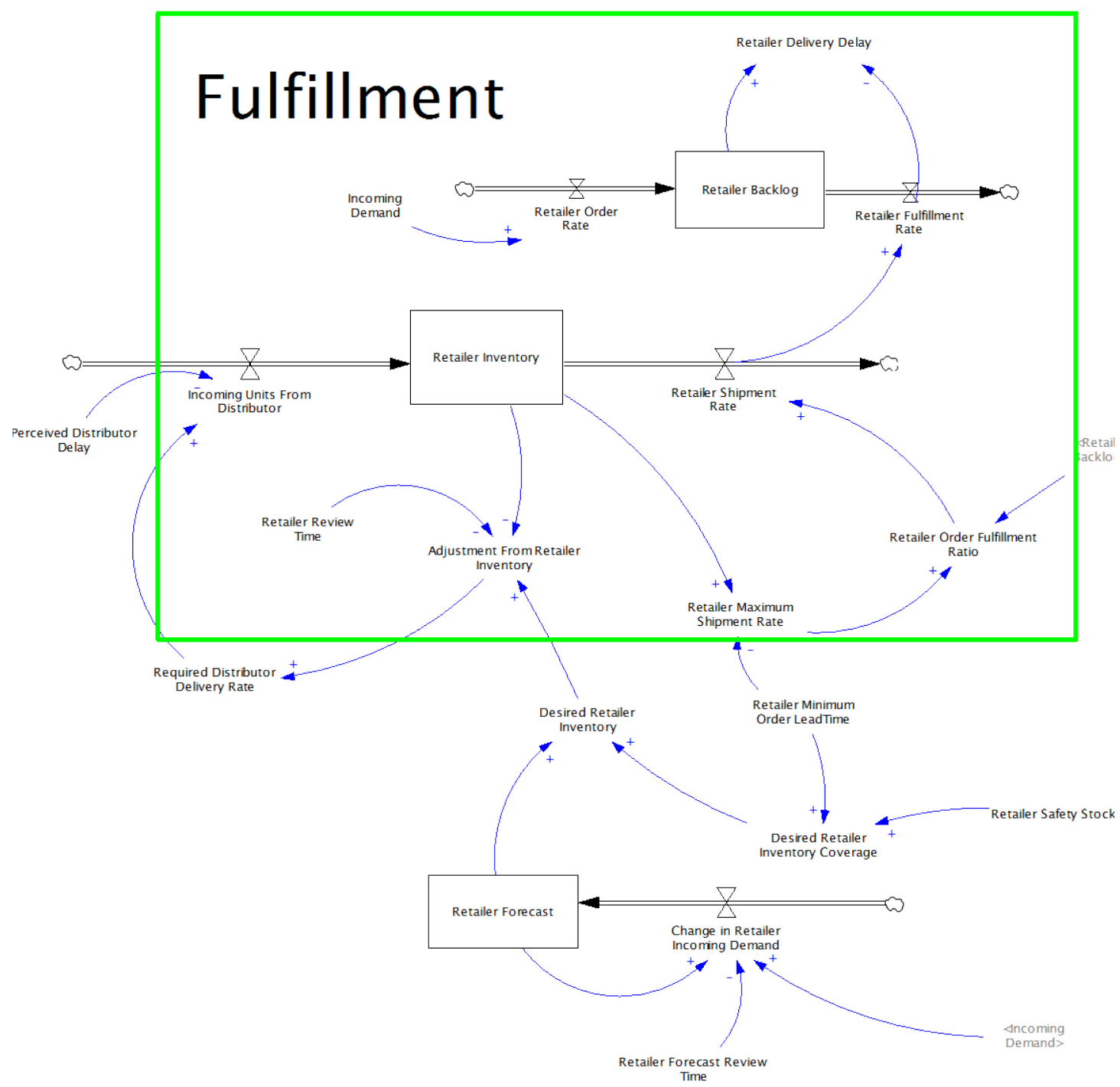

Figure 39. Overview of the SD Retailer Echelon Model 
The Retailer model is accurately described by the previous subsection 5.1.3.1. As in the previous Distributor section, the reader is asked to check the retailer model formulation with different names and values listed in Table 13.

Table 13. Retailer variable definition

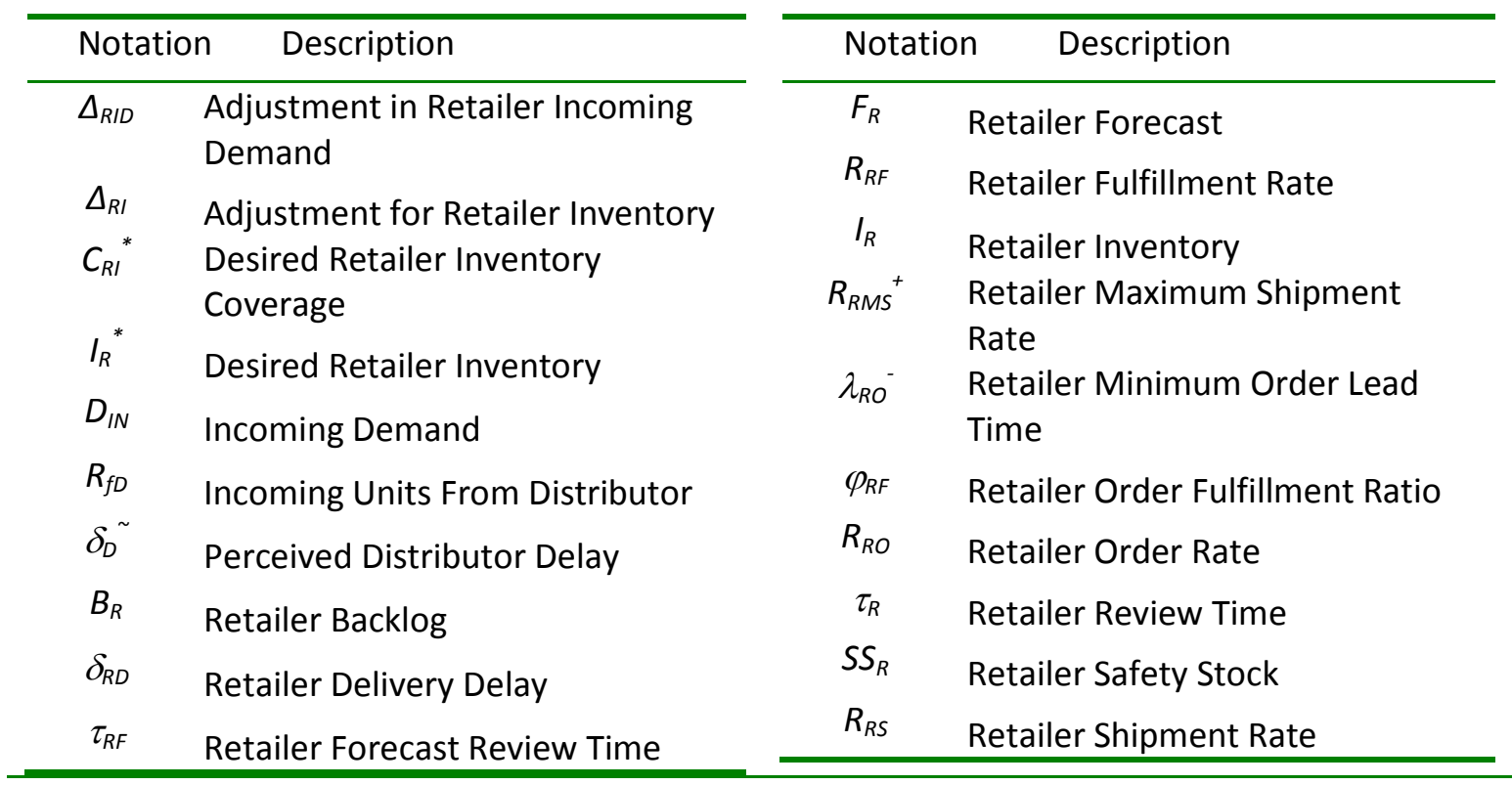

This section omits the retailer's equations, already described. Yet, it is important to highlight the input and output of the Retailer model. The Incoming Demand $\left(D_{I N}\right)$ is not only the retailer's input but the overall supply system's input. On the other side, there is the Required Distributor Delivery Rate $\left(R_{R D D}\right)$ which is the output demand placed to the Distributor, as already discussed in [48].

\subsubsection{MedLab Cost and Revenue Model}

Since the cash flow and monetary resources influence many decisions and policies in MedLab, this section focuses on the description of the dynamics of the 
financial inputs and outputs. In the course of the study, we only had access to MedLab's income and expenses information. Therefore, the modeling effort only considers the manufacturer's costs and sales logic and includes neither distributor nor retailer.

The main function of this sub-model is to measure and quantify the relevant costs generated by demand amplification, for MedLab and the global environment (overall supply chain). The model focuses on the variable operational costs and it does not intend to be comprehensive nor accurate in the cost estimation since it disregards administrative costs, staffing costs, financial costs, depreciation, and, in general, fixed operational costs. It is based on assumptions and estimates provided by the company. It partially deals with the most significant costs, if involved with demand amplification.

The model enables reviewing the evolution of the variable Gross Profit $(\mathrm{Pr})$, which registers MedLab's historic gains and losses. Later in the model analysis, it will prove to be very useful in finding the best set of policies that maximizes profit without significantly affecting the amplification of demand for the company. However, it must be stressed that this is only an estimation of profits since it only deals with partial costs.

MedLab's cost sub-model considers values associated with maintaining selected raw material and finished product inventory, raw material purchase amount, direct and indirect manufacturing costs, material handling and the cost of late deliveries for both domestic and international markets. On the other hand, product sales constitute the manufacturer income, taking into account the effect of volume discounts. 


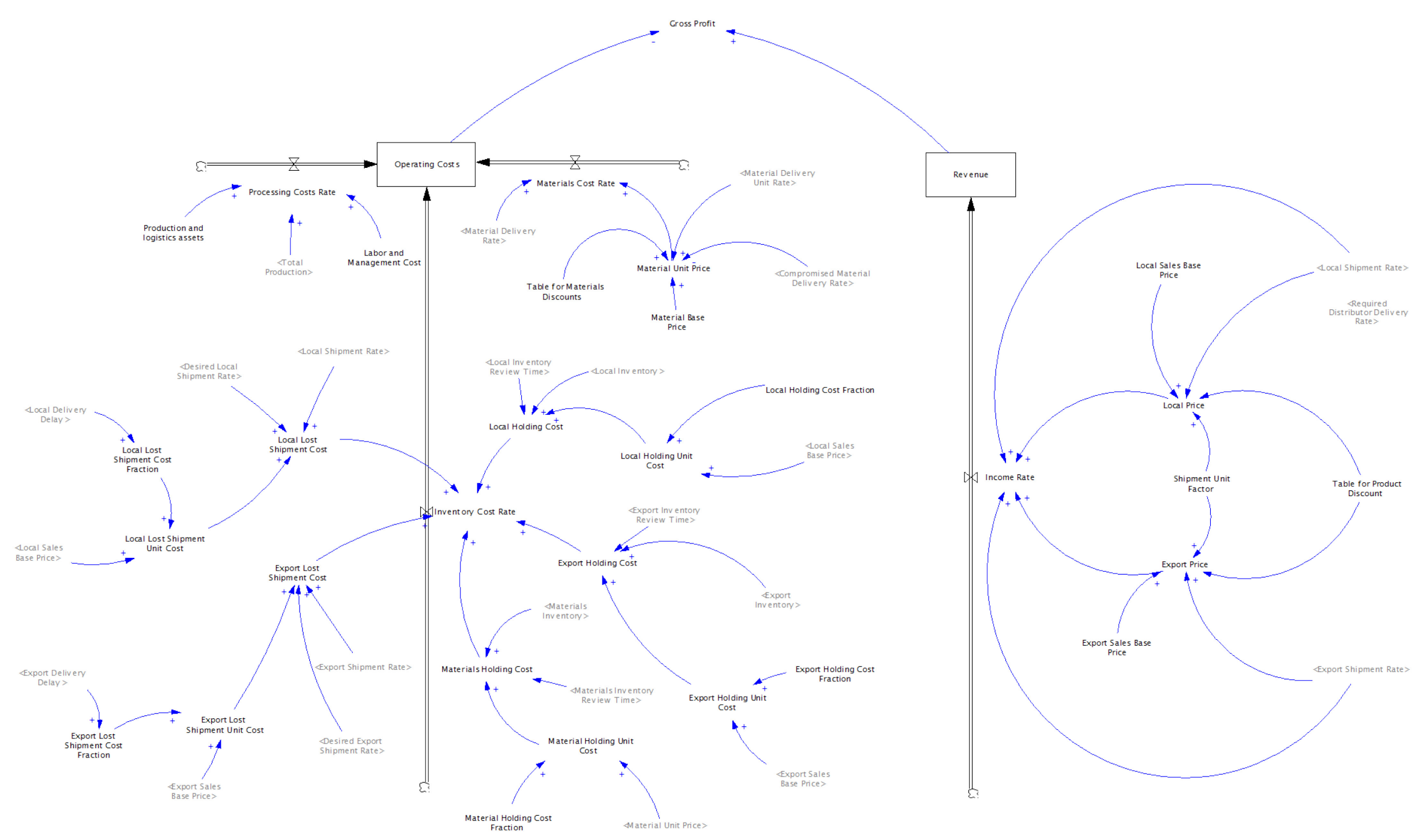

Figure 40. Overview of the SD Manufacturer Profits Model 
Figure 40 shows MedLab's profit model, divided into two main sections. The right features a single pipeline that ends into the Total Sales $(S)$ stock. To the left, there are three main rates and corresponding pipelines: Materials Cost Rate $\left(C R_{M}\right)$, Orders and Service Processing Cost Rate $\left(C R_{O \& S}\right)$ and Inventory Cost Rate $\left(C R_{I}\right)$; each one leads into the Total Operational Cost $(O C)$ stock. It follows that Gross Profit $(P r)$ is defined as,

$$
\begin{gathered}
\operatorname{Pr}=S-O C \\
\text { Where, } \\
(d / d t) \mathrm{OC}=E R_{I}+E R_{M}+E R_{F O}
\end{gathered}
$$

We start from [54] by describing its constituents. Let Inventory Cost Rate $\left(E R_{I}\right)$ be a repository of weekly based inventory costs, considering both holding and late delivery penalty costs.

Holding costs include local and export finished product inventory, and materials inventory as well. Consequently, we have a threefold cost input, namely Export Holding Cost $\left(\chi_{E H}\right)$, Local Holding Cost $\left(\chi_{L H}\right)$ and Material Holding Cost $\left(\chi_{M H}\right)$. All three share the same logic, we use here Local Inventory to illustrate the case: a Local Holding Unit Cost $\left(c_{L H}\right)$ is obtained by applying a Local Holding Cost Fraction $\left(f_{L H}\right)$, which is a percentage value of the holding cost per period, to the Local Sales Base Price $\left(\pi_{L S}\right)$. Such unit cost can be expanded considering the current weekly Local Inventory $\left(I_{L}\right)$, which gives the Local Holding Cost $\left(\chi_{L H}\right)$. Thus, 


$$
\chi_{L H}=f_{L H} \cdot \pi_{L S} \cdot I_{L}
$$

Extending to Exports and Material,

$$
\begin{aligned}
& \chi_{E H}=f_{E H} \cdot \pi_{E S} \cdot I_{E} \\
& \chi_{M H}=f_{M H} \cdot \chi_{M} \cdot I_{M}
\end{aligned}
$$

Note that [57] introduces the Materials Cost $\left(\chi_{M}\right)$, representing the purchase amount after discounts, that will be defined in coming lines.

Late delivery costs concern both local and export orders, and as in the previous case we illustrate only for one case due to their identical formulation. The cost of undelivered units, take for instance the Local Lost Shipment Unit Cost $\left(c_{L L}\right)$, is set as a fraction of the cost of the product, the Local Lost Shipment Cost Fraction $\left(f_{L L}\right)$. However, if delivery takes more than desired the fraction of the cost increases, because the company's main objective is set in maximum the Local Delivery Delay Target $\left(\delta_{L D}^{*}\right)$ for dispatching orders. Therefore,

$$
f_{L L}= \begin{cases}f_{R H}, & \delta_{L D} \leq \delta_{L D}^{*} \\ f_{D H}, & \delta_{L D}>\delta_{L D}^{*}\end{cases}
$$

Equation [58] introduces the Regular Handling Cost Fraction $\left(f_{R H}\right)$ and the Delayed Handling Cost Fraction $\left(f_{D H}\right)$, which corresponds respectively to the material handling and normal order set up cost fraction per order with respect to the regular product price, and the same for the expedited case; Notice as well the formerly defined Local Delivery Delay $\left(\delta_{\mathrm{LD}}\right)$ in [10]. Let us introduce the Local Sales Base Price $\left(\pi_{L S}\right)$ as 
the list price of local product, it follows that the Local Lost Shipment Unit Cost $\left(\mathrm{c}_{\mathrm{LL}}\right)$ in monetary units is expressed as,

$$
C_{L L}=f_{L L} \cdot \pi_{L S}
$$

Thus, the Local Lost Shipment Cost $\left(\chi_{L L}\right)$ factors the Local Lost Shipment Unit Cost $\left(\mathrm{c}_{\mathrm{LL}}\right)$ to the lost sales portion, computed as the difference between desired minus actual shipment rate,

$$
\chi_{L L}=c_{L L} \cdot\left(R_{E S}^{*}-R_{E S}\right)
$$

Correspondent equations can be obtained for export orders. Now, is possible to define Inventory Cost Rate $\left(E R_{I}\right)$ as,

$$
E R_{I}=\chi_{L L}+\chi_{E L}+\chi_{L H}+\chi_{E H}
$$

Next, Materials Cost Rate $\left(E R_{M}\right)$ describes MedLab's investment flow in purchasing raw material requirements. Recall that Material Delivery Rate $\left(R_{M D}\right)$ is the manufacturer's material input rate from the supplier. In addition, Material Unit Price $\left(\pi_{M}\right)$ defines the acquisition price of material considering volume discounts offered by the provider. Such discounts are modeled using the relationship between the Compromised Material Delivery Rate $\left(R_{M D}^{C}\right)$, or firm order to the supplier, and the Material Delivery Unit Rate $\left(R_{M D U}\right)$, the latter serving the purpose of normalizing such ratio. Taking as input the previous ratio, the Table for Material Discount $\left(T_{M D}\right)$ is 
defined as a nonlinear function that lowers the negotiated price as the demanded amount increases, as shown:

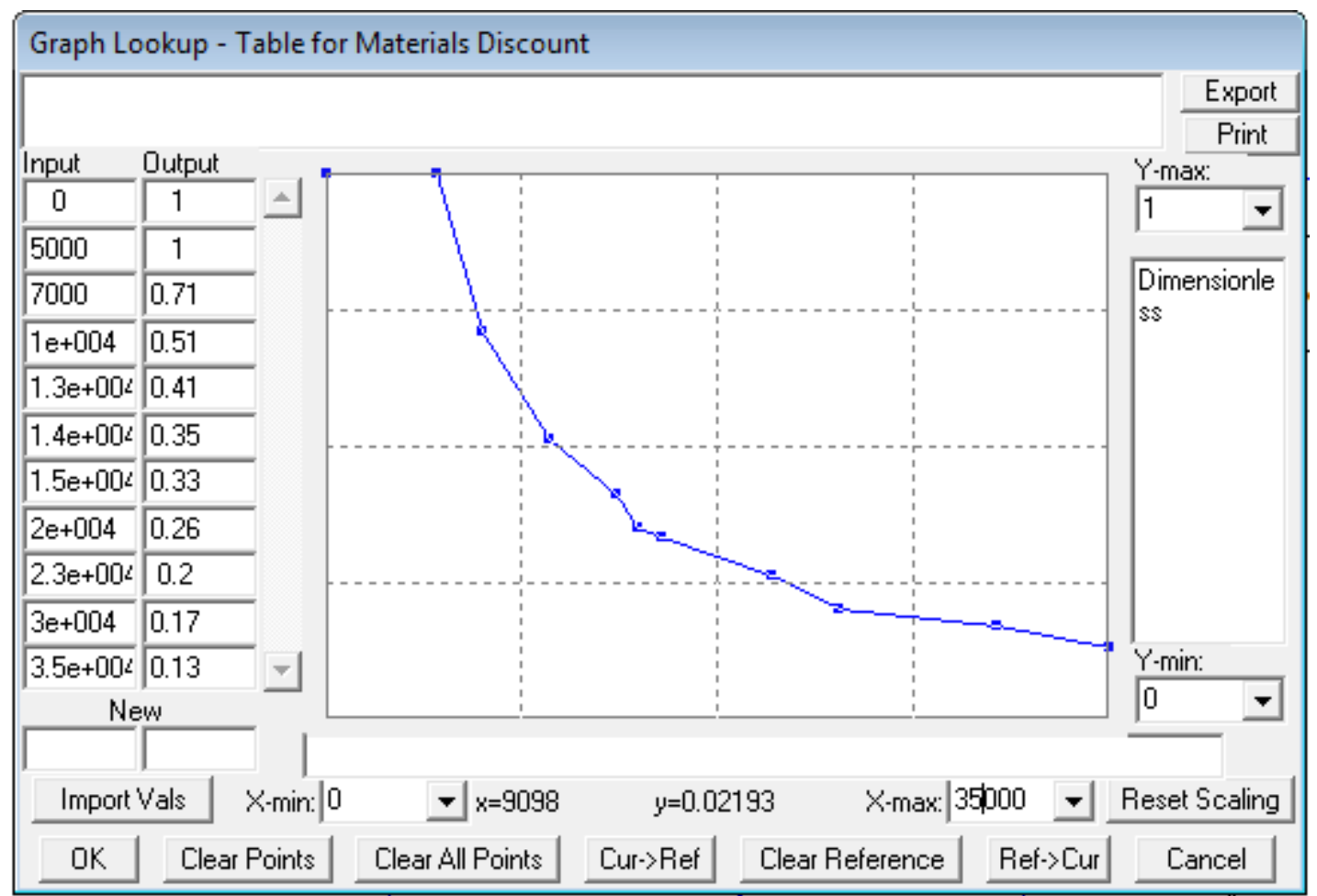

Figure 41. Table For Material Discount $\left(T_{M D}\right)$

The table function returns a discount fraction that adjusts the original Material Base Price $\left(\pi_{M}^{0}\right)$. Hence, Material Unit Price $\left(\pi_{M}\right)$ is expressed as,

$$
\pi_{M}=T_{M D}\left(R_{M D}^{c} / R_{M D U}\right) \cdot \pi_{M}^{0}
$$

In this way, the Materials Cost Rate $\left(E R_{M}\right)$ is defined as

$$
E R_{M}=R_{M D} \cdot \pi_{M}
$$


We finally describe the Fixed Operational Cost Rate $\left(E R_{F O}\right)$, which considers the Fixed Logistic Unit Cost $\left(c_{F L}\right)$, or the fixed unit cost associated with investment in physical spaces and transportation; and, the Fixed Mngmt and Manufacturing Unit Cost $\left(c_{F M \& M}\right)$, referring to the fixed indirect labor and manufacturing facilities costs. When computing these to the Total Production Rate $\left(R_{T P}\right)$ level, which aggregates both Production Rate For Export Orders $\left(R_{E P}\right)$ and Production Rate For Local Orders $\left(R_{L P}\right)$ we have

$$
\begin{gathered}
R_{T P}=R_{E P}+R_{L P} \\
E R_{F O}=R_{T P} \cdot\left(c_{F L}+c_{F M \& M}\right)
\end{gathered}
$$

From [61], [63] and [65] the definition of the Total Operational Cost $(O C)$ in [54] is complete.

Alternatively, the local and international market billing propels the revenue stream conducted through the pipeline on the right of Figure 40 . The company practice is to push demand, therefore company offers volume discounts which progressively increase the discount percentage as customers buy larger amounts, as shown in Figure 42. 


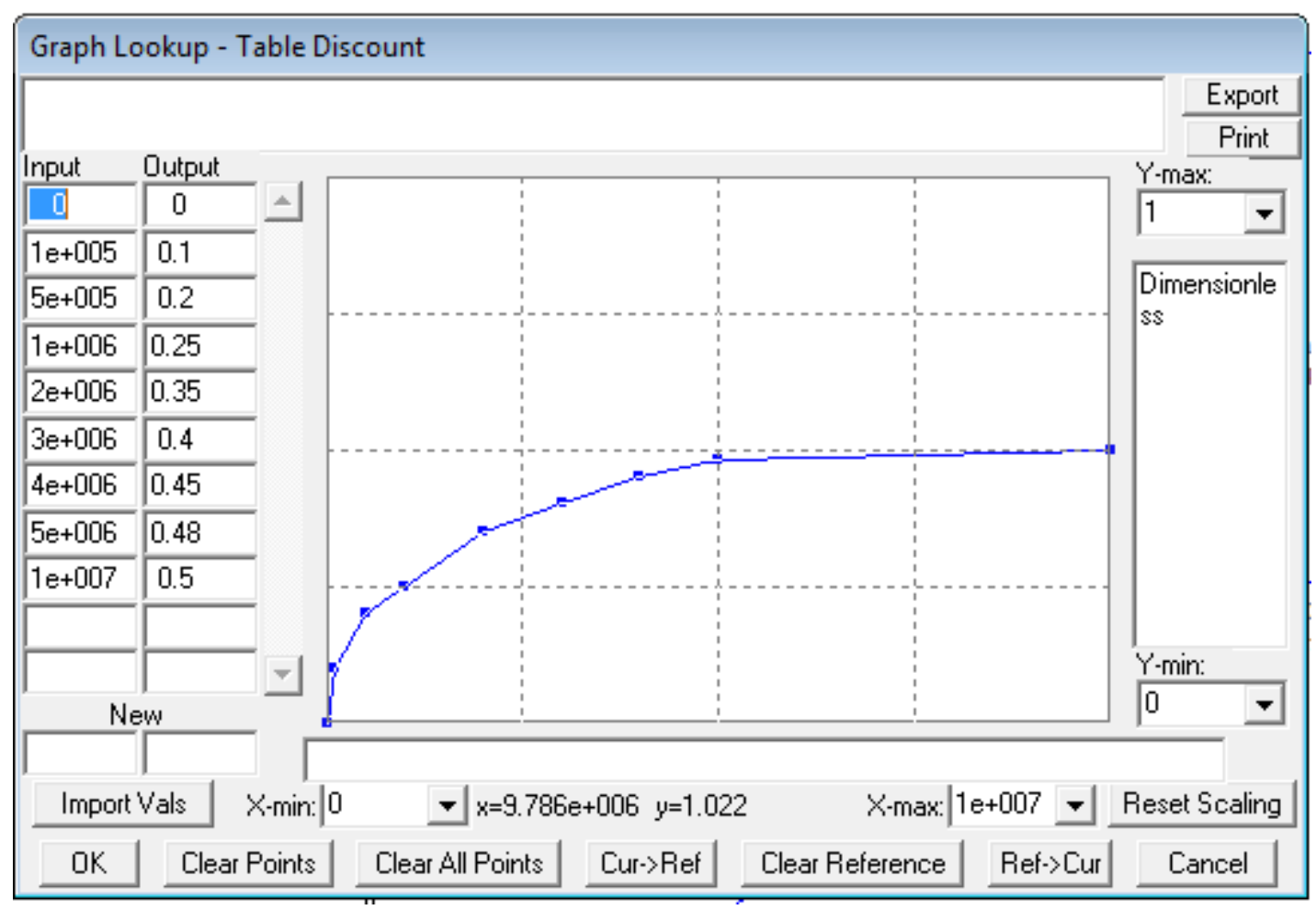

Figure 42. Table for Product Discount $\left(T_{P D}\right)$

Figure 42 shows the nonlinear behavior of the function Table for Product Discount $\left(T_{P D}\right)$, that takes as input the dimensionless quotient of the Local Shipment Rate $\left(R_{L S}\right)$ divided by the Shipment Unit Rate $\left(R_{S U}\right)$. Equivalently, this is the demanded amount normalized by a unitary rate, which constitutes the input of the function that returns a percentage discount applied to the Local Sales Base Price $\left(\pi_{L S}\right)$. In this way, we have

$$
\pi_{L}=\left(1-T_{P D}\left(R_{L S} / R_{S U}\right)\right) \pi_{L S}
$$


Where Local Price $\left(\pi_{L}\right)$ is defined. Identical formulation leads to obtain the Export Price $\left(\pi_{E}\right)$. Now, in conjunction with both local and export shipment rates, the Total Cash Rate $\left(I R_{C}\right)$ is defined as:

$$
I R_{C}=R_{L S .} \pi_{L S}+R_{E S .} \pi_{E S}
$$

Consequently, we can now define the Total Sales $(S)$ as:

$$
(d / d t) S=I R_{C}
$$

With the last equation, all terms of [53] are formulated. In addition, we formulate a disaggregate variable resembling Gross Profit, the Profit Rate $\left(R_{P r}\right)$ from [61], [63], [65] and [67] as:

$$
R_{P r}=I R_{C}-\left(E R_{I}+E R_{M}+E R_{F O}\right)
$$

We end up here the model description, and continue in the following section with the model's parameter estimation and adjustments that antecedes the analysis.

\subsection{Dynamic Model Calibration}

Calibrating SD models is the process of estimating model parameters so that there is an agreement between the simulated and the observed behavior (see Section 3.4 for a detailed description on the subject; see also Barlas (1996) and Oliva (2003) for additional references. 
In this study, model calibration is defined as a partitioned optimization problem (Oliva, 2003) to minimize the estimation risks inherent to the Automated Calibration (AC) used in large models. Since the model structure is inherently independent with autonomous political behavior at each echelon, an independent calibration problem is performed for each echelon. We use unique fitted variables and a number of parameters to calibrate along with their feasible range. We use three years of data collected from the operation of the actual supply chain.

In order to calibrate the model for each echelon, we use the automatic calibration (AC) tool of Vensim ${ }^{\circledR}$, which makes use of an optimization engine based on Powell's (1964) polynomial optimization algorithm. In this algorithm, the successive search directions are conjugate routes aimed at minimizing the quadratic objective function of the model's independent variables (see Section 3.4).

The calibration procedure follows a fixed set of steps that repeats for each calibration. It includes:

1.) Define the calibration reference variable.

2.) List auxiliary variables and their estimated values from actual data, to be used as known input for the calibration problem.

3.) Select the model's parameters to be calibrated, accompanied by a reasonable range of values that could be assumed. After running the calibration, it follows, 
4) Assess the resulting values from the automated calibration.

5.) Graphical and statistical evaluation of the calibration reference variable fit to actual time series.

Table 14. Calibration reference variable per echelon

\begin{tabular}{llll}
\hline & Manufacturer & Distributor & Retailer \\
\hline $\begin{array}{l}\text { Calibration } \\
\text { reference variable }\end{array}$ & $\begin{array}{l}\text { Materials } \\
\text { Inventory }\left(I_{M}\right)\end{array}$ & $\begin{array}{l}\text { Distributor } \\
\text { Inventory }\left(I_{D}\right)\end{array}$ & $\begin{array}{l}\text { Retailer } \\
\left(I_{R}\right)\end{array}$ \\
\hline
\end{tabular}

Table 14 shows the calibration reference variable for each echelon. The calibration reference variable is defined with Materials Inventory $\left(\mathrm{I}_{M}\right)$ as the fitted variable for the manufacturer model. This variable is selected because of the variability present in the historical context of the real system and due to its strategic relevance, as to being the most upstream stock variable of the model and therefore the input of the BWE measure. The reference variable for the distributor is defined in terms of the stock level variable Distributor Inventory $\left(I_{D}\right)$, whereas for the retailer it is the stock level variable Retailer Inventory $\left(I_{R}\right)$.

Table 15 lists the auxiliary variables and their estimated values from actual data, used as known input for the calibration problem. Table 16 shows the model parameters to be calibrated, accompanied by a reasonable range of values. The calibration was performed, hence note in the rightmost column of Table 15 the fitted value obtained after calibration. 
Table 15. Calibration inputs per echelon

\begin{tabular}{|c|c|c|c|}
\hline Manufacturer & Value & Distributor & Value \\
\hline Local Delivery Delay Target (Weeks) & 1 & Distributor Order Lead Time & 1 \\
\hline $\begin{array}{l}\text { Export Delivery Delay Target } \\
\text { (Weeks) }\end{array}$ & 5 & $\begin{array}{l}\text { (Weeks) } \\
\text { Distributor Delivery Delay }\end{array}$ & 1 \\
\hline $\begin{array}{l}\text { Minimum Local Order Lead Time } \\
\text { (Weeks) }\end{array}$ & 1 & $\begin{array}{l}\text { Target (Weeks) } \\
\text { Manufacturer Order Lead Time } \\
\text { (Weeks) }\end{array}$ & 1 \\
\hline $\begin{array}{l}\text { Minimum Material Request Lead } \\
\text { Time (Weeks) }\end{array}$ & 1 & $\begin{array}{l}\text { Distributor In Transit Units } \\
\text { Review Time (Weeks) }\end{array}$ & 1 \\
\hline Payment Time (Weeks) & 1 & & \\
\hline Material Delivery Unit Rate (Weeks) & 1 & & \\
\hline Material Usage per Item & 325 & Retailer & Value \\
\hline $\begin{array}{l}\text { Maximum Production Capacity } \\
\text { (Units/Weeks) }\end{array}$ & 3100000 & $\begin{array}{l}\text { Retailer Minimum Order Lead } \\
\text { Time (Weeks) }\end{array}$ & 1 \\
\hline $\begin{array}{l}\text { Minimum Manufacturing Lead Time } \\
\text { (Weeks) }\end{array}$ & 1 & & \\
\hline
\end{tabular}

Table 16. Parameters to be calibrated, feasible ranges and fitted value per echelon

\begin{tabular}{|c|c|c|c|c|}
\hline Echelon & Parameters to be calibrated & Min & Max & Fitted value \\
\hline \multirow{9}{*}{ 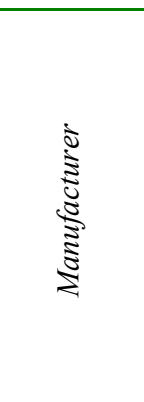 } & Export Inventory Review Time (Weeks) & 1 & 4 & 1.268 \\
\hline & Local Inventory Review Time (Weeks) & 1 & 4 & 1.591 \\
\hline & Local Safety Stock Coverage (Weeks) & 1 & 6 & 4.214 \\
\hline & Materials Average Review Time (Weeks) & 1 & 8 & 4.000 \\
\hline & Materials Inventory Review Time (Weeks) & 1 & 4 & 1.570 \\
\hline & Material Safety Stock Coverage (Weeks) & 1 & 6 & 3.820 \\
\hline & Minimum Export Order Lead Time (Weeks) & 1 & 2 & 1.500 \\
\hline & Perceived Supplier Lead Time (Weeks) & 2 & 16 & 12.000 \\
\hline & WIP Review Time (Weeks) & 1 & 4 & 1.000 \\
\hline \multirow{4}{*}{ 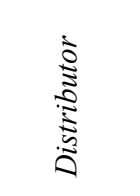 } & Distributor Inventory Review Time (Weeks) & 1 & 4 & 1.400 \\
\hline & Distributor Forecast Review Time (Weeks) & 1 & 6 & 4.000 \\
\hline & Distributor Safety Stock (Weeks) & 1 & 4 & 3.000 \\
\hline & Perceived Manufacturer Delay (Weeks) & 1 & 3 & 1.900 \\
\hline \multirow{4}{*}{$\frac{\bar{\Xi}}{\frac{\tilde{\Xi}}{\tilde{Z}}}$} & Retailer Review Time (Weeks) & 1 & 4 & 2.400 \\
\hline & Retailer Forecast Review Time (Weeks) & 1 & 4 & 2.000 \\
\hline & Retailer Safety Stock (Weeks) & 1 & 4 & 2.700 \\
\hline & Perceived Distributor Delay (Weeks) & 1 & 3 & 1.000 \\
\hline
\end{tabular}


We now analyze the fit for each echelon. We systematically use a graphical appraisal of the fit between simulated and actual series, and then perform a statistical analysis by means of traditional $\mathrm{r} 2$ statistic, also using Thiel's inequality statistics (Theil, 1966) to distinguish the sources of the model's unexplained behavior. The reader is asked to review Step 11 in Section 3.2.2.1 for an explanation of Thiel's inequality statistics interpretation (see also Sterman (1984)).

\subsubsection{Calibration for the manufacturer echelon}

Figure 43 shows the calibration results for Materials Inventory $\left(I_{M}\right)$. The time-series plot of Material Inventory shows that model captures the overall trend of inventory changes but does not capture the shorter-term variations. The model is missing the elements that lead to the short-term behavior. Consequently, the model is only useful for analysis of trends over a period of weeks and cannot be reliably used to analyze week-to-week changes in inventory.

Figure 44 shows the residuals plot analysis, showing an evenly distributed error around zero with no evidence of monotonic tendencies, although exhibiting a swinging pattern due to a certain delay in capturing a swinging pattern. This supports the assumption of a small error pattern that is due to imperfect covariation, which is fine since the fit excludes systematic errors that would otherwise suggest the model does not capture the intended behavior. 


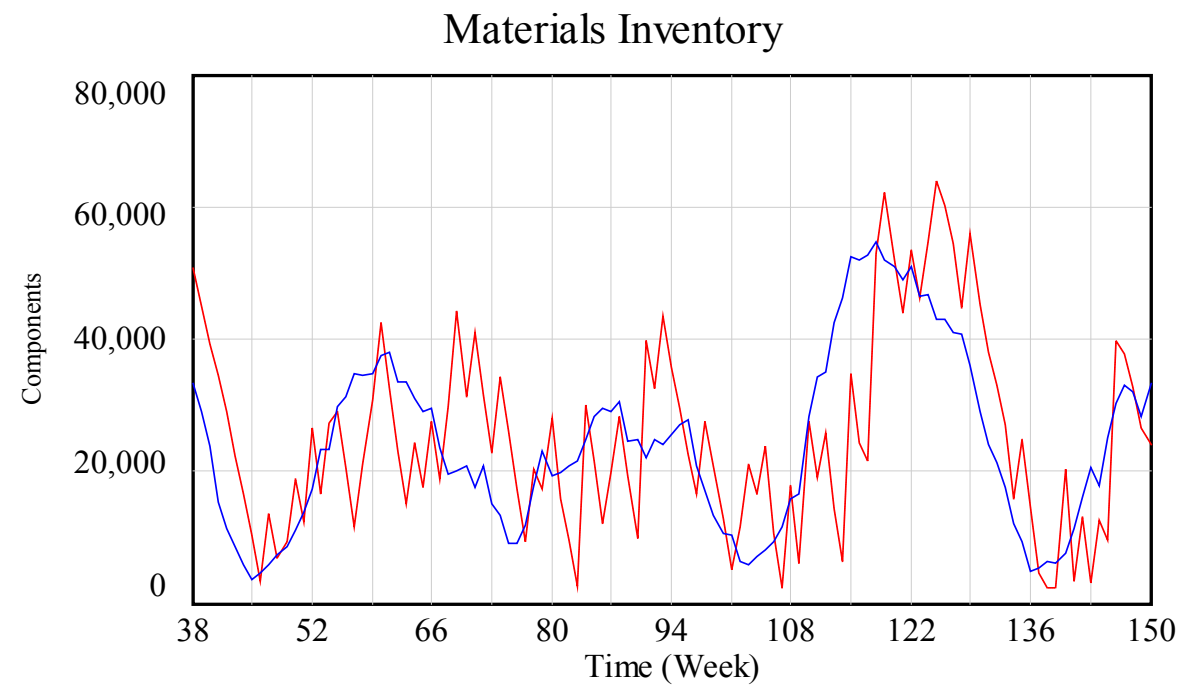

Materials Inventory : Manufacturer Simulation

Materials Inventory : Manufacturer Reference

Figure 43. Materials Inventory $\left(I_{M}\right)$ graphical fit and Manufacturer's calibrated parameters

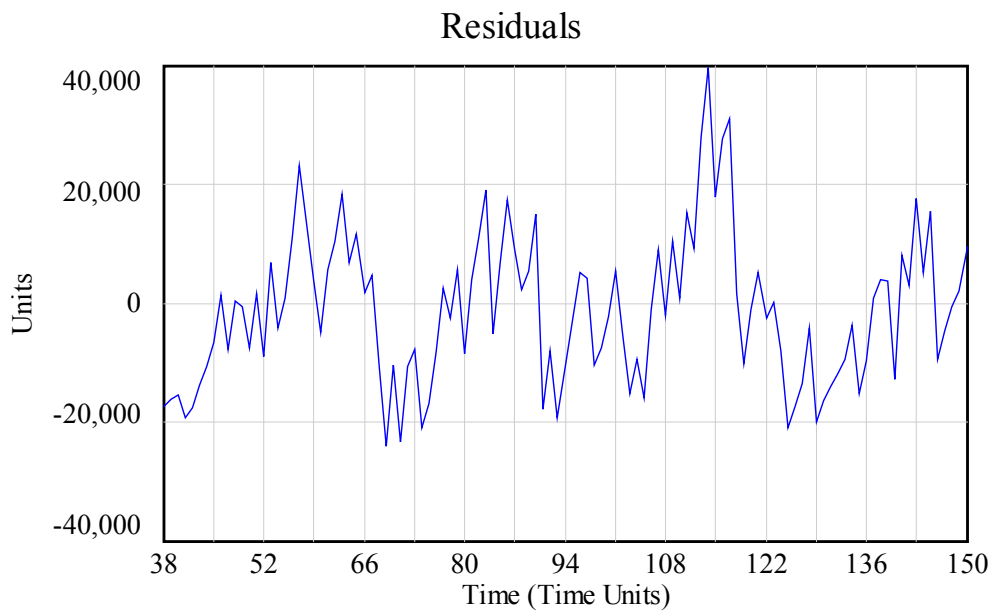

Analysis of Fit for

Materials Inventory $\left(I_{M}\right)$

R-squared statistic $\mathrm{R}^{2}=0,61$

Theil's Inequality Statistics $\operatorname{Bias}\left(\mathrm{U}^{\mathrm{m}}\right)=0,01$ Variation $\left(\mathrm{U}^{\mathrm{s}}\right)=0,01$ Covariation $\left(\mathrm{U}^{\mathrm{c}}\right)=0,97$

Residuals : Manufacturer Residuals

Figure 44. Manufacturer's residuals plot and analysis of fit for Materials Inventory $\left(I_{M}\right)$ 
For the analysis of the degree of adjustment of Materials Inventory $\left(I_{M}\right)$, we use both the traditional r-squared $\left(R^{2}\right)$ statistic and the Thiel's inequality statistics (Theil, 1966) shown in Figure 44. The r-squared value is 0.61 , which indicates a medium fit for the data or that $61 \%$ of the variation can be explained by the model While traditional error statistics provides a simple way to gauge the magnitude of total error between simulated and actual series, the Theil inequality statistics are well suited for system dynamics models because they allow the analyst to separate the fraction of error due to noise from the error due to systematic variances between the model and reality (Sterman, 1984). Theil's inequality statistics is less than $1 \%$, which indicates a good fit for the mean and variance of the series.

Most of the error, $97 \%$, is on Covariation, which indicates how closely correlated are the series. This behavior is sign of a good fit, expressing that most of the difference is due to different randomness of the series.

The same statistical goodness of fit analysis is applied to the output series of the stock variables Total Production Rate $\left(R_{T P}\right)$. In this way we verify whether the results obtained from the initial calibration exercise of Materials Inventory $\left(I_{M}\right)$ are consistent with the results of a sample of different variables of the partitioned model.

Figure 45 shows the fit for the Total Production Rate $\left(R_{T P}\right)$, which aggregates Production Rate For Local Orders $\left(R_{L P}\right)$ and the Production Rate For Export Orders $\left(R_{E P}\right)$. Overall, the simulation is capable of following the actual series but misses extreme points such as in weeks 53, 62 and 94 . 


\section{Total Production}

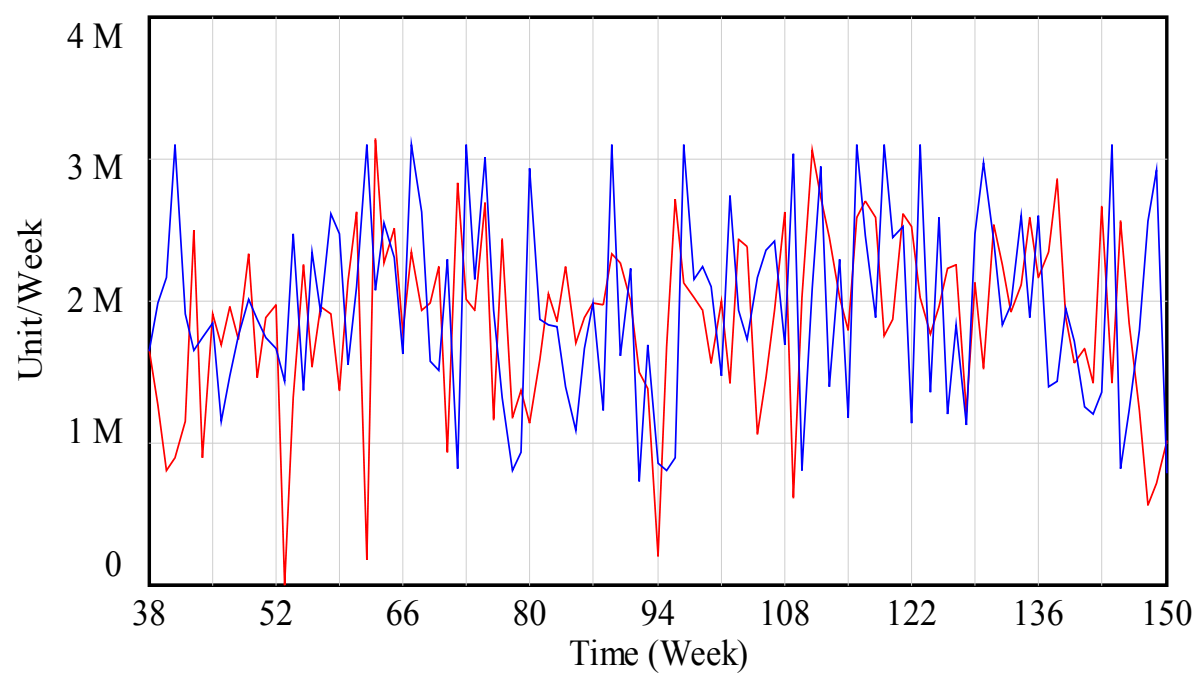

Total Production : Manufacturer Simulation

Total Production : Manufacturer Reference

Figure 45. Analysis of Fit for Total Production Rate $\left(R_{T P}\right)$

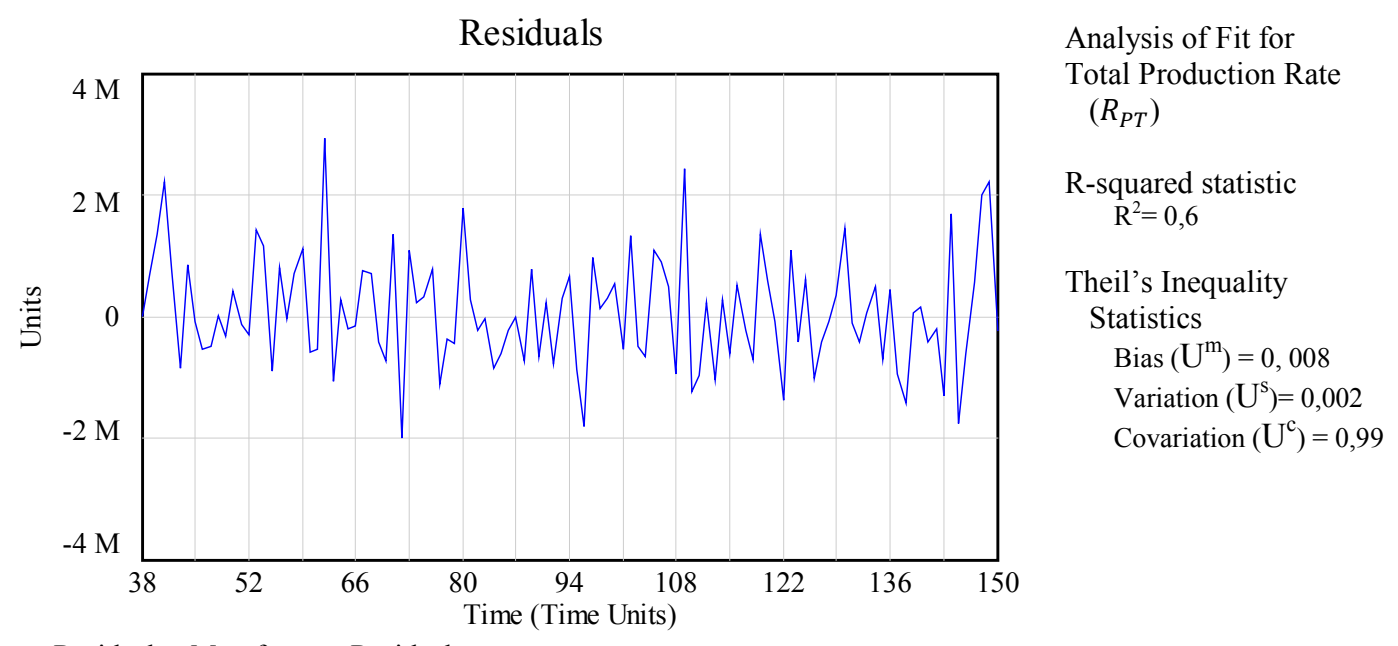

Residuals : Manufacturer Residuals

Figure 46. Manufacturer's residuals plot and analysis of fit for Total Production Rate $\left(R_{P T}\right)$ 
The calibration reached is acceptable and the numerical results supports this claim, since the r-squared measure accounts for $60 \%$ of variability explained and the Theil's displacement for the mean and variance are small, therefore leaving $99 \%$ of residual error for the imperfect covariation. In addition, the residuals in Figure 46 appear to be normally distributed and lack any visible trend.

\subsubsection{Calibration for the distributor echelon}

Figure 47 shows Distributor Inventory $\left(I_{D}\right)$ fit. The simulated series are able to capture the actual pattern although missing short-term variation that leads to an initial lag until week 30 and then stock-outs in particular weeks 10, 24 and 53.

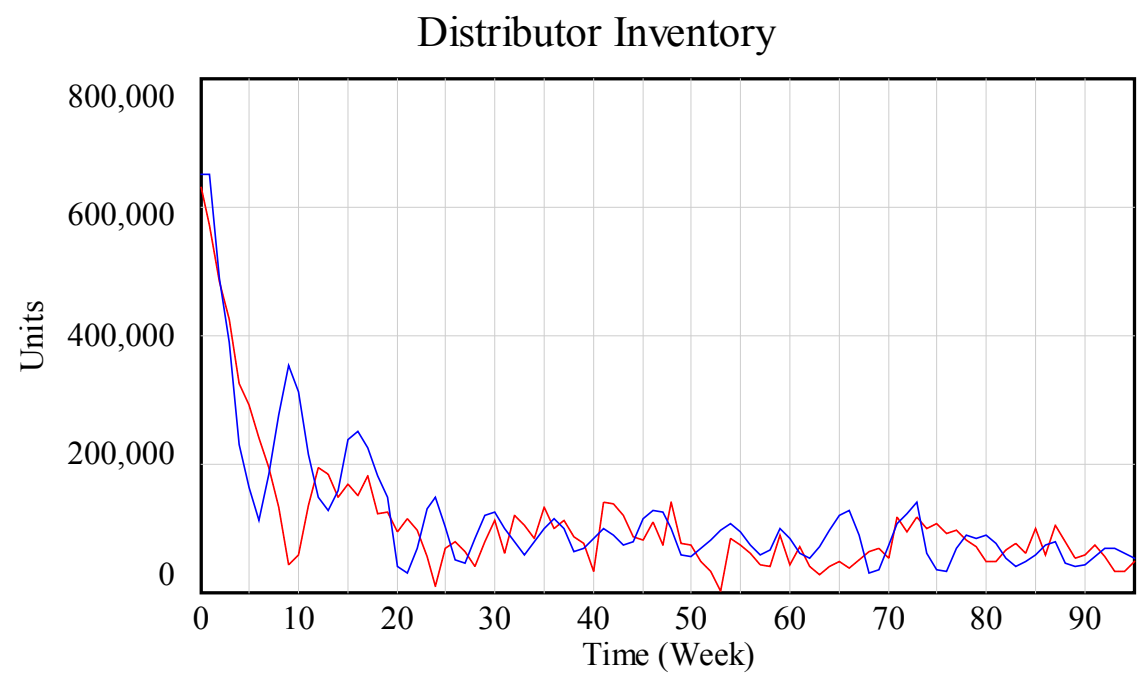

Distributor Inventory : Distributor Simulation Distributor Inventory : Distributor Reference

Figure 47. Analysis of Fit for Distributor Inventory $\left(I_{D}\right)$ 
Figure 48 shows the residuals plot analysis, with an evenly distributed error around the horizontal axis lacking any visible trend.
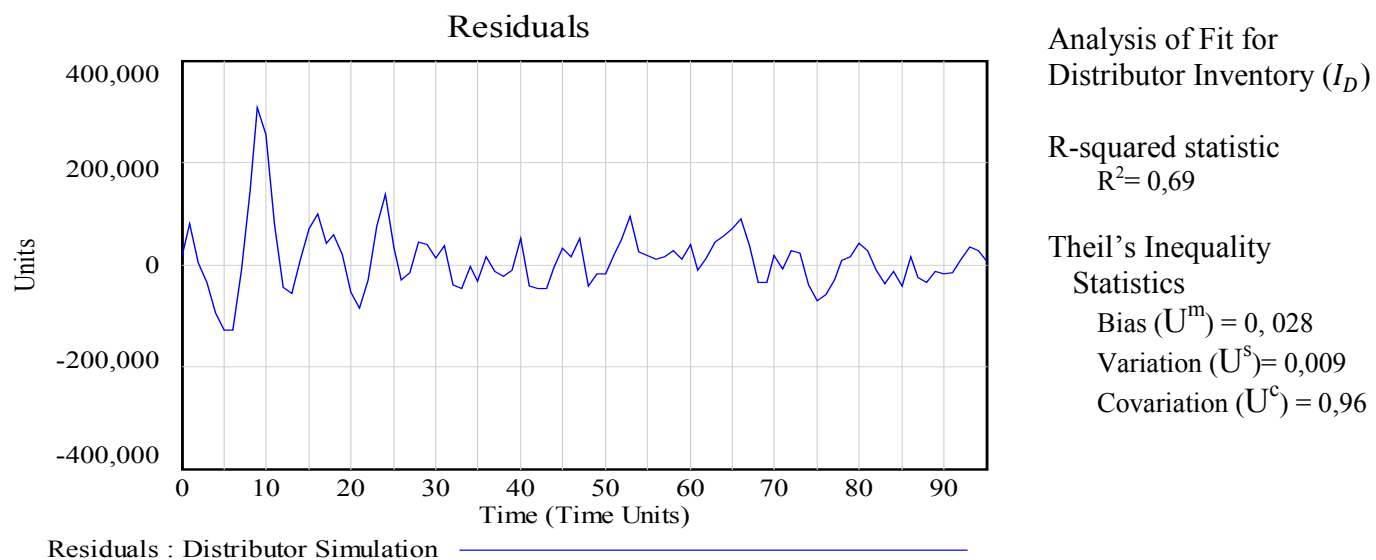

Figure 48. Distributor's residuals plot and analysis of fit for Distributor Inventory $\left(I_{D}\right)$

The degree of adjustment reached is good. The r-squared measure account for $69 \%$ of explained variability; the Theil's displacement for the mean is about $3 \%$ given the initial lagging of the simulation also appreciable in the residuals plot, and variance is less than $1 \%$, leaving $96 \%$ of residual error for the imperfect covariation. In addition, the residuals pattern in Figure 46 seems normal and lacking visible trends.

\subsubsection{Calibration for the retailer echelon}

Figure 49 shows Retailer Inventory $\left(I_{R}\right)$ fit. The simulated series follow the overall rising trend with an initial underestimation lasting through week 80 and then again loosely matching after week 129 . Other than that, the model captures peaks and troughs from the actual series. 


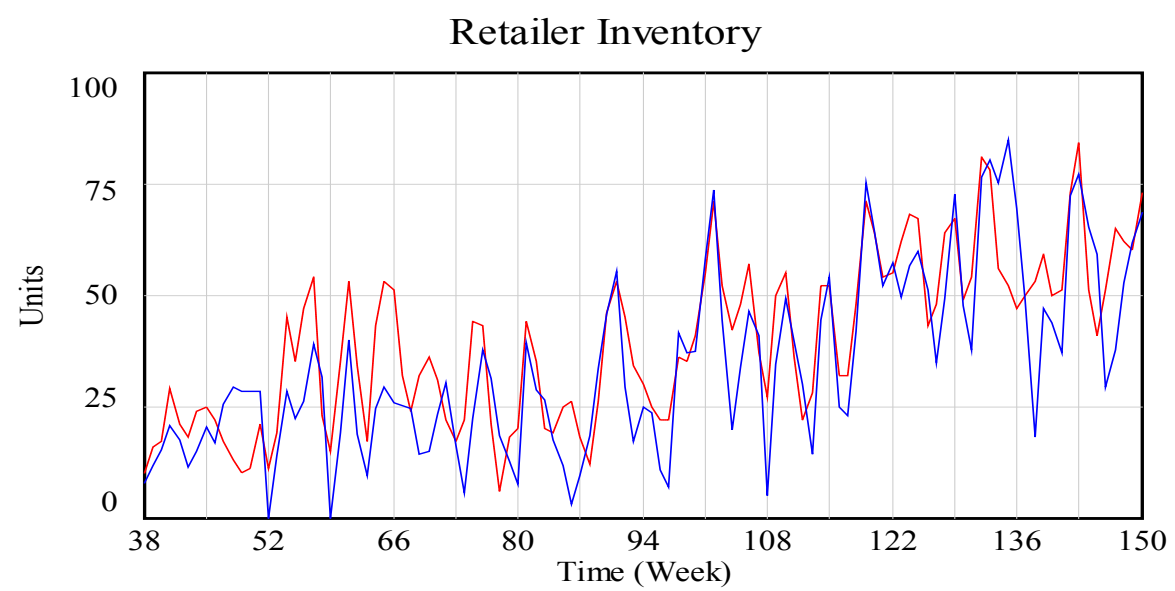

Retailer Inventory : Retailer Simulation

Retailer Inventory : Retailer Reference

Figure 49. Analysis of Fit for Retailer Inventory $\left(I_{R}\right)$

Figure 50 shows the residuals plot analysis, without abnormal patterns or tendencies.

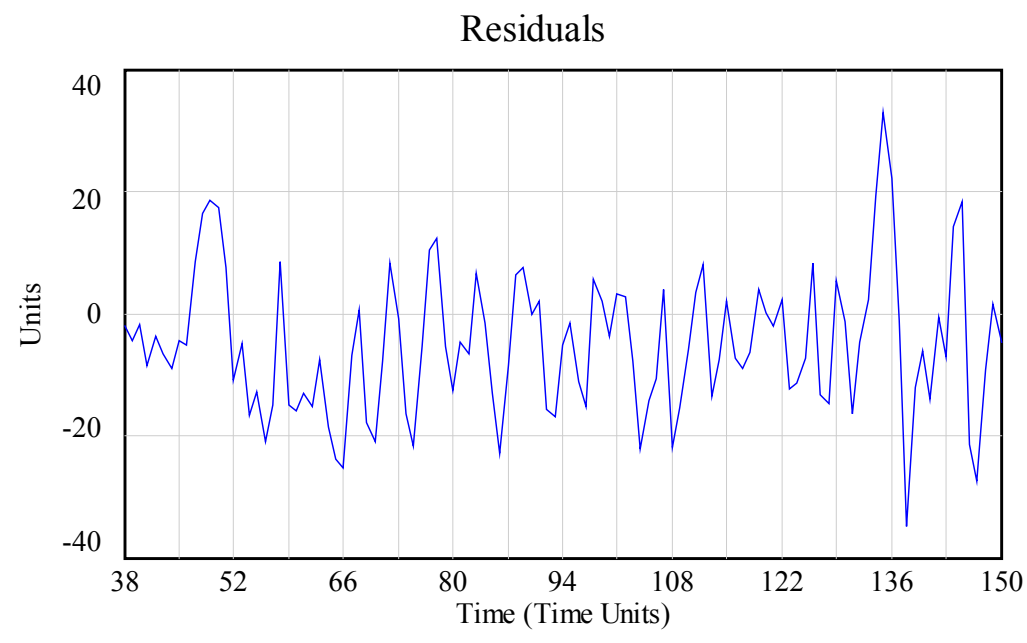

Analysis of Fit for

Retailer Inventory $\left(I_{R}\right)$

R-squared statistic $\mathrm{R}^{2}=0,67$

Theil's Inequality Statistics

$\operatorname{Bias}\left(\mathrm{U}^{\mathrm{m}}\right)=0,16$

Variation $\left(\mathrm{U}^{\mathrm{s}}\right)=0,023$

Covariation $\left(\mathrm{U}^{\mathrm{c}}\right)=0,82$

Residuals : Retailer Simulation

Figure 50. Retailer's residuals plot and analysis of fit for Retailer Inventory $\left(I_{R}\right)$ 
The degree of adjustment as in the previous cases is adequate, considering $67 \%$ of explained variability indicated by the r-squared; the Theil's displacement for the mean is $16 \%$ indicating an imperfect match; yet, variance is less than $3 \%$ showing a close variance resemblance. Thus, covariation accounts for the $82 \%$ of residual error.

\subsection{Dynamic Model Validation}

This section describes the tests and procedures performed to build confidence in the usefulness of the model for its intended purpose. This work has already started in the previous section, and the present and coming sections will document additional tests. Table 17 provides a summary guide of the validation assessment implemented in the study, out of a comprehensive list presented in Sterman (2000). The last column comments on its present implementation.

Table 17. Tests for assessment implemented in the model

\begin{tabular}{|c|c|c|}
\hline Test & Purpose of Test & Implementation in the study \\
\hline $\begin{array}{l}\text { 1. Boundary } \\
\text { Adequacy }\end{array}$ & $\begin{array}{l}\text { Are the important concepts for } \\
\text { addressing the problem endogenous } \\
\text { to the model? } \\
\text { Does the behavior of the model } \\
\text { change significantly when boundary } \\
\text { assumptions are relaxed? } \\
\text { Do the policy recommendations } \\
\text { change when the model boundary is } \\
\text { extended? }\end{array}$ & $\begin{array}{l}\text { As for boundary adequacy and logic verification we } \\
\text { used model boundary charts, causal diagrams } \\
\text { evolving from the Dynamic Hypothesis to the } \\
\text { detailed model, and direct inspection of model } \\
\text { equations. } \\
\text { We check model boundaries, and consequently it } \\
\text { was necessary to extend the model scope to } \\
\text { incorporate the exports market and the cash flow } \\
\text { constraints. } \\
\text { We used interviews, workshops to solicit expert } \\
\text { opinion, archival materials, review of literature and } \\
\text { direct inspection/participation in system processes. }\end{array}$ \\
\hline
\end{tabular}




\begin{tabular}{|c|c|c|}
\hline Test & Purpose of Test & Implementation in the study \\
\hline $\begin{array}{l}\text { 2. Structure } \\
\text { Assessment }\end{array}$ & $\begin{array}{l}\text { Is the model structure consistent } \\
\text { with relevant descriptive knowledge } \\
\text { of the system? } \\
\text { Is the level of aggregation } \\
\text { appropriate? } \\
\text { Does the model conform to basic } \\
\text { physical laws such as conservation } \\
\text { laws? } \\
\text { Do the decision rules capture the } \\
\text { behavior of the actors in the system? }\end{array}$ & $\begin{array}{l}\text { We used direct inspection of model behavior for } \\
\text { checking known responses against usual scenarios. } \\
\text { We conducted partial model tests of the intended } \\
\text { rationality of decision rules with experts from the } \\
\text { supply chain under study. } \\
\text { Iteratively, we disaggregate structures with suspect } \\
\text { response, then repeat calibration and sensitivity } \\
\text { analysis. } \\
\text { All calibrated parameters were checked for not } \\
\text { falling at extreme points of their calibration range, } \\
\text { hence indicating model structure not forced as to } \\
\text { reproduce expected behavior. }\end{array}$ \\
\hline $\begin{array}{l}\text { 3. Dimensional } \\
\text { Consistency }\end{array}$ & $\begin{array}{l}\text { Is each equation dimensionally } \\
\text { consistent without the use of } \\
\text { parameters having no real world } \\
\text { meaning? }\end{array}$ & $\begin{array}{l}\text { We used dimensional analysis available in Vensim } \\
\text { ( })\end{array}$ \\
\hline $\begin{array}{l}\text { 4. Parameter } \\
\text { Assessment }\end{array}$ & $\begin{array}{l}\text { Are the parameter values consistent } \\
\text { with relevant descriptive and } \\
\text { numerical knowledge of the system? } \\
\text { Do all parameters have real world } \\
\text { counterparts? }\end{array}$ & $\begin{array}{l}\text { We used Vensim's optimization engine to calibrate } \\
\text { parameters. The overall model was partitioned for } \\
\text { performing partial model tests to independently } \\
\text { calibrate each echelon. } \\
\text { If the result of the calibration fell at one of the limits } \\
\text { specified for the search space, the parameter was } \\
\text { double-checked. } \\
\text { Calibrated results were validated with experts } \\
\text { within each company. We exposed results and used } \\
\text { judgmental methods based on interviews, archival } \\
\text { materials, and direct experience. }\end{array}$ \\
\hline
\end{tabular}

Does each equation make sense even when its inputs take on

5. Extreme Conditions extreme values?

Does the model respond plausibly when subjected to extreme policies, shocks, and parameters?
We implemented Test response to extreme values of each input, included in this section.

The model was exposed to large shocks and extreme conditions.
Does the model reproduce the behavior of interest in the system (qualitatively and quantitatively)? Does it endogenously generate the symptoms of difficulty motivating

6. Behavior Reproduction the study?

Does the model generate the various modes of behavior observed in the real system?

Do the frequencies and phase relationships among the variables match the data?
We used both graphical analysis and statistical assessment of the model fit (see Section 5.2) for a selection of strategic outputs of the model, in particular those associated with BWE measure. We computed statistical measures of correspondence between model and data: $\mathrm{R}^{2}$ and Theil's Inequality statistics.

We compared model outputs and data qualitatively, including modes of behavior, shape of variables, asymmetries, relative amplitudes and phasing. In addition, examined response of the model to test inputs and shocks. 


\begin{tabular}{|c|c|c|}
\hline Test & Purpose of Test & Implementation in the study \\
\hline $\begin{array}{l}\text { 7. Sensitivity } \\
\text { Analysis }\end{array}$ & $\begin{array}{l}\text { Numerical sensitivity: Do the } \\
\text { numerical values change } \\
\text { significantly... } \\
\text { Behavioral sensitivity: Do the } \\
\text { modes of behavior generated by the } \\
\text { model change significantly... } \\
\text { Policy sensitivity: Do the policy } \\
\text { implications change significantly.. . } \\
\text {... when assumptions about } \\
\text { parameters, boundary, and } \\
\text { aggregation are varied over the } \\
\text { plausible range of uncertainty? }\end{array}$ & $\begin{array}{l}\text { Univariate and multivariate sensitivity analysis was } \\
\text { performed in the model. } \\
\text { Model boundary changes were implemented as } \\
\text { listed in (1) and (2) above. } \\
\text { We develop local and systemic measures for BWE, } \\
\text { and revenue and cost emulation for the } \\
\text { manufacturer. Several optimization scenarios were } \\
\text { run in order to find the best parameters and policies. } \\
\text { We implemented advanced sensitivity analysis } \\
\text { techniques, such as Data Screening Analysis aimed } \\
\text { to explore structural changes that would lead to } \\
\text { optimal results for BWE and costs (univariate and } \\
\text { multivariate optimization) }\end{array}$ \\
\hline
\end{tabular}

Source: adapted from (Sterman, 2000)

\subsubsection{Extreme tests}

The extreme test scenarios are simulations of high impact but low probability of occurrence for the system. The effects in the actual system are predictable and therefore directly comparable with the results of the model. For the sake of increasing the confidence in the model, it should be able to consistently reproduce the expected behavior in the face of the extreme situation.

The extreme tests are conducted in the manufacturer echelon (MedLab) because both the distributor and retailer echelons have fundamentally the same structure as the manufacturer's. Consequently, we only need to do an extreme test for one echelon to help validate the overall model.

\section{Extreme test $\quad \# 1$ - Variable Data Modification}

Test: Set Incoming Export Orders $\left(D_{E}\right)=0$ Units / Week 

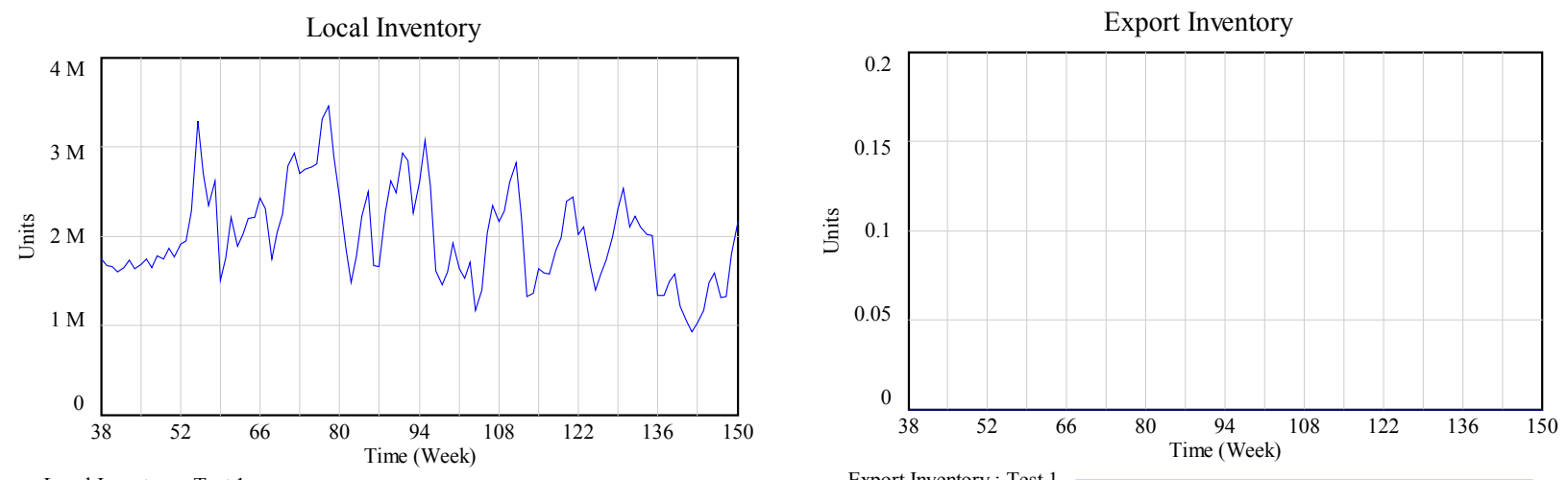

Local Inventory : Test 1

Export Inventory : Test 1
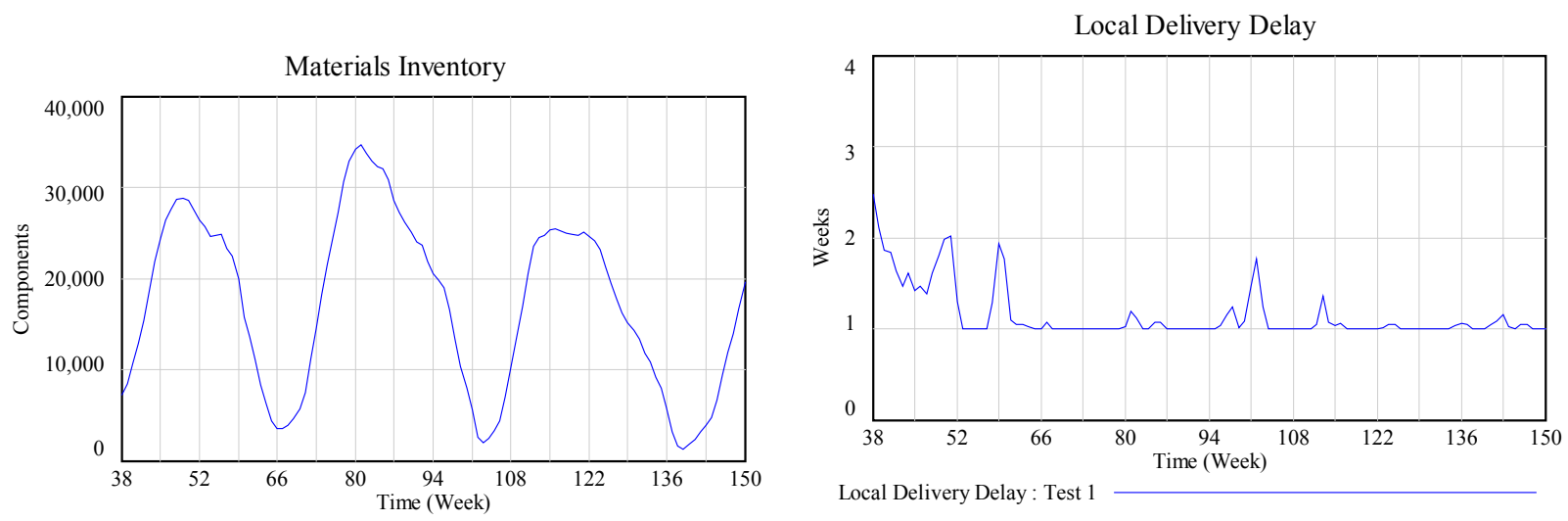

Materials Inventory : Test 1

Local Delivery Delay : Test 1

Figure 51. Results for Extreme Test \#1

The objective of this test is to assess the hypothetical case in which there are no export orders and local orders remains unchanged. The expected result is for MedLab to be able to deliver almost $100 \%$ of its orders within a week for the local market. It is of interest to observe the behavior of Materials Inventory, Local Inventory, Inventory Export and Local Delivery Delay. 
Local inventory fluctuates in a growing series of 1.5 to 3.5 millions, conserving the desired safety stock without any stockouts during the simulation. Export Inventory is constant and equal to zero throughout the simulation because it obeys a make-to-order policy, without the stimulus of demand. Materials Inventory shows cyclic behavior due to large batch requirements from production for the domestic market. Local Delivery Delay varies between 1 and 2 weeks, yet for the most part of the simulation it is in 1 week, indicating that the company would be able to deliver orders within a week. Hence, the model complies with the expected response.

\section{Extreme test \#2-Variable Data Modification}

$\underline{\text { Test: }}$ Set Incoming Export Orders $\left(D_{E}\right)=0$ Units / Week

$$
\text { Incoming Export Orders }\left(D_{E}\right)=0 \text { Units / Week }
$$

The objective of this test is to check the model response when there are neither export nor local orders in demand. The expected result is for MedLab to have no responses at all, with all the stock variables at constant zero level. Figure 52 shows the main stock variables of the model, all in zero level, as predicted. 


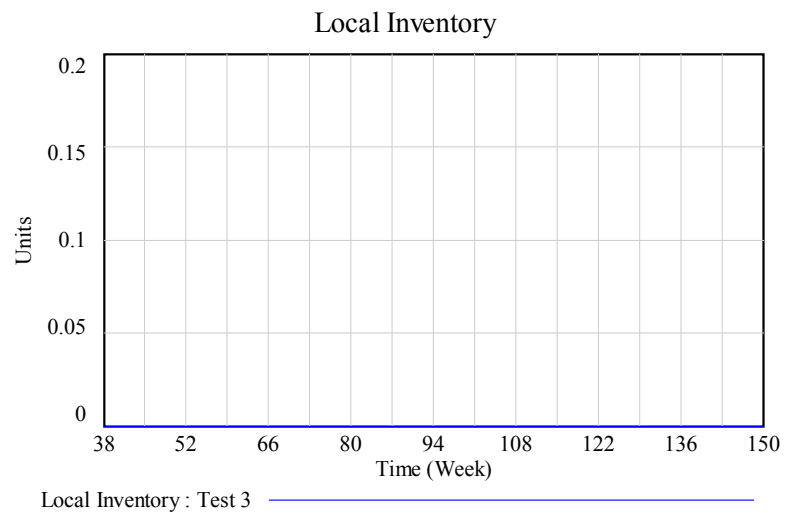

Local Inventory: Test 3

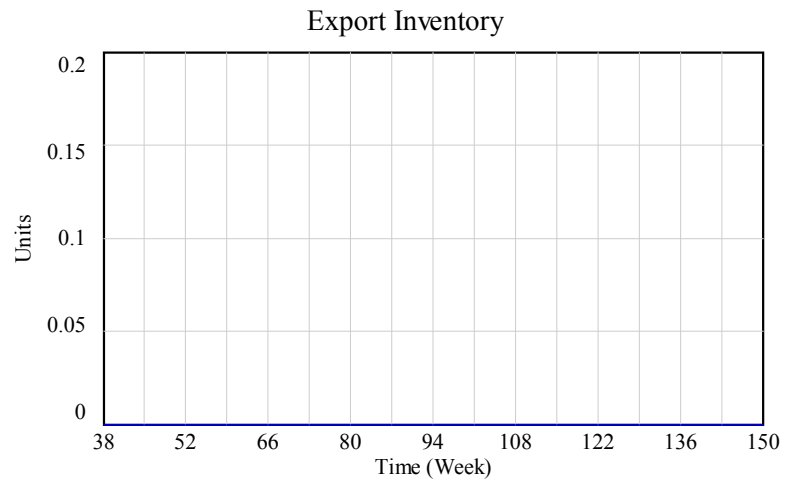

Export Inventory : Test 3

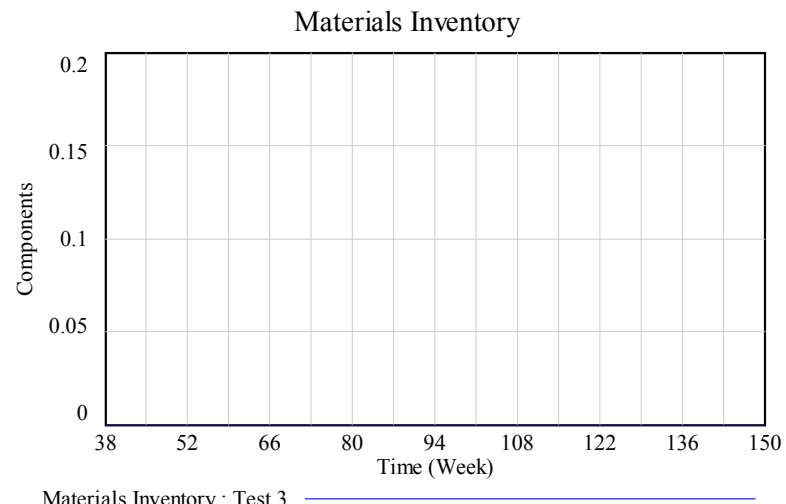

Figure 52. Results for Extreme Test \#2

\subsection{Analysis of results}

We divide the analyses into two main sections: Perturbational, referring to the model performance assessment in its present calibrated settings and the exploration of improved settings by means of custom SD methods exploring the balanced model responses to single shock inputs. Perturbational analysis also includes a look on partial economical results obtained from the manufacturer's model reflecting economical performance. 
Next, the Optimization analysis explores advanced techniques and algorithms devised to infer improved settings and assess its benefits. Computerized analysis introduces a combination of sensitivity analysis by means of design of experiments (DOE) used to statistically screen input parameters, followed by optimization in order to efficiently explore the solution space so as to point out to best possible settings.

\subsubsection{Perturbational Analyses}

\subsubsection{Profit and Loss Analysis for MedLab}

All economic results presented in this document are expressed in Colombian pesos $(\$ 1 \mathrm{USD} \approx \$ 1,800 \mathrm{COP}$ as of April/11). The present section presents estimates for the manufacturer's operating costs and sales income for the model logic introduced in Section 5.1.6. We disregard cost components such as administrative and staffing costs, financial costs, depreciation and fixed operational costs. The model makes available a useful estimate of profit.

Due to the fact that we did not get access to financial data, a goodness of fit analysis is not possible. However, these estimates were presented to MedLab's managers and in their opinion were found useful while not particularly accurate for the cost estimation. Therefore, we introduce financial results estimation from the model as a complementary measure that comes with an accuracy caveat for not literal results interpretation. 


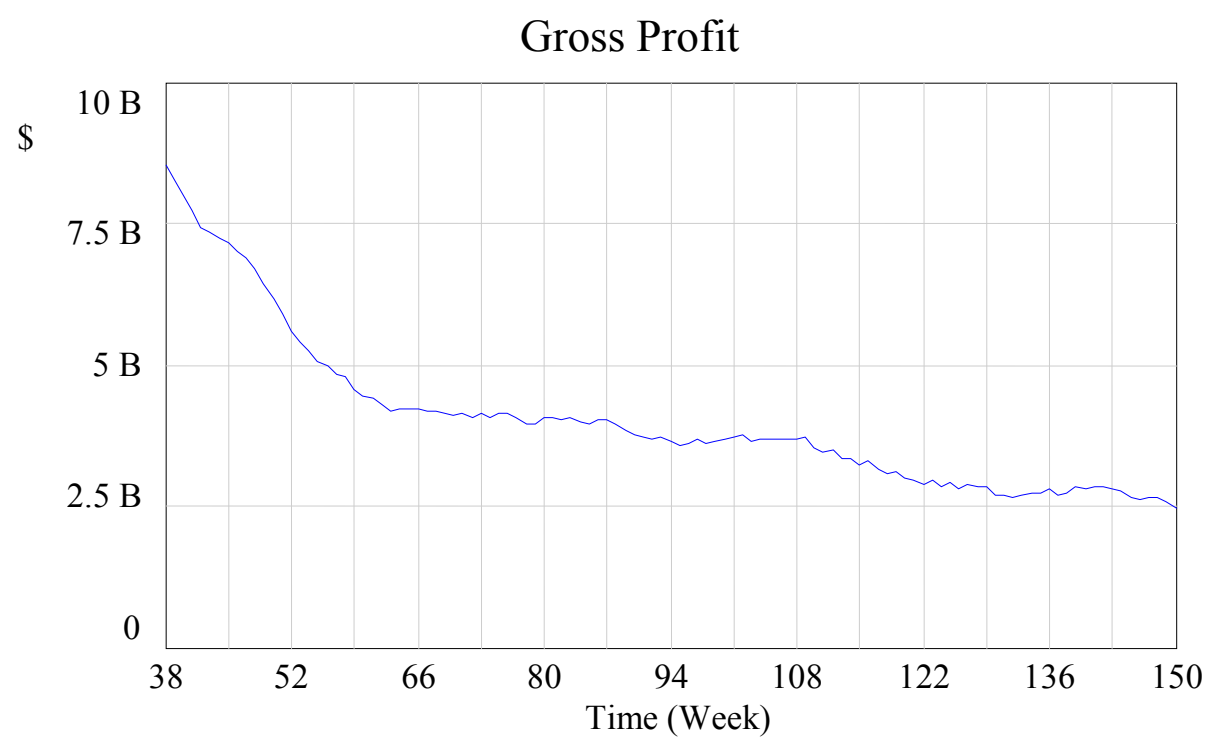

Total Profit : Manufacturer Simulation

Figure 53. Calibrated results for Gross Profit $(\mathrm{Pr})$

Figure 53 shows the Gross Profit $(P r)$ results from the calibrated model, which is the difference of sales income minus manufacturing costs. The results show a trend that decreases its slope by the end of the observed period. The downtrend is explained by the market loss to Asian competitors fueled by underperformance in lead times which especially affects the local market segment. Although the market loss has o stabilized lately, there has been recently in place an offshoring policy that has switched to a large extent material sourcing to China, hurting the cash flow cycle in exchange for lower cost in materials. This is due to the twofold effect of advanced downpayments in cash required from Chinese suppliers, and the larger investment in inventory pipeline because of longer lead times. 
Alternatively, Figure 54 shows the disaggregate weekly variation of profit registered by Profit Rate $\left(R_{P r}\right)$, which is represented by the continuous line. It follows that descents below the horizontal axis indicates periods with losses, and vice versa. Disregarding unstable results before week 60 , the conclusion is that the operation under study is not always profitable due to the proximity between sales income and operating costs.

Profit Rate $\left(R_{P r}\right)$ is composed of income and expenditure rates, and is shown in Figure 54. Income Rate exhibits large weekly variance that determines positive or negative profit margins. Notably, losses are the consequence of large sale drops caused mostly by dearth of exports. Notice here the BWE influence in financial results.

Inventory Cost Rate and Processing Cost Rate are relatively less variant than Materials Cost Rate, which shows a cyclical expanding pattern peaking at weeks 50, 77, 109 and 143 that generates negative profit. Most of the variance is due to the ordered material amounts from MedLab. Again, note here the BWE pressure on costs. 


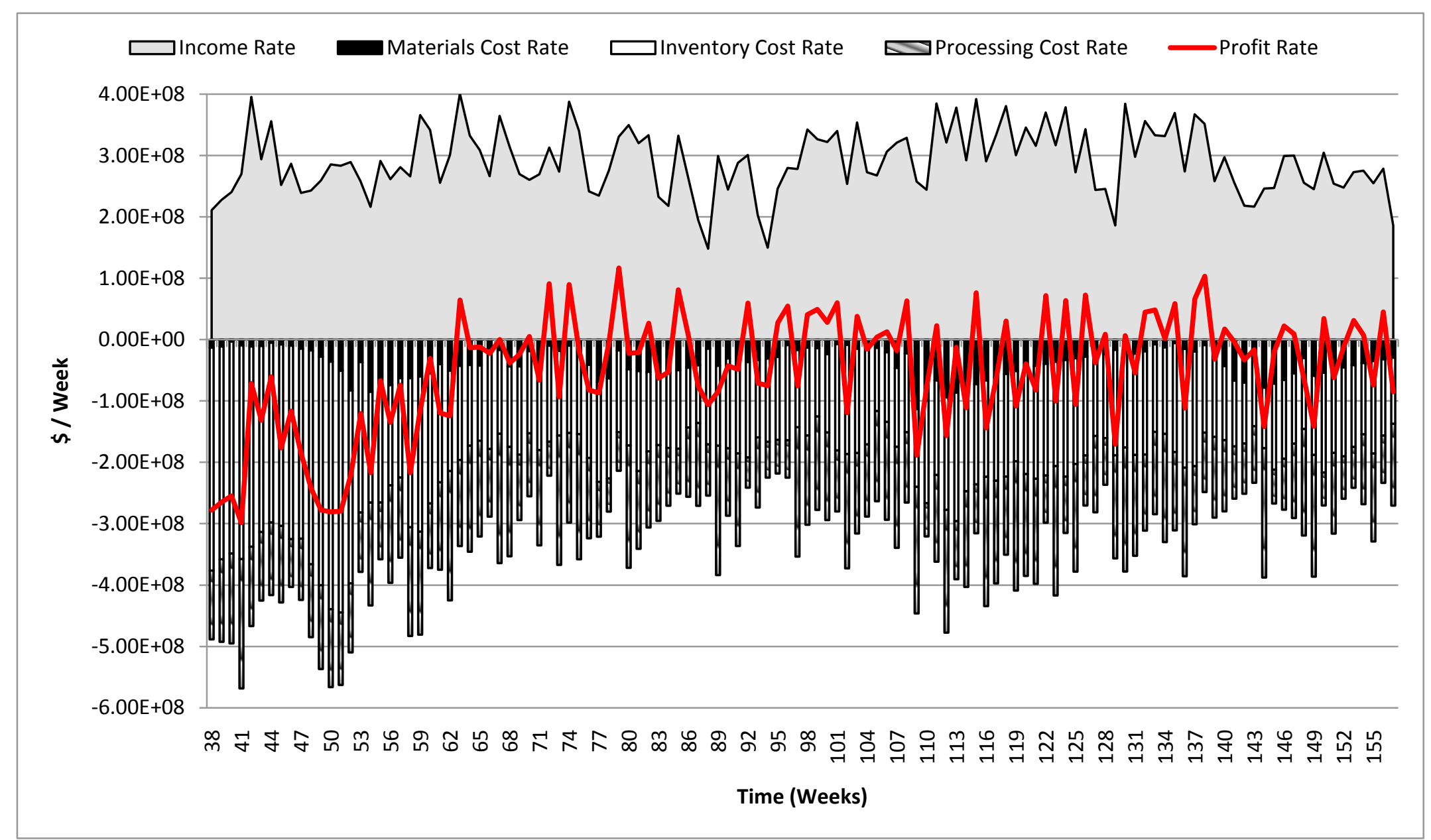

Figure 54. Calibrated results for Profit Rate $\left(R_{P r}\right)$ and components 
In summary, we have estimated the economical results from the observed system by extrapolating them from the model. Although these estimates have not been through a formal validation, it is possible to obtain some insights from the estimates that tie the BWE with the firm's finances. Given the fundamental importance of economical results in most companies' decision-making process, we will have as reference this cost estimation in coming analysis.

\subsubsection{Equilibrium Analysis}

The purpose is to determine how and where bullwhip emerges, that is, to be able to trace the supply system where the demand signal distortion occurs due to an input demand that comes from an exogenous party. What we do in this type of testing is to expose the model to a shock input and infer from the model where originates the distortion.

Equilibrium analysis requires a controlled experimentation process. In this way, the experimenter removes all uncontrollable and noise factors, and introduces an artificial input signal to the model so as to observe the sole net effect of the stimulus. Yet, for a clear-cut observation, it is necessary to initialize the model in a balanced equilibrium. This means that, given a flat input signal, all stocks in the system remain unchanged as a consequence of their inflows and outflows being equal. Ideally, in the absence of any bullwhip effect the Material Delivery Rate follows the original demand. Consequently, the comparison of the output demand with the input demand is a measure of the bullwhip effect. 
Table 18. Balanced equilibrium SC model conditions

\begin{tabular}{|c|c|c|c|}
\hline & Manufacturer & Distributor & Retailer \\
\hline 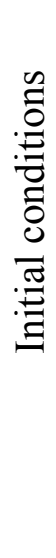 & $\begin{array}{c}B_{E}\left(t_{0}\right)=R_{E O} * \delta_{E D}^{*} \\
B_{L}\left(t_{0}\right)=R_{L O} * \delta_{L D}^{*} \\
F_{L}\left(t_{0}\right)=R_{L O} \\
F_{M}\left(t_{0}\right)=R_{M U} \\
I_{E}\left(t_{0}\right)=I_{E}^{*} \\
I_{L}\left(t_{0}\right)=I_{L}^{*} \\
I_{W I P}\left(t_{0}\right)=I_{W I P}^{*} \\
I_{M}\left(t_{0}\right)=I_{M}^{*}\end{array}$ & $\begin{array}{c}I_{D}\left(t_{0}\right)=I_{D}^{*} \\
B_{D}\left(t_{0}\right)=R_{D O} * \delta_{D D}^{*} \\
F_{D}\left(t_{0}\right)=R_{D O} \\
I_{D I T}\left(t_{0}\right)=I_{D I T}^{*}\end{array}$ & $\begin{array}{c}I_{R}\left(t_{0}\right)=I_{R}^{*} \\
B_{R}\left(t_{0}\right)=I_{R}^{*} \\
F_{R}\left(t_{0}\right)=R_{R O}\end{array}$ \\
\hline 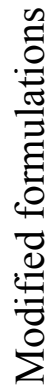 & $\begin{array}{c}R_{E P}^{*}=\max \left(0, \Delta_{E I}+R_{E S}^{*}\right) \\
R_{L P}^{*}=\max \left(0, \Delta_{L I}+F_{L}\right) \\
R_{P S}=\max \left(0, \Delta_{W I P}+R_{E P}^{*}\right. \\
\left.+R_{L P}^{*}\right) \\
R_{M D}^{*}=\max \left(0, \Delta_{M I}+R_{M U}^{*}\right)\end{array}$ & $\begin{array}{r}R_{D R}^{*}=\max \left(0, \Delta_{D I}\right. \\
\left.+F_{D}\right) \\
R_{R M D}=\max \left(0, \Delta_{D I T}\right. \\
\left.+R_{D R}^{*}\right)\end{array}$ & $\begin{array}{l}R_{R D D} \\
=\max \left(0, \Delta_{R I}\right. \\
\left.+F_{R}\right)\end{array}$ \\
\hline
\end{tabular}

A balanced equilibrium implies that all stocks are equal to their desired values (Sterman, 2000). In order to balance the model, initial conditions are specified in terms of other variables and parameters finding algebraic expressions for each initial condition. Table 18 lists the conditions and modified settings introduced to balance the supply chain model.

Figure 55 shows the exogenous inputs affecting both individually and collectively the model. As for balanced equilibrium analysis, we use two types of settings: manufacturer equilibrium and supply chain equilibrium. The first one considers 
only the manufacturer flow, and makes use of inputs 1 and 2 respectively for export and local sales. The second makes use of input 4 which jointly affects all (connected) echelons exposed to a local demand, as well as input 1 introduces export demand only to the manufacturer.
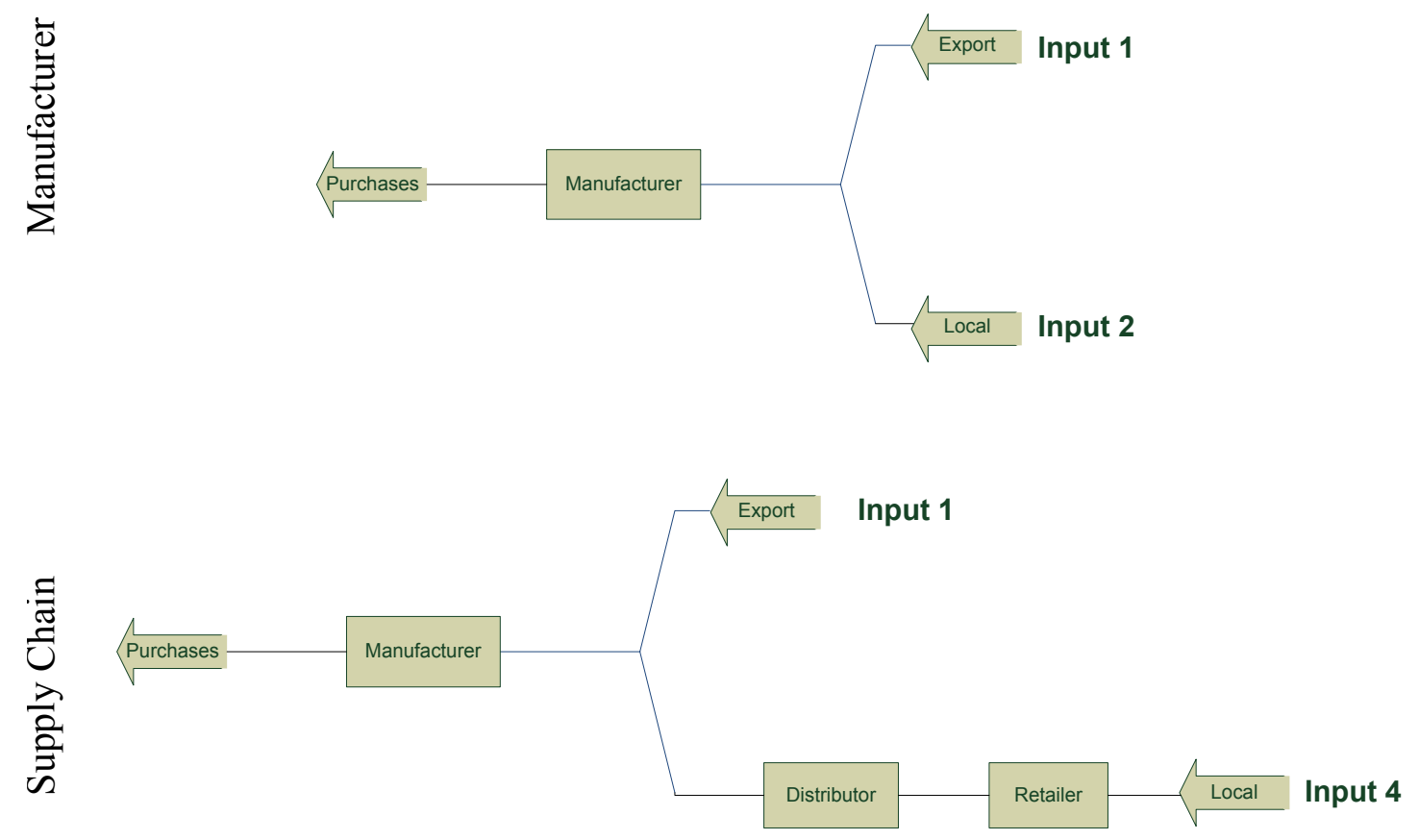

Figure 55. Equilibrium settings and inputs map

An appropriate shock input to the model should stress the model in a way that produces the effect of interest, enabling us to identify BWE. We use the settings reported in Table 19 with demand of $1 \mathrm{M}$ and $2 \mathrm{M}$ units for local and export inputs respectively. The time of introducing the step is week 50 . 
Table 19. Step function parameters used

\begin{tabular}{cccc}
\hline & Local & Export & Combined \\
\hline Test level & $1,000,000$ & $2,000,000$ & $3,000,000$ \\
Test step & 111,111 & 833,333 & 944,444 \\
$\%$ step height & $11 \%$ & $42 \%$ & $29 \%$ \\
\hline
\end{tabular}

\subsection{Manufacturer equilibrium analysis}

With the settings listed in Table 19, we introduce the manufacturer response to the step input in what is termed as Manufacturer step run. Table 20 lists three sets of demand amplification results relative to the local, export, and combined inputs.

Table 20. Manufacturer Step Amplification Results

\begin{tabular}{|c|c|c|c|c|c|c|}
\hline MedLab (Local step) & $\begin{array}{c}\text { Local Order } \\
\text { Rate }\end{array}$ & $\begin{array}{l}\text { Local Shipment } \\
\text { Rate }\end{array}$ & $\begin{array}{l}\text { Production Rate } \\
\text { For Local Orders }\end{array}$ & $\begin{array}{c}\text { Production Start } \\
\text { Rate }\end{array}$ & $\begin{array}{c}\text { Compromised Material } \\
\text { Delivery Rate }\end{array}$ & $\begin{array}{c}\text { Material } \\
\text { Delivery Rate }\end{array}$ \\
\hline Week of peak & 50 & 51 & 53 & 51 & 442 & 294 \\
\hline Peak value & $1,110,000$ & $1,110,000$ & $1,474,091$ & $4,500,000$ & $12,793,499$ & $7,770,813$ \\
\hline Normal value & $1,000,000$ & $1,000,000$ & $1,000,000$ & $3,000,000$ & $3,000,000$ & $3,000,215$ \\
\hline Increase (\%) & $11 \%$ & $11 \%$ & $47 \%$ & $50 \%$ & $326 \%$ & $159 \%$ \\
\hline $\begin{array}{l}\text { demand amplification } \\
\text { ratio }\end{array}$ & 1.00 & 1.00 & 4.31 & 4.55 & 29.68 & 14.46 \\
\hline $\begin{array}{l}\text { MedLab (Export } \\
\text { step) }\end{array}$ & $\begin{array}{l}\text { Export } \\
\text { Order Rate }\end{array}$ & $\begin{array}{l}\text { Export Shipment } \\
\text { Rate }\end{array}$ & $\begin{array}{c}\text { Production Rate } \\
\text { For Export Orders }\end{array}$ & $\begin{array}{l}\text { Production Start } \\
\text { Rate }\end{array}$ & $\begin{array}{c}\text { Compromised Material } \\
\text { Delivery Rate }\end{array}$ & $\begin{array}{c}\text { Material } \\
\text { Delivery Rate }\end{array}$ \\
\hline Week of peak & 50 & 113 & 52 & 51 & 442 & 294 \\
\hline Peak value & $2,840,000$ & $2,840,000$ & $3,356,171$ & $4,500,000$ & $12,793,499$ & $7,770,813$ \\
\hline Normal value & $2,000,000$ & $2,000,000$ & $2,000,000$ & $3,000,000$ & $3,000,000$ & $3,000,215$ \\
\hline Increase (\%) & $42 \%$ & $42 \%$ & $68 \%$ & $50 \%$ & $326 \%$ & $159 \%$ \\
\hline $\begin{array}{l}\text { demand amplification } \\
\text { ratio }\end{array}$ & 1.00 & 1.00 & 1.61 & 1.19 & 7.77 & 3.79 \\
\hline $\begin{array}{l}\text { MedLab (Combined } \\
\text { step) }\end{array}$ & Order Rate & Shipment Rate & Production Rate & $\begin{array}{l}\text { Production Start } \\
\text { Rate }\end{array}$ & $\begin{array}{c}\text { Compromised Material } \\
\text { Delivery Rate }\end{array}$ & $\begin{array}{c}\text { Material } \\
\text { Delivery Rate }\end{array}$ \\
\hline Week of peak & 50 & 113 & 52 & 51 & 442 & 294 \\
\hline Peak value & $3,950,000$ & $3,950,000$ & $4,500,000$ & $4,500,000$ & $12,793,499$ & $7,770,813$ \\
\hline Normal value & $3,000,000$ & $3,000,000$ & $3,000,000$ & $3,000,000$ & $3,000,973$ & $3,000,215$ \\
\hline Increase (\%) & $32 \%$ & $32 \%$ & $50 \%$ & $50 \%$ & $326 \%$ & $159 \%$ \\
\hline $\begin{array}{l}\text { demand amplification } \\
\text { ratio }\end{array}$ & 1.00 & 1.00 & 1.58 & 1.58 & 10.30 & 5.02 \\
\hline
\end{tabular}


Table 20 shows from left to right all relevant flow variables while moving upstream in the model. These are basic measure points since each propels material flow and from its observation BWE appearance becomes evident.

Observe from Table 20 the maximum values reached by each of the rates affecting the flow of materials, as well as their moment of occurrence. There is also the percentage of increment when compared to their normal levels. The last row shows the demand amplification ratio as the coefficient of the maximum percentage change in the variable to the maximum percentage change in the input. The demand amplification ratio allows the dimensionless comparison of the induced amplification to the initial disturbance.

By examining the demand amplification ratio in Table 21, it is apparent that it increases the further one moves from the point of demand, like an increasing wave through the system that resembles a whip. Noticeably, there are two variables where demand is greatly amplified, we call this breaking points for demand amplification: Production (Production Rate) amplifies 4.31 and 1.61 times the local and export demand right after week 50, for a combined effect of 1.58 amplification. Local demand amplification is much greater due to the less variation in its input signal compared to a significant production variance as result of delayed scheduling introduced by the lower priority of local sales (see Section 1.3 for further reference). Because of the greater influence of exports to the flow and the minor disturbance introduced by the local step, the combined amplification tends to be closer to exports but further reduced due to pooling effects that diminishes variance. Again, the feasible production planning 
(Production Start Rate) is amplified for local production but dampened for exports because of the reduced priority of local materials that might end up as exports. Yet, production planning remains stable as expected for the joint production, and is equivalent to the raw material flow from the warehouse (Materials Usage Rate).

The second breaking point lies in inbound logistics. The most upstream decision point considered for both the firm and the supply chain is in Purchasing, where all flows converge since material orders obey the pull of undifferentiated WIP. Most definitively a BWE source, materials planning (Compromised Material Delivery Rate) features the largest amplification respectively of 29.68 and 7.77 indicating the will to purchase. The combined input suggests a magnified will of purchasing at least ten times in excess of the original demand. For the case at hand, the $326 \%$ of increase reached can be sustained on the firm's batching practice for imported purchases and the search for volume discounts.

After a financial delay and supplier action, material planning becomes material dispatches from MedLab's supplier (Material Delivery Rate). With regard to material planning, we observe dampen material arrivals in magnitudes of 14.46 and 3.79 for local and export inputs respectively. Due to demand amplification and financial constraints, the firm has been forced to implement a lean purchasing practice otherwise it would have fulfilled its will of purchase. 
The raw material family considered for the model is hi-2053 P, which interestingly enough yields a combined demand amplification ratio of 5.02 against a 3.3 Demand Amplification Quotient $(\omega)$ back in Section 4.3.2.
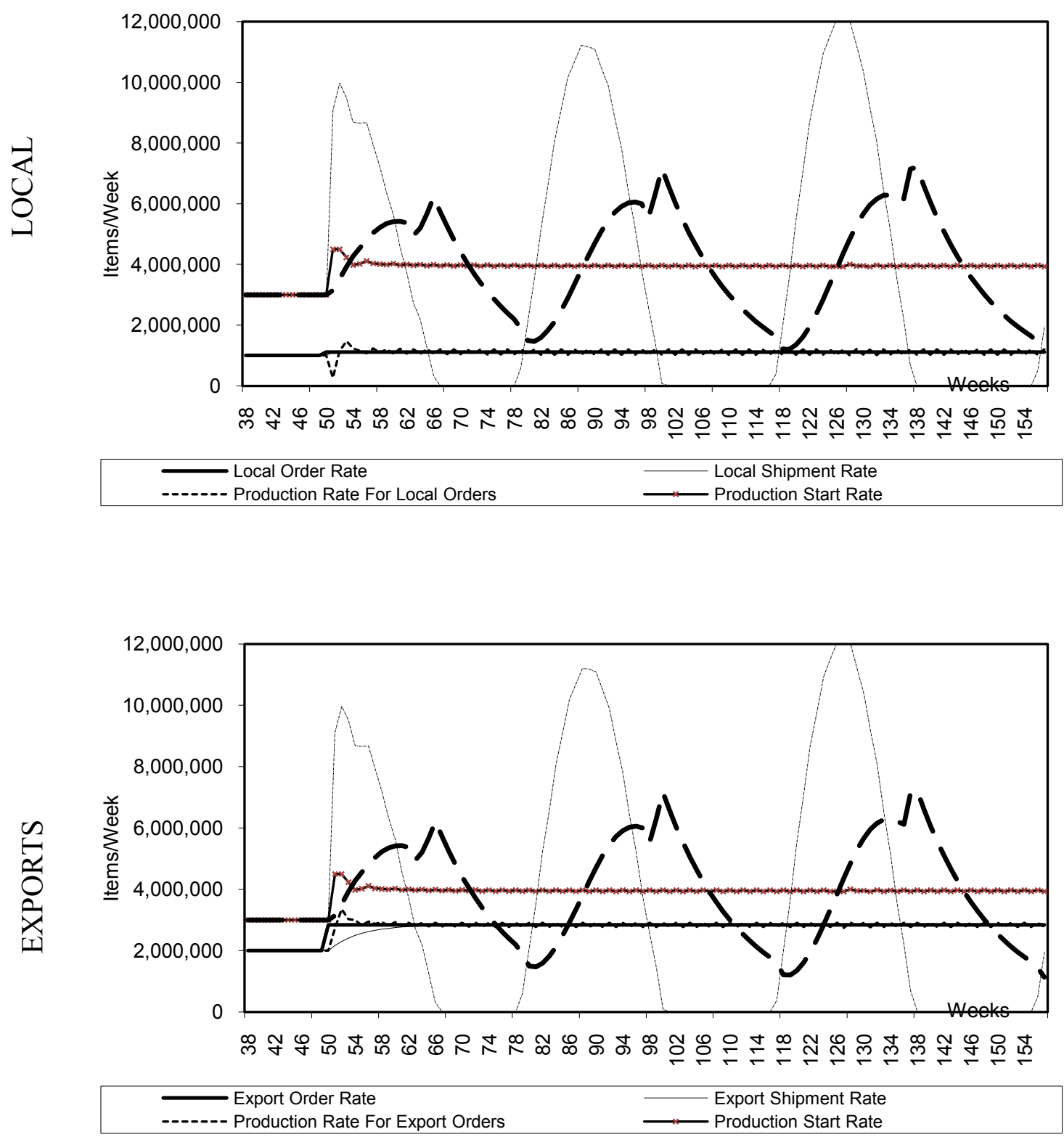

Figure 56. MedLab Model's reaction to a Local and Export step 
Figure 56 shows the demand amplification introduced to the firm in relation to local and export signals. Notice that the local and export charts share the same series for Production Start, Compromised Material Delivery and Material Delivery rates. Furthermore, the non-shared series are similar but scaled in both charts, reflecting the demand amplification breaking points brought earlier. Note in the local settings that Local Shipment Rate increases whereas Production Rate for Local Orders drops and climbs to continually overshoot the new level. As a consequence, Local Inventory first falls and then continually overshoots the new target introducing the initial instability. Conversely, Production Rate for Export Orders remains unconstrained due to its higher priority and, although does not fall behind its target, it shares the instability introduced by Production Rate for Local Orders since both serves from the same fixed capacity and one is the complement of the other. Yet, it is perceptible a larger oscillating pattern of Production Rate for Local Orders, which justifies a larger production demand amplification for the local setting.

Note how the oscillating pattern of Production Rate disappears when both Local and Export inputs are pooled into one in Figure 57. The figure shows the BWE due to the combined input signal, showing how after the disturbance in week 50 , most variables slowly swing back to the new level. 


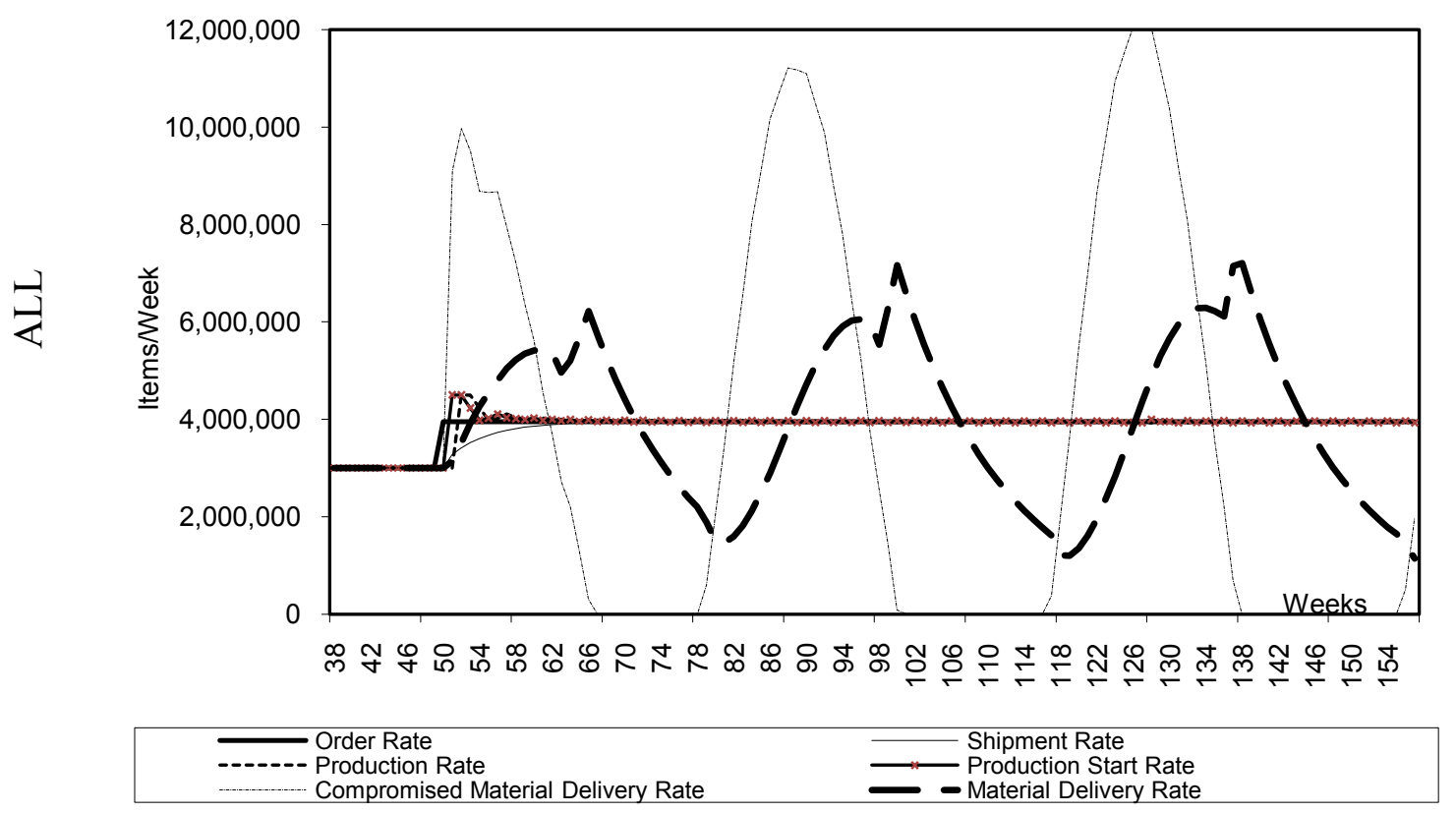

Figure 57. MedLab Model's reaction to a Combined demand step

The exception is that both Compromised Material Delivery Rate and Material Delivery Rate have cyclical pattern that stabilizes in a new oscillating equilibrium. On a closer observation, the cyclical pattern is shared with Production Starts although with a diminished amplitude.

\subsection{Supply chain equilibrium analysis}

This section concentrates in the analysis of results obtained from the balanced supply chain model when exposed to the same step function described in Table 19. The model configuration corresponds to what is shown in the lower part of Figure 55, and it is been referenced as SC step run. 
Table 21. Supply chain step amplification results for separate inputs

\begin{tabular}{|c|c|c|c|c|c|c|c|c|}
\hline \multirow{2}{*}{$\begin{array}{l}\text { Local step } \\
\text { Supply Chain }\end{array}$} & \multicolumn{4}{|c|}{ Retailer } & \multicolumn{4}{|c|}{ Distributor } \\
\hline & $\begin{array}{c}\text { Retailer Order } \\
\text { Rate }\end{array}$ & $\begin{array}{l}\text { Retailer Shipment } \\
\text { Rate }\end{array}$ & $\begin{array}{c}\text { Incoming Units } \\
\text { from Distributor } \\
\text { Rate }\end{array}$ & $\begin{array}{l}\text { Required Distributor } \\
\text { Delivery Rate }\end{array}$ & $\begin{array}{l}\text { Distributor } \\
\text { Arrival Rate }\end{array}$ & $\begin{array}{l}\text { Incoming Units } \\
\text { from Manufacturer }\end{array}$ & $\begin{array}{l}\text { Distributor } \\
\text { Forecast }\end{array}$ & $\begin{array}{l}\text { equired Manufacturer } \\
\text { Delivery Rate }\end{array}$ \\
\hline Week of peak & 50 & 50 & 54 & 53 & 78 & 77 & 57 & 61 \\
\hline Peak value & $1,110,000$ & $1,110,000$ & $1,255,235$ & $1,255,235$ & $2,892,041$ & $2,892,041$ & $1,162,426$ & $3,218,128$ \\
\hline Normal value & $1,000,000$ & $1,000,000$ & $1,000,000$ & $1,000,000$ & $1,000,000$ & $1,000,000$ & $1,000,000$ & $1,000,000$ \\
\hline Increase (\%) & $11 \%$ & $11 \%$ & $26 \%$ & $26 \%$ & $189 \%$ & $189 \%$ & $16 \%$ & $222 \%$ \\
\hline $\begin{array}{l}\text { demand amplification } \\
\text { ratio }\end{array}$ & 1.00 & 1.00 & 2.32 & 2.32 & 17.20 & 17.20 & 1.48 & 20.16 \\
\hline Local step & \multicolumn{8}{|c|}{ Manufacturer } \\
\hline Supply Chain & $\begin{array}{l}\text { Local Order } \\
\text { Rate }\end{array}$ & $\begin{array}{l}\text { Local Shipment } \\
\text { Rate }\end{array}$ & $\begin{array}{l}\text { Desired Local } \\
\text { Production }\end{array}$ & $\begin{array}{l}\text { Production Rate } \\
\text { For Local Orders }\end{array}$ & $\begin{array}{l}\text { Desired Production } \\
\text { Start Rate }\end{array}$ & $\begin{array}{l}\text { Production } \\
\text { Start Rate }\end{array}$ & $\begin{array}{c}\text { Compromised Material } \\
\text { Delivery Rate }\end{array}$ & $\begin{array}{l}\text { Material Delivery } \\
\text { Rate }\end{array}$ \\
\hline Week of peak & 61 & 77 & 78 & 134 & 79 & 51 & 250 & 259 \\
\hline Peak value & $3,218,128$ & $2,892,041$ & $4,223,553$ & $2,500,270$ & $11,209,872$ & $4,500,000$ & $15,112,077$ & $9,127,384$ \\
\hline Normal value & $1,000,000$ & $1,000,000$ & $1,392,857$ & $1,000,000$ & $3,000,000$ & $3,000,000$ & $3,000,973$ & $3,000,215$ \\
\hline Increase (\%) & $222 \%$ & $189 \%$ & $203 \%$ & $150 \%$ & $274 \%$ & $50 \%$ & $404 \%$ & $204 \%$ \\
\hline $\begin{array}{l}\text { demand amplification } \\
\text { ratio }\end{array}$ & 20.16 & 17.20 & 18.48 & 13.64 & 24.88 & 4.55 & 36.69 & 18.57 \\
\hline Export step & \multicolumn{8}{|c|}{ Manufacturer } \\
\hline MedLab & $\begin{array}{l}\text { Export Order } \\
\text { Rate }\end{array}$ & $\begin{array}{l}\text { Export Shipment } \\
\text { Rate }\end{array}$ & $\begin{array}{l}\text { Desired Export } \\
\text { Production }\end{array}$ & $\begin{array}{l}\text { Production Rate } \\
\text { For Export Orders }\end{array}$ & $\begin{array}{l}\text { Desired Production } \\
\text { Start Rate }\end{array}$ & $\begin{array}{l}\text { Production } \\
\text { Start Rate }\end{array}$ & $\begin{array}{c}\text { Compromised Material } \\
\text { Delivery Rate }\end{array}$ & $\begin{array}{c}\text { Material Delivery } \\
\text { Rate }\end{array}$ \\
\hline Week of peak & 50 & 113 & 79 & 59 & 79 & 51 & 250 & 259 \\
\hline Peak value & $2,840,000$ & $2,840,000$ & $4,095,506$ & $4,433,269$ & $11,209,872$ & $4,500,000$ & $15,112,077$ & $9,127,384$ \\
\hline Normal value & $2,000,000$ & $2,000,000$ & $1,607,143$ & $2,000,000$ & $3,000,000$ & $3,000,000$ & $3,000,973$ & $3,000,215$ \\
\hline Increase (\%) & $42 \%$ & $42 \%$ & $155 \%$ & $122 \%$ & $274 \%$ & $50 \%$ & $404 \%$ & $204 \%$ \\
\hline $\begin{array}{l}\text { demand amplification } \\
\text { ratio }\end{array}$ & 1.00 & 1.00 & 3.69 & 2.90 & 6.52 & 1.19 & 9.61 & 4.86 \\
\hline
\end{tabular}


Table 22. Supply chain step amplification results for combined input

\begin{tabular}{|c|c|c|c|c|c|c|c|c|}
\hline \multirow{2}{*}{$\begin{array}{c}\text { All (Combined step) } \\
\text { MedLab }\end{array}$} & \multicolumn{4}{|c|}{ Retailer } & \multicolumn{4}{|c|}{ Distributor } \\
\hline & $\begin{array}{c}\text { Retailer Order } \\
\text { Rate }\end{array}$ & $\begin{array}{l}\text { Retailer Shipment } \\
\text { Rate }\end{array}$ & $\begin{array}{l}\text { Incoming Units from } \\
\text { Distributor Rate }\end{array}$ & $\begin{array}{c}\text { Required } \\
\text { Distributor } \\
\text { Delivery Rate }\end{array}$ & $\begin{array}{l}\text { Distributor Arrival } \\
\text { Rate }\end{array}$ & $\begin{array}{c}\text { Incoming Units } \\
\text { Form Manufacturer }\end{array}$ & $\begin{array}{l}\text { Distributor } \\
\text { Forecast }\end{array}$ & $\begin{array}{c}\text { Required Manufacturer } \\
\text { Delivery Rate }\end{array}$ \\
\hline Week of peak & 50 & 50 & 54 & 53 & 78 & 77 & 57 & 61 \\
\hline Peak value & $1,110,000$ & $1,110,000$ & $1,255,235$ & $1,255,235$ & $2,892,041$ & $2,892,041$ & $1,162,426$ & $3,218,128$ \\
\hline Normal value & $1,000,000$ & $1,000,000$ & $1,000,000$ & $1,000,000$ & $1,000,000$ & $1,000,000$ & $1,000,000$ & $1,000,000$ \\
\hline Increase (\%) & $11 \%$ & $11 \%$ & $26 \%$ & $26 \%$ & $189 \%$ & $189 \%$ & $16 \%$ & $222 \%$ \\
\hline $\begin{array}{l}\text { demand amplification } \\
\text { ratio }\end{array}$ & 1.00 & 1.00 & 2.32 & 2.32 & 17.20 & 17.20 & 1.48 & 20.16 \\
\hline
\end{tabular}

\begin{tabular}{|c|c|c|c|c|c|c|c|c|}
\hline \multirow{2}{*}{$\begin{array}{c}\text { All (Combined step) } \\
\text { MedLab }\end{array}$} & \multicolumn{8}{|c|}{ Manufacturer } \\
\hline & Order Rate & Shipment Rate & $\begin{array}{c}\text { Desired } \\
\text { Production }\end{array}$ & Production Rate & $\begin{array}{l}\text { Desired Production } \\
\text { Start Rate }\end{array}$ & $\begin{array}{l}\text { Production } \\
\text { Start Rate }\end{array}$ & $\begin{array}{c}\text { Compromised } \\
\text { Material Delivery } \\
\text { Rate }\end{array}$ & $\begin{array}{c}\text { Material } \\
\text { Delivery Rate }\end{array}$ \\
\hline Week of peak & 61 & 77 & 79 & 55 & 79 & 51 & 250 & 259 \\
\hline Peak value & $6,058,128$ & $5,730,010$ & $7,854,936$ & $4,500,000$ & $11,209,872$ & $4,500,000$ & $15,112,077$ & $9,127,384$ \\
\hline Normal value & $3,000,000$ & $3,000,000$ & $3,000,000$ & $3,000,000$ & $3,000,000$ & $3,000,000$ & $3,000,973$ & $3,000,215$ \\
\hline Increase (\%) & $102 \%$ & $91 \%$ & $162 \%$ & $50 \%$ & $274 \%$ & $50 \%$ & $404 \%$ & $204 \%$ \\
\hline $\begin{array}{l}\text { demand amplification } \\
\text { ratio }\end{array}$ & 9.27 & 8.27 & 14.71 & 4.55 & 24.88 & 4.55 & 36.69 & 18.57 \\
\hline
\end{tabular}


Table 21 and Table 22 list some of the results obtained from the model, differentiating as in the former section responses for both separate inputs (local and export step) and combined input (local + export step). Note from Figure 55 the long course and number of nodes the local step input goes through. This is why the is divided in two sections, while the export step only has a smaller table since only deals with the manufacturer. Again, the column order from left to right reflects in upstream fashion the flow variable position in the model.

Figure 58 introduces organization and summarizes the data into graphical information. A sample of the most relevant rates are included in the horizontal axis, denoting as well the echelon where each belongs, informing the degree of amplification reached by each rate considering the local, export and combined steps. The variance introduced is represented as areas in Figure 58, which goes further amplified crossing a large number of flow variables. Since a relative measure, and provided that each rate is prone to amplification rather than dampening, it makes sense larger demand amplification the longer the chain is. 


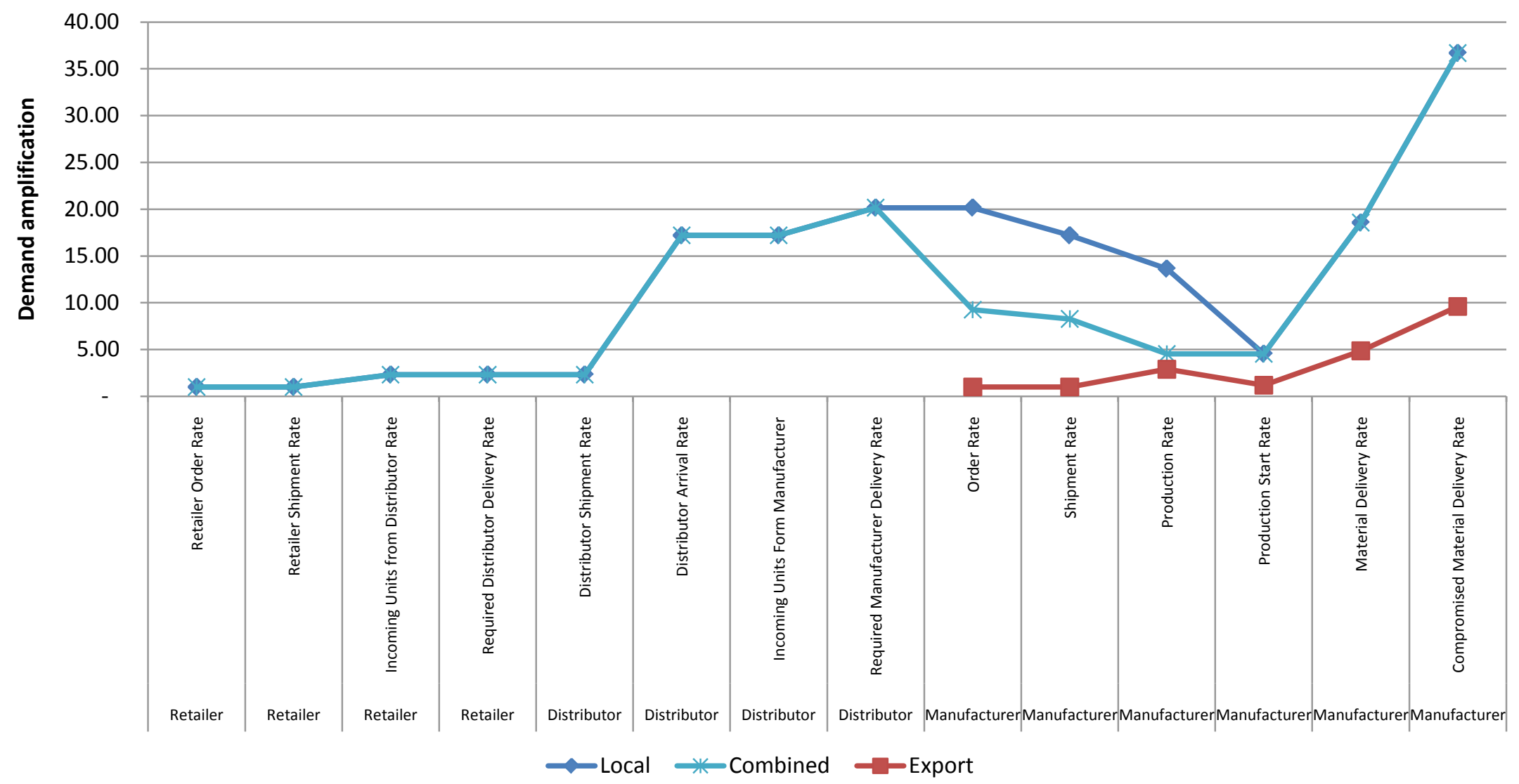

Figure 58. Demand amplification breaking points 
Figure 58 signals to several demand amplification breaking points. The Retailer contribution to demand amplification, although amplifying 2.32 times the original input, is not the main source of variation. Both the local and combined areas highlight major amplification arising from the Distributor, particularly for Incoming Units From Manufacturer which is passed unchanged by Distributor Arrival Rate, accounting for a magnitude of 17.2.

Incoming Units From Manufacturer constitutes the output of the manufacturer's supply process which is basically pushed over the materials pipeline constituting in-transit inventory before getting to the Distributor. This is the response from the manufacturer to the Required Manufacturer Delivery Rate placed by the Distributor, which accounts for the Distributor's forecast, safety stocks, inventory and pipeline corrections with a magnification of 20 .

Note from Figure 58 that at this point the Order Rate amplification is kept at 20 for the local input, but decreases for the combined and export inputs. The export input observation is abandoned here because is simply an incoming demand branch that starts at this point replicating what was already observed in the previous section, but with the consideration that the materials supply now incorporates an additional variance from the local pipeline.

For the combined input, the reduction is merely due to pooling effects of adding the export signal in, therefore reducing the relative variance because of a larger and less variant flow until reaching Production Start Rate. This case exemplifies the 
issues that an experimenter has to deal with when measuring several demand pipelines with uneven variation, a subject on which Section 3.3 extends thoroughly. Yet, taking into consideration that the combined flow is in actuality what decision makers face, we will continue to follow the combined signal.

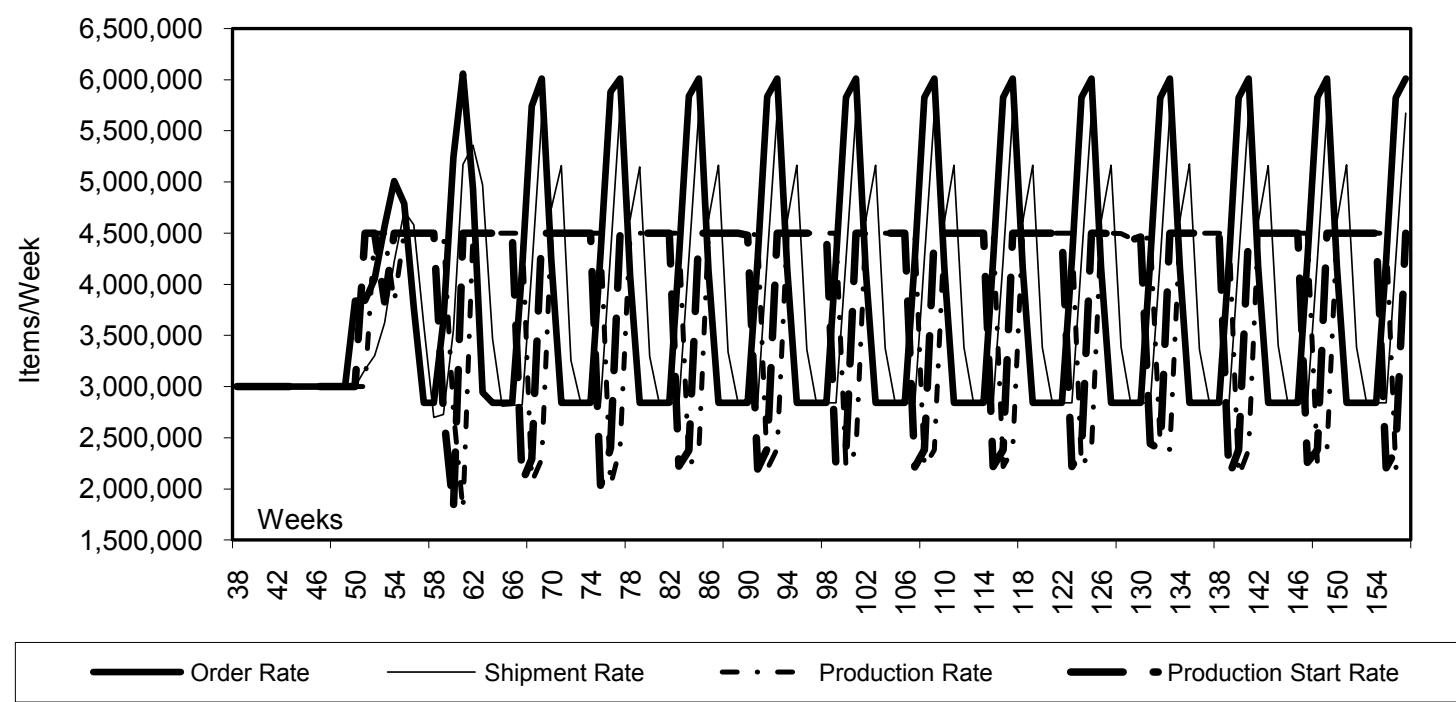

Figure 59. Manufacturer's demand amplification response for a combined step function

Starting from Order Rate and continuing through Production Start Rate, it is observable a negative slope in amplification that leads to a 4.5 amplification magnitude. What happens here is that Production oscillates but constrained by production capacity, whereas demand placed to manufacturer Order Rate freely oscillates after the Required Manufacturer Distributor Delivery Rate, or the planned replenishment from the Distributor. Note as well that Order Rate in time is emulated by the Shipment Rate, hence oscillating as well but limited by a less tight Inventory constraint, as shown in Figure 59. These results are congruent with the findings shown in former Figure 25. 
Back to Figure 58, Material Delivery Rate climbs up to 18.6 times the original input variation, because of the same reasons described in the former section. The model does not constrain the will to purchase portrayed by Compromised Material Delivery Rate further increasing orders to suppliers to 36.7 times. Yet, those orders are made unfeasible by the cash flow limitations introduced.

Summarizing, the overall demand amplification prescribed by the model is 18.6 times the original input variation. Figure 60 shows the dynamics of a sample of rate variables from all the chain. The figure provides perspective of the dimension of the original disturbance introduced by the Retailer Order Rate, moving from 1 to 1.11 millions, further extending to production and material replenishment decisions. An important insight for the origin of oscillations was provided in the earlier section, where the constrained capacity and the higher priority of exports introduce swings in local production that stabilizes in a permanent overshoot of the new target.

Previously reported BWE supply chain results in Section 4.3.2 are not directly comparable, because both chains are different given the measured and modeled echelons corresponding to different firms, periods of time, as well as metrics used. 


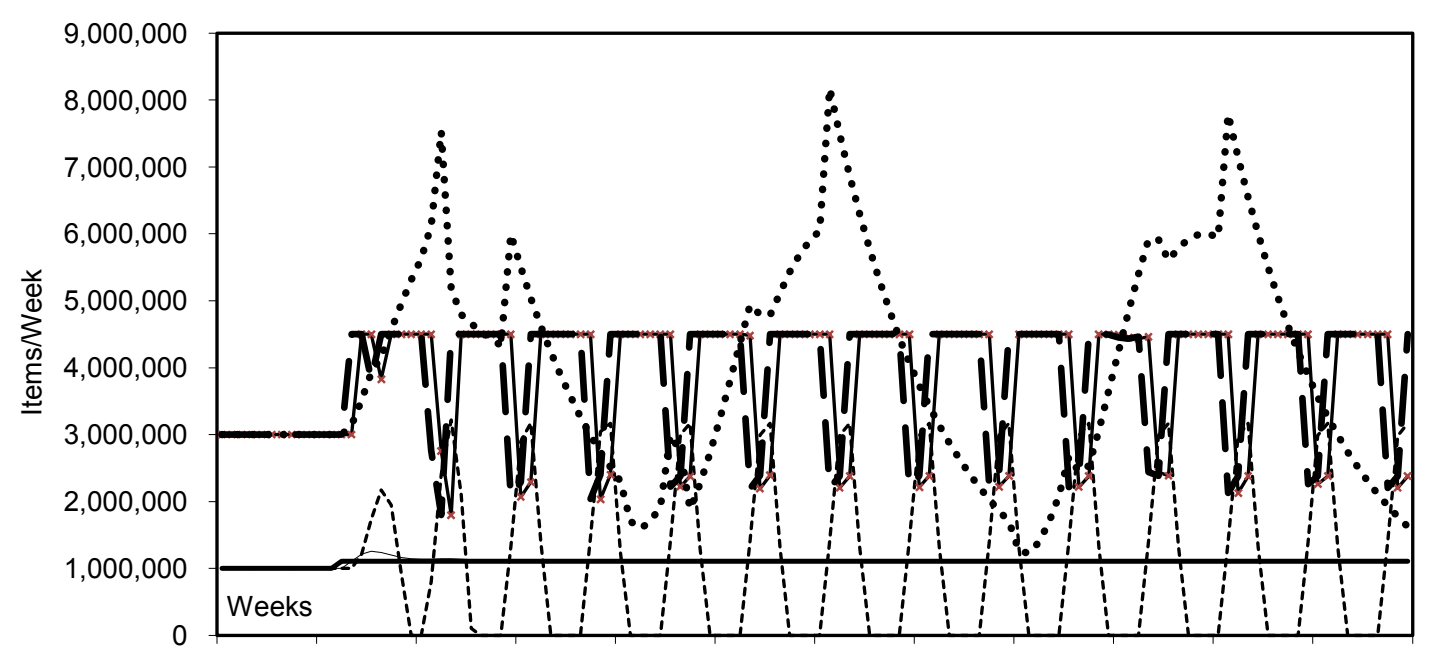

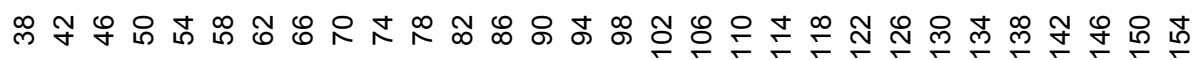

\begin{tabular}{|c|c|}
\hline $\begin{array}{l}\text { Retailer Order Rate } \\
- \\
- \text { - Required Manufacturer Delivery Rate } \\
\end{array}$ & $\begin{array}{l}\text { Required Distributor Delivery Rate } \\
\ldots \ldots \text { Production Rate } \\
\ldots \ldots \text { Material Delivery Rate }\end{array}$ \\
\hline
\end{tabular}

Figure 60. Demand amplification propagation through the supply chain model

\subsubsection{Optimization Analyses}

In this section, we use statistical screening and optimization to identify the system parameters that will minimize the bullwhip and maximize profit. Considering the large number of parameters existing in most dynamic systems an arbitrary search of the most sensitive would be highly complex and time-consuming (Tank-Nielsen, 1976). Therefore, the next section illustrates a method providing a structured and more efficient search.

\subsubsection{SS-Opt: a combined sensitivity analysis and model optimization method}

Ford and Flynn (2005) described a pragmatic method to find the most important uncertain parameters in system dynamics models. Based on statistical studies performed in the 1980 's, they showed how the key model's inputs could be identified 
with the simple correlation coefficient delivering time series of each inputs effect to the main output.

The relative importance of each input is determined by calculating the correlation coefficients between the main results of the model and the values assigned to each entry in a sensitivity analysis using the Vensim ${ }^{\circledR}$ software. They used the Latin Hypercube Sampling (LHS) option, which iteratively samples variables using an even sampling method. Then, randomly combined sets of those variables are used for computing the model's main output ${ }^{15}$. This analysis, known as statistical screening, strives to find which parameters are significantly influential, with the twofold purpose of directing further sampling efforts to the most significant inputs (and ensure a refined estimation) and providing confidence intervals of estimation (Ford and Flynn (2005).

In this work, we take Ford and Flynn's original development and introduced some changes to better serve our purpose. We use an interface developed by Soto (2010) to automate the process and interact with data changes from Excel. In addition, we forgo the use of simple correlation coefficient and introduce design of experiments (DOE) to gain sampling efficiencies, instead of the LHS in the original version. We call this procedure as SS-Opt, conveying the combined treatment of Statistical Screening and optimization features offered by Vensim ${ }^{\circledR}$.

Although the computational development brings in considerable processing capability as to handle fractional experiments $\left(2^{\mathrm{k}}\right)$, it is reasonable to consider order

\footnotetext{
${ }^{15}$ A good illustration of LHS is available in: http://mathieu.fenniak.net/latin-hypercube-sampling/
} 
interactions up to two factors since our purpose is to identify significant inputs, which are marked once appearing whether as main or interaction effects. Therefore, it is enough to obtain information from lower order designs running a fractional factorial experiment $\left(2^{\mathrm{k}-\mathrm{p}}\right)$.

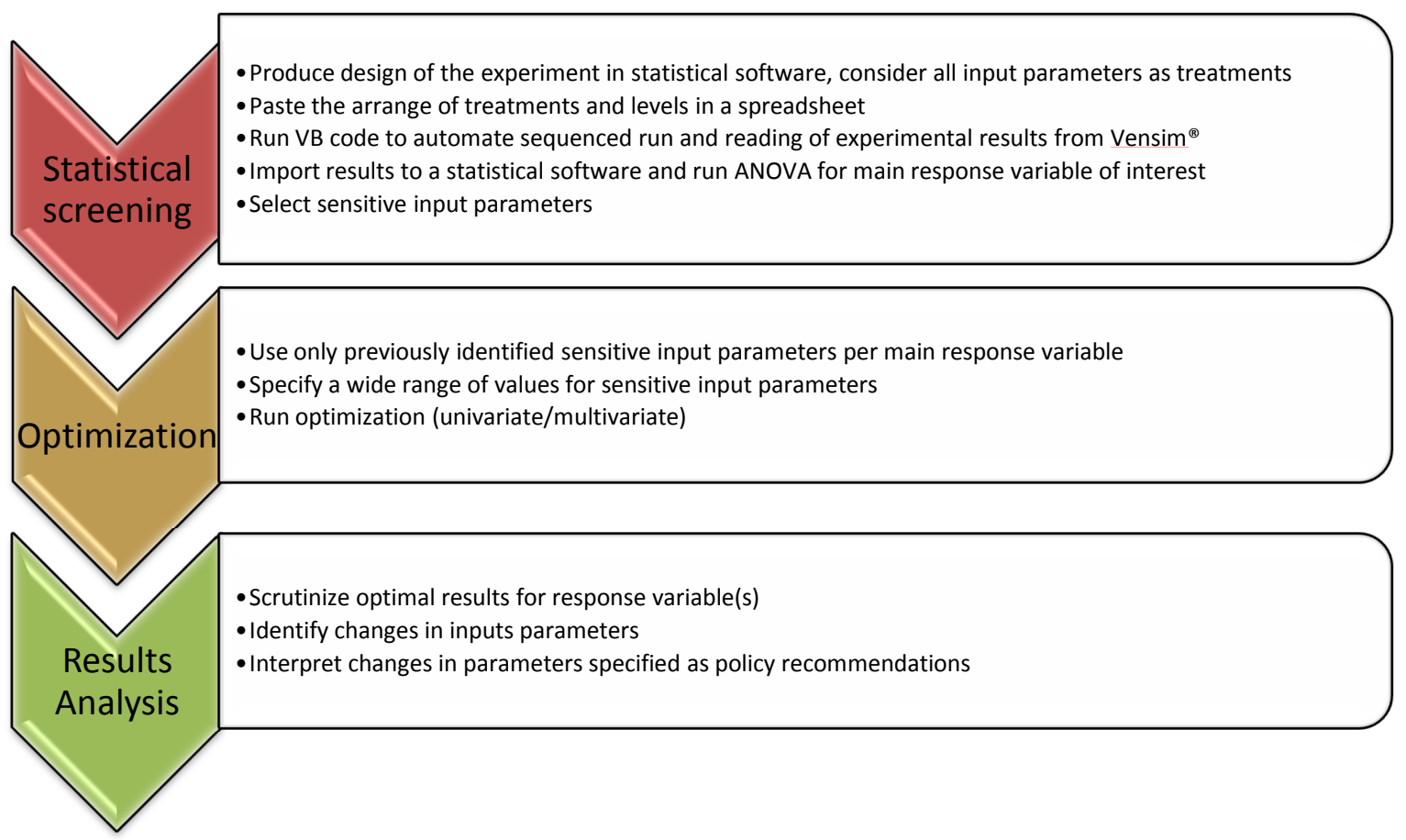

Figure 61. SS-Opt flow chart

The proposed procedure for performing the statistical screening analysis is as follows: the computational interface automates the process of setting up and running the simulations to obtain the experiment's data, then the results obtained are analyzed by means of statistical software such as Statgraphics ${ }^{\circledR}$ signaling significant statistical inputs at the $95 \%$ level of significance. Next, set an optimization range for the significant parameters considering a wide choice (see Sterman (2000), pp. 884) of feasible values certified by expert's opinion. Then, introduce significant inputs and 
ranges to optimize the main output towards the desired effects, using Vensim's optimization engine.

We now describe the SS-Opt scenarios considered in this investigation. We start with the manufacturer statistical screening and optimization. Then we include the distributor and retailer and the overall supply chain. Let us term both, respectively, as local and global scenarios. We are interested in demand amplification primarily, which is in the center of this dissertation, yet we are interested as well in considering economical implications. Ultimately, we use a bi-variate optimization criterion that considers both demand amplification and MedLab's profit; we call this a compromise solution, since to a certain extent it balances competing objectives.

Note also that the use of the bi-variate criterion is limited, especially for the global scenario. Recall that economic variables had only been considered for the manufacturer echelon in Section 5.1.6, hence the model lacks a global profit measure and does not allow for a global bi-variate optimization. Therefore, for the global scenario what we do is we perform optimization in a sequenced fashion: first, we only regard demand amplification as optimization criterion for the three-echelon system. As a result, the optimization engine should be able to find a combination of parameters that yields an optimal global demand amplification magnitude. After this, we update the former optimal parameters on the overall model but set up the bi-variate optimization for changing exclusively the manufacturer's parameters. Note how this is a different optimization setting than the former local scenario, since now the demand input enters from the retailer and gets affected by both current distributor and retailer's parameters 
before entering to the manufacturer. In this way, we obtain an optimal BWE solution for the chain and a compromise solution at least for the manufacturer.

We will next describe the statistical screening for the local and global scenarios to identify the significant model inputs to the corresponding outputs of interest. Subsequently, we separately address both local and global optimization.

\subsection{Input parameter screening analysis}

We start with the local setting using only the manufacturer model. Since we consider a bi-variate criterion for response variables Demand Amplification Material Delivery (DAMD) and Gross Profit (GPRT), we screen the model after sensitive input parameters for both outputs.

Table 23 lists Manufacturer's input parameters regarded for the sensitivity analysis with low and high levels. Given sparsity-of-effects principle, it is expected for the system's response to be dominated by some of the main effects and interactions of lower order.

Table 23. Screened manufacturer's variables with levels

\begin{tabular}{cccccc}
\hline ID & Variable name & Short & Low & High & Units \\
\hline A & Export Inventory Review Time & (EIRT) & 1 & 4 & Weeks \\
B & Forecast Review Time & (FRT) & 1 & 16 & Weeks \\
C & Local Inventory Review Time & (LIRT) & 1 & 4 & Weeks \\
D & Local Safety Stock Coverage & (LSSC) & 1 & 8 & Weeks \\
E & Materials Average Review Time & (MART) & 1 & 4 & Weeks \\
F & Maximum Capacity & (MC) & $3,000,000$ & $6,000,000$ & Units/Week \\
G & Manufacturing LeadTime & (MLT) & 1 & 3 & Weeks \\
H & Material Safety Stock Coverage & (MSSC) & 1 & 8 & Weeks \\
I & Perceived Supplier Lead Time & (PSLT) & 1 & 16 & Weeks \\
J & WIP Review Time & (WIP) & 1 & 4 & Weeks \\
\hline
\end{tabular}


We first analyze the effects for DAMD. It is posed a $2^{10-3}$ fractional design with 72 degrees of freedom (df) where interactions greater than two were confounded in 7 blocks. Note that for larger models implying a considerable number of inputs alternative designs, e.g. Plackett-Burman designs, might be suitable. If interactions between the factors can be considered negligible, the design allows for using an economical number of experiments.

\begin{tabular}{|c|c|c|c|c|c|}
\hline Source & Sum of squares & d.f. & Mean square & $F$ value & $\mathrm{p}$-value \\
\hline I:PSLT & 530.906 & 1 & 530.906 & 11.49 & 0.0012 \\
\hline J:WIP & 417.792 & 1 & 417.792 & 9.04 & 0.0037 \\
\hline $\mathrm{GH}$ & 718.614 & 1 & 718.614 & 15.55 & 0.0002 \\
\hline HJ & 625.171 & 1 & 625.171 & 13.53 & 0.0005 \\
\hline
\end{tabular}

Table 24 enlists significant variables and interactions filtering for a $95 \%$ statistical significance. Below, Figure 62 summarizes the main and second order effects for demand amplification using the ID of variables listed in Table 23. Adequacy tests are available for the reader upon request. 


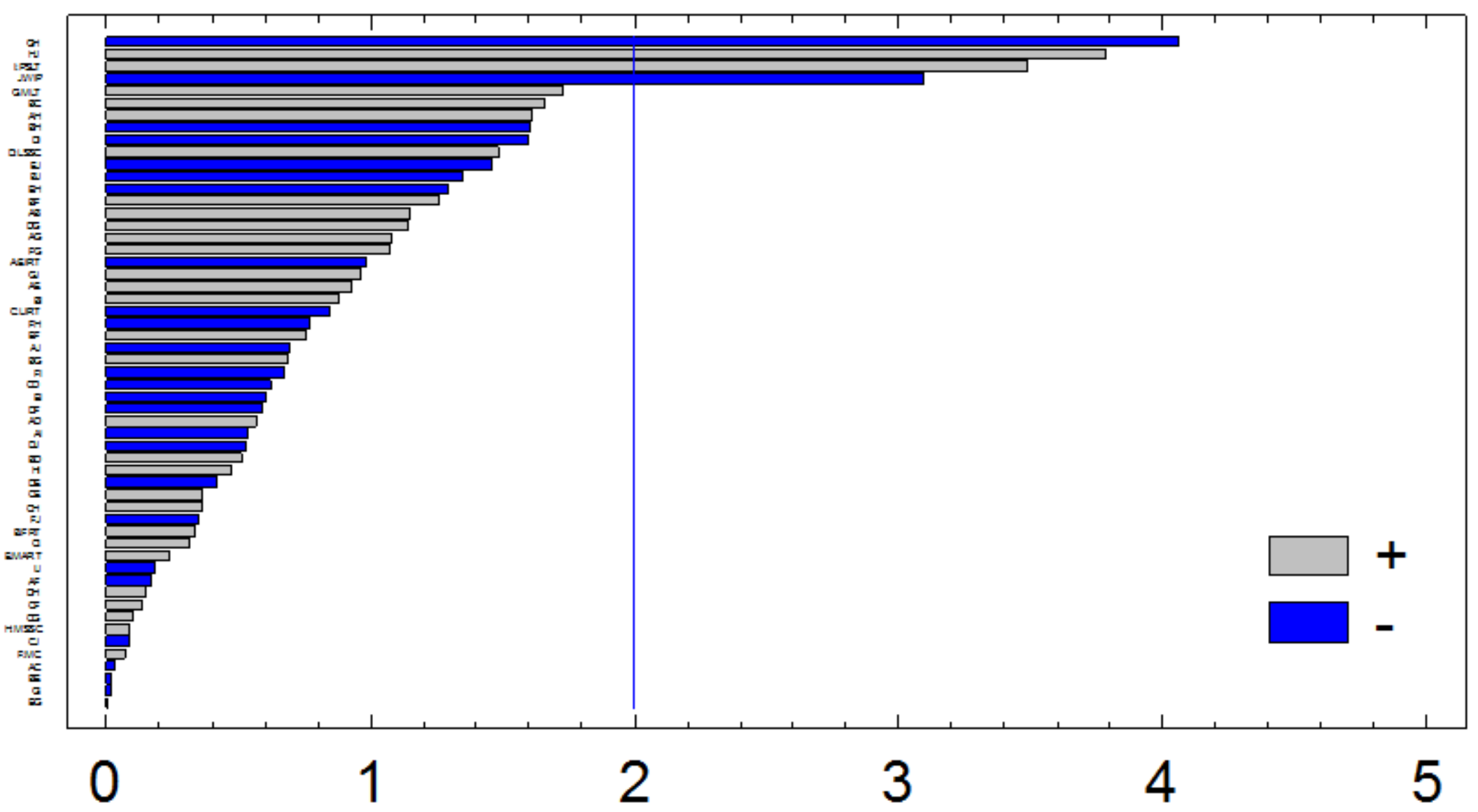

Figure 62. Standardized effects for DAMD screening 
Similarly, the Gross Profit (GPRT) is subject as well to a screening analysis. Considering the input parameters contained in Table 23, we observe the ANOVA results in Table 25.

Table 25. Parameters for GPRT and statistical significance

\begin{tabular}{cccccc}
\hline Source & Sum of squares & d.f. & Mean square & F value & p-value \\
\hline C:LIRT & $2.88005 \mathrm{E} 19$ & 1 & $2.88005 \mathrm{E} 19$ & 30.68 & 0.0000 \\
D:LSSC & $3.06175 \mathrm{E} 20$ & 1 & $3.06175 \mathrm{E} 20$ & 326.18 & 0.0000 \\
G:MLT & $4.54517 \mathrm{E} 18$ & 1 & $4.54517 \mathrm{E} 18$ & 4.84 & 0.0310 \\
J:WIP & $1.55852 \mathrm{E} 19$ & 1 & $1.55852 \mathrm{E} 19$ & 16.60 & 0.0001 \\
AF & $6.54649 \mathrm{E} 19$ & 1 & $6.54649 \mathrm{E} 19$ & 69.74 & 0.0000 \\
CD & $6.51425 \mathrm{E} 19$ & 1 & $6.51425 \mathrm{E} 19$ & 69.40 & 0.0000 \\
DG & $2.20847 \mathrm{E} 19$ & 1 & $2.20847 \mathrm{E} 19$ & 23.53 & 0.0000 \\
DJ & $2.8811 \mathrm{E} 19$ & 1 & $2.8811 \mathrm{E} 19$ & 30.69 & 0.0000 \\
GJ & $6.23439 \mathrm{E} 18$ & 1 & $6.23439 \mathrm{E} 18$ & 6.64 & 0.0120 \\
\hline
\end{tabular}

Note as well in Figure 63 the standardized results for the experiment detailing magnitudes of main and low order effects for GPRT.

In summary, Table 26 pools all significant results for both GPRT and DAMD responses at $95 \%$ of significance.

Table 26. Manufacturer significant parameters per response variable

\begin{tabular}{ccccc}
\hline Output & ID & Variable & Short & Units \\
\hline GPTR & A & Export Inventory Review Time & (EIRT) & Weeks \\
& C & Local Inventory Review Time & (LIRT) & Weeks \\
& D & Local Safety Stock Coverage & (LSSC) & Weeks \\
& F & Maximum Capacity & (MC) & Units/Week \\
\hline $\begin{array}{c}\text { GPTR } \\
\cap\end{array}$ & G & Manufacturing LeadTime & (MLT) & Weeks \\
DAMD & WIP Review Time & (WIP) & Weeks \\
\hline DAMD & H & Material Safety Stock & (MSSC) & Weeks \\
& I & Perceived Supplier Lead Time & (PSLT) & Weeks \\
\hline
\end{tabular}




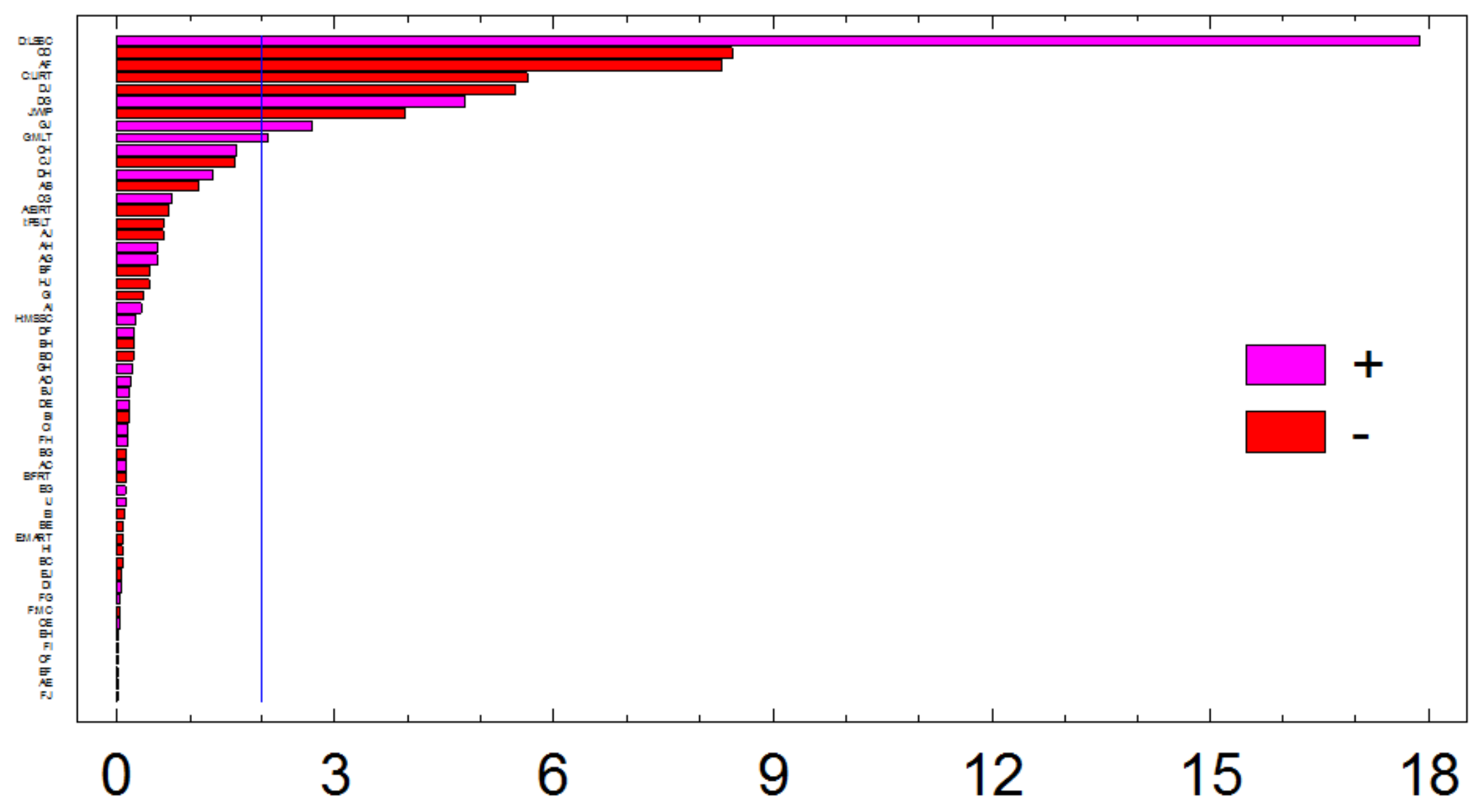

Figure 63. Standardized effects for GPRT screening 
As for the global setting, the procedure is identical but now referred to the Demand Amplification RetManuf (RETMAN) variable, which records the largest demand amplification now contrasting the retailer's input demand with the manufacturer's materials reception rate.

Table 27 shows the supply chain model's input parameters, levels and short names as introduced in Statgraphics ${ }^{\circledR}$ for the correspondent experiment. Since we now have sixteen inputs for the overall model, we used a Plackett-Burman design with twenty-three degrees of freedom.

Table 27. Screened supply chain's variables with levels

\begin{tabular}{cccccc}
\hline ID & Variable name & Short & Low & High & Units \\
\hline A & Retailer Safety Stock & RSS & 1 & 8 & Weeks \\
B & Retailer Forecast Review Time & RFRT & 1 & 12 & Weeks \\
C & Retailer Review Time & RRT & 1 & 4 & Weeks \\
D & Distributor Safety Stock & DSS & 1 & 8 & Weeks \\
E & Distributor Forecast Review Time & DFRT & 1 & 4 & Weeks \\
F & Distributor Enlistment Time & DET & 1 & 4 & Weeks \\
G & Distributor Inventory Review Time & DIRT & 1 & 4 & Weeks \\
H & Local Safety Stock Coverage & LSSC & 1 & 8 & Weeks \\
I & Forecast Review Time & FRT & 1 & 12 & Weeks \\
J & Local Inventory Review Time & LIRT & 1 & 4 & Weeks \\
K & Manufacturing LeadTime & MLT & 1 & 3 & Weeks \\
L & Maximum Capacity & MC & $3.00 \mathrm{E}+06$ & $6.00 \mathrm{E}+06$ & Units/Week \\
M & WIP Review Time & WIP & 1 & 4 & Weeks \\
N & Material Safety Stock Coverage & MSSC & 1 & 8 & Weeks \\
O & Materials Inventory Review Time & MIRT & 1 & 4 & Weeks \\
P & Perceived Supplier Lead Time & PSLT & 1 & 16 & Weeks \\
\hline
\end{tabular}

Table 28 shows the ANOVA table for RETMAN listing variables and interactions detailing their statistical significance. Figure 64 shows the individual impact of each input to RETMAN. 
Table 28. Significant parameters for RETMAN

\begin{tabular}{cccccc}
\hline Source & Sum of squares & d.f. & Mean square & F value & p-value \\
A:RSS & 99.5203 & 1 & 99.5203 & 2.57 & 0.1228 \\
B:RFRT & 95.7859 & 1 & 95.7859 & 2.47 & 0.1297 \\
C:RRT & 20.0582 & 1 & 20.0582 & 0.52 & 0.4793 \\
D:DSS & 168.87 & 1 & 168.87 & 4.35 & 0.0482 \\
E:DFRT & 78.4819 & 1 & 78.4819 & 2.02 & 0.1683 \\
F:DET & 17.9287 & 1 & 17.9287 & 0.46 & 0.5033 \\
G:DIRT & 15.5102 & 1 & 15.5102 & 0.40 & 0.5333 \\
H:LSSC & 34.4244 & 1 & 34.4244 & 0.89 & 0.3559 \\
I:FRT & 2.40862 & 1 & 2.40862 & 0.06 & 0.8054 \\
J:LIRT & 21.639 & 1 & 21.639 & 0.56 & 0.4626 \\
K:MLT & 0.03238 & 1 & 0.03238 & 0.00 & 0.9772 \\
L:MC & 173.7 & 1 & 173.7 & 4.48 & 0.0453 \\
M:WIP & 0.289884 & 1 & 0.289884 & 0.01 & 0.9318 \\
N:MSSC & 50.5501 & 1 & 50.5501 & 1.30 & 0.2653 \\
O:MIRT & 101.971 & 1 & 101.971 & 2.63 & 0.1185 \\
P:PSLT & 17.7779 & 1 & 17.7779 & 0.46 & 0.5051 \\
\hline
\end{tabular}
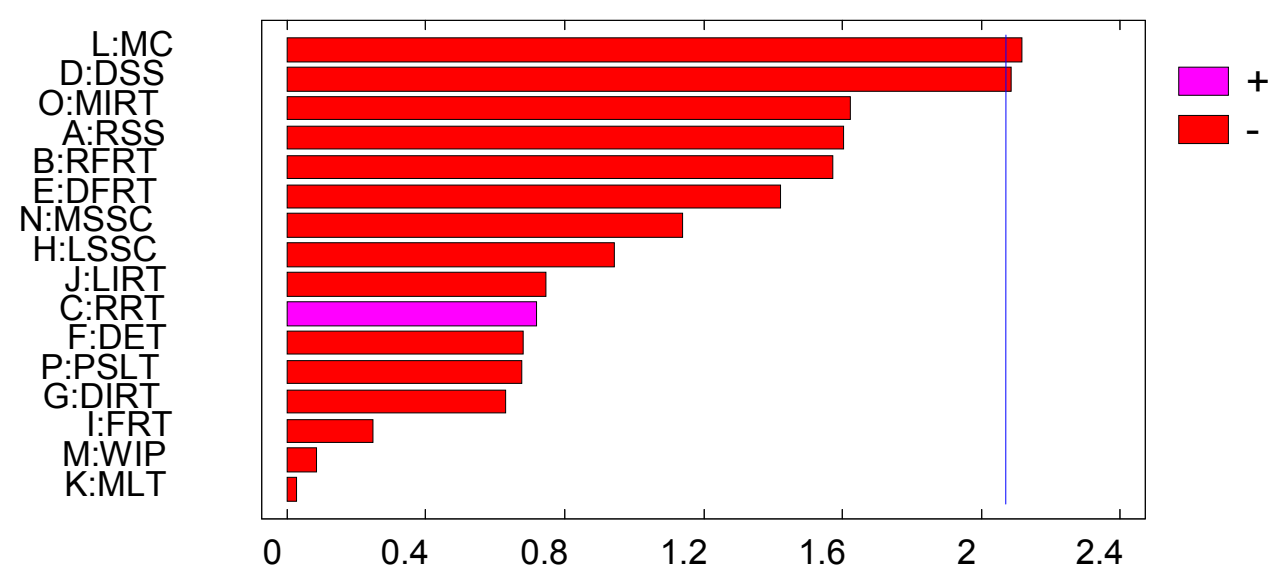

Figure 64. Standardized effects for RETMAN screening

From the Figure 64 and Table 28 , we can identify the most impacting input parameters for RETMAN. We have selected the top seven most impacting variables up 
to $85 \%$ significant level as inputs for the coming optimization, allowing for a less strict significance since we discarded interactions. Selected variables are shown in Table 29.

Table 29. Supply chain significant parameters for RETMAN

\begin{tabular}{ccccc}
\hline Output & ID & Variable & Short & Units \\
\hline & L & Maximum Capacity & MC & Weeks \\
& D & Distributor Safety Stock & DSS & Weeks \\
& O & Materials Inventory Review Time & MIRT & Weeks \\
& A & Retailer Safety Stock & RSS & Units/Week \\
& B & Retailer Forecast Review Time & RFRT & Weeks \\
& E & Distributor Forecast Review Time & DFRT & Weeks \\
& N & Material Safety Stock Coverage & MSSC & Weeks \\
& H & Local Safety Stock Coverage & LSSC & Weeks \\
\hline
\end{tabular}

\subsection{Optimization}

\section{Local scenario (Manufacturer model)}

We begin with the manufacturer optimization, in what we termed as local scenario. The ultimate objective is to change parameters aimed at jointly converging Material Delivery Demand Amplification (DAMD) to the closest value of one while maximizing the value of Gross Profit $(\text { GPRT })^{16}$, or equivalently, minimize costs. In this way, the expectation is to obtain insights for policies aimed at reducing the demand amplification effect in a way that will not hurt the firm's cost. Since the optimization is based on both demand amplification and profit variables, we call it bi-variate.

\footnotetext{
${ }^{16}$ Equivalent to minimizing the operating costs, since in the model the income is fixed by the input and currently there are no endogenous ways to increase revenue..
} 
We will use a combined demand step of $20 \%$ of magnitude as input to the manufacturer echelon to stimulate bullwhip and the optimization ranges listed in Table 30.

Table 30. Input parameters for Manufacturer's optimization

\begin{tabular}{ccccc}
\hline Output & Variable & Min & Max & Units \\
\hline GPRT & Export Inventory Review Time & 1 & 8 & Weeks \\
& Local Inventory Review Time & 1 & 4 & Weeks \\
& Local Safety Stock Coverage & 1 & 8 & Weeks \\
& Maximum Capacity & $3.0 \mathrm{E}+06$ & $6.0 \mathrm{E}+06$ & Units/Week \\
\hline $\begin{array}{c}\text { GPRT } \\
\text { Manufacturing Lead Time }\end{array}$ & 1 & 4 & Weeks \\
DAMD & WIP Review Time & 1 & 2 & Weeks \\
\hline DAMD & Material Safety Stock & 1 & 8 & Weeks \\
& $\begin{array}{c}\text { Coverage } \\
\end{array}$ & & & Weeks \\
\hline
\end{tabular}

Optimized results for Demand Amplification Material Delivery (DAMD) are shown in Figure 65. Derived from the sequential optimization proposed, we observe two series in the chart: $M n f g D A$ stands for the first optimization performed over DAMD but considering exclusively demand amplification. Then, $M n f g D A+\$ \$$ represents DAMD bi-variate optimization run minimizing demand amplification to the unity while maximizing profit.

The DAMD variable scans over the time series of the model's input (the step) and Material entrance. It first determines the magnitude and time occurrence of each time series maximum peak, to confront with its baseline before the disturbance. The variable expresses the relative order of magnitude from the increase observed for DAMD in relation to the increase in the input. Thus, the time series display the largest 
demand amplification found at a given time, which remains unchanged until a larger one is detected, ultimately delivering the maximal demand amplification observed.

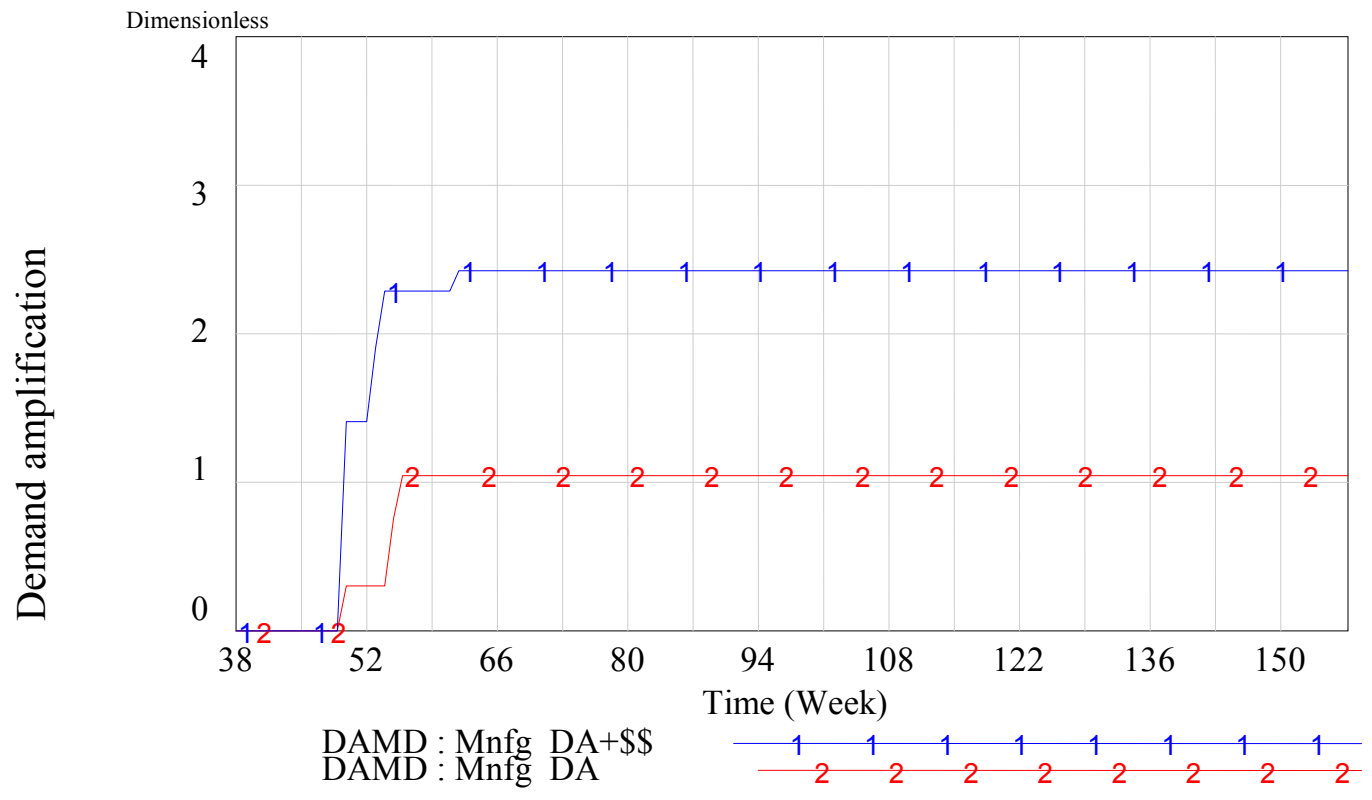

Figure 65. Optimization results for Manufacturer's Demand Amplification considering a $20 \%$ increase step

Recall from the equilibrium analysis in Section 5.4.2.1.2, we obtained demand amplification results for DAMD in the magnitude of five, regarded as a baseline for the optimization results. However, Mnfg $D A$ optimization is able to find settings that yield minimal demand amplification, as shown very close to one. Yet, when introducing profit (GPRT) as additional criterion, $M n f g D A+\$ \$$ denotes the final 
optimization run that takes DAMD up to 2.4 of demand magnification, as shown in Table 31 .

Table 31. Bi-variate optimization results for Manufacturer's demand amplification

\begin{tabular}{ccccc}
\hline Variable & $\begin{array}{c}\text { Normal } \\
\text { Value }\end{array}$ & Time & $\begin{array}{c}\text { Peak } \\
\text { Value }\end{array}$ & Increment \\
\hline Order Rate & 20000 & 50 & 24000 & $20 \%$ \\
Material Delivery & 59.46 & 62 & 88.17 & $48.28 \%$ \\
Rate & & & & \\
\hline Local Demand & & 2.414 & \\
Amplification & & & & \\
Production Rate & & & & \\
\hline
\end{tabular}

At first sight, demand amplification results are disappointing since they do not converge to one. After all, extant literature suggests that ideal treatment should make demand amplification as close to one as possible, therefore eradicating bullwhip.

With a balanced optimization function that incorporates as well the profit criterion, the best performance setting is not the amplification of demand equal to one. The conclusion here is to encourage the use of alternative criterions such as profit (e.g., cost) in order not to lose an integral perspective from what is the best policy for the companies. Results for profit are available at Figure 66.

Note in Figure 66 the same two series: $M n f g D A$ and $M n f g D A+\$ \$$. They appear to be straight lines, which is just in appearance given the scale of the graph; recall that Gross Profit is a stock variable that accumulates profits or losses for the period, therefore the slope of the series is of greatest interest. Notice how during the first year the two series yield very close results, yet in the longer term the configuration 
achieved for $M n f g D A+\$ \$$ is notoriously superior, with an expected profit estimates of more than $25 \%$ increase from the baseline model up to week 158 . The bottom line is, we are able to decrease demand amplification more than hundred percent (from 5.02 to 2.4) while increasing profits in $25 \%$.

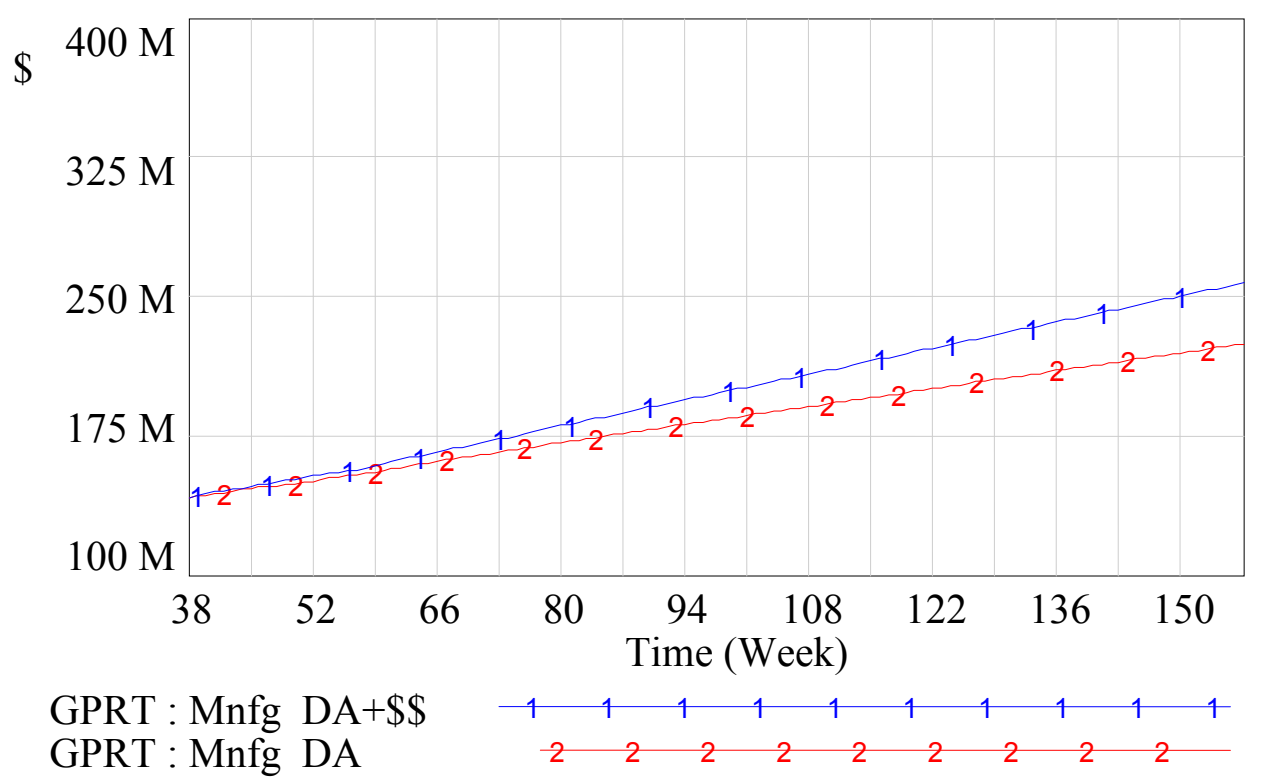

Figure 66. Optimized results for Manufacturer's Gross Profit considering a 20\% increase step

The optimization suggests changes in parameters that need further interpretation, in this way is commonly regarded that SD models focuses in overall tendencies that delineates policy instead of specific actions. Such changes are listed in Table 32, relating the variables with MedLab's management areas. 
The optimal settings propose alternative procurement and production policies than current. For the material supply (sourcing), results poses a vendor with a lower average response time to the company (from a quarter to a week) so it is perceived as faster, as well as lower material safety stock in accordance with the improved supply effectiveness.

Table 32. Manufacturer's parameters changes for DAMD and GPRT optimality

\begin{tabular}{|c|c|c|c|c|}
\hline Area & Variable & Unit & $\begin{array}{l}\text { Original } \\
\text { value }\end{array}$ & $\begin{array}{l}\text { Optimized } \\
\text { value }\end{array}$ \\
\hline \multirow{2}{*}{ 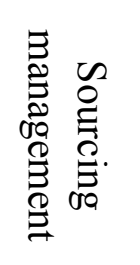 } & $\begin{array}{l}\text { Perceived Supplier } \\
\text { Lead Time }\end{array}$ & Weeks & 12 & 1.02 \\
\hline & $\begin{array}{c}\text { Material Safety Stock } \\
\text { Coverage }\end{array}$ & Weeks & 3.82 & 1.42 \\
\hline \multirow{3}{*}{ 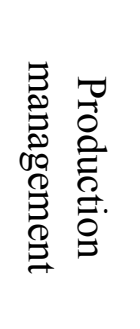 } & $\begin{array}{l}\text { Manufacturing } \\
\text { LeadTime }\end{array}$ & Weeks & 1 & 2.37 \\
\hline & WIP Review Time & Weeks & 1 & 1.95 \\
\hline & Maximum Capacity & Units/Week & 3100000 & 3400000 \\
\hline \multirow{3}{*}{ 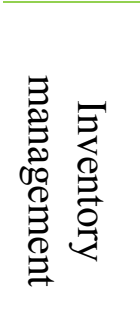 } & $\begin{array}{l}\text { Local Inventory } \\
\text { Review Time }\end{array}$ & Weeks & 1.59 & 1 \\
\hline & $\begin{array}{l}\text { Export Inventory } \\
\text { Review Time }\end{array}$ & Weeks & 1.268 & 1.6 \\
\hline & $\begin{array}{c}\text { Local Safety Stock } \\
\text { Coverage }\end{array}$ & Weeks & 4.214 & 2.76 \\
\hline
\end{tabular}

There are changes in production as well, specifically for the WIP inventory review time and manufacturing lead time to increase at least to its double. The measure 
is associated with current production methods and contravenes established practices in production (i.e., improve efficiency with reduced times). Changes suggest a rethinking of the production network in order to reduce the disparity between variances from the materials and demand side. In addition, the model suggests increased capacity that might help enhance flexibility, thus enabling a closer match between production and demand; a sensitive need particularly for the local sales. Inventory management advice translates to cut in half (finished product) inventory levels and reduce review periods in the same amount.

\section{Global scenario}

In order to perform the optimization for the global scenario, we follow the sequential procedure mentioned in Section 5.4.2.1. We review the optimization settings and discuss results taking in a demand step of $20 \%$ of increase as input to the retailer echelon for bullwhip initial disturbance.

Table 33. Input parameters for demand amplification optimization

\begin{tabular}{cccccc}
\hline Output & ID & Variable & Min & Max & Units \\
\hline & L & Maximum Capacity & 3xE6 & $6 x E 6$ & Weeks \\
& D & Distributor Safety Stock & 1 & 8 & Weeks \\
& O & Materials Inventory Review Time & 1 & 4 & Weeks \\
& A & Retailer Safety Stock & 1 & 4 & Units/Week \\
& N & Material Safety Stock Coverage & 1 & 12 & Weeks \\
& H & Local Safety Stock Coverage & 1 & 8 & Weeks \\
\hline
\end{tabular}

As in the local scenario, we will perform sequential optimization considering demand amplification. Table 33 collects the sensitive parameters ${ }^{17}$ for the variable

\footnotetext{
${ }^{17}$ Notice that the variables Retailer Forecast Review Time and Distributor Forecast Review Time are excluded from the optimization. Given the relative nature of the BWE measure, it came to our attention that
} 
Demand Amplification RetManuf (RETMAN). This variable registers the successive demand peaks (in percentual increase to its base value) during the simulation time of the variable Material Delivery Rate and scans the maximum change to the original disturbance introduced to the retailer by the step, similarly as in Table 20. Material Delivery Rate is the most upstream flow variable for both manufacturer and the overall supply chain model, and captures the demand placed to suppliers, hence is the most favorable output variable for demand amplification measures.

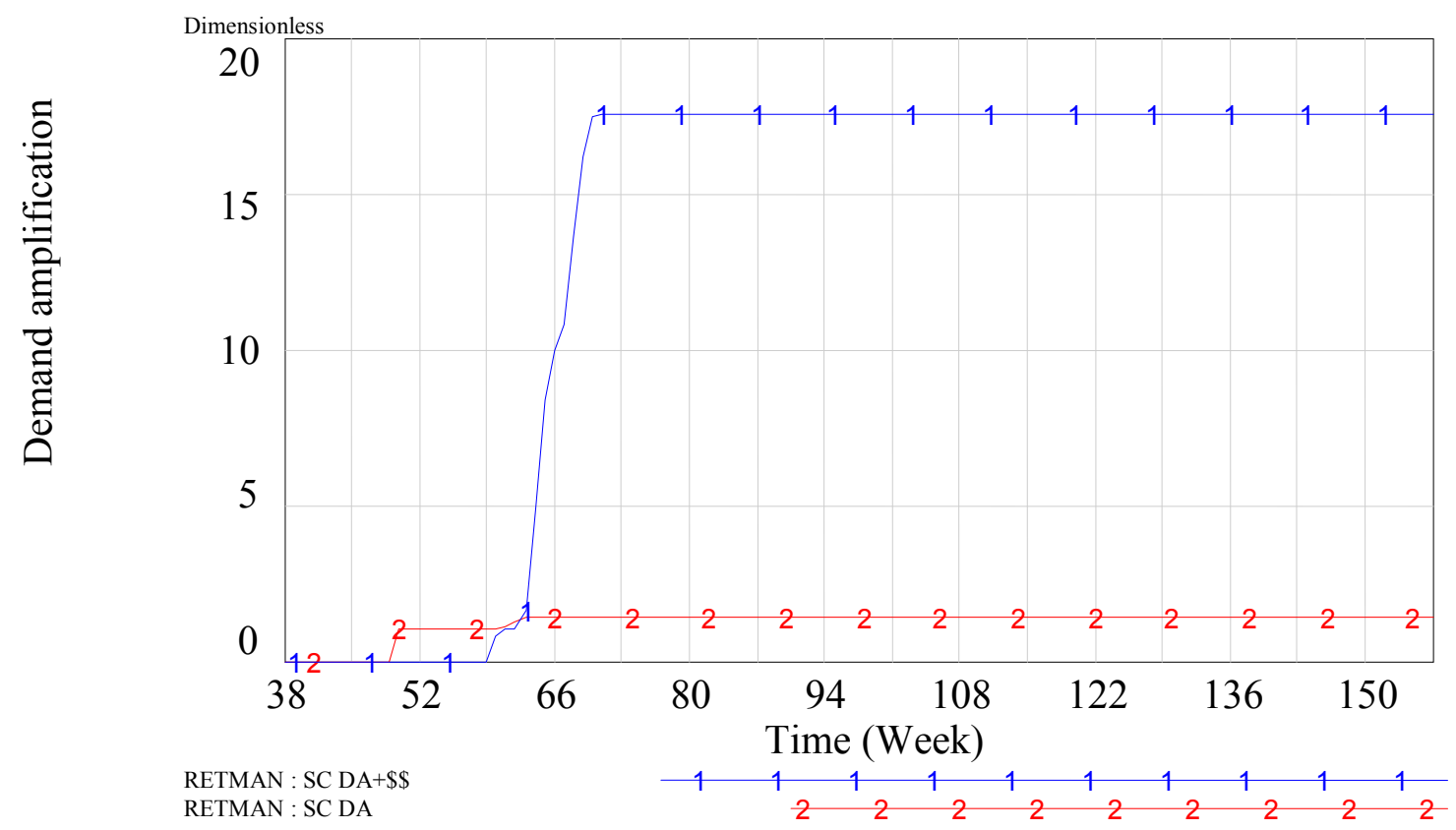

Figure 67. Optimization results for Supply Chain's Demand Amplification considering a $20 \%$ increase step on the chain

the optimization engine in search of a better payoff tended to pervert specific variable settings, in particular the two listed above. Thus, for getting best mathematical results it assigned illogical values to the most downstream variables in order to compensate for the upstream 'bad' behavior (recall the BWE measure is a relative one). For this reason, we did not take them into account. 
RETMAN returns the global demand amplification, which is splitted in two series shown in Figure 68. We first analyze demand amplification for the supply chain, denoted by the $S C D A$ run in the figure. We report a demand amplification reaching a maximal value of 1.411 , with optimal settings found in Vensim. This is an outstanding performance, considering the former 18.54 times amplification reported in Table 22 for the baseline model (calibrated and balanced As-Is).

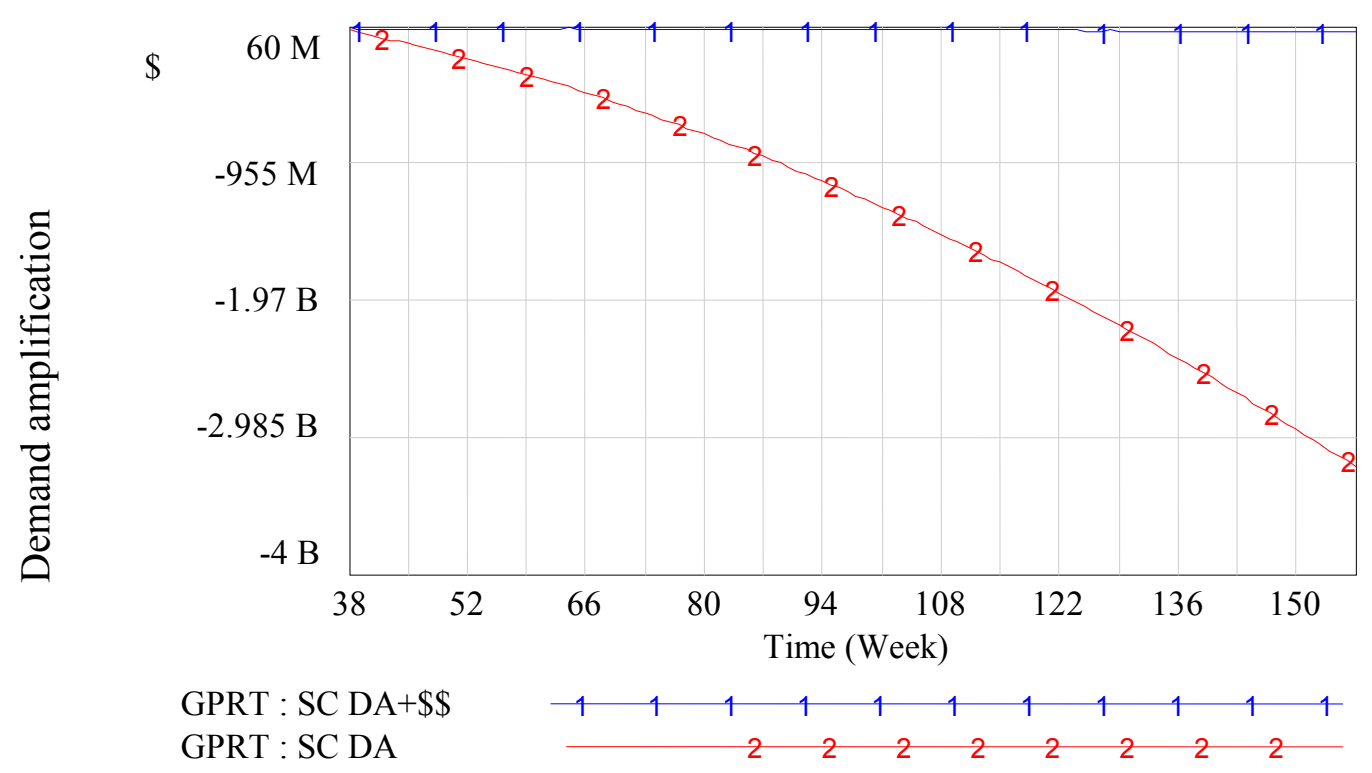

Figure 68. Optimized results for Gross Profit (GPRT) considering a 20\% increase step on the supply chain

At this point is very useful a complementary look on the economical results of the chain. However, we do not have this possibility due to the limitations we discussed earlier. Our second best, then, is to consider the Gross Profit (GPRT) variable which accounts for the accumulated profits of the manufacturer. Results are shown in 
Figure 68 series $S C D A$, which shows a dramatic deterioration of profit for the manufacturer that most probably is extended to other echelons and the chain.

The logical step is to perform a bi-variate optimization for the global scenario. Unfortunately, the lack of an overall supply chain model measure prevents its proper implementation. However, we propose an alternative for the model assessment adjusted for the partial use of the bi-variate criterion devised for improving current results and taking advantage of what we do have available.

Starting from the adjusted parameters from Vensim ${ }^{\circledR}$ 's RETMAN optimization, we set the model to run a new bi-variate optimization only considering the manufacturer and their significant inputs. However, this time we keep the step of $20 \%$ of magnitude but as an input to the retailer echelon. Another change is we use RETMAN (global BWE) instead of DAMD (local BWE), along with the Manufacturer's Gross Profit (GPRT) variable as equally weighted optimization criterions. Finally, we set up as varying parameters the manufacturer' sensible to GPRT (see Table 25) and RETMAN (Table 30) as well, but keeping unchanged former optimal settings from $S C D A$ for both distributor and retailer. The results of such setting we termed as $S C D A+\$ \$$, and are shown in previous Figure 67 and Figure 68. An important result of this procedure is that prevents the optimization engine to pervert results by optimizing costs for the manufacturer at the expense of the downstream echelons.

Table 34 shows the optimization results for RETMAN after the bi-variate optimization for the manufacturer. Note that the value for RETMAN hardly improves 
the baseline demand amplification $(18.54 \rightarrow 17.54)$, but it does remarkably improves profit from the univariate results in $S C D A$ shown in Figure 68.

Table 34. Results for Supply Chain's demand amplification after bi-variate manufacturer optimization

\begin{tabular}{ccccc}
\hline Variable & Time & $\begin{array}{c}\text { Normal } \\
\text { Value }\end{array}$ & $\begin{array}{c}\text { Peak } \\
\text { Value }\end{array}$ & Increment \\
\hline Local SC Input & 50 & 10000 & 12000 & 0.2 \\
$\begin{array}{c}\text { Material Delivery } \\
\text { Rate }\end{array}$ & 71 & 31110 & 45.94 & 0.72 \\
\hline RETMAN & \multicolumn{3}{c}{17.54} \\
\hline
\end{tabular}

However, we stress that reliable results aimed at guiding improvement and establishing supply chain policy should be obtained from global variables optimization. The shortcomings of mixing local and global scenarios and attempting global optimization by means of local variables end up in limited results, such as those in Table 34. These are posted just for illustrative purposes and will not be taken into account for policy formulation in the coming section. 


\section{CHAPTER 6 - CONCLUSIONS}

This dissertation presented a framework called Demand Amplification Protocol (DAMP) that enables demand amplification diagnosis in actual supply chains. After more than fifty years of Bull-whip (BWE) awareness and plentiful appearances in the literature, the fact of the matter is that demand amplification is widespread and in force, and is capable of taking away up to $50 \%$ of profits (McCullen and Towill 2002).

We assert that even though there is a solid body of knowledge and well developed theory around the demand amplification issue, the bridge between theory and practice is fragile. Behind this, there is the lack of an engineering diagnostic framework capable of capturing subtleties of the BWE origins arising from the specifics of each actual case, which prevents systematic detention from practitioners.

Existing diagnostic approaches are based on general principles that owe their success more to the analyst's expertise than to a systematical and structured approach to resolve demand amplification. A customizable diagnostic approach is valuable when demand amplification sources are blurry and might hide or intertwine with others, as shown in Section 1.3.

Our literature review concluded that the Cardiff Approach is the only extant method capable of delivering a demand amplification analysis for an actual supply chain. Although of independent inception, there is resemblance within the Cardiff approach and the DAMP framework, because of the use of similar tools for analogous

purposes of diagnosing actual supply chains, and central to it is the use of system 
dynamics modeling as a basis for both diagnoses. Nonetheless, there are significant differences in aspects such as different 'soft' tools for system characterization and data gathering, process mapping, BWE measurement. Remarkably, there is a whole development used in DAMP for measuring BWE in actual cases (Amaya and Giachetti, 2009) that corrects estimations errors introduced in classical BWE metrics such as the ones used in the Cardiff Approach (Fransoo and Wouters, 2000). On the other hand, LSDG proposes alternate diagnostic basis to SD, such as Control Theory and Statistical Analysis. Moreover, Cardiff's SD use is conventional and from the literature reviewed it mainly focus on generic cases instead of actual cases. LSDG modelers do not use advancements available in contemporary SD software suites, such as Automated Calibration (AC), Automated Sensitivity Analysis (ASA) and Model Optimization (MO).

DAMP has three phases for average implementation of sixteen months. The main phase (Examination) comprehends Business Process and Dynamic Diagnoses, respectively devised for exploring BWE sources associated with, herein termed, conventional and dynamic complexity. Business Process Diagnosis provides the means to depict and measure the informational and physical flow of the supply chain by means of the SCOR Reference Model, improved with a bullwhip measurement framework denoted as BWE Scorecard. Dynamic diagnosis prototypes the real system capturing relevant variables pertaining demand amplification using system dynamics (SD), along with state-of-the-art validation, sensitivity analysis and optimization techniques we term as SS-Opt. 


\subsection{Contributions}

The contributing value of DAMP relies in effective and implementable means for diagnosing bullwhip. The reason why is effective is because not only deals with the conventional sources of bullwhip, provided by the Business Process Diagnosis, but by means of the Dynamic Diagnosis also captures custom details of the supply chain structure and current policy that, although not evidently, might be accountable for significant bullwhip occurrence. In this way, it provides a generic and a custom filter to identify and treat both general and particular BWE sources.

Proof of its implementability is given by the case study herein reported. We had the opportunity to put into practice DAMP in a live supply chain, where during a period of three years of interchange with contacts at all levels from the manufacturer, distributor and retailer network we extracted important insights and validated methodological design, procedure sequence, communication approach, data treatment, and policy recommendations. Most importantly, we concluded the study and shared the findings and policy recommendations to the firms, most of which deemed as relevant and convenient so hence supporting as well its effectiveness. Furthermore, the overall DAMP procedure and case study results had also approval of Colciencias (the Colombian national science government agency) and Universidad del Norte, which jointly disbursed a grant of USD $\$ 114 \mathrm{~K}$ to sponsor this investigation.

The contribution of DAMP also results from the introduction of original approaches and new tools, as well as from enhancing existing methods. The current work presented: a) an approach for estimating the overall bullwhip effect in actual 
multi-echelon supply chains. b) the BWE scorecard, an instrument for monitoring in a single view a set of BWE known-cause metrics related to a central BWE index. c) SSOpt, a procedure based on statistical screening (Ford and Flynn, 2005) and Design of Experiments (DOE) to determine sensitive inputs applied in a subsequent multi-variate optimization of the model.

Regarding SS-Opt, it provides with structure to Systems Dynamics (SD) procedures. SD lacks formal methods to associate structure and behavior of models so as to identify variables or loops behind a given response. Such task takes long even for an experienced SD modeler to master; thus, results are proportional to experience and may vary between different analysts. SS-Opt provides a procedure to obtain specific parameter values associated to desired behavior. In this way, it achieves relating structure and behavior, yet misses more elaborated constructs of the model since unable to modify relations between variables (i.e., table modifications, new variables/relations, feedback loops) as responsible for behavior.

As for the case study, it focuses on MedLab' supply chain and the extent on which demand amplification is present so as to reduce it. MedLab is a mid-sized manufacturer of sterile disposable medical devices located in Colombia (South America). They offer a complete line of plastic widgets and related laboratory supplies, and the organization has deployed a differentiated strategy based on an ample portfolio of high quality products with impeccable delivery compliance, which in practice exhibits serious issues. MedLab supply chain is composed by a manufacturer (MedLab), a distributor and a retailer. 


\subsection{Findings}

We now summarize important findings extracted from DAMP's examination phase. Starting from the Business Process Diagnosis, we distinguished between process review and BWE scorecard examination. From the first, we identified BWE triggers in the manufacturer such as poor or inexistent forecasting, push-based large manufacturing batches, long overseas supplier lead times that justifies further enlarged batches in purchase orders, high inventories splitting operations and consent on non-planned export orders (with higher processing priority) that clash with domestic orders. We also found the presence of volume discount policy throughout the distribution channel and individual forecasts badly executed/nonexistent for both the distributor and retailer.

Now, from the Business Process Diagnosis' BWE scorecard, we learned that all companies of the supply chain individually amplify demand variability, more markedly when relative to imported materials. In addition, most of BWE resides in the manufacturer while it manifests moderately in the downstream links. Furthermore, after a finer measure breaking down operations for determining BWE origins, we also noted that within MedLab's operations BWE concentrates in the interface between purchasing and production decisions. BWE scorecard enabled identifying variables connected with BWE phenomenon, such as price variation, forecast error, internal organizations misalignment, batching and response time among relevant causes.

It turns out that getting in touch with the actual process while performing the process review enables to quickly identify some BWE causes, which are further confirmed by the process assessment from the BWE scorecard. Moreover, BWE metrics 
introduces further refinements to the extent of signaling where and when BWE happens, and why. In example, we notice especial causes during 2004 that produced the noticeable BWE surge, being a general price raise and markedly planning issues reflected in a underestimating forecast. Yet, in later periods where BWE stabilizes, we can identify purchase batching as the predominant cause, because the bullwhip metrics signal that MedLab's purchasing/manufacturer interface concentrates bullwhip occurrence, where the incidence of long supplier lead times (given the recent supplier base moved to Asia) and resulting increased batching are determinant.

In addition, it should be noted that most insights from the process review comes from personal experience and exposure to processes, rather than particular signals or pattern identification from process maps. DAMP does not enriches existing SCOR features, yet serves from them for a structured review processes and a standard communication of process particularities. Thus, although SCOR does not in itself provide a BWE diagnosis foundation, it provides an ordered method for recollecting valuable process information.

Conversely, the BWE scorecard is fundamental in specifying the source of bullwhip whose presence might have been previously identified, but not its impact. The BWE scorecard can be expected to uncover additional sources of bullwhip, such as MedLab's purchasing business information disruptions and poor response time in particular for the domestic market.

Up to this point we have discussed methods and findings related to the actual supply chain observation. We now take as reference the dynamic model of the supply 
chain, and start to discuss DAMP's Dynamic Diagnosis with most notable findings. We have divided the model analysis into two main approaches: Perturbational, exploring the balanced model responses to shock inputs and Optimization, which makes use of the SS-Opt procedure.

The Perturbational analysis allows an observer to identify BWE surges allocated in flow variables while moving upstream in the model, we call these BWE breaking points. It serves from the demand amplification ratio to compare the induced amplification to the initial disturbance, and thus quantify BWE as an index. For the balanced equilibrium analysis, we use two types of settings: manufacturer equilibrium and supply chain equilibrium. The first one regards the manufacturer balanced model analysis when exposed to shock inputs, while the second similarly regards the overall supply chain. The model takes as output reference purchase orders (of an imported material), and considers as inputs both domestic and export (exogenous) sales.

Noticeably, there are two breaking points extracted from the manufacturer equilibrium: referencing to both the local and exports inputs, Production (Production Rate) amplifies 4.31 and 1.61 times the local and export demand right after week 50, and materials planning (Compromised Material Delivery Rate) features the largest amplification respectively of 29.68 and 7.77 respectively, indicating the will to purchase. BWE breaking points can be sustained on the firm's production policy (formerly referred as consent on non-planned export orders) for the case of production; regarding purchasing, batching practices for imported purchases, the search for volume discounts are mainly responsible for demand amplification, which could have been 
greater if it were to exclude current manufacturer's financial restrictions. We conclude from the model results that demand amplification presence is considerably much stronger for the local orders branch of operations, and indeed, it signals the original instability of the system to the continued overshooting of domestic orders' production scheduling.

Regarding the supply chain equilibrium, we are able to register demand amplification magnitudes of 20 times the original variance, with its sources concentrated in both the distributor and manufacturer echelons. Major demand amplification breaking points includes the Distributor's orders placed to the manufacturer (20.16) and, in turn, the Manufacturer's orders placed to suppliers (18.6). Extending the analysis of demand amplification to downstream nodes leads to the conclusion that BWE tends to arise from the echelons interfaces and, again, is brought about by a disproportionate parties' will to source with regards to their actual need. For the case, such will is incentivized by the volume discounts offered by the manufacturer and manufacturer' search for economies of scale in purchasing (batching and volume discounts from suppliers). We also learned that such amplification is, on one side, encouraged by each party to their corresponding customers as in a typical push-based schema, but internally damped, on the other side, by constraints such as manufacturing, warehousing, inventory or financial capacity, which ends up in firm's capacity full utilization.

We end up the model discussion with the findings from the SS-Opt procedure, and conclude DAMP's Dynamic Diagnosis. We conducted first a statistical 
screening in search of sensitive input parameters to response variables associated to both demand amplification and the manufacturer's profit. Next, we ran a sequenced optimization on demand amplification (univariate) and then jointly considering demand amplification and the manufacturer's profit (bivariate), comparing results. Such are the constituting steps of SS-Opt, which as in the previous analysis were applied to both the manufacturer (local scenario) and the overall supply chain (global scenario).

Because of the introduction of an economical optimization criterion counterbalancing demand amplification, we learned from both local and global scenarios that eradicating bullwhip can be more costly than to compromise to a certain extent with existing practices that brings about bullwhip. Such conclusion emphasizes the payback of refined modeling for introducing economical metrics and further addressing the supply chain cash flow.

\subsection{Recommendations}

Table 35 shows at a glance the outcome of DAMP's diverse diagnosis analysis, specifying the cause and the firm where it happens, as well as marking with ones entries where a given cause was identified by which analysis. As seen, diagnosed causes overlap between different analysis and coherently most notorious BWE conditions are marked several times. Yet, they are complementary as well since not all highlight the same causes. In the rightmost column treatments are aligned with the correspondent causes/conditions that are meant to be corrected by each. 
Table 35. Summary of diagnosis and correspondent treatment

\begin{tabular}{|c|c|c|c|c|c|c|c|}
\hline \multirow{2}{*}{ Echelon } & \multirow[b]{2}{*}{ Cause } & \multicolumn{2}{|c|}{ BUSINESS PROCESS DIAGNOSIS } & \multicolumn{2}{|c|}{ DYNAMIC DIAGNOSIS } & \multirow[b]{2}{*}{ Total } & \multirow[b]{2}{*}{ TREATMENT } \\
\hline & & Process Rev & BWE Scard & Perturbational & SS-Opt & & \\
\hline \multirow{2}{*}{ Retailer } & Commercial campaigns & 1 & & & & 1 & \\
\hline & Forecast & 1 & 1 & & & 2 & \multirow{4}{*}{$\begin{array}{c}\text { Collaborative } \\
\text { Forecasting and } \\
\text { Replenishment }\end{array}$} \\
\hline \multirow{2}{*}{ Distributor } & Forecast & 1 & 1 & & & 2 & \\
\hline & Volume discount & 1 & 1 & 1 & & 3 & \\
\hline \multirow{12}{*}{ Manufacturer } & Response time & & 1 & & & 1 & \\
\hline & Forecast & 1 & 1 & & & 2 & \\
\hline & Exports conflict & 1 & & 1 & & 2 & \multirow{4}{*}{ Postponement } \\
\hline & High inventory & 1 & & & 1 & 2 & \\
\hline & Prod. Batch & 1 & & 1 & & 2 & \\
\hline & Prod. Scheduling & & & & 1 & 1 & \\
\hline & Capacity & & & & 1 & 1 & \\
\hline & Purch. Batch & 1 & 1 & 1 & 1 & 4 & \multirow{2}{*}{$\begin{array}{c}\text { Supply Network } \\
\text { Redesign }\end{array}$} \\
\hline & Supplier Lead time & 1 & & & 1 & 2 & \\
\hline & Internal misalignment & & 1 & & & 1 & \\
\hline & Volume discount & & & 1 & & 1 & \\
\hline & Total & 6 & 4 & 4 & 5 & & \\
\hline
\end{tabular}


Table 35 shows the most visible policy recommendations for MedLab' supply chain and addresses the contribution and findings enabled by DAMP. The significance of the contributions are sustained in improved and affordable means for conveniently reducing demand amplification while at the same time improving profit. Based on the case study figures, this is possible in amounts of demand amplification decrease of more than hundred percent whilst increasing profits in $25 \%$. Such figures are promising and impacting, when considering that current industrial and services practices predominantly follow the purchasing, manufacturing and distribution policies herein described for our case study.

\subsection{Limitations}

We will now address what was found to be strengthen or limiting features affecting the present research. We realize that system dynamics (SD) allows for the convenient use of generic models albeit with modifications in parameters and simple model structure customization, which is good for diminishing modeling effort and facilitates non-experts access. In our experience, small model changes in existing structure and a lot on calibration provides good matches with actual firms behavior. Yet, the hardest part is on performing calibration, which is where non-experts would have problems. We have learned that SD calibration features are very powerful and useful in producing a reliable model. It provides a clear guide on whether keeping the extant or to extend the model in order to get a good fit.

As a limitation, during the last part of this research we realize the benefits of introducing economical metrics for the model. We modeled a profit indicator for the 
case of the manufacturer, which lacked a proper validation, and given time limitations was not perfectioned. We also had serious limitations in terms of information availability, so that critical financial data related to the distributor and retailer could not be obtained. For this reason, we could not afford the development of metrics for the other echelons and further modeling of the firm's financial flow. Therefore, this work leaves as a pending research path further elaboration of SD financial flow modeling in addition to material and information flow, to better understand BWE and cost interactions. We envision this type of analysis, with further refinements, as means for finding financial leverage points for both firms and supply chains.

\subsection{Future research}

We also propose as future research the introduction of a more powerful method for enabling to understand and change the system' structure originating bullwhip, such as the use of LEEA as means of sensitivity analysis. We further hypothesize improvement of DAMP's trade-off solutions with even better demand amplification conciliated with profit and/or cost.

Lastly, we mention the need to develop an improved metric for demand amplification in dynamic models, which is posed as another future research path. The demand amplification ratio poses significant problems when implementing SS-Opt. The problem is the relativity of the measure, which leaves space for the optimization engine to increase its payoff to the expense of worse settings in the most extreme points of the model (upstream and downstream). There is the risk for the optimization engine to 
pervert specific variable settings, assigning illogical values to obtain best mathematical results in search of a better payoff. 


\section{LIST OF REFERENCES}

Agrawal, N. and Nahmias, S. (1997) Rationalization of the supplier base in the presence of yield uncertainty, Prod. Oper. Manage., vol. 6, no. 3, pp. 291-308.

Akkermans, H., and Dellaert, N. (2005). The rediscovery of industrial dynamics: The contribution of system dynamics to supply chain management in a dynamic and fragmented world. System Dynamics Review, 21(3), 173-186.

Allvine, D. W., and Gore, T. (2003). Supply chain diagnostics. In J. Gattorna, R. Ogulin and M. W. Reynolds (Eds.), Gower handbook of supply chain management (5th Edition ed., pp. 105-119) Gower Publishing Company.

Amaya, R., and Giachetti, R. E. (2009). A practical measure of the bullwhip effect in supply chains. IIE Annual Conference and Expo 2009 (IERC 2009), Innovations Revealed. Miami, USA.

Angerhofer, B. J., and Angelides, M. C. (2000). System dynamics modelling in supply chain management: Research review. Proceedings of the 32nd Conference on Winter Simulation, Orlando, Fl. USA. 351.

Aracil, J., and Gordillo, F. (1995). Dinámica de sistemas. Isdefe.

Ballou, Ronald H. (1999) Business Logistics Management, 4th Edition. PrenticeHall, Inc. New Jersey

Barlas, Y. (1989). Multiple tests for validation of system dynamics type of simulation models. European Journal of Operational Research, 42(1), 59.

Barlas, Y. (1996). Formal aspects of model validity and validation in system dynamics. System Dynamics Review, 12(3), 183-210.

Beck, R. and Weitzel, T. (2005). Some Economics of Vertical Standards: Integrating SMEs in EDI Supply Chains. Electronic Markets. London: Nov 1, 2005.Vol.15, Iss. 4; pg. 313

Berry, D., and Naim, M. M. (1996). Quantifying the relative improvements of redesign strategies in a P.C. supply chain. International Journal of Production Economics, 46-47, 181.

Bolstorf, P., and Rosenblaum, R. (2003). Supply chain excellence: A handbook for dramatic improvement using the SCOR model. N.Y.: AMACOM.

Bovet, D. and Martha, J. (2000), "From supply chain to value nets", Journal of Strategic Management, July/August, pp. 24-8. 
Bowersox, D. J. and Closs, D. J. (1996). Logistical Management: The Integrated Supply Chain Process. McGraw-Hill, USA.

Bowersox, D.J. and Calantone, R.J. (1998). Executive insights: global logistics. Journal of International Marketing, Vol. 6 No. 4, pp. 83-93.

Burbidge, J. L. (1961). The new approach to production. Production Engineer, 40(12), 769-784.

Busi, M., and Bititci, U. S. (2006). Collaborative performance management: Present gaps and future research. International Journal of Productivity and Performance Management, 55(1), 7-25.

Caplin, A. S., (1985). The variability of aggregate demand with (s, S) inventory policies, Econometrica, 53.

Chan, F. T. S., Qi, H. J., Chan, H. K., Lau, H. C. W., and Ip, R. W. L. (2003). A conceptual model of performance measurement for supply chains. Management Decision, 41(7), 635-642.

Checkland, P. (1999). Systems thinking, systems practiceJohn Wiley and Sons.

Childerhouse, P., and Towill, D. R. (2003). Simplified material flow holds the key to supply chain integration. Omega, 31(1), 17-27.

Childerhouse, P., and Towill, D. R. (2004). Reducing uncertainty in european supply chains. Journal of Manufacturing Technology Management, 15(7), 585-598.

Childerhouse, P., Disney, S. M., and Towill, D. R. (2004). Tailored toolkit to enable seamless supply chains. International Journal of Production Research, 42(17), 3627-3646.

Childerhouse, P., Hermiz, R., Mason-Jones, R., Popp, A., and Towill, D. R. (2003). Information flow in automotive supply chains - present industrial practice. Industrial Management and Data Systems, 103(3), 137-149.

Chopra, S. and Meindl, P. (2004). Supply Chain Management: Strategy, Planning and Operation, 2nd Ed. Pearson Education, India London.

Christopher, M. (1992a), Logistics: The Strategic Issues, Chapman and Hall,

Christopher, M. (1992b), Logistics and Supply Chain Management, Pitman Publishing, London.

Christopher, M. (1998). Logistics and Supply Chain Management: Strategies for Reducing Cost and Improving Service, Second Edition. Financial Times / Prentice-Hall, USA. 
Cigolini, R., Cozzi, M., and Perona, M. (2004). A new framework for supply chain management: Conceptual model and empirical test. International Journal of Operations and Production Management, 24(1), 7-41.

Davis, S.M. (2001). Management: Managing the Future Now, Simon and Schuster, London, 1987.

Dejonckheere, J., Disney, S. M., Lambrecht, M. R., and Towill, D. R. (2002). Transfer function analysis of forecasting induced bullwhip in supply chains. International Journal of Production Economics, 78(2), 133-144.

Dell, M. and Fredman, C. (1999), Direct From Dell: Strategies That Revolutionized an Industry, Harper Collins, London.

Disney, S. M., Lambrecht, M., Towill, D. R., and Van de Velde, W. (2008). The value of coordination in a two-echelon supply chain. IIE Transactions, 40(3), 341-355.

Disney, S.M. and Towill, D.R., (2003). Vendor-managed inventory and bullwhip reduction in a two-level supply chain. International Journal of Operation and Production Management, Vol 23 No 6, pp. 625-651

Donovan, R. M. (N.D.) Supply Chain Management: Cracking The Bullwhip Effect - Part III -. On line at: http://www.rmdonovan.com/pdf/SCM_PartIII.pdf

Eberlein, R. L., and Peterson, D. W. (1992). Understanding models with vensim (TM). European Journal of Operational Research, 59(1), 216-219.

Edghill, J. S., Olsmats, C. M. G., and Towill, D. R. (1988). Industrial case-study on the dynamics and sensitivity of a close-coupled production-distribution system. International Journal of Production Research, 26(10), 1681-1693.

Fisher, M.L., Raman, A. and McClelland, A.S. (2000), Rocket science retailing is almost here: are you ready? Harvard Business Review, Vol. 78 No. 4, pp. 115-24.

Foggin, J. H., Mentzer, J. T., and Monroe, C. L. (2004). A supply chain diagnostic tool. International Journal of Physical Distribution and Logistics Management, 34(10), 827-855.

Ford, A., and Flynn, H. (2005). Statistical screening of system dynamics models. Systems Dynamics Review, 21(4), 273-303.

Forrester, J. W. (1958). Industrial dynamics: A major breakthrough for decision makers. Harvard Business Review, 36(4), 37-66.

Forrester, J., and Senge, P. (1980). Tests for building confidence in SD models. TIMS Studies in the Management Sciences, 14, 208-228. 
Forrester, J.W. (1961), Industrial Dynamics, MIT Press, Cambridge, MA.

Forrester, N. B. (1982). A dynamic synthesis of basic macroeconomic theory: Implications for stabilization policy analysis. Massachusetts Institute of Technology). Ph.D. Thesis, Sloan School of Management,

Fransoo, J. C., and Wouters, J. F. (2000). Measuring the bullwhip effect in the supply chain. Supply Chain Management: An International Journal, 5(2), 78-89.

Frohlich, M. T. and Westbrook, R. (2001). Arcs of integration: an international study of supply chain strategies. Journal of Operations Management 19, 185-200

Gailbraith, J. Designing Complex Organizations. London, U.K.: Addison-Wesley, 1973.

Gonçalves, P., Hines, J., Sterman, J., and Lertpattarapong, C. (2005). The impact of endogenous demand on push-pull production systems. System Dynamics Review, 21(3), 187-216.

Graham, A. K. (1976). Parameter estimation in systems dynamics. In J. Randers (Ed.), Elements of the systems dynamics method (pp. 143-161). U.S.A.: MIT Press/Wright Allen series in Systems Dynamics.

Greene, W. H. (1997). Econometric analysis (3rd) (Third edition ed.). Upper Saddle River, NJ.: Prentice Hall.

Griffiths, M., Hafeez, K., and Nairn, M. M. (1993). Use of statistical techniques in the dynamic modeling of an industrial supply chain. Proceedings of" the 30th International MATADOR Conference, Manchester, United Kingdom, 413-422.

Güneralp, B. (2004). A principle on structure-behavior relations in system dynamics models. Proceedings of the 2004 International System Dynamics Conference, Oxford, UK.

Güneralp, B. (2006). Towards coherent loop dominance analysis: Progress in eigenvalue elasticity analysis. System Dynamics Review, 22(3), 263-289.

Hamilton, M. S. (1976). Estimating lenghts and orders of delays. In J. Randers (Ed.), Elements of the systems dynamics method (pp. 162-183). U.S.A.: MIT Press/Wright Allen series in Systems Dynamics.

Handfield, R. and Pannesi, R. (1992). An empirical study of delivery speed and reliability. International Journal of Operations and Production Management, Vol. 12 No. 2, pp. 60-74.

Handfield, R. B. and Nichols, E. L. (1999) Introduction to Supply Chain Management. Englewood Cliffs, NJ: Prentice-Hall. 
Harland, C. (1996). Supply network strategies - the case of health supplies, European Journal of Purchasing and Supply Management, Vol. 2 No. 4, pp. 183-92.

Heinrich, C.E. and Simchi-Levi, D. (2005), Do IT Investments Really PAY OFF? Supply Chain Management Review; May/Jun 2005; 9, 4; ABI/INFORM Global, pg. 22

Holmberg, S. (2000). A systems perspective on supply chain measurements. International Journal of Physical Distribution and Logistics Management, 30(10), 847868.

Holmstrom, J. (1997). Product range management: A case study of supply chain operations in the european grocery industry. Supply Chain Management: An International Journal, 2(3), 107-115.

Homer, J. B. (1983). Partial-model testing as a validation tool for system dynamics. Proceedings of the 1983 International System Dynamics Conference, 919-932.

Hong, J.; Hayya, J.C. (1992) Just-in-time purchasing: single or multiple sourcing? International Journal of Production Economics. Vol. 27, no. 2, pp. 175-181. 1992

Houlihan, J. B. (1993). International supply chain management. International Journal of Physical Distribution and Logistics Management, 17(2), 51-66.

Hum, S. and H. Sim (1996) Time-based competition: literature review and implications for modeling. International Journal of Operations and Production Management, Vol. 16 No. 1, pp. 75-90.

International Conference on Systems Dynamics, Norway. (1976). In Randers J. (Ed.), Elements of the systems dynamics method. U.S.A.: MIT Press/Wright Allen series in Systems Dynamics.

Jayaram,J., Vickery, S.K. and Droge, C. (1999). An empirical study of time-based competition in the North American automotive supplier industry. International Journal of Operations and Production Management, Vol. 19 No. 10, 1999, pp. 1010-1033.

Kahneman, D., P. Slovic and Tversky, A. (1982) Judgment under Uncertainty: Heuristics and Biases. Cambridge, England: Cambridge University Press.

Kampmann, C. E. (1996). Feedback loop gains and system behavior (unpublished manuscript). Proceedings of 1996 Int System Dynamics Conference, Cambridge, MA. 260-263.

Kampmann, C. E., and Oliva, R. (2006). Loop eigenvalue elasticity analysis: Three case studies. System Dynamics Review, 22(2), 141-162.

Kaoa, H.Y.; Huangb, C.H. and Li, H.L., (2005). Supply chain diagnostics with dynamic Bayesian networks. Computers and Industrial Engineering 49 339-347 
Kasanen, E., and Lukka, K. (1993). The constructive approach in management accounting research. Journal of Management Accounting Research, (5), 243.

Kasi, V. (2005). Systemic assessment of SCOR for modeling supply chains. System Sciences, 2005.HICSS'05. Proceedings of the 38th Annual Hawaii International Conference on, , 87b-87b.

Kay, E. (2005), Sears Holding Corp. Faces Massive Supply Chain Integration Challenge. Frontline Solutions; Jun 2005; 6, 5; ABI/INFORM Global, pg. 14.

Kleijnen, J. P. C. (2005). An overview of the design and analysis of simulation experiments for sensitivity analysis. European Journal of Operational Research, 164(2), 287-300.

Kurt Salmon Associates, Efficient Consumer Response: Enhancing Consumer Value in the Grocery Industry, The Joint Industry Project on Efficient Consumer Response, Washington D.C., 1993

Lambert, D.M. and Stock, J.R.(2001).Strategic Logistics Management. McGrawHill Education - Europe.

Lee, H. L. (2000). Creating value through supply chain integration. Supply Chain Management Review, 4(4), 30-36.

Lee, H. L., and Whang, S. (2001). E-business and supply chain integration. Standford Global Supply Chain Management Forum, 2

Lee, H. L., Padmanabhan, V., and Whang, S. (1997). Information distortion in a supply chain: The bullwhip effect. Management Science, 43(4), 546-558.

Lee, H. L., Padmanabhan, V., and Whang, S. (1997a). The bullwhip effect in supply chains. Sloan Management Review, 38(3), 93-102.

Long, J. D., and Cliff, N. (1997). Confidence intervals for kendall's tau. British Journal of Mathematical and Statistical Psychology,

Lowson, B.; King, R. and A. Hunter (1999). Quick Response: Managing the supply chain to meet consumer demand. Chichester, West Sussex, England: Wiley.

Lukka, K., and Kasanen, E. (1995). The problem of generalizability: Anecdotes and evidence in accounting research. Accounting, Auditing and Accountability Journal, 8(5), $71-90$.

Lyneis, J. M., and Pugh, A. L. (1996). Automated vs. 'hand'calibration of system dynamics models: An experiment with a simple project model. Proceedings of the 1996 International System Dynamics Conference, 42 
Mariño, N. (2003, 2003-02-25). Óptimos globales y cadena de suministro. Diario La República,

Martín-Andino Benítez, R. (2006). El efecto látigo (bullwhip) en las cadenas de suministro y la dependencia de los agentes que las integran. Unpublished Universidad Pontificia Comillas de Madrid, ETS De Ingeniería (ICAI), Departamento De Organización Industrial, Madrid, España.

Mason-Jones, R., and Towill, D. R. (1998). Shrinking the supply chain uncertainty circle. Control, (September), 17-22.

McCullen, P., and Towill, D. (2002). Diagnosis and reduction of bullwhip in supply chains. Supply Chain Management: An International Journal, 7(3), 164-179.

McCullen, P., and Towill, D. R. (2001). Practical ways of reducing bullwhip: The case of the glosuch supply chain. Control, December/January, , 24-30.

Metters, R. (1997). Quantifying the bullwhip effect in supply chains. Journal of Operations Management, 15(2), 89-100.

Moberg, C.R; Speh, T.W. and Freese, T.L. (2003).SCM: Making the vision a reality. Supply Chain Management Review; Sep/Oct 2003; 7, 5; pg. 34

Mojtahedzadeh, M., Andersen, D., and Richardson, G. P. (2004). Using digest to implement the pathway participation method for detecting influential system structure. System Dynamics Review, 20(1), 1-20.

Monczka, R. and Morgan, J. (1997). What's wrong with supply chain management? Purchasing; Jan 16, 1997; 122, 1; pg. 69

Morecroft, J (1982) A critical review of diagramming tools for conceptualizing feedback models. Dynamica 8(I), 20-29

Morecroft, J. D. W. (1988). System dynamics and microworlds for policymakers. European Journal of Operational Research, 35(3), 301-320.

Naim, M. M., and Towill, D. R. (1994). Establishing a framework for effective materials logistics management. International Journal of Logistics Management, 5, 189197.

Naim, M. M., Childerhouse, P., Disney, S. M., and Towill, D. R. (2002). A supply chain diagnostic methodology: Determining the vector of change. Computers and Industrial Engineering, 43(1-2), 135-157.

Oliva, R. (1996). A dynamic theory of service delivery: Implications for managing service quality. Unpublished Ph.D., Massachusetts Institute of Technology. 
Oliva, R. (2003). Model calibration as a testing strategy for system dynamics models. European Journal of Operational Research, 151(3), 552-568.

Oliva, R. (2004). Partition heuristics and feedback structure decomposition. System Dynamics Review, 20(4), 313-336.

Oliva, R., and Mojtahedzadeh, M. T. (2004). Keep it simple: Dominance assessment of short feedback loops. Proceedings of the 2004 International System Dynamics Conference, Oxford, UK.

Peterson, D. W. (1969). Hypothesis, estimation, and validation of dynamic social models--energy demand modeling Unpublished Doctor of Philosophy, Massachusetts Institute of Technology, Cambridge M.A., USA.

Peterson, D. W. (1980). Statistical tools for system dynamics. In J. Randers (Ed.), Elements of the system dynamics method (pp. 224-241) MIT Press. Cambridge, Mass.

Porter, Michael E. (1985). Competitive advantage : creating and sustaining superior performance. New York : Free Press ; London : Collier Macmillan.

Power, D. (2005). Supply chain management integration and implementation: A literature review. Supply Chain Management: An International Journal, 10(4), 252-263.

Prida, B. and Gutierrez, G. (1996). Logística de Aprovisionamientos: el cambio en las relaciones proveedor-cliente, un nuevo desafío para la empresa del siglo XXI. Mc Graw-Hill, Madrid.

Purchasing. SCOR model users get new benchmarking tool. Purchasing.Com, 126(5), July 16, 2006. Retrieved July 16, 2006, from http://www.purchasing.com/article/CA125752.html

Randers, J. (. ). (1976). In Randers J. (Ed.), Elements of the systems dynamics method. U.S.A.: MIT Press/Wright Allen series in Systems Dynamics.

Richardson, G. P., and Pugh, A. L. (1981). Introduction to system dynamics modelling with DYNAMO. Cambridge: MIT Press.

Rommel, G. (1995). Simplicity wins: How Germany's mid-sized industrial companies succeed. Harvard Business School Press.

Rubiano Ovalle, O., and Crespo Marquez, A. (2003). The effectiveness of using ecollaboration tools in the supply chain: An assessment study with system dynamics. Journal of Purchasing and Supply Management, 9(4), 151-163.

Sabath, R.E. and Fontanella, J. (2002), The unfulfilled promise of supply chain collaboration. Supply Chain Management Review, Vol. 6 No. 4, pp. 24-9. 
Sahin, F. and Robinson, E.P. (2002). Flow coordination and information sharing in supply chains: Review, implications and directions for future research. Decision Sciences; Fall 2002; 33, 4; ABI/INFORM Global, pg. 505.

Saleh, M. (2002). The characterization of model behavior and its causal foundation. Unpublished Ph.D., University of Bergen, Bergen,

Saleh, M., and Davidsen, P. (2000). An eigenvalue approach to feedback loop dominance analysis in nonlinear dynamic models. Proceedings of the 2000 International System Dynamics Conference,

Saleh, M., and Davidsen, P. (2001). The origins of business cycles. Proceedings of the 2001 International System Dynamics Conference,

Saleh, M., Oliva, R., Kampmann, C. E., and Davidsen, P. I. (2009). A comprehensive analytical approach for policy analysis of system dynamics models. European Journal of Operational Research,

Schonberger, R. J. (1982). Japanese manufacturing techniques: Nine hidden lessons in simplicity. Free Press.

Seifert, D. Collaborative Planning, Forecasting and Replenishment: How to Create a Supply Chain Advantage. American Management Association, NY. 2003

Senge, P. M. (1993). The fifth discipline: The art and practice of the learning organization. NY: Century Business.

Shister, N. (2005), 50\% of Companies Fail to Meet the Cost of Capital in their Global Value Chains. World Trade. Troy: Jul 2005. Vol. 18, Iss. 7; p. 25.

Simatupang, T. M. and R. Sridharan (2002). The collaborative supply chain. International Journal of Logistics Management; 13, 1; pg. 15

Simatupang, T. M., and Sridharan, R. (2005). The collaboration index: A measure for supply chain collaboration. International Journal of Physical Distribution and Logistics Management, 35(1), 44-62.

Simchi-Levi, D., Kaminsky, P. and Simchi-Levi, E. (2000) Designing and Managing the Supply Chain. Mc Graw-Hill, USA.

Simchi-Levi, D., Kaminsky, P. and Simchi-Levi, E. (2004). Managing the Supply Chain: The Definitive Guide for the Business Professional. Mc Graw-Hill, USA.

Sinha, R. K., and Babu, A. S. (1998). Quality of customer service in supply chain system: A diagnostic study. International Journal of Quality and Reliability Management, 15(8/9), 844-859. 
Soto, M. (2010). Calibración y Data Screening en Dinámica de Sistemas como Estrategia para la Cuantificación de Amplificación de Demanda en Cadenas de Suministro. Unpublished Magíster en Ingeniería Industrial, Universidad del Norte, Barranquilla, Colombia.

Stalk, G.(1988). Time: the next source of competitive advantage. Harvard Business Review, July-August 1988, pp. 41-51.

Stephens, S., (2001). Supply Chain Operations Reference Model Version 5.0: A New Tool to Improve Supply Chain Efficiency and Achieve Best Practice. Information Systems Frontiers 3:4, 471-476

Sterman, J. D. (1984). Appropriate summary statistics for evaluating the historical fit of system dynamics models. Dynamica, 10(2), 51-66.

Sterman, J. D. (2000). Business dynamics: Systems thinking and modeling for a complex world Irwin/McGraw-Hill.

Sterman, J.D. (1987). Expectation formation in behavioral simulation models. Behavioral Science Vol 32, pp 190-211.

Sterman, J.D. (1989). Modeling managerial misbehavior: misperceptions of feedback in a dynamic decision making experiment. Management Science Vol 35, No. 3, March 1989. pp 321-339

Sterman, J.D. (2000). Business Dynamics: systems thinking and modeling for a complex world. Irwin Mc Graw-Hill, USA.

Stevens, G. C. (1989). Integrating the supply chain. International Journal of Physical Distribution and Logistics Management, 19(8), 3-8.

Stock, G.N.; Greis, N.P. and Kasarda, J.D. (2000). Enterprise logistics and supply chain structure: the role of fit. Journal of Operations Management 18, pp. 531-547.

Supply-Chain Council. (2003). Supply-chain operations reference Model-SCOR version 6.0. Supply-Chain Council, Inc,

Supply-Chain Council. (2008). Supply-chain operations reference Model-SCOR version 9.0. Supply-Chain Council, Inc,

Suri, R. (1998). Quick Response Manufacturing: A company-wide approach to reduce lead times. Portland, Ore. : Productivity Press.

Suryani, E., Chou, S., and Chen, C. (2010). Air passenger demand forecasting and passenger terminal capacity expansion: A system dynamics framework. Expert Systems with Applications, 37(3), 2324-2339. 
Svensson, G. (2003). The bullwhip effect in intra-organisational echelons. International Journal of Physical Distribution and Logistics Management, 33(2), 103-131.

Tank-Nielsen, C. (1976). Sensitivity analysis in system dynamics. In J. Randers (Ed.), Elements of the systems dynamics method (pp. 187-203). U.S.A.: MIT Press/Wright Allen series in Systems Dynamics.

Theil, H. (1966). Applied economic forecasting Amsterdam.

Towill, D. R. (1996). Industrial dynamics modelling of supply chains. International Journal of Physical Distribution and Logistics Management, 26(2), 23-42.

Towill, D. R. (1996). Time compression and supply chain management-a guided tour. Supply Chain Management: An International Journal, 1(1), 15-27.

Towill, D. R. (1997). FORRIDGE-principles of good practice in material flow. Production Planning and Control, 8(7), 622-632.

Towill, D. R. (1997). The seamless supply chain - the predator's strategic advantage. International Journal of Technology Management, 13(1), 37-56.

Towill, D. R. (1999). Simplicity wins: Twelve rules for designing effective supply chains. Control, (March), 9-13.

Towill, D. R., and Vecchio, A. D. (1994). The application of filter theory to the study of supply chain dynamics. Production Planning and Control, 5(1), 82-96.

Towill, D. R., Naim, M. M., and Wikner, J. (1992). Industrial dynamics simulation models in the design of supply chains. International Journal of Physical Distribution and Logistics Management, 22(5), 3-13.

Towill, D.R.; Childerhouse, P. and Disney, S.M., (2000). Speeding up the progress curve towards effective supply chain management. Supply Chain Management: an International Journal, Vol 5 No 3, pp. 122-130

Towill, D.R.; Childerhouse, P. and Disney, S.M., (2002). Integrating the automotive supply chain: where are we now? International Journal of Physical Distribution and Logistics, Vol 32 No 2, pp. 79-95

Trkman, P., Stemberger, M. I., Jaklic, J., and Groznik, A. (2007). Process approach to supply chain integration. Supply Chain Management: An International Journal, 12(2), 116-128.

Vachon, S. and Klassen, R.D. (2002). An Exploratory Investigation of the Effects of Supply Chain Complexity on Delivery Performance. IEEE Transactions on Engineering Management, Vol. 49, No. 3, August 2002. 
Van Landeghem, R., and Persoons, K. (2001). Benchmarking of logistical operations based on a causal model. International Journal of Operations and Production Management, 21(1/2), 254-267.

Ventana Systems, I. Vensim documentation. Retrieved July/12, 2006 from http://www.vensim.com/documentation.html

Vrijhoef, R. (2009). Supply chain integration in construction. Retrieved September 21, 2009, from http://www.citg.tudelft.nl/live/pagina.jsp?id=51777052-f02f-4633-a5f47973faa7c597andlang=en

Wolf, W.B. (1994) The Parable of Diagnostics. Journal of Organizational Change Management, Vol. 7 No. 3, 1994, pp. 6-7. MCB University Press, 0953-4814.

Wood, A. (1997) Extending the supply chain: strengthening links with IT, Chemical Week, Vol. 159 No. 25, p. 26. 


\section{APPENDIX A. HOW TO DEFINE A SUPPLY CHAIN}

The diagnostic team needs to define the scope of the project in terms of how far it will reach through the firms involved in the project, and what functions, processes and products will be included. Since there could be a massive number of combinations of products/processes embedded in a logistics system, it is essential for success the right selection of an affordable sample to study. In the present work, we make use of simple matrixes to help align and organize together factors such as $\operatorname{product}(\mathrm{s})$, customer/market/geography and supplier(s), after the guidelines from Bolstorf, P., and Rosenblaum, R. (2003).

The initial step consists of identifying the major players of the Supply Chain, from the perspective of the primary firm. The market is defined as a group of customers and potential customers who operate on similar business models (i.e. direct-toconsumer, retail, distributor, and original equipment manufacturer (OEM)). A strategic tool for identifying the critical customers consists of Pareto lists, using as sorting criteria revenue and profit. However, there are additional considerations that could be brought by the firm as complementing criteria. Then, further differentiation should be made in terms of geographical market served and the market channel used to supply the customer.

The next step is to define representative products to be included in the audit. It is helpful to start looking on high-aggregated levels of product families or groups, which most often will make easier the data gathering since might be aligned with how 
the business units are organized and managed, or how they are reported in financial statements. As a result, a convenient reduction of the complexity of the modeling and process mapping that lies ahead is achieved.

Table A- 1. Supply Chain Definition Matrix

\begin{tabular}{|c|c|c|c|c|c|c|c|c|c|}
\hline \multirow{3}{*}{\multicolumn{2}{|c|}{$\begin{array}{l}\text { Supply Chain } \\
\text { Definition Matrix }\end{array}$}} & \multicolumn{8}{|c|}{ Customer/Channel/Market } \\
\hline & & \multicolumn{5}{|c|}{ Local Market } & \multicolumn{3}{|c|}{ International } \\
\hline & & Retail & Distributors & $\begin{array}{c}\text { Direct } \\
\text { Consumer }\end{array}$ & $\begin{array}{c}\text { Key } \\
\text { Accounts }\end{array}$ & $\begin{array}{c}\mathrm{e}- \\
\mathrm{biz}\end{array}$ & $\begin{array}{c}\text { U.S. } \\
\text { Exports }\end{array}$ & $\begin{array}{l}\text { Wal- } \\
\text { Mart }\end{array}$ & EU \\
\hline \multirow{5}{*}{ 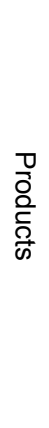 } & Construction & & $x$ & & $x$ & & & & \\
\hline & Plastics & $x$ & $x$ & $\mathrm{x}$ & & & $x$ & & \\
\hline & Resins & & & & $x$ & $x$ & & & \\
\hline & Agro/chem & & $x$ & & & & & & $x$ \\
\hline & Animal Food & & $x$ & & & & & $x$ & \\
\hline
\end{tabular}

Source: adapted from Bolstorf, P. and Rosenblaum, R. (2003)

Hence, the use of a representative customer/channel/market dimension combined with an aggregation of products, as formerly described, conform a matrix such as the one described above in Table A-1. Note that some of the cells are marked denoting an suitable client/product combination for the firm, which specifies a particular supply chain within the organization, unique on each logistic system and/or diagnostic effort. Once this information is exposed in such a structure, it clearly suggests the potential supply chain candidates to be investigated.

In a similar way, strategic suppliers can be categorized as customers by means of Pareto lists, using as ranking criteria material spending. Then, an additional 
categorization will be identifying largest suppliers for each major commodity type (packaging; tooling; process materials; maintenance, repair and operations (MRO); value-added services; and the like). Once again, supplemental criteria can be brought by the team as important considerations.

The expected outcome is to simplify the complexity of the multiple mixtures of product-customer-supplier, in order to be able to identify the most critical candidates to be subjects of this kind of auditing. The most impacting combinations should be selected to narrow down the scope of the project.

It follows that the subsequent screening of each of the selected supply chains in the pre-diagnostic phase (including process mapping to analyze flows, and key performance indicators) provides an alternate basis to assess the suitability of the candidates. 


\section{APPENDIX B. SENSITIVITY ANALYSIS IN SYSTEM DYNAMICS MODELS}

Sensitivity analysis is a primary concern in system dynamics model building and review. Problems commonly analyzed in system dynamics necessitate the incorporation of relationships and parameters for which little empirical data are available, altogether with the difficulty of quantifying the system elements. Furthermore, models are often hard to understand, and sensitivity analysis provides means to gain increased understanding of how they work.

In general, sensitivity analysis deals with the systematic study of the responses obtained as a consequence of changes introduced to the model. Sensitivity analysis asks whether conclusions change in ways important to the modeler's purpose when assumptions are varied over the plausible range of uncertainty (Sterman, 2000). Tank-Nielsen (1976) poses that the main objectives pursued by sensitivity analysis include:

A.) Test the Effects of Uncertainties in Parameter Values. In most cases, there is limited information about certain model parameters, or there are doubts about their static (deterministic) behavior over the reference period of analysis. Typically, their values will be known within a range, but not precisely. In system dynamics, often making a rough model at an early stage and subjecting it to a sensitivity analysis can be useful in identifying what is important data. As system dynamics models normally will be insensitive to variations in most model parameters (J. W. Forrester, 1961) provided that the variations are kept within a realistic range, an important role of sensitivity testing aims at identifying those parameters to which the model is sensitive. It is 
expected that sensitivity testing will reveal what few parameters have the potential to alter the model's behavior mode (Ford and Flynn, 2005). Hence, effort should be put into estimating or reformulating these parameters, while the other parameters are left at their low level of precision - which still is sufficient to let the model fulfill its purpose. Afterwards, sensitive parameters should be varied within their assumed range of uncertainty in order to see if that changes overall model behavior. Moreover, sensitivity testing ideally reveals what feedback loops govern the model's behavior (N. B. Forrester, 1982). Consequently, further work should be directed toward verification and understanding of this part of the structure. In particular, one promising technique, loop eigenvalue elasticity analysis (N.B. Forrester, 1982; Kampmann, 1996; Kampmann and Oliva, 2006; Oliva and Mojtahedzadeh, 2004) have interesting applications to determine in a systematic way the impact of feedback loops in oscillating systems.

B.) Generate Insight. First, a distinction between insights about structure and behavior - the relation between changes in model' structure or parameters and model's behavior — and insights about real world — to establish a valid concordance between real-world and model behaviors. As for the first one, important considerations include: discovering which behavior modes the model can generate; identifying the model changes which can shift the model from one behavior mode to another; identifying the active and dormant parts of the model structure; evaluating whether the dynamic behavior in models with exogenous inputs is generated by external or internal forces. The second one focuses on building confidence on the model, in a way that if the model 
matches the real-world system it is meant to portray, insights can be transferred to the real-world from alternative scenarios devised.

On the other hand Sterman (2000) classifies sensitivity analysis corresponding to three types, as follows:

Numerical sensitivity: exists when a change in assumptions changes the numerical values of the results. For example, changing a given input in the model will change its output. All models exhibit numerical sensitivity.

Behavior mode sensitivity: exists when a change in assumptions changes the patterns of behavior generated by the model. For example, if plausible alternative assumptions changed the behavior of a model from behaviors ${ }^{18}$ like smooth adjustment to oscillation or from s-shaped growth to overshoot and collapse, the model would exhibit behavior mode sensitivity.

Policy sensitivity: exists when a change in assumptions reverses the impacts or desirability of a proposed policy. If a given policy under one set of assumptions is beneficial but led to a ruinous situation under another, the model would exhibit policy sensitivity.

The types of sensitivity of concern in any project depend on the purpose of the model. In particular, in modeling entrepreneurial systems as in the present work, numerical sensitivity may be relatively less of a concern when compared to policy sensitivity, since the goal is to be able to diagnose and further propose a robust policy to

${ }^{18}$ For a complete reference on system behaviors see Sterman (2000), Ch 4. 
avoid demand amplification. The uncertainty in parameter values is important and must be tested, but models are typically much more sensitive to assumptions about the boundary and formulations than to uncertainty in numerical values (Sterman, 2000).

When assessing sensitivity to parametric assumptions identify first the plausible range of uncertainty in the values of each parameter or nonlinear relationship. Then, test the sensitivity to those parameters over a much wider range, to avoid overconfidence in judgemental parameters. Sterman specifies as a good rule of thumb to test over a range at least twice as wide as statistical and judgmental considerations suggest.

Most system dynamics and simulation software packages include automated sensitivity analysis tools, which provide an invaluable assistance in performing sensitivity analysis (including model parameters calibration and optimization; see Eberlein and Peterson (1992)). By specifying which parameters to vary and then providing a range of values for each, the software then runs the model several times, using the specified values for each parameter, either one at a time (univariate testing) or all at once (multivariate testing) providing appropriate confidence intervals of the output.

A final comment on sensitivity analysis stresses its importance all along the modeling effort. It is often viewed as a test to be performed after the model is complete, yet in system dynamics, modeling sensitivity analysis is more an activity spread throughout the model-building process (Tank-Nielsen, 1976). 


\section{APPENDIX C. LIST OF PARAMETERS ACTUALLY USED IN THE MODEL}

The dynamic model makes use a set of exogenous variables that has been used both in the dynamic model description and calibration sections. This section alphabetically enlists all of the external inputs to the models, or parameters, declaring the actual values used in the model after adjustments, as shown in Table C- 1 .

Similarly, subsequent Table C- 2 shows the Table Functions and corresponding data pairs that define them. Note that in the last column of Table C- 2 the reported values starts with a pair of coordinates between brackets, denoting the extreme points of the function; then, it follows the series of coordinates that define the function. 
Table C- 1. Exogenous Variables and Values

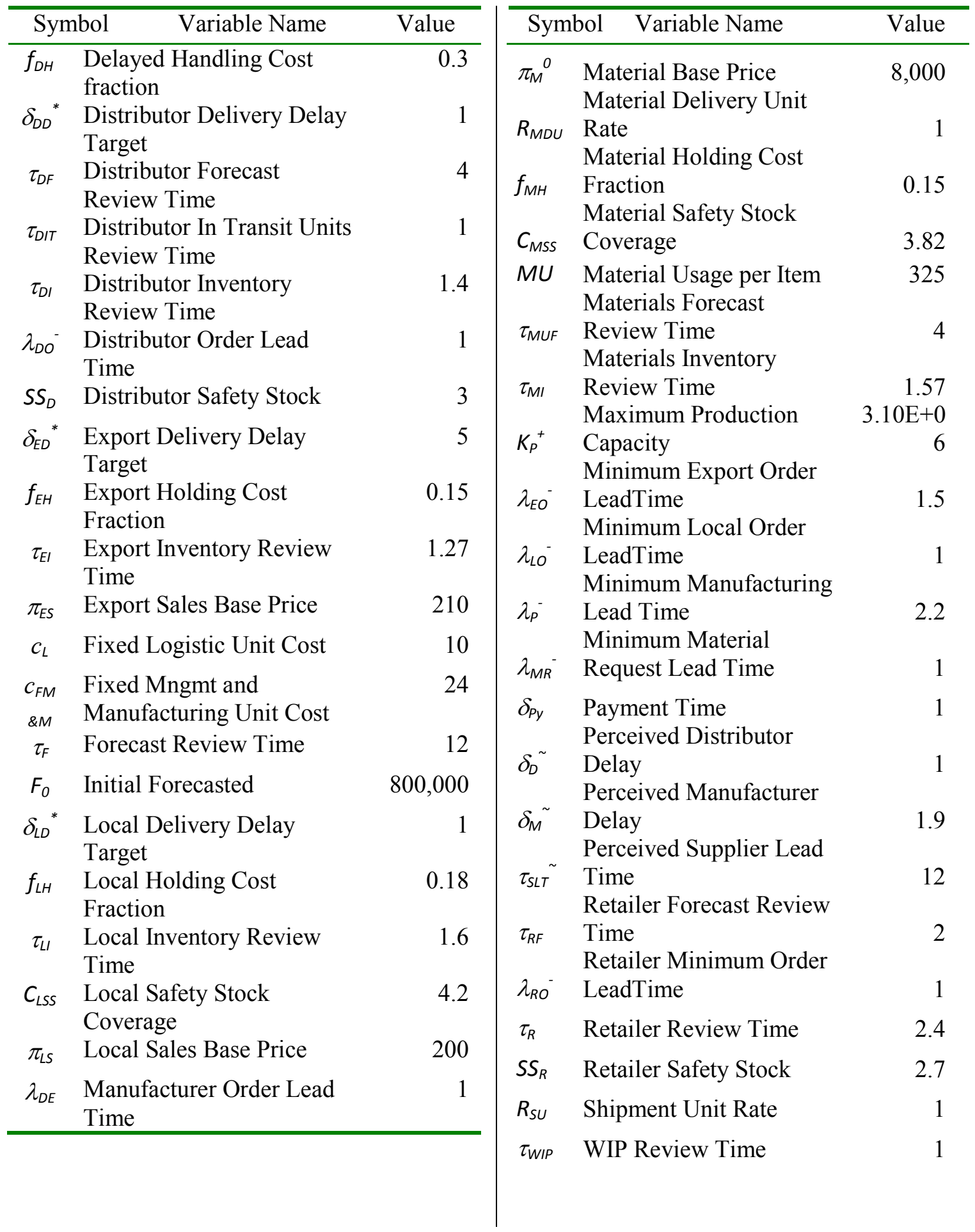


Table C- 2. Table Functions and Values

\begin{tabular}{lll}
\hline Symbol & Table name & Function Coordinates \\
\hline$T_{D O}$ & Table for Distributor & {$[(0,0)-(10,1)],(0,0),(0.2,0.2),(0.4,0.4),(0.6,0.58)$,} \\
& Orders & $(0.8,0.7),(0.9,0.8),(1,0.9),(1.2,1),(2,1),(3,1),(10,1))$ \\
$T_{E F}$ & Table for Export & {$[(0,0)-(10,1)],(0,0),(0.2,0),(0.4,0.1),(0.6,0.2),(0.8,0.3)$,} \\
& Order Fulfillment & $(1.1,0.5),(1.2,0.8),(1.4,1),(2,1),(3,1),(4,1),(10,1))$ \\
$T_{I}$ & Table for Inventory & {$[(0,0)-(10000,10)],(1,10),(10,8),(50,7),(100,6),(200,5.6)$,} \\
& & $(352.94,5.27),(500,5),(847.06,4.6)$, \\
& & $(1294.12,4.06),(1905.88,3.34),(2500,2.5),(5000,1),(10000,1))$ \\
$T_{L F}$ & Table for Local & {$[(0,0)-(600,1)],(0,0),(0.2,0.08),(0.4,0.25),(0.6,0.5)$,} \\
& Order Fulfillment & $(0.8,0.6),(1,0.8),(1.2,0.9),(1.4,0.95),(1.6,0.97),(1.8,1),(2,1)$, \\
& & $(2.2,1),(2.4,1),(2.6,1),(2.8,1),(3,1),(4,1),(5,1),(10,1),(100,1)$, \\
$T_{M U}$ & & $(500,1))$ \\
& Table for Material & {$[(0,0)-(1000,1)],(0,0),(0.2,0.2),(0.4,0.4),(0.6,0.58)$,} \\
& Usage & $(0.8,0.73),(1,0.85),(1.2,0.93),(1.4,0.97),(1.6,0.99),(1.8,1),(2,1)$, \\
$T_{M D}$ & & $(10,1),(20,1),(100,1),(1000,1))$ \\
& Table for Materials & {$[(0,0)-(35000,1)],(0,1),(5000,1),(7000,0.71),(10000,0.51)$,} \\
& Discounts & $(13000,0.41),(14000,0.35),(15000,0.33),(20000,0.26),(23000,0$ \\
$T_{P y}$ & & $(2),(30000,0.17),(35000,0.13))$ \\
& Table for Payment & {$[(0,0)-(8 \mathrm{e}+008,10)],(0,0),(1000,0),(2000,1),(3000,1)$,} \\
& Delay & $(4000,2),(5000,3),(6000,3),(7000,4),(8000,5),(9000,5),(10000$, \\
$T_{D}$ & & $4),(1 \mathrm{e}+006,4))$ \\
& Table for Product & {$[(0,0)-(1 \mathrm{e}+007,1)],(0,0),(100000,0.1),(500000,0.2)$,} \\
& Discount & $(1 \mathrm{e}+006,0.25),(2 \mathrm{e}+006,0.35),(3 \mathrm{e}+006,0.4),(4 \mathrm{e}+006,0.45),(5 \mathrm{e}+$ \\
$T_{P}$ & & $006,0.48),(1 \mathrm{e}+007,0.5))$ \\
& Table for Production & {$[(0,0)-(100,1)],(0,0),(0.2,0),(0.3,0),(0.5,0),(0.7,0.2)$,} \\
& & $(0.8,0.3),(1,0.4),(1.3,0.6),(2,0.8),(3,0.9),(5,1),(10,1),(100,1))$ \\
\hline & & \\
& &
\end{tabular}


RENE A. AMAYA

August 1, 1969

1997

2000

2000 - present

2010 - present
Born, Barranquilla, Colombia

B.Sc., Industrial Engineering

Universidad del Norte

Barranquilla, Colombia

M.Sc., Industrial Engineering

Universidad de Los Andes

Bogotá D.C., Colombia

Full-time Professor

Department of Industrial Engineering

Universidad del Norte

Barranquilla, Colombia

Chairman

Department of Industrial Engineering

Universidad del Norte

Barranquilla, Colombia

\section{PUBLICATIONS AND PRESENTATIONS}

Amaya-Mier, R. (2000). Estudio de Implementación Conjunta de las Técnicas de Simulación y DOE para el Mejoramiento de Procesos Productivos. Memos de Investigación CIFI", Universidad de Los Andes (198): pp.1 - 29.

Cure-Vellojín, L., Meza-Gonzalez, J. C. and Amaya-Mier, R. (2006). Logística Inversa: una herramienta de apoyo a la competitividad de las organizaciones. Ingeniería y Desarrollo No. 20 (Julio-Diciembre): pp. 184202

Amaya-Mier, R. y Soto, M. (2009) Modelación y Calibración en Dinámica de Sistemas para la Medición de Amplificación de Demanda y sus Efectos en Cadenas de Suministro. In:"Latinoamérica, una comunidad que aprende Dinámica de Sistemas y con Dinámica de Sistemas“, Universidad Industrial de Santander , p.483 - 502 , v.1 <, fasc. 1 